\title{
Reverse remodeling in bradycardia induced volume overload : the role of optimizing the pacing site
}

Citation for published version (APA):

Heutink-Peschar, M. (2003). Reverse remodeling in bradycardia induced volume overload: the role of optimizing the pacing site. [Doctoral Thesis, Maastricht University]. Universiteit Maastricht. https://doi.org/10.26481/dis.20030124mh

Document status and date:

Published: 01/01/2003

DOI:

10.26481/dis.20030124mh

Document Version:

Publisher's PDF, also known as Version of record

\section{Please check the document version of this publication:}

- A submitted manuscript is the version of the article upon submission and before peer-review. There can be important differences between the submitted version and the official published version of record.

People interested in the research are advised to contact the author for the final version of the publication, or visit the DOI to the publisher's website.

- The final author version and the galley proof are versions of the publication after peer review.

- The final published version features the final layout of the paper including the volume, issue and page numbers.

Link to publication

\footnotetext{
General rights rights.

- You may freely distribute the URL identifying the publication in the public portal. please follow below link for the End User Agreement:

www.umlib.nl/taverne-license

Take down policy

If you believe that this document breaches copyright please contact us at:

repository@maastrichtuniversity.nl

providing details and we will investigate your claim.
}

Copyright and moral rights for the publications made accessible in the public portal are retained by the authors and/or other copyright owners and it is a condition of accessing publications that users recognise and abide by the legal requirements associated with these

- Users may download and print one copy of any publication from the public portal for the purpose of private study or research.

- You may not further distribute the material or use it for any profit-making activity or commercial gain

If the publication is distributed under the terms of Article $25 \mathrm{fa}$ of the Dutch Copyright Act, indicated by the "Taverne" license above, 
Reverse remodeling in bradycardia induced volume overload 
(O) Maaike Peschar, Maastricht, 2003 ISBN 90-9016469-3

Vormgeving en druk: Datawyse | Universitaire Pers Maastricht 


\section{Reverse remodeling in bradycardia induced volume overload}

The role of optimizing the pacing site

\section{PROEFSCHRIFT}

ter verkrijging van de graad van doctor

aan de Universiteit Maastricht, op gezag van de Rector Magnificus,

Prof. Dr. A.C. Nieuwenhuijzen Kruseman, volgens het besluit van het College van Decanen,

in het openbaar te verdedigen

op vrijdag 24 januari 2003 om 14.00 uur

door

Maaike Heutink-Peschar 


\section{Promotores}

Em. Prof. dr. R.S. Reneman

Prof. dr. L.H.E.H. Snoeckx (Technische Universiteit Eindhoven)

\section{Co-promotores}

Dr. F.W. Prinzen

Dr. M.A. Vos

\section{Beoordelingscommissie}

Prof. dr. M.A. Allessie (voorzitter)

Prof. dr. T. Arts (Technische Universiteit Eindhoven)

Prof. dr. H.J.G.M. Crijns

Dr. M.D. Gammage (Queen Elizabeth Hospital Birmingham, United Kingdom)

Dr. K.R. Sipido (Katholieke Universiteit Leuven, België)

Financial support by the Netherlands Heart Foundation (grant 95.043) and the Stichting RESCAR Maastricht for the publication of this thesis is gratefully acknowledged.

Additional support was granted by Bakken Research Center BV and Stichting SWOOF. 


\section{ADDENDUM}

The study described in this thesis was supported by a grant of the Netherlands Heart Foundation (NHF-95.043).

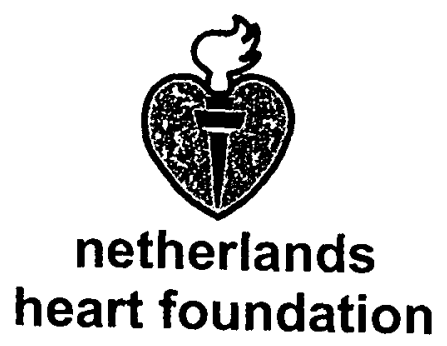




\section{CONTENTS}

Chapter 1 General introduction 7

Chapter 2 Relation between the pacing induced sequence of activation and left ventricular pump function in animals 25

Chapter 3 Biphasic contractile and progressive structural remodeling during chronic volume overload in dogs 53

Chapter 4 Metabolic remodeling in global and regional hypertrophy of the canine heart 69

Chapter 5 Absence of reverse electrical remodeling during regression of volume overload hypertrophy in canine ventricles $\quad 81$

Chapter 6 Reverse structural and contractile but not electrical remodeling following chronic AV-block. Comparison of biventricular and right ventricular apex pacing 97

Chapter 7 Left ventricular septal and apex pacing for optimal pump function in canine hearts 113

Chapter 8 General discussion 129

Summary 143

Samenvatting 147

Uitleiding 151

Curriculum Vitae 153

Publications $\quad 155$ 


\section{CHAPTER 1}

\section{General introduction}

Review of the literature and introduction

to this thesis 


\section{Introduction}

The heart is a hollow muscle which pumps blood through the body. Like any other muscle it continuously adapts its structure and function to changes in workload. Under normal circumstances the heart increases its weight from approximately $20 \mathrm{~g}$ at birth to about $325 \mathrm{~g}$ in adulthood '. This progressive increase in heart weight and intraventricular volume goes in harmony with the growth of the body and, as a consequence, the enhanced circulatory demand. In the first days after birth cardiac growth results from an increase in the number of myocytes (hyperplasia) ${ }^{2}$. Further growth is in principle caused by hypertrophy (increase in myocyte volume). This hypertrophy is considered to be physiological, as in endurance athletes, because it reverses when the stressor is removed. Sustained cardiac overload in the adult heart, however, can lead to pathological hypertrophy, because cellular growth is often accompanied by several other remodeling processes. Pathological hypertrophy generally originates from increased pressure or volume overload.

In the present thesis volume overload hypertrophy, as induced by bradycardia was studied. Bradycardia (slow heart rate) was accomplished by means of atrio-ventricular (AV) block. Two forms of AV-block exist in the clinic: congenital AV-block, which may be associated with antibody-induced injury to the fetal conduction system ${ }^{3}$, and acquired AV-block due to (local) ischemia of the AV-node or myocardial infarction. Despite the normal life expectancy of children with congenital AV-block ${ }^{4}$, little is known about the structural, contractile and electrophysiological sequelae of congenital AV-block in man ${ }^{5}$.

AV-block is clinically treated by pacing. Because volume overload is due to bradycardia, pacing at physiological heart rate can be expected to take away the stimulus for hypertrophy. In this sense, pacing in AV-block may be comparable to anti-hypertensive therapy in hypertension or valve surgery in valvular abnormalities. While such therapies reduce workload for the heart, relatively little is known as to whether all processes in hypertrophic myocardium reverse to normal upon application of therapy. Reverse remodeling refers to the processes occurring during treatment of cardiac overload.

While ventricular pacing restores heart rate in AV-block hearts, an important side effect of ventricular pacing, however, is the change in sequence of electrical activation. Several studies show that such abnormal activation sequence impairs ventricular pump function ${ }^{6-8}$.

In this chapter an overview on remodeling, reverse remodeling and pacing will be given. This is followed by the rationale of the thesis. 


\section{Remodeling}

Cardiac remodeling can be defined as a time-dependent process, involving changes in geometry and in proteins that represent many functions. Structural remodeling involves alterations in cavity and wall volume as well as alterations in cell size and/or amount and composition of extracellular matrix. Because the content of all cellular components is not necessarily changed in proportion to growth, the cellular phenotype can change accordingly. Changes in amount and function of proteins, involved in contraction and calcium homeostasis, can alter the mechanical properties of the heart (contractile remodeling). Likewise, alterations in the membrane bound ion channels can lead to changes in action potential duration (electrical remodeling), while changes in specific enzymes may affect metabolism (metabolic remodeling). Table 1 shows structural, contractile and electrical remodeling in various animal models.

Table 1.

Selection of the different remodeling processes in animal models.

\begin{tabular}{|c|c|c|c|c|c|c|}
\hline Model & Type & Species & Structural & Contractile & Electrical & Ref. \# \\
\hline AV-block & vo & Dog & $\uparrow$ & $\uparrow$ & $\uparrow \uparrow$ MAPD & $38,50,69,70$ \\
\hline MR & vo & Dog & $\uparrow$ & $\downarrow$ & $?$ & 65 \\
\hline Aortic band & $\mathrm{PO}$ & Dog & $=/ \uparrow$ & $=/ \downarrow$ & $?$ & 63,71 \\
\hline ASD & VO & Cat & $\uparrow$ & $=$ & $?$ & 72 \\
\hline Aortic band & $\mathrm{PO}$ & Cat & $\uparrow$ & $?$ & $=/ \uparrow \mathrm{MAPD}$ & 54 \\
\hline $\mathrm{R}+\mathrm{N}$ & $\mathrm{PO}$ & Rabbit & $\uparrow$ & $?$ & $\uparrow \mathrm{APD}$ & 51 \\
\hline AC shunt & vo & Rat & $\uparrow$ & $\uparrow$ & $?$ & 64 \\
\hline $\mathrm{SH}$ & $\mathrm{PO}$ & Rat & $\uparrow$ & $=$ & $\uparrow \mathrm{APD}$ & 66,73 \\
\hline Aging & - & Rat & $\uparrow$ & $?$ & $\uparrow \mathrm{APD}$ & 67 \\
\hline
\end{tabular}

VO: volume overload, PO: pressure overload, (M)APD: (monophasic) action potential duration, MR: mitral regurgitation, ASD: atrial septum defect, $\mathrm{R}+\mathrm{N}$ : renovascular hypertension, $\mathrm{AC}$ : aorto-caval shunt, $\mathrm{SH}$ : spontaneous hypertension. $\uparrow$ increased, $\downarrow$ decreased, = no change and ? not determined.

\section{Structural remodeling}

Cardiac hypertrophy develops most frequently as a consequence of external factors, like pressure or volume overload, but genetic mutations can also be at its origin.

\section{Pressure overload hypertrophy}

Pressure overload hypertrophy is the most common type of hypertrophy and develops as a structural adaptation to systemic hypertension or left or right ventricular outflow obstruction. Ventricular growth occurs mainly through parallel addition of new 
sarcomeres to myofibrils. As a result, in the left ventricle, concentric hypertrophy develops, which is characterized by a decreased cavity to wall volume ratio (Figure 1B). This type of hypertrophy is often associated with an enhanced sensitivity to ischemia, presumably due to the increased diffusion distance for oxygen. This phenomenon plays at two levels, i.e. at the level of the individual myocytes, the volume of which grows faster than the number of feeding capillaries, and at the level of the subendocardial tissue, the perfusion of which is limited due to the increased wall thickness ${ }^{9-13}$.

Pressure overload hypertrophy is often associated with an activation of the renin-angiotensin-aldosteron system. Increased circulating levels of angiotensin II can cause fibrosis, characterized by enhanced collagen accumulation ${ }^{14.15}$, probably through activation of aldosteron ${ }^{16}$. In patients, left ventricular (LV) mass index, as determined by $2 \mathrm{D}$-echocardiography, can increase by up to $60 \%$ in hypertension ${ }^{17-19}$ and by up to $75 \%$ in aortic valve stenosis ${ }^{20,21}$.

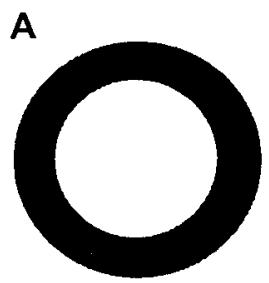

Normal

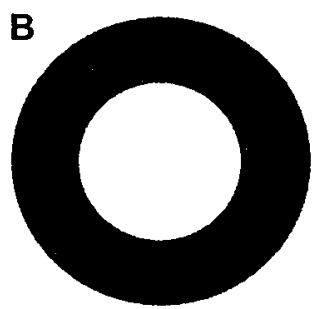

Pressure overload hypertrophy

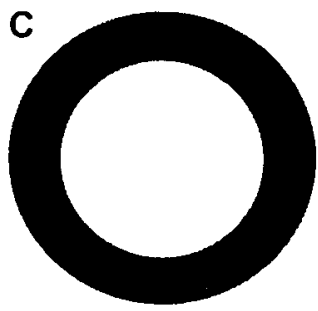

Volume overload
hypertrophy

Figure 1. Different types of hypertrophy. Schematic drawing of cavity and wall geometry in cross section of a normal left ventricle (A) and of a left ventricle with pressure (B) and volume overload hypertrophy $(C)$. Pressure overload results in concentric hypertrophy and volume overload in eccentric hypertrophy. Adapted from thesis M.F.M. van Oosterhout ${ }^{\text {/. }}$.

Volume overload hypertrophy

Volume overload hypertrophy develops as a consequence of AV-block, mitral or aortic valve insufficiency or left-to-right shunts. When myocardial growth is stimulated by increased volume load, new sarcomeres are added (almost exclusively) in series. Consequently, so-called eccentric hypertrophy of the left ventricle develops, in which the ratio between cavity and wall volume remains unchanged or even increases (Figure 1C). In this way, volume overload hypertrophy resembles 'normal' growth more than pressure overload hypertrophy and is generally not associated with fibrosis and diastolic stiffness ${ }^{16}$ or increased sensitivity to ischemia ${ }^{22}$. In 6 years old children with congenital AV-block, LV mass was found to be $\sim 25 \%$ higher than in age-matched healthy children ${ }^{4}$. In adult patients long-term mitral regurgitation was found to be associated with a $\sim 40 \%$ increase in LV mass and impaired LV contractile function ${ }^{23}$. 


\section{Contractile remodeling}

In cardiac excitation-contraction coupling (Figure $2 \mathrm{~A}$ ), the calcium ion $\left(\mathrm{Ca}^{2+}\right)$ plays a central role. The contraction-relaxation cycle is started when depolarization leads to entry of $\mathrm{Ca}^{2+}$ into the cell via voltage-dependent $\mathrm{L}$-type $\mathrm{Ca}^{2+}$ channels (a). This $\mathrm{Ca}^{2+}$ entry triggers a much larger amount of $\mathrm{Ca}^{2+}$ to be released from the sarcoplasmic reticulum $\left(\mathrm{Ca}^{2+}\right.$ induced $\mathrm{Ca}^{2+}$ release, $b$ ). These processes increase intracellular $\mathrm{Ca}^{2+}$ from $\sim 100 \mathrm{nM}$ to a few $\mu \mathrm{M}$, which is sufficient to facilitate interaction between myosin and actin filaments leading to contraction (c). Relaxation occurs as $\mathrm{Ca}^{2+}$ dissociates from the contractile apparatus $(d)$ and is re-uptaken by the sarcoplasmic reticulum through the action of the sarcoplasmic reticular $\mathrm{Ca}^{2+}$-ATPase (SERCA, e). Intracellular $\mathrm{Ca}^{2+}$ homeostasis is also maintained through action of the $\mathrm{Na}^{+} / \mathrm{Ca}^{2+}$ exchanger (NCX). Normally, this exchanger removes $\mathrm{Ca}^{2+}$ from the cell (forward mode, $f$ ). Under certain circumstances, such as increased intracellular concentration of $\mathrm{Na}^{+}$, however, it can also function in the reverse mode, leading to an increase in intracellular $\mathrm{Ca}^{2+}{ }^{24}$. A tracing of an action potential and accompanying $\mathrm{Ca}^{2+}$ transient are given in Figure $2 \mathrm{~B}$.

For large mammals SERCA handles $\sim 70 \%$ of the removal of $\mathrm{Ca}^{2+}$, while the NCX takes care of the remaining $\sim 30 \%{ }^{25,26}$. In smaller mammals the balance between the $\mathrm{Ca}^{2+}$ handling of these two proteins is generally more in favor of SERCA ${ }^{25}$. The relation between these $\mathrm{Ca}^{2+}$ handling proteins changes in heart failure, where SERCA has been

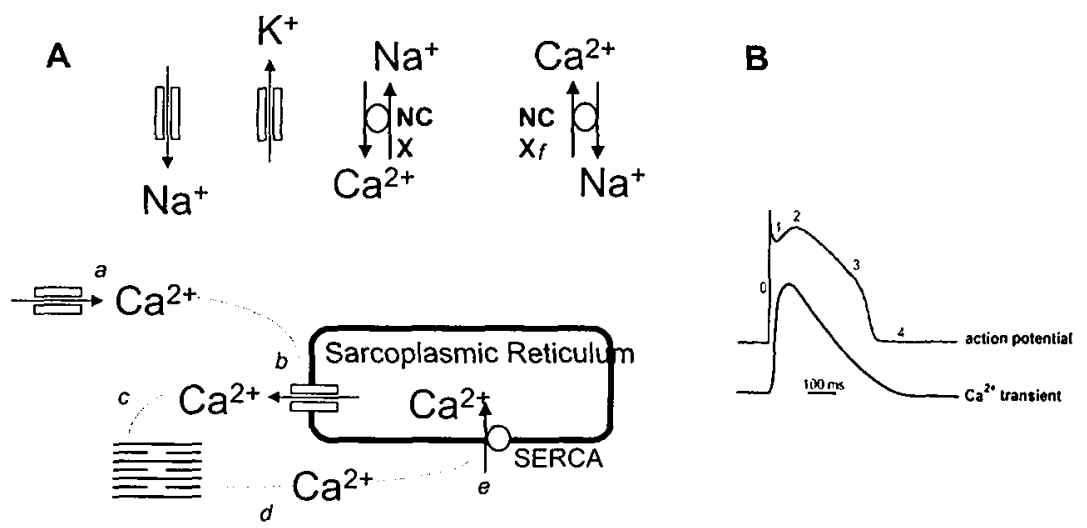

Figure 2. A: Schematic representation of the major pathways involved in $\mathrm{Ca}^{2+}$ homeostasis in the cardiomyocyte. a: $\mathrm{Ca}^{2+}$ entry via $\mathrm{L}$-type $\mathrm{Ca}^{2+}$ channel, $\mathrm{b}: \mathrm{Ca}^{2+}$ induced $\mathrm{Ca}^{2+}$ release from the sarcoplasmic reticulum, $\mathrm{c}$ : $\mathrm{Ca}^{2+}$ induced contraction, d: dissociation of $\mathrm{Ca}^{2+}$ from the contractile apparatus, e: re-uptake of $\mathrm{Ca}^{2+}$ via the sarcoplasmic reticular $\mathrm{Ca}^{2+}$-ATPase (SERCA) and $\mathrm{f}: \mathrm{Ca}^{2+}$ efflux via the $\mathrm{Na}^{+} / \mathrm{Ca}^{2+}$ exchanger (NCX). $\mathrm{B}$ : tracings of a myocardial $\mathrm{Ca}^{2+}$ transient and action potential. The numbers 0 to 4 indicate the different phases of the action potential, 0 : upstroke, 1: fast early depolarization, 2: plateau phase, 3: repolarization phase and 4: resting membrane potential. Adapted from thesis P.G.A. Volders ${ }^{75}$. 
reported to be downregulated ${ }^{27-31}$. On the one hand a reduced SERCA amount leads to less $\mathrm{Ca}^{2+}$ loading of the sarcoplasmic reticulum and to less $\mathrm{Ca}^{2+}$ release during the subsequent activation, thereby resulting in a weaker contraction (systolic dysfunction). On the other hand, during diastole $\mathrm{Ca}^{2+}$ removal from the cytosol is slow and incomplete, leading to a slower relaxation and a larger diastolic stiffness (diastolic dysfunction). A frequently proposed compensating mechanism is the upregulation of the (reverse mode of the) $\mathrm{NCX}{ }^{32-34}$, probably due to increased intracellular $\mathrm{Na}^{+}{ }^{35}$. In this way $\mathrm{Ca}^{2+}$ can enter the cell and thereby enhance systolic function. If, in the long run, structural and contractile remodeling cannot keep up with the sustained cardiac overload, cardiac function may become compromised, ultimately leading to heart failure.

Presumably due to such changes in expression and function of proteins involved in $\mathrm{Ca}^{2+}$ homeostasis, the adaptation of contractility to higher heart rates is different between normal and failing hearts. In isolated muscle strips from normal hearts, an increase in frequency is accompanied by an increase in force, resulting in a positive force-frequency relation ${ }^{29}$. In heart failure, however, the force-frequency relation is negative ${ }^{29,36,37}$, indicating that force cannot be maintained at higher heart rates, suggesting particular adaptations in $\mathrm{Ca}^{2+}$ homeostasis. In dogs with chronic AV-block contractility is increased ${ }^{38}$. This increase seems to be due to an increased $\mathrm{Ca}^{2+}$ transient and an increased NCX current in isolated myocytes ${ }^{39}$. This increase in contractility, however, has a different rate adaptation, i.e. contractility is more increased at low than at high heart rates ${ }^{38}$. As a consequence, the force-frequency relation in cardiac hypertrophy due to of AV-block is negative, but has a higher $y$-axis (force-axis) intercept ${ }^{38}$.

\section{Electrical remodeling}

Figure 3 illustrates the ionic currents, pumps and exchangers involved in the development of the ventricular action potential. The depolarization phase $(0)$ is the result of a sudden increase in permeability of the cell membrane for $\mathrm{Na}^{+}$, leading to a $\mathrm{Na}^{+}$influx. This leads to activation of the transient outward current $\left(l_{\mathrm{tol}}\right)$, which causes a fast early repolarization (1). Cardiac action potentials last much longer than skeletal muscle or neuronal action potentials, due to a delay in repolarization. This plateau (2) is the result of a relatively long and strong influx of $\mathrm{Ca}^{2+}$, which counteracts the efflux of $\mathrm{K}^{+}$ for a considerable time. Finally repolarization ensues (3). In this way the resting membrane potential is normalized (4) and the cycle can start all over again.

In many forms of hypertrophy repolarization is prolonged, often due to an decreased $I_{t 01}$ current ${ }^{40,41}$. In the canine model of chronic AV-block, however, the prolonged repolarization seems to be predominantly associated with an increased $N C X^{39}$ and a decreased $I_{k}$ current ${ }^{42}$.

Electrical remodeling is not just characterized by a prolongation of the cellular or monophasic action potential and QT-time. Also the intrinsic differences in 


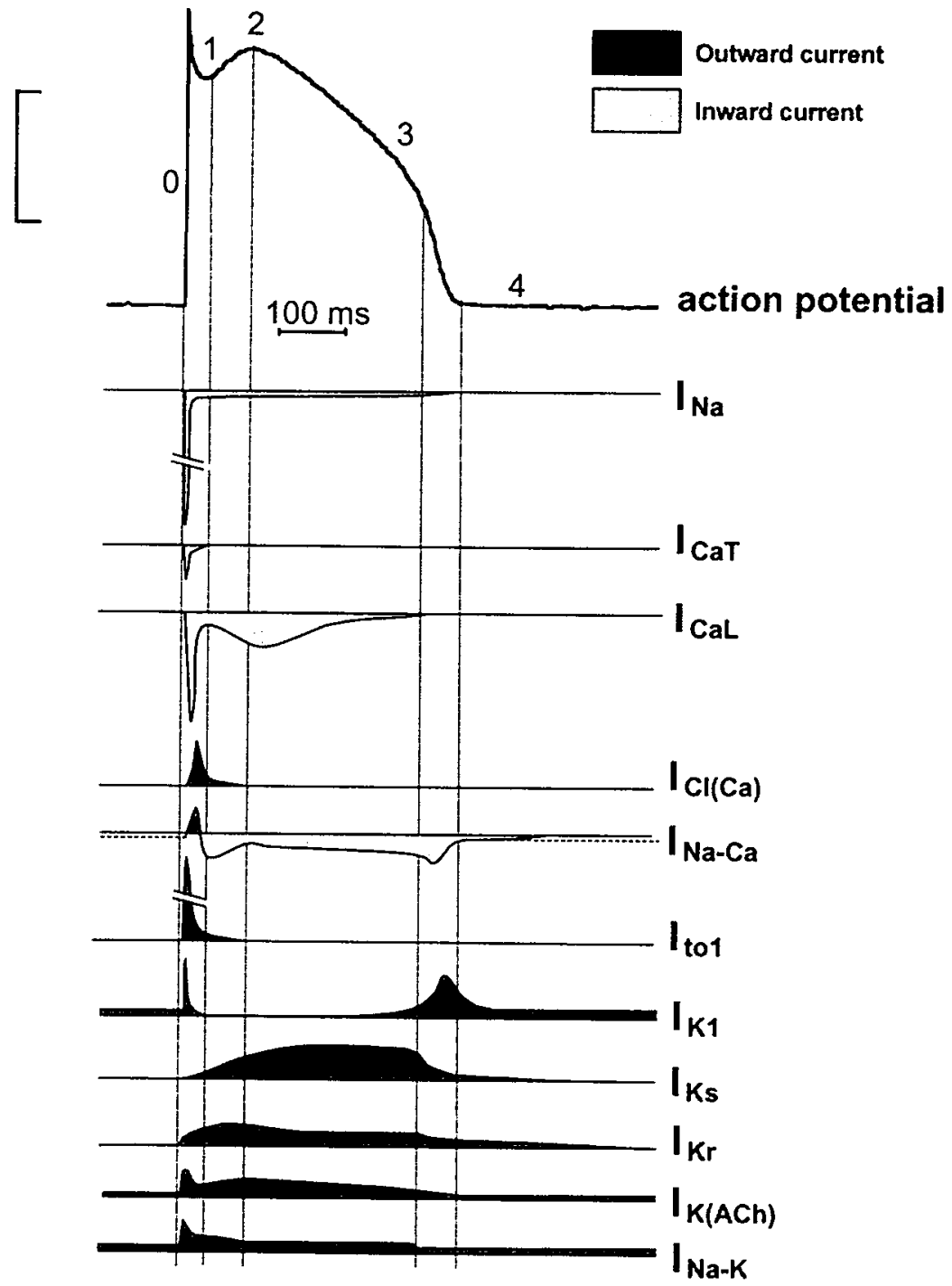

Figure 3. Schematic representation of ionic currents (l) occurring during depolarization and subsequent repolarization. For explanation of numbers see Figure 2. Currents: $\mathrm{I}_{\mathrm{Na}}$ : fast $\mathrm{Na}^{+}$current, $\mathrm{I}_{\mathrm{CaT}}$ : T-type $\mathrm{Ca}^{2+}$ current, $\mathrm{I}_{\mathrm{Cat}}:$ L-type $\mathrm{Ca}^{2+}$ current, $\mathrm{I}_{\mathrm{Cl}(\mathrm{Ca})}: \mathrm{Ca}^{2+}$-activated $\mathrm{Cl}^{-}$current, $\mathrm{I}_{\mathrm{N}_{3}-\mathrm{Ca}_{3}}: \mathrm{Na}^{+}-\mathrm{Ca}^{2+}$ exchange current, $I_{t o l}$ : transient outward $K^{+}$current, $I_{k 1}$ : inward rectifier $K^{+}$current, $I_{k s}$ : slowly activating component of the delayed rectifier $\mathrm{K}^{+}$current, $I_{\mathrm{kr}}$ : rapidly activating component of the delayed rectifier $K^{+}$current, $I_{K(A c h)}$ : acetylcholine-sensitive $K^{+}$current and $I_{\mathrm{Na}-K^{-}}: \mathrm{Na}^{+}-K^{+}$pump current. Adapted from thesis P.G.A. Volders ${ }^{75}$. 
repolarization within and between the ventricles (dispersion) as present in the normal heart, become more accentuated during hypertrophy ${ }^{43-46}$. This remodeling results in an increased risk for ventricular arrhythmias and sudden (arrhythmic) death ${ }^{43,47-50}$. The canine model of AV-block is characterized by a larger increase in repolarization than in other models of hypertrophy ${ }^{51-54}$. In patients and dogs with (acute) AV-block, this extreme prolongation can lead to Torsade de Pointes arrhythmia ${ }^{50,55-57}$.

Metabolic remodeling

Under normal conditions fatty acids are the major fuel for the heart, covering up to $70 \%$ of the energy need ${ }^{58}$. Lactate and glucose are used as additional substrates. The contribution of fatty acids to cardiac energy production may alter, amongst others, in hypertrophy and heart failure. More specifically, the contribution of carbohydrates increases at the expense of fatty acids ${ }^{59,60}$. The major metabolic pathways and some of their key enzymes are presented in Figure 4.

The important question remains whether metabolic remodeling is a cause or a consequence of hypertrophy and failure. It is also unknown whether metabolic remodeling depends on the type or degree of hypertrophy.

\section{Reverse remodeling}

In the clinical situation hypertrophy is treated rather than prevented. This raises the question as to whether the various remodeling processes are reversible. It turns out that even less is known about regression than about development of hypertrophy. Regression of hypertrophy may not simply be the mirror image of its development: regressed myocardium does not necessarily have to be the same tissue as before onset of hypertrophy ${ }^{61}$. Moreover, it is not clear whether reverse structural remodeling automatically implies reversal of other remodeling processes.

Reverse structural remodeling

The first study on regression of hypertrophy was reported in 1969 by Beznak et al. These authors showed that cardiac hypertrophy due to (a) unilateral nephrectomy and salt loading, (b) experimental hyperthyroidism, (c) experimental aortic banding and (d) nutritional anemia in rats were all reversible when the stressor was removed ${ }^{62}$.

Regression of pressure overload hypertrophy

After Beznak et al. other groups showed that the time for (complete) regression of pressure overload hypertrophy can vary substantially. In different animal models, regression of pressure overload hypertrophy was obtained 3-6 months after removing 


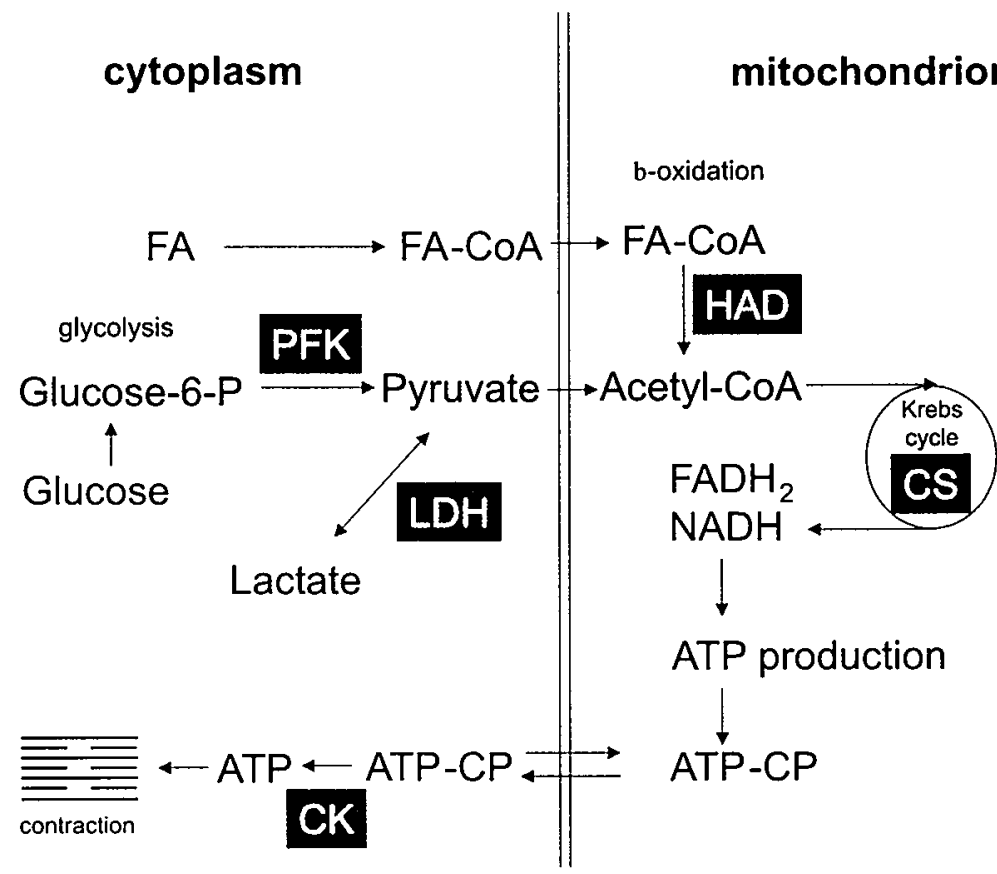

Figure 4. Schematic representation of myocardial substrate metabolism and the site of action of five key metabolic enzymes involved. Fatty acids (FA) have to be activated in order to become metabolized (FA-CoA). During the mitochondrial $\beta$-oxidation FA-CoA is converted into to acetyl-CoA, which can enter the Krebs cycle, ultimately resulting in production of ATP. This energy of ATP is transferred by creatine-phosphate (CP) to the cytoplasm, where free ATP can be used as an energy source for contraction. Glucose is metabolized into pyruvate, which can subsequently be converted into lactate or into acetyl-COA. This acetyl-COA can then enter the Krebs cycle, as described above. HAD: 3-hydroxy-acyl-COA dehydrogenase, CS: citrate synthase, CK: creatine kinase, PFK: 6-phoshofructo-1-kinase and LDH: lactate dehydrogenase. Adapted from theses K.A.J.M. van der Lee ${ }^{76}$ and M. Gorselink ${ }^{77}$.

the stressor ${ }^{51,54.63}$. In hypertensive patients cardiac hypertrophy was significantly decreased after only 6 months of treatment with angiotensin converting enzyme (ACE) inhibitors ${ }^{17-19}$, while it took up to about 8 years after aortic valve replacement ${ }^{20,21}$. This could be due to the (probably) longer presence of the stressor in patients, which could also require a longer time of recovery.

Regression of volume overload hypertrophy

The results after intervention for treatment of volume overload hypertrophy are more variable. Closure of aorto-caval fistula in rats resulted in regression of hypertrophy ${ }^{6.4}$. Valve replacement in dogs with mitral regurgitation, however, was not associated with 
reverse structural remodeling ${ }^{65}$, but in patients treated the same way regression of hypertrophy occurred after 3 months ${ }^{23}$.

Reverse contractile and electrical remodeling

Reverse remodeling has been studied considerably less than its development. In most cases where reverse structural remodeling was established, contractile ${ }^{64}$ or electrical remodeling was reversible too ${ }^{51,54,66}$. In dogs with mitral regurgitation, however, reverse contractile remodeling was not associated with reverse structural remodeling ${ }^{65}$ and in the aging rat, reverse structural remodeling was not accompanied by reverse electrical remodeling ${ }^{67}$.

\section{Electrical activation}

Normal electrical activation

Each cardiac cycle is initiated by the spontaneous generation of electrical activity in the sinus node, located in the lateral wall of the right atrium (Figure 5B). From here the action potential travels through both atria towards the AV-node (Figure 5C). Subsequently, the His bundle, left and right bundle branches and the specialized Purkinje network are activated (Figure 5D). This electrical activation can be registered with an electrocardiogram (ECG). An ECG tracing during normal sinus rhythm consists of several well-defined 'waves' (Figure 5E). The P-wave is caused by spread of depolarization over the atria, which is followed by atrial contraction. After a small pause, due to delay of impulse propagation in the AV-node, the QRS-complex appears as a result of activation of the ventricles. Finally, the $T$-wave represents repolarization of the ventricles.

\section{Abnormal electrical activation}

\section{Electrical activation during atrio-ventricular block}

During complete AV-block, conduction via the AV-node is blocked (Figure 6A), characterized by uncoupling of the atrial and ventricular activation, seen in the ECG as a dissociation of $P$-waves and $Q R S$-complexes. The ventricles are capable of generating an escape rhythm (idioventricular rhythm), but at a much lower rate. The atrial rate remains $\sim 80$ beats $/ \mathrm{min}$, while the ventricular rate will be $\sim 40$ beats $/ \mathrm{min}$. Because the ventricles are not activated via the fast conducting Purkinje system, in AV-block the QRS-complex can be widened. 

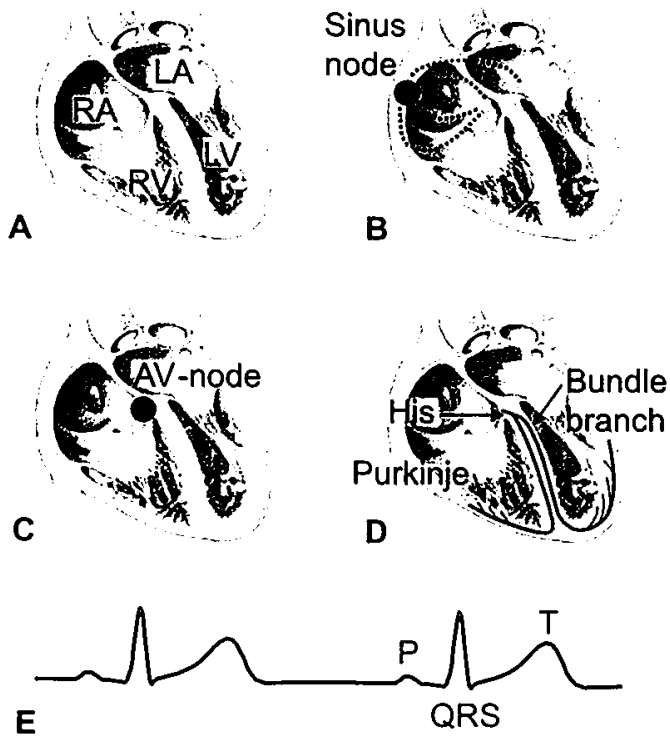

Figure 5. Overview of the heart. A: The four chambers of the heart, RA: right atrium, LA: left atrium, RV: right ventricle and LV: left ventricle. B: Spontaneous activation of the sinus node is followed by depolarization of both atria. C: Location of the AV-node in the lower part of the right atrium near the interatrial seplum. D: activation of the AV-node is followed by depolarization of the His-bundle, right and left bundle branches and Purkinje fibers. E: ECC recording (lead II) during normal sinus rhythm, P-wave: atrial depolarization, QRS complex: ventricular depolarization and T-wave: ventricular repolarization.

\section{Electrical activation during pacing}

In order to 'treat' bradycardia, patients with AV-block often receive a pacemaker. While older pacemakers are only capable of generating one steady ventricular rate, modern pacemakers are equipped to restore AV-synchrony (see also chapter 2). For this purpose two pacing electrodes are placed in the heart: one in the right atrium for sensing atrial activation and one in the ventricle for stimulation. The conventional pacing site is the right ventricular (RV) apex (Figure 6B). The pacemaker electrodes are positioned via transvenous approach and are connected to the pacemaker, which is positioned under the skin. The pacemaker can be programmed in such a way that the ventricle is activated when atrial activation is sensed, which leads to restoration of normal AV-synchrony and physiological heart rate (VDD-mode).

As mentioned before, induction of asynchronous electrical activation also causes asynchronous mechanical activation, which leads to decreased contractility (see also chapter 2). In order to overcome this additional side effect of pacing, the right and left ventricle can be stimulated simultaneously (biventricular pacing), which then leads to a more synchronous activation (Figure 6C). 


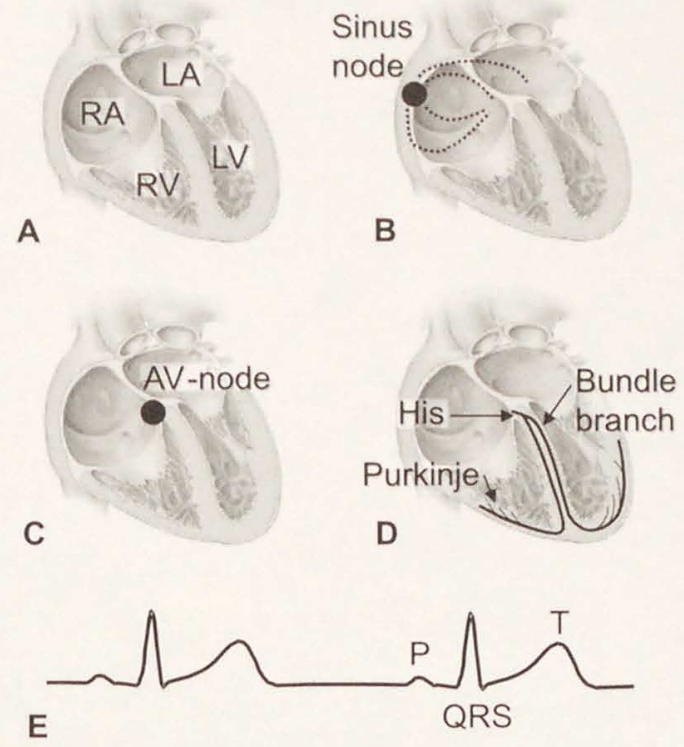

Figure 5. Overview of the heart. A: The four chambers of the heart, RA: right atrium, LA: left atrium, RV: right ventricle and LV: left ventricle. B: Spontaneous activation of the sinus node is followed by depolarization of both atria. C: Location of the AV-node in the lower part of the right atrium near the interatrial septum. D: activation of the AV-node is followed by depolarization of the His-bundle, right and left bundle branches and Purkinje fibers. E: ECG recording (lead II) during normal sinus rhythm, P-wave: atrial depolarization, QRS complex: ventricular depolarization and T-wave: ventricular repolarization.

Electrical activation during pacing

In order to 'treat' bradycardia, patients with AV-block often receive a pacemaker. While older pacemakers are only capable of generating one steady ventricular rate, modern pacemakers are equipped to restore AV-synchrony (see also chapter 2). For this purpose two pacing electrodes are placed in the heart: one in the right atrium for sensing atrial activation and one in the ventricle for stimulation. The conventional pacing site is the right ventricular (RV) apex (Figure 6B). The pacemaker electrodes are positioned via transvenous approach and are connected to the pacemaker, which is positioned under the skin. The pacemaker can be programmed in such a way that the ventricle is activated when atrial activation is sensed, which leads to restoration of normal AV-synchrony and physiological heart rate (VDD-mode).

As mentioned before, induction of asynchronous electrical activation also causes asynchronous mechanical activation, which leads to decreased contractility (see also chapter 2). In order to overcome this additional side effect of pacing, the right and left ventricle can be stimulated simultaneously (biventricular pacing), which then leads to a more synchronous activation (Figure 6C). 
A
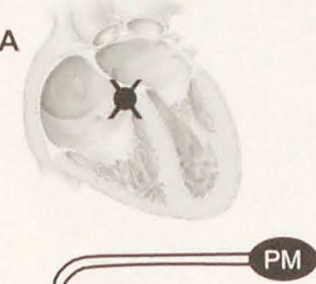

B
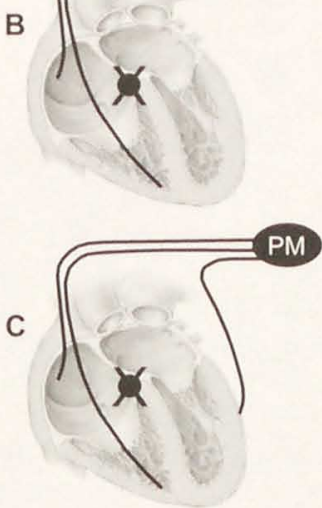

M
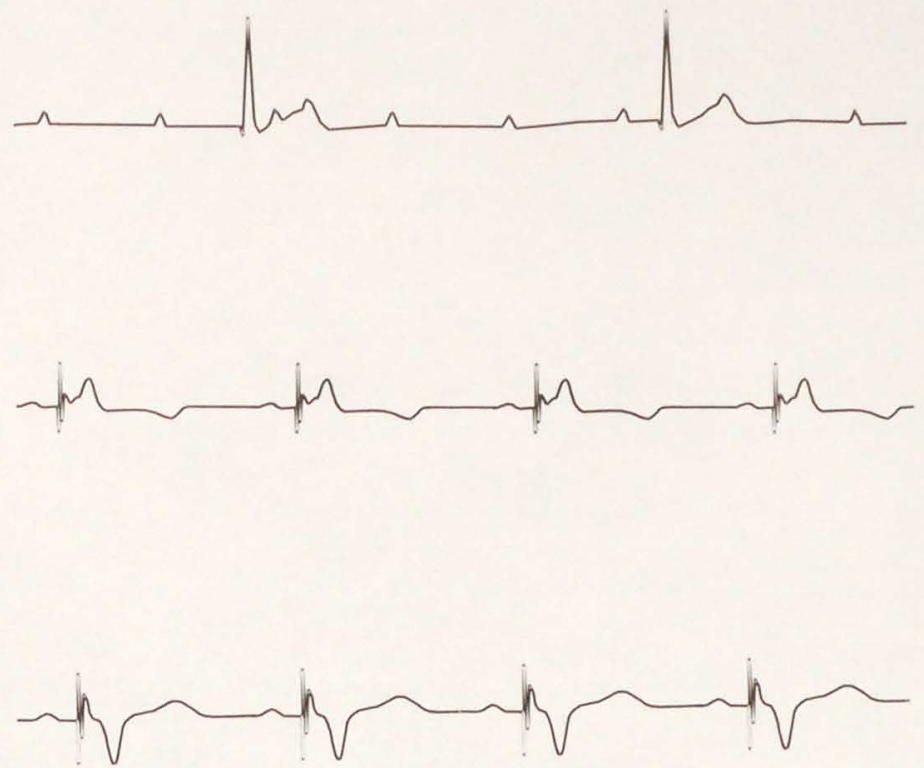

Figure 6. ECG recordings (lead II) of cardiac activation during A: AV-block, B: RV apex pacing and C: biventricular pacing. PM: pacemaker.

\section{Rationale}

Although it is known that AV-block induces cardiac remodeling, a comprehensive view, incorporating cellular and integrative data of all remodeling processes and their time course, is limited ${ }^{68}$. Even less is known about reverse remodeling. Because pacing normalizes heart rate, thereby reducing end-diastolic volume, pacing may induce reverse remodeling. However, beside the pacing mode (see above), the site of pacing may be an important determinant of pacing therapy. A review on the literature concerning this issue is given in chapter 2 .

The goal of this thesis was to investigate the various remodeling and reverse remodeling processes in a canine model of bradycardia induced volume overload. Volume load was normalized by restoration of physiological heart rate using ventricular pacing. In this way the stressor was removed without the need of surgical or pharmacological intervention, as in most other studies on reverse remodeling. Furthermore, we studied the relevance of pacing site for cardiac function and to what extent this determines reverse remodeling. 
In the first experimental chapter (chapter 3) data on the time-course of cardiac structural and contractile remodeling in dogs during 16 weeks of AV-block are presented. Structural remodeling was monitored by serial 2D-echocardiography. Contractile remodeling was studied by measuring $L V \mathrm{dP} / \mathrm{dt}_{\max }$ as function of heart rate to determine the force-frequency relation. Also LV protein contents of two $\mathrm{Ca}^{2+}$ handling enzymes, i.e. SERCA and NCX, were determined. Changes in force-frequency relation were related to changes in SERCA and NCX. In chapter 4 metabolic remodeling after volume overload hypertrophy was compared to that after pressure overload hypertrophy due to aortic banding and to that after asymmetrical hypertrophy due to chronic LV pacing. For this purpose activities of various enzymes, involved in energy metabolism, were measured in LV tissue samples.

In chapter 5 it was investigated whether structural and electrical remodeling are reversible. Electrical remodeling was examined by serial measurements of QT-time and LV and RV monophasic action potential duration. Eight weeks of AV-block was followed by 8 weeks of pacing. Pacing was performed at the conventional site, the RV apex. Subsequently, the results on reverse remodeling, including reverse contractile remodeling, obtained by pacing at the RV apex were compared with those obtained after biventricular pacing, presumaby leading to more synchronous electrical activation of the left ventricle (chapter 6). Finally, in a series of acute experiments on normal dogs, we investigated which was the optimal (combination of) pacing site(s), with respect to LV pump function (chapter 7 ). In a general discussion the conclusions and the relevance of this thesis are presented (chapter 8 ). 


\section{References}

1. Vliegen HW. Myocardial changes in ventricular hypertrophy. A morphometric, flow cytometric and biochemical study. PhD thesis, Leiden University, the Netherlands; 1987.

2. Anversa $P$, Kajstura J, Cheng W, et al. Insulin-like growth factor-1 and myocyte growth: the danger of a dogma part II. Induced myocardial growth: pathologic hypertrophy. Cardiovasc Res. 1996;32:484-95.

3. Michaelsson $M$, Riesenfeld $T$, Jonzon A. Natural history of congenital complete atrioventricular block. Pacing Clin Electrophysiol. 1997;20:2098-101.

4. Udink ten Cate FE, Breur JM, Cohen MI, et al. Dilated cardiomyopathy in isolated congenital complete atrioventricular block: early and long-term risk in children. I Am Coll Cardiol. 2001;37:1129-34.

5. Kertesz NJ, Friedman RA, Colan SD, et al. Left ventricular mechanics and geometry in patients with congenital complete atrioventricular block. Circulation. 1997;96:3430-5.

6. Burkhoff D, Oikawa RY, Sagawa K. Influence of pacing site on canine left ventricular contraction. Am I Physiol. 1986;251:H428-35.

7. Park RC, Little WC, O'Rourke RA. Effect of alteration of left ventricular activation sequence on the left ventricular end-systolic pressure-volume relation in closed chest dogs. Circ Res. 1985;57:706-717.

8. Prinzen FW, Van Oosterhout MF, Vanagt WY, et al. Optimization of ventricular function by improving the activation sequence during ventricular pacing. Pacing Clin Electrophysiol. 1998;21:2256-60.

9. Rakusan K, Hrdina PW, Turek Z, et al. Cell size and capillary supply of the hypertensive rat heart: quantitative study. Basic Res Cardiol. 1984;79:389-95.

10. Henquell $\mathrm{L}$, Odoroff $\mathrm{Cl}$, Honig $\mathrm{CR}$. Intercapillary distance and capillary reserve in hypertrophied rat hearts beating in situ. Circ Res. 1977;41:400-8.

11. Engelmann GL, Vitullo JC, Gerrity RG. Morphometric analysis of cardiac hypertrophy during development, maturation, and senescence in spontaneously hypertensive rats. Circ Res. 1987; 60:487-94.

12. Qian $S F$, Brum JM, Bove AA. Energy production, $\mathrm{O}_{2}$ consumption, and blood flow reserve in experimental aortic valve disease. Am / Physiol. 1987;252:H243-51.

13. Snoeckx LH, van der Vusse G), Coumans WA, et al. Differences in ischaemia tolerance between hypertrophied hearts of adult and aged spontaneously hypertensive rats. Cardiovasc Res. 1993; 27:874-81.

14. Morgan HE, Baker KM. Cardiac hypertrophy. Mechanical, neural, and endocrine dependence. Circulation. 1991;83:13-25.

15. Motz W, Strauer BE. Therapeutic effect on left ventricular hypertrophy by different antihypertensive drugs. Clin Investig. 1992;70:\$87-92.

16. Weber KT, Brilla CG, Janicki JS. Myocardial fibrosis: functional significance and regulatory factors. Cardiovasc Res. 1993;27:341-8.

17. Karpanou EA, Vyssoulis GP, Psichogios A, et al. Regression of left ventricular hypertrophy results in improvement of QT dispersion in patients with hypertension. Am Heart 1. 1998;136:765-8.

18. Gonzalez Fernandez RA, Rivera M, Rodriguez P], et al. Prevalence of ectopic ventricular activity after left ventricular mass regression. Am / Hypertens. 1993;6:308-13.

19. Muiesan ML, Zulli $R$, Rizzoni $D$, et al. Effect of changes in blood pressure and left ventricular mass induced by antihypertensive treatment on ventricular arrhythmias in essential hypertension. I Hypertens. 1993;11 Suppl 5:S104-5.

20. Monrad ES, Hess OM, Murakami T, et al. Time course of regression of left ventricular hypertrophy after aortic valve replacement. Circulation. 1988;77:1345-55.

21. Gilchrist IC, Waxman HL, Kurnik PB. Improvement in early diastolic filling dynamics after aortic valve replacement. Am / Cardiol. 1990;66:1124-9.

22. Carabello BA, Nakano K, Ishihara K, et al. Coronary blood flow in dogs with contractile dysfunction due to experimental volume overload. Circulation. 1991;83:1063-75.

23. Starling MR, Kirsh MM, Montgomery DG, et al. Impaired left ventricular contractile function in patients with long-term mitral regurgitation and normal ejection fraction. / Am Col/ Cardiol. 1993;22:239-50. 
24. Morgan JP, Erny RE, Allen PD, et al. Abnormal intracellular calcium handling, a major cause of systolic and diastolic dysfunction in ventricular myocardium from patients with heart failure. Circulation. 1990;81:1ii21-32.

25. Bers DM. Excitation-contraction coupling and cardiac contractile force (2nd edition). Dordrecht, the Netherlands: Kluwer Academic; 2001.

26. Pogwizd SM, Schlotthauer K, Li L, et al. Arrhythmogenesis and contractile dysfunction in heart failure: Roles of sodium-calcium exchange, inward rectifier potassium current, and residual beta-adrenergic responsiveness. Circ Res. 2001;88:1159-67.

27. Studer $R$, Reinecke $\mathrm{H}$, Bilger J, et al. Gene expression of the cardiac $\mathrm{Na}^{*}-\mathrm{Ca}^{2}$ exchanger in end-stage human heart failure. Circ Res. 1994;75:443-53.

28. Kiss E, Ball NA, Kranias EG, et al. Differential changes in cardiac phospholamban and sarcoplasmic reticular $\mathrm{Ca}^{2 *}$-ATPase protein levels. Effects on $\mathrm{Ca}^{2 "}$ transport and mechanics in compensated pressure-overload hypertrophy and congestive heart failure. Circ Res. 1995;77:759-64.

29. Hasenfuss G, Reinecke $H$, Studer $R$, et al. Relation between myocardial function and expression of sarcoplasmic reticulum $\mathrm{Ca}^{2}{ }^{2}$-ATPase in failing and nonfailing human myocardium. Circ Res. 1994; 75:434-42.

30. de la Bastie D, Levitsky D, Rappaport L, et al. Function of the sarcoplasmic reticulum and expression of its Ca" ${ }^{2}$-ATPase gene in pressure overload-induced cardiac hypertrophy in the rat. Circ Res. 1990; 66:554-64.

31. Flesch $M$, Schwinger $R H$, Schiffer $F$, et al. Evidence for functional relevance of an enhanced expression of the $\mathrm{Na}^{\circ}-\mathrm{Ca}^{2 *}$ exchanger in failing human myocardium. Circulation. 1996;94:992-1002.

32. O'Rourke B, Kass DA, Tomaselli GF, et al. Mechanisms of altered excitation-contraction coupling in canine tachycardia-induced heart failure, I: experimental studies. Circ Res. 1999;84:562-70.

33. Pogwizd SM, Qi M, Yuan W, et al. Upregulation of $\mathrm{Na}^{*} / \mathrm{Ca}^{2 *}$ exchanger expression and function in an arrhythmogenic rabbit model of heart failure. Circ Res. 1999;85:1009-19.

34. Ito $K$, Yan $X$, Tajima $M$, et al. Contractile reserve and intracellular calcium regulation in mouse myocytes from normal and hypertrophied failing hearts. Circ Res. 2000;87:588-95.

35. Verdonck $F$, Volders PGA, Vos MA, et al. Cardiac hypertrophy is associated with an increase in subsarcolemmal Na'. / Biophys. 2001;80:598a.

36. Hasenfuss G, Holubarsch C, Hermann HP, et al. Influence of the force-frequency relationship on haemodynamics and left ventricular function in patients with non-failing hearts and in patients with dilated cardiomyopathy. Eur Heart /. 1994;15:164-70.

37. Houser SR, Piacentino V, 3rd, Mattiello J, et al. Functional properties of failing human ventricular myocytes. Trends Cardiovasc Med. 2000;10:101-7.

38. de Groot $\mathrm{SH}$, Schoenmakers $\mathrm{M}$, Molenschot $\mathrm{MM}$, et al. Contractile adaptations preserving cardiac output predispose the hypertrophied canine heart to delayed afterdepolarization-dependent ventricular arrhythmias. Circulation. 2000;102:2145-51.

39. Sipido KR, Volders $\mathrm{PG}$, de Groot $\mathrm{SH}$, et al. Enhanced Ca"* release and $\mathrm{Na} / \mathrm{Ca}$ exchange activity in hypertrophied canine ventricular myocytes : potential link between contractile adaptation and arrhythmogenesis. Circulation. 2000;102:2137-44.

40. Nabauer M, Kaab S. Potassium channel down-regulation in heart failure. Cardiovasc Res. 1998; 37:324-34.

41. Beuckelmann DJ, Nabauer $M$, Erdmann E. Alterations of $\mathrm{K}^{\prime}$ currents in isolated human ventricular myocytes from patients with terminal heart failure. Circ Res. 1993;73:379-85.

42. Volders PGA, Sipido KR, Vos MA, et al. Downregulation of delayed rectifier $K^{*}$ currents in dogs with chronic complete atrioventricular block and acquired Torsades de Pointes. Circulation. 1999; 100:2455-2461.

43. Tomaselli GF, Marban E. Electrophysiological remodeling in hypertrophy and heart failure. CardiovasC Res. 1999;42:270-83.

44. Nattel S. Acquired delayed rectifier channelopathies: how heart disease and antiarrhythmic drugs mimic potentially lethal congenital cardiac disorders. Cardiovasc Res. 2000;48:188-90.

45. Opthof $T$, Coronel $R$, Rademaker HM, et al. Changes in sinus node function in a rabbit model of heart failure with ventricular arrhythmias and sudden death. Circulation. 2000;101:2975-80. 
46. Vos MA, van Opstal JM, Leunissen HDM, et al. Electrophysiologic parameters and predisposing factors in the generation of drug induced Torsade de Pointes arrhythmias. Pharmacol Ther. 2001;92:109-122.

47. Kannel WB, Gordon T, Offutt D. Left ventricular hypertrophy by electrocardiogram. Prevalence, incidence, and mortality in the Framingham study. Ann Intern Med. 1969;71:89-105.

48. Messerli FH, Grodzicki T. Hypertension, left ventricular hypertrophy, ventricular arrhythmias and sudden death. Eur Heart /. 1992;13 Suppl D:66-9.

49. Swynghedauw B, Chevalier B, Charlemagne D, et al. Cardiac hypertrophy, arrhythmogenicity and the new myocardial phenotype. II. The cellular adaptational process. Cardiovasc Res. 1997;35:6-12.

50. Vos MA, de Groot SH, Verduyn SC, et al. Enhanced susceptibility for acquired torsade de pointes arrhythmias in the dog with chronic, complete AV block is related to cardiac hypertrophy and electrical remodeling. Circulation. 1998;98:1125-35.

51. Rials SJ, $W u$ Y, Xu X, et al. Regression of left ventricular hypertrophy with captopril restores normal ventricular action potential duration, dispersion of refractoriness, and vulnerability to inducible ventricular fibrillation. Circulation. 1997;96:1330-6.

52. Mayet J, Shahi M, McGrath K, et al. Left ventricular hypertrophy and QT dispersion in hypertension. Hypertension. 1996;28:791-6.

53. Gonzalez Juanatey JR, Garcia Acuna JM, Pose A, et al. Reduction of QT and QTc dispersion during long-term treatment of systemic hypertension with enalapril. Am / Cardiol. 1998;81:170-4.

54. Rials Sl, Wu Y, Ford $N$, et al. Effect of left ventricular hypertrophy and its regression on ventricular electrophysiology and vulnerability to inducible arrhythmia in the feline heart. Circulation. 1995; 91:426-30.

55. Gladman G, Davis AM, Fogelman R, et al. Torsade de pointes, acquired complete heart block and inappropriately long QT in childhood. Can / Cardiol. 1996;12:683-5.

56. Kurita T, Ohe T, Marui $N$, et al. Bradycardia-induced abnormal QT prolongation in patients with complete atrioventricular block with torsades de pointes. Am / Cardiol. 1992;69:628-33.

57. Vos MA, Verduyn SC, Gorgels APM, et al. Reproducible induction of early afterdepolarizations and Torsade de Pointes arrhythmias by d-sotalol and pacing in the dog with chronic atrioventricular block. Circulation. 1995;91:864-872.

58. van der Vusse G), Glatz JF, Stam HC, et al. Fatty acid homeostasis in the normoxic and ischemic heart. Physiol Rev. 1992;72:881-940.

59. Allard MF, Schonekess BO, Henning SL, et al. Contribution of oxidative metabolism and glycolysis to ATP production in hypertrophied hearts. Am I Physiol. 1994;267:H742-50.

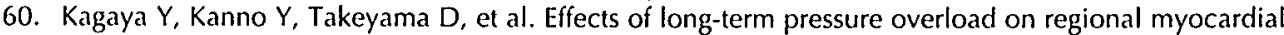
glucose and free fatty acid uptake in rats. A quantitative autoradiographic study. Circulation. 1990;81:1353-61.

61. Simko F. Left ventricular hypertrophy regression as a process with variable biological implications. Can I Cardiol. 1996;12:507-13.

62. Beznak M, Korecky B, Thomas G. Regression of cardiac hypertrophies of various origin. Can / Physiol Pharmacol. 1969;47:579-86.

63. Ishihara K, Zile MR, Tomita M, et al. Left ventricular hypertrophy in a canine model of reversible pressure overload. Cardiovasc Res. 1992;26:580-5.

64. Gerdes AM, Clark LC, Capasso JM. Regression of cardiac hypertrophy after closing an aortocaval fistula in rats. Am / Physiol. 1995;268:H2345-51.

65. Nakano $K$, Swindle MM, Spinale $F$, et al. Depressed contractile function due to canine mitral regurgitation improves after correction of the volume overload. / Clin Invest. 1991;87:2077-86.

66. Yokoshiki $H$, Kohya $T$, Tomita $F$, et al. Restoration of action potential duration and transient outward current by regression of left ventricular hypertrophy. I Mol Cell Cardiol. 1997;29:1331-9.

67. Kreher P, Ristori MT, Corman B, et al. Effects of chronic angiotensin I-converting enzyme inhibition on the relations between ventricular action potential changes and myocardial hypertrophy in aging rats. I Cardiovasc Pharmacol. 1995;25:75-80.

68. Verduyn SC, Ramakers C, Snoep G, et al. Time course of structural adaptations in chronic AV block dogs: evidence for differential ventricular remodeling. Am / Physiol Heart Circ Physiol. 2001; 280:H2882-90. 
69. van Opstal IM, Schoenmakers M, Verduyn SC, et al. Chronic amiodarone evokes no Torsade de Pointes arrhythmias despite QT lengthening in an animal model of acquired long-QT syndrome. Circulation. 2001;104:2722-7.

70. Volders PG, Sipido KR, Vos MA, et al. Cellular basis of biventricular hypertrophy and arrhythmogenesis in dogs with chronic complete atrioventricular block and acquired Torsade de Pointes. Circulation. 1998;98:1136-47.

71. Sasayama S, Ross J, Jr., Franklin D, et al. Adaptations of the left ventricle to chronic pressure overload. Circ Res. 1976;38:172-8.

72. Cooper G, Puga Fl, Zujko Kl, et al. Normal myocardial function and energetics in volume-overload hypertrophy in the cat. Circ Res. 1973;32:140-8.

73. Cerbai $E$, Crucitti $A$, Sartiani $L$, et al. Long term treatment of spontanesously hypertensive rats with losartan and electrophysiological remodeling of cardiac myocytes. Cardiovasc Res. 2000;45:388-396.

74. van Oosterhout, MFM. Local myocardial adaptations during chronic ventricular pacing. PhD thesis, Maastricht University, the Netherlands; 1999.

75. Volders, PGA. Cellular mechanisms of acquired Torsade de Pointes in the hypertrophied canine heart. The substrate and the trigger. PhD thesis, Maastricht University, the Netherlands; 1999.

76. van der Lee, KAIM. Fatty acid-mediated gene expression in the cardiac muscle. PhD thesis, Maastricht University, the Netherlands; 2001.

77. Corselink, M. The development of an experimental model to assess mechanical performance of skeletal muscle in the intact mouse. PhD thesis, Maastricht University, the Netherlands; 2001. 



\section{CHAPTER 2}

\section{Relation between the pacing induced sequence of activation and left ventricular pump function in animals}

Frits W. Prinzen and Maaike Peschar

Department of Physiology,

Cardiovascular Research Institute Maastricht, Maastricht University, the Netherlands

Published in: Pacing Clin Electrophysiol. 2002;25:484-498. 


\begin{abstract}
The main goal of this paper is to review animal experimental work on the effect of asynchronous activation on ventricular pump function. During normal sinus rhythm and atrial pacing the Purkinje system contributes significantly to the rapid electrical activation of the ventricles. In contrast, during ventricular pacing the impulse is almost exclusively conducted through the normal myocardium. As a consequence, electrical activation of the ventricles becomes asynchronous and has an abnormal sequence. The abnormal impulse conduction causes considerable disturbances occur in regional systolic fiber shortening, mechanical work, blood flow and oxygen consumption; low values occurring in early-activated regions and values above normal being present in late-activated regions. Many animal studies have now shown that the abnormal electrical activation, induced by ventricular pacing, leads to a depression of systolic and diastolic left ventricular (LV) function. Pacing at the right ventricular apex (the conventional pacing site) reduces LV function more than pacing at the high ventricular septum or at LV sites. In canine hearts with experimental left bundle branch block (LBBB) LV pacing significantly improves LV pump function. Differences in LV pump function between (combinations of) pacing sites are poorly correlated with QRS duration. Therefore, the cause of the depression of LV function during abnormal electrical activation appears to be a combination of the asynchrony and the sequence of activation. These experimental findings justify continuing attention for optimizing the site(s) of ventricular pacing in patients with normal and abnormal ventricular impulse conduction.
\end{abstract}




\section{Introduction}

During the first three decades of clinical pacing much attention has been paid to proper thresholds (sensing and stimulation) and proper synchronization between atria and ventricles. The latter was regarded to be more important for hemodynamic function than the sequence of ventricular electrical activation. Recently interest for the latter is growing, due to the increasing evidence that chronic pacing at the conventional pacing site, the right ventricular (RV) apex, is associated with pathological changes in the heart ${ }^{1-6}$. These changes have been related to increased mortality and morbidity in patients with ventricular pacemakers ${ }^{6-11}$. Another part of the recent interest in the ventricular activation sequence comes from findings that pacing at the left ventricle (LV) or at LV and RV simultaneously (biventricular pacing) can improve cardiac function in patients with heart failure and conduction disturbances ${ }^{12-14}$.

The goal of this paper is to review the literature on the effect of asynchronous activation, induced by ventricular pacing, on myocardial function in animal experiments. For obvious reasons animal experiments have presented more detailed information than clinical studies, which helps to explore potential mechanisms. Data from animal experiments may be qualitatively similar to those in man, but important quantitative differences may be present. This may be due to the fact that most animal studies are performed in (initially) healthy animals and that various preparations have been used, which differ from the clinical and intact human situation. At some points clinical data are mentioned in this paper, to place the experimental data in a wider perspective.

\section{Normal impulse conduction}

Normal activation of the ventricles starts with conduction of the electrical impulse from the atrio-ventricular (AV) node to the His-bundle. The His-bundle splits into the right and left bundle branches, which on their turn divide first into a few major branches (fascicles) and subsequently into a network of subendocardially located Purkinje fibers ${ }^{15-17}$. In the LV these Purkinje fibers form a network in the lower third of the septum and free wall, which also covers the papillary muscles ${ }^{15,17}$. There are significant interspecies differences in the size and extent of the rapid conduction system. In hearts from ox and sheep the bundles were significantly thicker and their branches extended much more towards the epicardium than in hearts from dog, pig and man ${ }^{18,19}$.

Impulse conduction in the Purkinje system is from base to apex and occurs very quickly $(3-4 \mathrm{~m} / \mathrm{s})^{17,20}$. The right and left bundle branches and their major tributaries are electrically isolated from the adjacent myocardium. The impulses exit the Purkinje system in the lower fourth of the RV and the lower third of the LV wall (Figure 1A) ${ }^{17}$. This exit site corresponds with the site where earliest activation of the ventricular muscle has been measured ${ }^{17,21-23}$. The activation of the myocardial muscular tissue in 

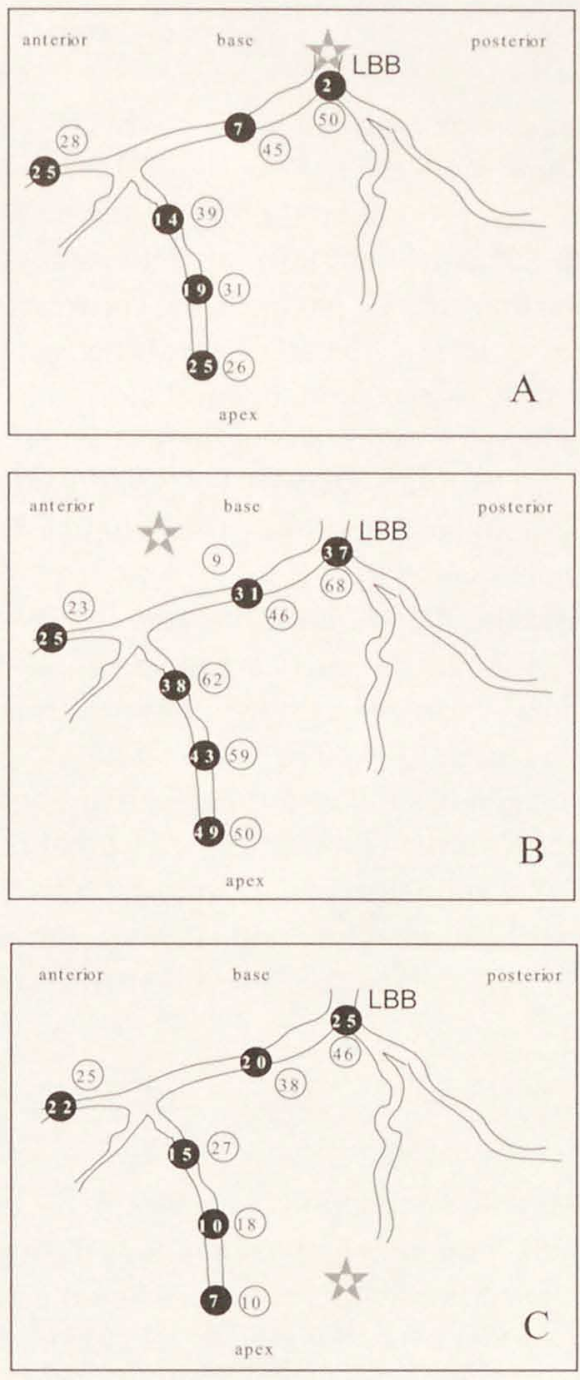

Figure 1. Electrical activation during pacing in the left bundle branch (LBB, A) and in high LV septal (B) and LV apical myocardium (C) in an isolated canine heart preparation. The closed symbols denote activation time ( $\mathrm{ms}$ ) of sites in the rapid conduction system and the open symbols denote activation time of sites in normal myocardium. Asterisks denote the site of pacing. In A, a normal pattern of activation occurred, with rapid conduction of the impulse within the Purkinje system from base to apex and a slower conduction in the normal myocardium from apex to base. In B, the impulse spread radially through myocardial muscle until it reached the nearest point of entry into the conduction system on the high paraseptal free wall $(23 \rightarrow 25 \mathrm{~ms})$. It then spread rapidly through conducting tissue and back out into ordinary muscle on the lower septum $(49 \rightarrow 50$ $\mathrm{ms}$ ), setting up a complex pattern of interacting wave fronts in ventricular muscle. In $\mathrm{C}$, the impulse entered the conducting tissue and normal myocardium and traveled towards the base through both tissues, albeit faster in the rapid conduction system. Redrawn from ref 17 . 
the septum occurs mainly from apex to base ${ }^{23-25}$. In the LV and RV free wall impulse conduction also occurs from apex to base and from endocardium to epicardium ${ }^{23,26,27}$. As a consequence of this impulse conduction, the posterobasal area is the last activated part of the ventricles. The electrical impulse is conducted approximately four times slower $(0.3$ to $1 \mathrm{~m} / \mathrm{s})$ in the normal myocardium than in the Purkinje system ${ }^{20-22,25,27}$. In man total ventricular activation lasts 62 to $80 \mathrm{~ms}$, corresponding with a QRS duration of $70-80 \mathrm{~ms}^{23}$, in dogs QRS duration is $40-50 \mathrm{~ms}^{28,29}$.

\section{Abnormal impulse conduction}

Abnormal impulse conduction generally implies a more asynchronous activation in combination with an abnormal sequence of activation. Such abnormal activation occurs in diseases affecting the ventricular conduction system, like blockade of the left or right bundle branch ${ }^{30}$ or the presence of an accessory pathway bypassing the AV node, like in the Wolff-Parkinson-White syndrome ${ }^{31}$. Also ectopic impulse generation, occurring during ventricular extrasystoles and, most relevant to this review, during ventricular pacing ${ }^{28,32}$, leads to abnormal impulse conduction.

Data from the literature indicate that the synchrony and sequence of activation during ventricular pacing are determined by at least four myocardial properties. 1) The poor coupling of the ectopically generated impulse to the rapid conduction system $17,26,28,33$. Myerburg et al. ${ }^{17}$ elegantly showed that impulses coming from the normal myocardium can enter the Purkinje system only at the apical part, the sites where during normal conduction the impulse exits this system (Figure $1 \mathrm{~B}$ and $\mathrm{C}$ ). Therefore, in most cases the sequence of activation during ventricular pacing is governed by the slow conduction through the normal myocardium, away from the pacing site ${ }^{28,32,34,35}$. 2) Because conduction through the myocardium is up to four times slower than conduction through the Purkinje system, activation of the entire ventricular wall is more asynchronous than during normal sinus rhythm and atrial pacing (Figure $1 \mathrm{C}$ and Figure 2). 3) Conduction is approximately two times faster along the muscle fibers than perpendicular to them ${ }^{36}$. Therefore, in a particular layer, the wavefront has an elliptic shape ${ }^{37}$. This may explain the similar shape of the early contracting epicardial region in Figure $2 \mathrm{C}$. Because fiber orientation changes by more than 90 degrees across the LV wall, and because impulses are also conducted in transmural direction, a complex three-dimensional helical wavefront is present in the LV wall during pacing ${ }^{37} .4$ ) The most endocardial fibers, even though not part of the Purkinje system, conduct impulses faster than the fibers in the major part of the LV wall ${ }^{38}$. This can be appreciated in Figure $2 \mathrm{C}$ as a relatively large early contracting (white) region in the endocardial layers. Therefore, total time required for electrical activation is shorter for LV endocardial than for LV epicardial pacing ${ }^{37}$.

Mapping of mechanical activation (Figure 2) indicates that RV apex pacing activates the septum relatively quickly ${ }^{39}$. However, in most canine hearts a significant 


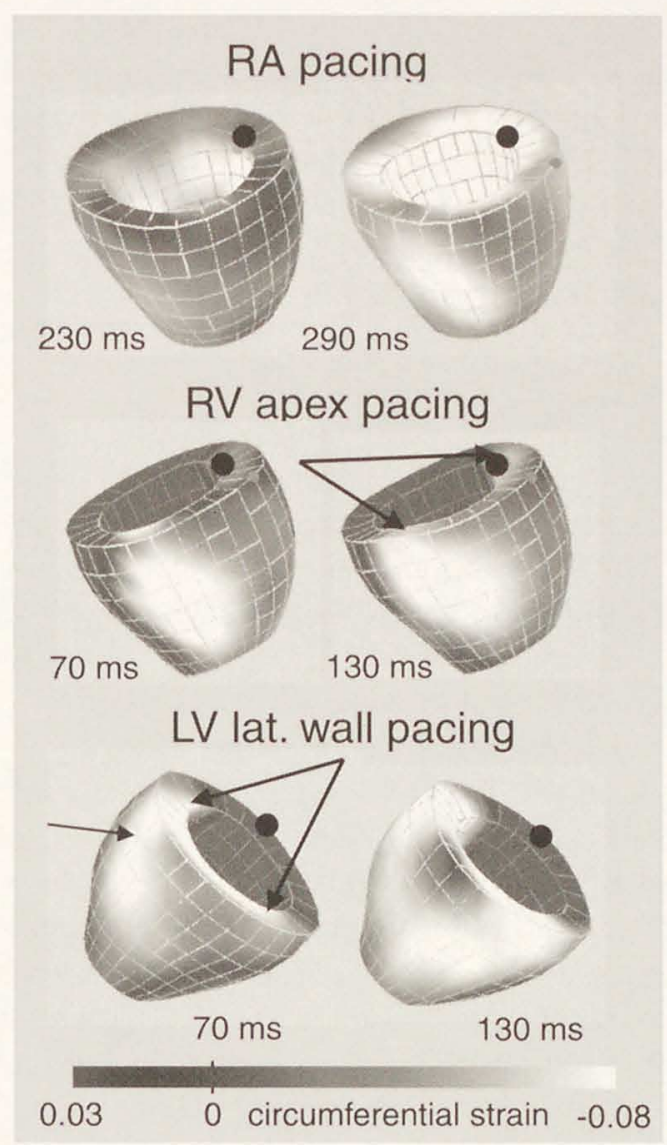

Figure 2. Patterns of LV contraction 230 and $290 \mathrm{~ms}$ after pacing the right atrium (RA pacing, upper panels) and 70 and $130 \mathrm{~ms}$ after pacing the RV apex (middle panels) and LV lateral wall (lower panels), as obtained using MRI tagging in anesthetized dogs (data from studies reported in refs $39,62,65)$. The shape of the LV wall was reconstructed from the MRI images. The black dot indicates the mid-septum. The gray level represents values of circumferential strain: dark gray = length at end-diastole (strain $=0$ ), white = shortening, black = stretching. During RA pacing all LV regions start to contract more or less simultaneously (upper left frame) and continue to shorten to the same extent (upper right frame). During RV apex pacing early shortening occurs in the posterior septum, spreading quickly towards other septal regions, but stretching the LV free wall. During pacing at the epicardium of the LV lateral wall early pronounced shortening is observed in an elliptical region at the epicardium (single arrow), the long axis of this ellipse being oriented parallel to the epicardial muscle fibers. Pronounced early shortening is also present along the endocardium, in a region extending beyond the region of early contracting epicardial tissue, suggesting more rapid impulse conduction in the endocardial layers (double arrow). During LV lateral wall pacing the septum is stretched. In the middle and lower panel the wavefront of contraction moves relatively slowly around the LV cavity, suggesting minor involvement of the Purkinje system in conduction of the ectopically generated impulse. 
delay occurred between mechanical activation of the septum and the LV free wall. This is probably due to slow trans-septal conduction, as observed in canine hearts during RV and LV free wall pacing ${ }^{33}$. Despite some differences endocardial activation ${ }^{32}$ some investigators use $A V$ sequential $R V$ apex pacing as model for "experimental left bundle branch block (LBBB)" $+10,12,+13$, because of the similarities in the QRS configuration of the surface ECG ${ }^{30,40,41}$.

Pacing at the LV lateral wall results in a mechanical activation sequence, which is virtually opposite to that during RV apex pacing (Figure 2). In epicardial electrical activation maps isochrone lines are close to each other in the vicinity of the site of pacing, and larger distances between the isochrone lines more remote from the pacing site $28,4,37,44$. This is probably due to conduction of the impulse to the endocardial layers and subsequently quick endocardial conduction (all or not via the Purkinje system, see above) and epicardial break-through in remote regions.

Information on impulse conduction during pacing in patients is limited. During RV apex pacing Vassallo et al. mapped LV endocardial activation at 12 sites in 40 patients, only 4 of them without underlying heart disease. Breakthrough of the impulse at the LV endocardium occurred at a single site in 39 out of 40 patients, breakthrough time being approximately $50 \mathrm{~ms}$. The impulse was conducted from the septum towards the distal free wall in a gradual manner, the site of latest activation being generally the inferoposterior wall ${ }^{32}$.

Due to the time consuming myocardial conduction ventricular pacing often leads to a doubling of QRS duration as compared to sinus rhythm ${ }^{28,29,32,45}$. Generally QRS duration is less prolonged during RV apex than during $L V$ lateral wall pacing. Longest QRS durations are found when pacing at the LV posterobasal wall ${ }^{28,29}$.

In order to avoid the abnormal activation during ventricular pacing investigators are attempting to pace in or close to the rapid conduction system. Indeed, several animal studies showed reduced QRS duration when pacing in the high ventricular septum as compared to RV apex pacing 3,45,46. Shortest QRS durations and normal QRS configurations occur during pacing in the His-bundle ${ }^{17-49}$. An alternative to the technically difficult His-bundle pacing is to pace at multiple sites. Pacing at two or three sites, more or less opposite to each other, reduces QRS duration by no more than $20 \%$ as compared with single site pacing ${ }^{29}$. This limited reduction is, most likely, explained by the fact that at each pacing site the initial impulse conduction occurs through the slow muscular conduction, rather than through quicker conduction through endocardial or Purkinje fibers.

\section{Abnormal contraction patterns}

The effect of abnormal electrical activation on contraction patterns of the LV wall appears to depend on the spatial resolution used. At the level of the whole ventricle the principal directions and magnitudes of deformation ${ }^{50}$ and systolic torsion ${ }^{51}$ were 
hardly affected by ventricular pacing. Using three pairs of orthogonally oriented ultrasound crystals, Owen et al. showed a more elliptical shape of the LV short axis during ventricular pacing ${ }^{52}$. More pronounced derangements have been found at the local level. Regional wall thickening ${ }^{53.55}$ and regional wall motion abnormalities ${ }^{56.59}$ have been observed during ventricular pacing by means of cineangiography and echocardiography. With pairs of strain gauges situated close to and remote from a pacing site in dog hearts it was shown that systolic segment shortening is considerably larger remote from than close to the pacing site ${ }^{56,60}$. Even more complex derangements of three-dimensional deformation of the myocardium was demonstrated using $\mathrm{X}$-ray markers detection from biplane angiography ${ }^{61}$.

Badke et al. ${ }^{56}$ were the first to observe early onset and rapid negative strain in early-activated regions and prestretch in late activated regions. Early-activated muscle fibers shorten by up to $10 \%$ in the isovolumic contraction phase. This rapid early systolic shortening is followed by minimal systolic shortening, sometimes even holo-systolic stretch, and premature relaxation (see site A in Figure 3). In contrast, in late-activated regions the fibers are stretched by as $15 \%$ during early systole, which is followed by doubling of net systolic shortening and by delayed relaxation (site $\mathrm{C}$ in Figure 3) ${ }^{34.62}$. Therefore, during ventricular pacing local contraction patterns do not only differ in the onset of contraction, but also, and more importantly, in the pattern of contraction.

Mapping of epicardial deformation with a video technique ${ }^{63,64}$ and MRI tagging studies (Figure 3 ) $^{39,62,65}$ have shown that the pattern of deformation gradually changes with increasing distance from the pacing site. With the growing potential to map ventricular contraction patterns, it is also interesting that during acute ventricular pacing the onset of local (fiber) shortening correlates well with the moment of electrical activation. This was shown using sonomicrometers ${ }^{56}$ epicardial videomarkers ${ }^{44}$ and MRI tagging ${ }^{39}$. The availability of algorithms to estimate the onset of shortening ${ }^{39,66}$ and the non-invasive nature of the MRI tagging technique allow non-invasive three-dimensional assessment of "mechanical activation" ${ }^{39,67}$. In case of pacing in the MRI scanner, however, special precautions are required ${ }^{65}$. Temporal differences in contraction have also been assessed using phase analysis of radionuclide angiography ${ }^{68,69}$ and tissue Doppler imaging ${ }^{70}$.

Cause of abnormal contraction patterns

The cause of the complicated regional differences in contraction pattern is most likely related to the local differences in myocardial fiber length during the early systolic phase. Fiber length is presumably closely related to sarcomere length, an important determinant of contractile force (for review see refs 71,72 ). Such a relationship has also been shown when in isolated hearts ventricular cavity volume is quickly increased or decreased during early systole ${ }^{73}$. Also, during asynchronous stimulation of two isolated 


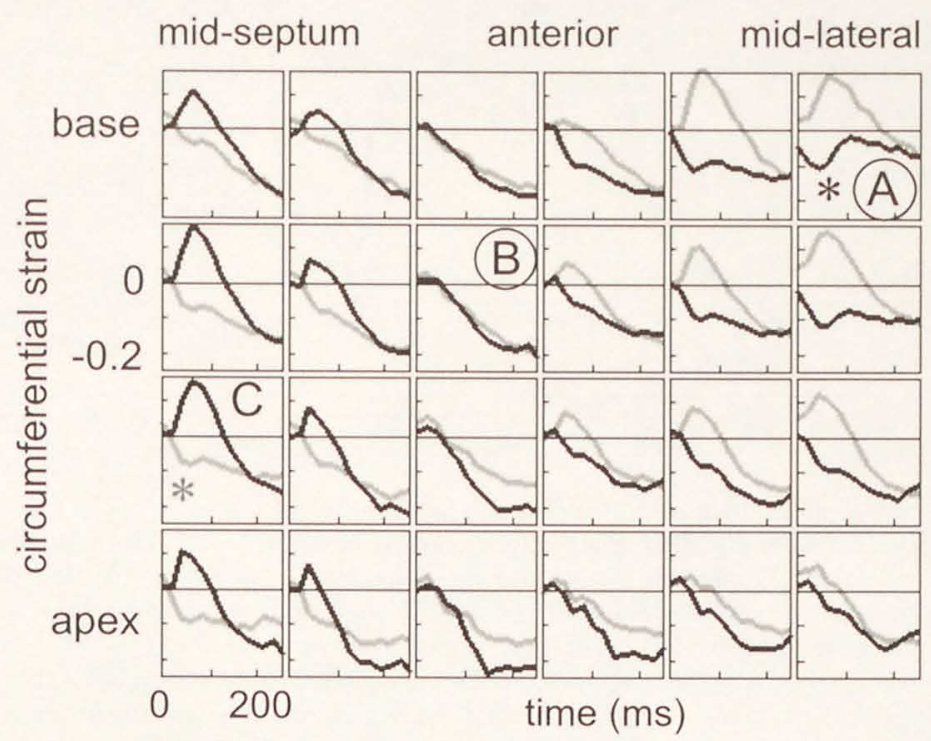

Figure 3. Contraction patterns in 24 regions of the anterior septum and anterior $\mathrm{LV}$ free wall during pacing at the LV lateral wall pacing (gray lines) and RV apex (black lines). Each graph in the array represents circumferential strain versus time in a specific region. The LV is displayed by cutting down the septum and folding the surface out onto the page. Rows represent different levels from base (top row) to apex (bottom row) of the LV and columns are circumferential position from mid septum (left most column) via the LV anterior wall to the LV lateral wall (rightmost column). The posterior half of the LV wall showed similar patterns, but is not shown to limit the size of the figure. Tics at the vertical axis denote a strain of $0.1(\sim 10 \%$ shortening), tics on the horizontal axis denote $100 \mathrm{~ms}$. Please note the early shortening near the pacing site $(*$ in the corresponding gray level) and prestretch in regions remote from the pacing site. Because LV lateral wall and RV apex are virtually opposite pacing sites, the contraction patterns during these pacing modes are almost each others mirror image. Gray strain patterns in regions $A, B$ and $C$ underlie the stress-strain relations in the corresponding panels in figure 4 . Data derived from studies reported in refs 39,62 .

papillary muscles, placed in series, the force-velocity relation shifted downward in the earlier activated muscle and upward in the later activated one ${ }^{74}$. Therefore, the regional differences in contraction pattern during ventricular pacing are most likely caused by regional differences in effective preload. Accordingly, during ventricular pacing regional systolic fiber shortening increases with increasing isovolumic stretch ${ }^{75}$. Similarly, a close correlation exists between the time of local electrical activation and systolic fiber shortening ${ }^{63}$.

Redistribution of local work, blood flow and metabolism

Delhaas et al. have shown that the local differences in wall motion and deformation, mentioned above, reflect regional differences in myocardial work ${ }^{64}$. These 


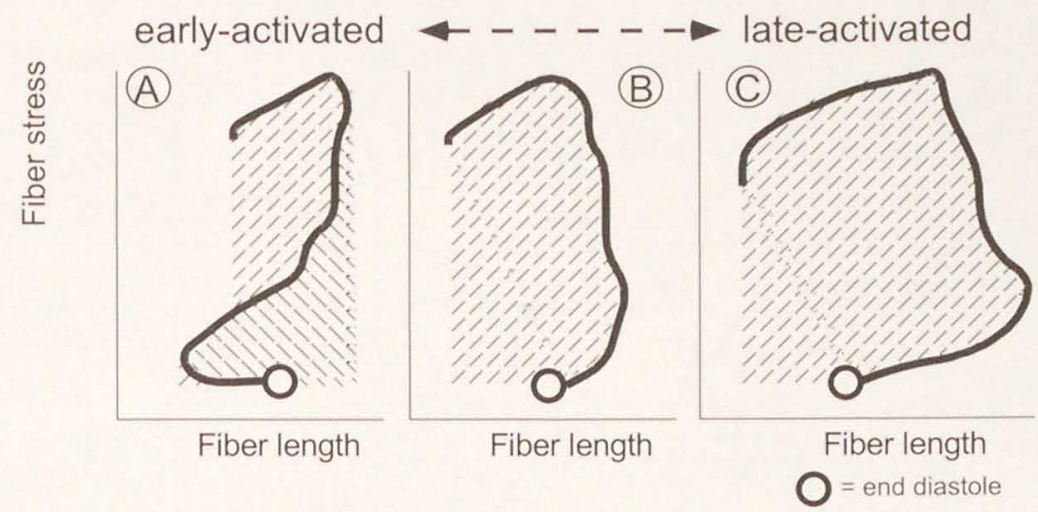

Figure 4. Regional stress-strain diagrams during normal (B), early (A) and late electrical activation (C). Data obtained using MRI tagging and LV pressure measurement ${ }^{62}$. The hatched area represents external work. Usually the stress-strain loop runs counterclockwise, indicating positive external work. However, in early activated myocardium the loop may run counterclockwise during part of the systolic phase, indicating negative external work (indicated by the different hatching pattern). Negative work means that work is being done $\mathrm{ON}$ the region rather than BY the region. External work during a complete cardiac cycle is almost zero in early-activated myocardium, whereas in late-activated myocardium external work is larger than in normally activated myocardium. Data derived from studies reported in ref 62.

investigators constructed local fiber stress-fiber strain diagrams using measurements of LV cavity pressure and volume as well as local epicardial strains. External work was calculated as the area of the fiber stress-strain diagram and total myocardial work as the sum of external work and potential energy, according to the pressure-volume (P-V) area concept used for the entire LV ${ }^{76,77}$. Similar data were obtained within the entire LV wall using MRI tagging (Figure 4) ${ }^{62}$. Close to the pacing site the area of the stress-strain loops is small, due to a figure-eight like shape, indicating the absence of external work. In regions remote from the pacing site the loops are wide, indicating increased external work (Figure 4). Total myocardial work is reduced by $50 \%$ in early-activated regions and is increased by $50 \%$ in late-activated regions, as compared with the situation during normal electrical activation, as during atrial pacing ${ }^{62,64}$.

Several studies report regional differences in myocardial blood flow 34,43,64,78, glucose uptake ${ }^{43}$ and oxygen consumption ${ }^{64}$ during ventricular pacing, which are similar to the differences in mechanical workload. As compared to sinus rhythm myocardial blood flow and oxygen consumption are approximately $30 \%$ lower in early-activated regions and approximately 30\% higher in late-activated regions ${ }^{34,64}$. Several observations support the idea that the regional differences in myocardial blood flow and oxygen consumption are caused by the regional differences in workload. Lactate extraction decreases and oxygen extraction increases when perfusion becomes insufficient. When varying the pacing site, regional lactate and oxygen extraction did not change, indicating that regional perfusion adapts well to altered mechanical load ${ }^{64}$. 
Accordingly, a good correlation was found between local mechanical work and oxygen consumption during ventricular pacing ${ }^{64}$. Furthermore, the regional differences in blood flow during pacing disappears during total coronary vasodilation by adenosine ${ }^{79}$. Therefore, it seems likely that regional differences in mechanical work increase regional oxygen requirements, which are met by local autoregulation of myocardial blood flow ${ }^{80}$.

Partly in contradiction with the data mentioned above, results from other studies suggest that (part of) the regional differences in blood flow could be due to impediment of perfusion by the abnormal contraction and relaxation patterns ${ }^{43,78,81}$. These studies were, however, performed at higher heart rates (up to $>200$ beats $/ \mathrm{min}$ ), when myocardial perfusion becomes more critical ${ }^{12}$. Therefore, at high heart rates the abnormal contraction patterns, induced by pacing, may contribute to inadequate perfusion.

\section{Influences of ventricular pacing on cardiac pump function}

\section{Influence of pacing rate and atrio-ventricular synchronization}

Ventricular pump function during pacing may be modified by the following factors: the pacing rate, the coupling and the interval between atrial and ventricular activation and the site of pacing. As maintaining a proper heart rate during AV-block was the first clinical application of ventricular pacing, it is not surprising that ventricular pacing at normal heart rate increases cardiac output as compared with the low ventricular rates during AV-block. This increase was larger when the idioventricular rhythm was lower ${ }^{83}$.

In the early years of pacing the electrical stimulus was selectively applied to the ventricle (ventricular single chamber pacing, $V$-pacing). Doing so the contraction of atria and ventricles is uncoupled, leading to an atrial contribution to LV filling which varies from beat to beat. This also results in large beat-to-beat variations in stroke volume, systolic pressure and other hemodynamic variables ${ }^{83}$. The introduction of sequential AV pacing resulted in more regular heart beats and improved hemodynamics in animals ${ }^{84,85}$ and in patients ${ }^{86}$. Further improvement was obtained by optimizing the interval between atrial and ventricular stimulation (AV-interval) to values close to the natural $A V$-interval during sinus rhythm ${ }^{48}$. In pacemaker patients cardiac output increased by $4-20 \%$ when increasing the $A V$-interval from 0 to $100-130$ $\mathrm{ms}^{86-89}$.

\section{Influence of abnormal electrical activation of the ventricles}

Although the importance of normal electrical activation of the ventricle for optimal pump function was already recognized by Wiggers in $1925^{90}$, it took about seventy years before it gained broad interest. Several investigators ${ }^{84,86}$ regarded the abnormal activation of little importance, because AV-sequential pacing significantly improved cardiac pump function over $V$-pacing. Nevertheless, one of these groups ${ }^{8.4}$ showed 
better pump function during LV apex pacing than during pacing at RV sites. Kosowsky et al. compared RV apex pacing with His-bundle pacing, the latter maintaining the normal activation but allowing to vary AV-delay ${ }^{18}$. These investigators concluded that AV-synchrony and proper sequence of activation are equally important. This conclusion has been confirmed by more recent studies in animals and man ${ }^{85,91,92}$.

The importance of the sequence of activation for pump function can further be derived from results of animal studies on the influence of the pacing site on ventricular pump function. Several studies, using single chamber pacing, suggested little or no influence of the site of pacing on ventricular performance ${ }^{50,83,93-97}$. In contrast, other studies using single chamber pacing ${ }^{28,98-102}$ and virtually all studies using AVsequential pacing ${ }^{29,34,44,45,57,63,103,104}$ showed a significant influence of the site of pacing on hemodynamic performance.

Because the majority of the studies using AV-sequential pacing found a consistent effect of pacing site on pump function, the inconsistent findings in the older studies are likely to be explained by the use of single chamber pacing. The beat-to-beat differences in atrial contribution cause large beat-to-beat differences in hemodynamics during this kind of pacing, thus obscuring changes due to varying the site of pacing. Another confounding factor is the pacing rate. In single chamber pacing the natural rhythm has to be overpaced to gain capture. Some investigators (may) have used the lowest possible pacing rate for each pacing site, whereas others (may) have used the same rate for each pacing site, which requires high rates (often above 140 beats $/ \mathrm{min}$ ). While the latter range of heart rates is unphysiological, the lower, but variable heart rates may induce rate-dependent modifications in contractility (force-frequency relation) or may obscure decreases in stroke volume by increases in heart rate.

\section{Systolic and diastolic function}

The hemodynamic effect of switching from atrial to ventricular pacing varies between studies (Table 1). Generally ventricular pacing does not influence measures of preload (LV end-diastolic pressure or volume), except for some studies where AV-interval is abnormally short or AV-synchronization is absent ${ }^{50,84,103}$.

Ventricular pacing reduces systolic and diastolic function independent of pre and afterload. This can be concluded from studies using preparations where pre and afterload were controlled ${ }^{102,105}$ and in experiments where pre and afterload independent indices of ventricular function were determined ${ }^{1,52,99,102,103}$ (Table 1).

With respect to systolic function, $L V d P / d_{\max }$ appears to be the most sensitive marker of reduced systolic function ${ }^{29,45,85,102,106}$. $\mathrm{LV} \mathrm{dP/dt} t_{\max }$ is dependent on preload, but since this parameter hardly changes with changing pacing site or mode, it appears a reliable marker of LV contractility. The sensitivity of this isovolumic measure of contractility may be due to the large differences in muscle fiber length changes during this phase (see above). Probably forces, generated by the already activated fibers, are 
Table 1.

Comparison of hemodynamic effects of atrial and ventricular pacing in animal experiments.

\begin{tabular}{|c|c|c|c|c|c|c|c|c|}
\hline Ref. & Model & Prep & VIAV & $\mathrm{CO}$ & LVSP & LVEDP & LV dP/dimax & LV dP/dtmin \\
\hline 1 & & C & AV & & $A=I V^{2}$ & $A=L V$ & $A>L V$ & $A>L V$ \\
\hline 29 & & $\mathrm{O}$ & $A V$ & $A=L V^{*}>R V$ & $A=L V^{*}=R V$ & $A=L V^{*}>R V$ & $A=L V^{*}>R V$ & $A=L V^{*}>R V$ \\
\hline 34 & & $\mathrm{O}$ & AV & $\Lambda>L V=R V$ & $A=L V=R V$ & $A=L V=R V$ & $A>L V=R V$ & \\
\hline 45 & $A \vee B$ & C & $A V$ & $\wedge>R \mathrm{a}$ & $A=R V_{A}$ & $A=R V$ & $A>R V$ & $A>R V$ \\
\hline 48 & & $\mathrm{O}$ & $\Lambda V$ & $\wedge \geq H>V$ & $A \geq H>V$ & & $A \geq H>V$ & \\
\hline 50 & & C & V & $\Lambda=L V=R V$ & $A=L V=R V$ & & & \\
\hline 52 & & C & V & $A>V$ & $=$ & & & \\
\hline 63 & & $\mathrm{O}$ & $A V$ & $A>I V^{*}=R V$ & $A>L V^{*}=R V$ & $A=L V^{*}=R V$ & $A>L V^{*}=R V$ & \\
\hline 83 & & $\mathrm{O}$ & V & $A>V$ & $A>V$ & & & \\
\hline 85 & & $\mathrm{O}$ & $V, A V$ & & $A=A V>V$ & $A=A V>V$ & $A>A V>V$ & $A>A V>V$ \\
\hline 93 & & 0 & V & $A>L V^{*}=R V^{*}$ & & $A=L V^{*}=R V$ & & \\
\hline 99 & & $\mathrm{O}$ & V & $A>V$ & & & & \\
\hline 102 & & 1 & V & & $A>L V^{*}>R^{*} *$ & & & \\
\hline 103 & & $\mathrm{C}$ & $A V$ & & $A>L V=R V^{*}=$ & $A>L V=R V^{*}$ & $A>L V=R V^{*}$ & $A>L V=R V^{*}$ \\
\hline 105 & Bypass & 0 & v & & $A>V$ & & $A>V$ & \\
\hline 113 & & 0 & V & & $A>V$ & & & $A<V($ Tau $)$ \\
\hline
\end{tabular}

AVB: AV-block, prep: preparation, being either $C$ (closed) or $O$ (open) chest, $V$ : single chamber ventricular pacing, AV: AV sequential pacing, CO: cardiac output, LVSP: LV systolic pressure, LVEDP: LV end-diastolic pressure, $L V \mathrm{dP} / \mathrm{dt}_{\max }$ and $L V \mathrm{dP} / \mathrm{dt}_{\min }$ are the maximal rates of rise and fall of $L V$ pressure, ${ }^{*}$ indicates multiple sites tested, \# indicates that the results are based on end-systolic pressure-volume relations.

dissipated by internal resistances of not yet activated fibers. As discussed in the paragraph on the cause of the abnormal contraction patterns, contractility of the individual cells is probably hardly affected. In chloralose anesthetized dogs the effect of

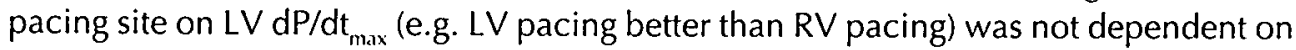
sympathetic and/or vagal stimulation ${ }^{107}$.

Many studies report differences in cardiac output and systolic arterial and LV pressure (Table 1). In general, stroke volume is affected more than systolic LV pressure $29,34,45,103,106$. The sensitivity of stroke volume to asynchronous activation could be explained by the finding that total duration of systole is hardly influenced by pacing 102,105, but that the rates of rise and fall of LV pressure are slower. As a consequence the isovolumic phases last longer, leaving less time for ejection ${ }^{108}$. Stroke work may indicate the effects of pacing even better than stroke volume, because changes in systolic pressure usually parallel the changes in stroke volume ${ }^{109}$.

With regard to the changes in stroke volume, it is important to note that ventricular pacing, especially RV apex pacing, can induce mitral valve regurgitation in animals ${ }^{55,93}$ 


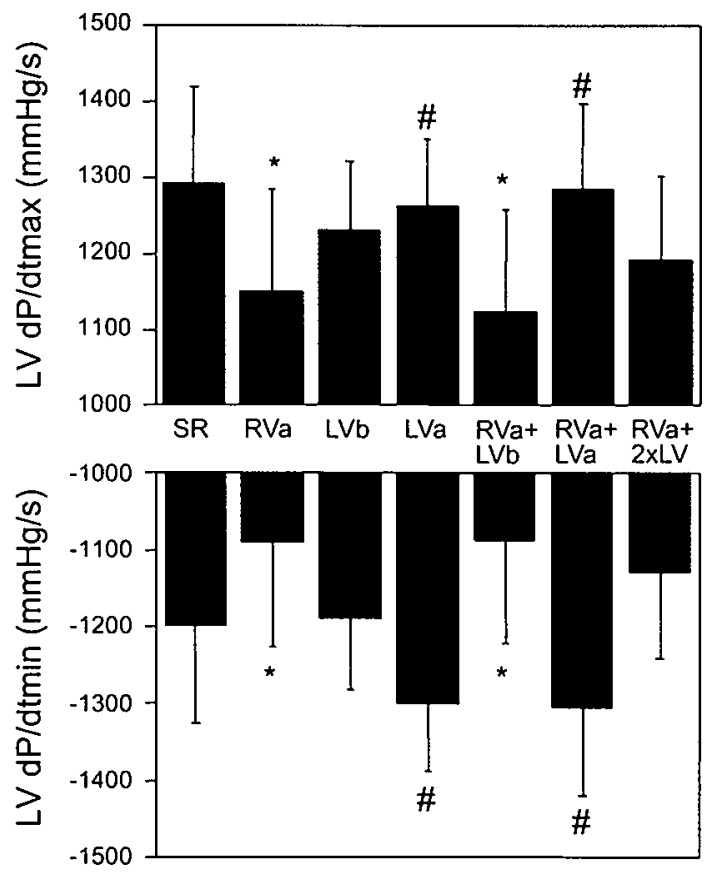

Figure 5. $L V d P / d t_{\text {max }}$ and $L V d P / d t_{\text {min }}$ during sinus rhythm (SR), RV apex (RVa), LV base (LVb), LV apex (LVa) pacing and during RVa pacing in combination with one or two LV sites. Experiments were performed in anesthetized open-chest dogs. Pacing was VDD pacing with AV-interval 25-30 ms. ${ }^{*} p<0.05$ vs. SR and $\# p<0.05$ vs. RVa pacing (reproduced with permission of the publisher from ref 29).

and patients ${ }^{110,111}$. Unfortunately, these studies present only qualitative data, so that it is not clear what part of stroke volume is returned to the left atrium.

The negative inotropic effect of pacing has also been characterized using the LV function curve, i.e. output at varying preload ${ }^{99}$ and the end-systolic P-V relation. In isovolumically beating isolated hearts Burkhoff et al. found that pacing reduced the slope of the end-systolic P-V relation with only minimal change in the P-V intercept on the volume axis ${ }^{102}$. In contrast to in vivo studies the major effect of pacing appeared to be an increased $P-V$ intercept ${ }^{152,103,104}$. In all these studies ventricular pacing reduced contractility as compared to atrial pacing or sinus rhythm.

According to the "triple control of relaxation" theory "1/2 ventricular relaxation is dependent on preload, afterload and the uniformity of contraction and relaxation processes. Because ventricular pacing increases the degree of inhomogeneity in contraction and relaxation, it is not surprising that ventricular pacing also impairs ventricular relaxation. Isovolumic relaxation parameters, like $\mathrm{LV} \mathrm{dP/dt} t_{\min }$ and tau, are strongly influenced by pacing ${ }^{29,85,107,113-115}$. Parameters of auxotonic relaxation (rate of segment lengthening or LV volume increase) are also lower during ventricular pacing 
than during sinus rhythm, but the difference is less pronounced than for the isovolumic relaxation parameters 85.114 .

Interestingly, pacing at the various sites had similar effects on LV dP/dt ${ }_{\max }$ and LV $\mathrm{dP} / \mathrm{dt}_{\min }$ (Figure 5) ${ }^{29,167}$. This link between contractility and relaxation parameters could be explained in two ways. When assuming a fixed duration of contraction for each region a more synchronous contraction is expected to lead to more synchronous relaxation. Alternatively a larger stroke volume, induced by a better sequence of activation, reduces end-systolic load, which is known to accelerate relaxation ${ }^{112}$.

Another important consequence of ventricular pacing, is its effect on ventricular oxygen consumption. Burkhoff et al. ${ }^{102}$ showed that in isolated, isovolumically beating hearts ventricular pacing reduced oxygen consumption and developed LV pressure to the same amount, so that efficiency was not influenced. In a similar preparation Boerth et al. reported a smaller reduction in oxygen consumption than in pressure development, resulting in a decrease in efficiency ${ }^{105}$. In anesthetized open-chest ${ }^{116}$ and in conscious dogs ${ }^{52}$ ventricular pacing at the RV apex decreased mechanical output, whereas myocardial oxygen consumption was unchanged ${ }^{52}$ or even increased ${ }^{116}$, as compared to atrial pacing. Therefore, efficiency decreased by $20-30 \%$ decrease in these studies. Such inefficiency of conversion of metabolic to pumping energy may be of concern if ventricular pacing is performed in patients with compromised coronary circulation.

Search for the optimal pacing site(s)

While the negative effects of ventricular pacing on ventricular pump function appear to hold for all pacing sites, many studies showed that pacing at the RV apex resulted in the most pronounced reduction (discussed in more detail below, in relation to Tables 1,2 and 3). The relatively poor pump during $R V$ apex pacing is of great practical importance, because the RV apex is the traditional pacing site in patients. Probably at least as important as the acute disturbances in pump function are the maladaptations during longer lasting ventricular pacing. Such chronic changes consist of asymmetric hypertrophy ${ }^{1,117}$, ventricular dilatation ', fiber disarray ${ }^{2,3}$ increased myocardial catecholamine concentrations ${ }^{4}$ and disturbed perfusion ${ }^{5.6}$. The combination of reduced pump function and long-term maladaptations could be involved in higher morbidity and mortality in patients with chronic RV apex pacing than with atrial pacing ${ }^{6-11}$.

Therefore, investigators are exploring alternative sites for pacing. Already in the 1960s the group of Scherlag ${ }^{17.18}$ showed that His-bundle pacing resulted in the same QRS duration and pressure development as sinus rhythm and atrial pacing and better hemodynamics than during RV apex pacing (Table 2). More recent studies in dogs and man focused on the effect of pacing in the high ventricular septum, also called RV outflow tract (RVOT). Pacing at this location synchronized contraction patterns ${ }^{3}$ and improved pump function as compared to RV apex pacing in dogs ${ }^{45}$ (Table 2) and 
Table 2.

Comparison of hemodynamic effects of pacing at the RV apex, His bundle and high RV septum in animal experiments.

\begin{tabular}{|c|c|c|c|c|c|c|c|c|}
\hline Ref. & Model & Prep & V/AV & $\mathrm{CO}$ & LVSP & LVEDP & LV dP/ditmax & LV dP/dımin \\
\hline 45 & $A \vee B$ & $\mathrm{C}$ & AV & $R V s>R V_{a}$ & $R V_{5}=R V_{s}$ & $R V_{s}<R V_{a}$ & $\mathrm{RV}_{s}>\mathrm{RVa}$ & RVS > RVa \\
\hline 48 & & 0 & AV & $A \geq H>V$ & $A \geq H>V$ & & $A \geq H>V$ & \\
\hline 95 & $A \vee B$ & $\mathrm{O}$ & V & $\mathrm{LV}^{*}=\mathrm{RV}^{*}=\mathrm{H}$ & & & & \\
\hline 96 & $A \vee B$ & $\mathrm{O}$ & V & $L V^{*}=R V^{*}=H$ & & $L V^{*}=R V=H$ & $I V^{*}=R V^{*}=H$ & \\
\hline
\end{tabular}

RVs and RVa are RV seplum and apex, respectively, H: His bundle. Other abbreviations as in Table 1.

patients 118-121, although QRS duration and configuration were still abnormal as compared to atrial pacing. Combined pacing at RV apex and RVOT in patients reduced QRS duration as compared to RVOT pacing alone, but did not lead to further improvement of cardiac output ${ }^{119}$. The clinical effects of RVOT pacing have been recently reviewed elsewhere in more detail ${ }^{122}$.

Beside the RVOT also LV pacing sites become increasingly popular, especially since newly developed leads for trans-coronary venous approach makes pacing of the LV epicardium clinically feasible ${ }^{123}$. LV function is consistently better when pacing LV sites than when pacing RV sites ${ }^{28,29,4598-101,106,124}$ (Table 3). Among all LV pacing sites, the LV apex generally results in the best maintenance of pump function in normal animal hearts ${ }^{28,29,100,101}$ (Table 4). The better LV function during LV pacing than during $R V$ pacing is not associated with shorter QRS duration ${ }^{20}$. When pacing the LV apex simultaneous with the RV apex, or simultaneous with the RV apex and the basal LV lateral wall, QRS duration is reduced but LV function does not improve or sometimes even deteriorates (Table 4, see also Figure 5) ${ }^{29,100,106}$. However, pacing the LV apex in combination with the RV apex and RVOT ${ }^{100}$ or in combination with RV apex, RVOT and LV base ${ }^{106}$ slightly increases cardiac output compared to LV apex pacing alone.

In the studies mentioned above the animal hearts had an intact ventricular conduction system. It is important to note that in all these studies the best pacing site (LV apex, RVOT, His-bundle) at best prevented a reduction of pump function, compared to atrial pacing or sinus rhythm, but never improved it. Moreover, it is important to acknowledge that in most studies on cardiac function the focus is on LV function, whereas little is known about RV function. Also, even though LV pacing resulted in better LV pump function than RV pacing, long-term LV pacing causes structural adaptations, like asymmetric hypertrophy and ventricular dilatation ${ }^{1}$. Immediately after stopping the long-term (6 months) LV pacing LV function returned to the initial level, indicating that the structural alterations had not (yet) resulted in irreversible changes in function. A similar observation was made in patients after $22 \pm 7$ months of RV apex pacing ${ }^{6}$. 
Table 3.

Comparison of hemodynamic effects of RV apex and LV pacing in animal experiments.

\begin{tabular}{|c|c|c|c|c|c|c|c|c|}
\hline Ref. & Model & Prep & V/AV & $\mathrm{CO}$ & LVSP & I.VEDP & IV dP/dtmax & $\mathrm{LV} \mathrm{dP} / \mathrm{d} t \min$ \\
\hline 28 & $A \vee B$ & $\mathrm{O}$ & $v$ & $\mathrm{LV}^{*}>\mathrm{RV}$ & & & & \\
\hline 29 & & $\mathrm{O}$ & AV & $\mathrm{LV}^{*}>\mathrm{RV}$ & $\mathrm{LV}^{*}=\mathrm{RV}$ & $L V^{*}>R V$ & $\mathrm{LV}^{*}>\mathrm{RV}$ & $L V^{*}>\mathrm{RV}$ \\
\hline 34 & & $\mathrm{O}$ & AV & $\mathrm{LV}=\mathrm{RV}$ & $\mathrm{IV}=\mathrm{RV}$ & $\mathrm{LV}=\mathrm{RV}$ & $L V=R V$ & \\
\hline 50 & & $\mathrm{C}$ & $v$ & $L V=R V$ & $L V=R V$ & & & \\
\hline 63 & & $\mathrm{O}$ & AV & $L V^{*}=R V$ & $I V^{*}=R V$ & $L V^{*}=R V$ & $\mathrm{LV}^{*}=\mathrm{RV}$ & \\
\hline 84 & Bypass & $\mathrm{O}$ & $V, A V$ & & & & $L V>R V$ & \\
\hline 93 & & 0 & v & $L V^{*}=R V^{*}$ & & $\mathrm{LV}^{*}=\mathrm{RV}$ & & \\
\hline 95 & $A \vee B$ & $\mathrm{O}$ & v & $\mathrm{LV}^{*}=R \mathrm{~V}^{*}$ & & & & \\
\hline 96 & AVB & $\mathrm{O}$ & V & $\mathrm{LV}^{*}=\mathrm{RV}^{*}$ & & $\mathrm{LV}^{*}=\mathrm{RV}$ & $L V^{*}=R V^{*}$ & \\
\hline 98 & & 0 & V & $\mathrm{LV}^{*}>\mathrm{RV}$ & I.V* $>$ RV & $\mathrm{LV}^{*}>\mathrm{RV}$ & $L V^{*}>\mathrm{RV}$ & \\
\hline 101 & $A \vee B$ & C & V & $\mathrm{LV}^{*}>\mathrm{RV}$ & & & & \\
\hline 102 & & 1 & V & & $\mathrm{LV}^{*}>\mathrm{RV}^{*}=$ & & & \\
\hline 103 & & $c$ & AV & & $L V=R V^{*}=$ & $\mathrm{LV}=\mathrm{RV} \cdot$ & $L V=R V^{*}$ & $\mathrm{IV}=\mathrm{RV}^{*}$ \\
\hline 106 & $A \vee B$ & $\mathrm{O}$ & AV & $L V>R V$ & $L V=R V$ & $\mathrm{LV}=\mathrm{RV}$ & $L V>R V$ & IV $>$ RV \\
\hline 107 & $A \vee B$ & $\mathrm{O}$ & V & & & & LV $>$ RV & $\mathrm{LV}>\mathrm{RV}$ \\
\hline
\end{tabular}

For abbreviations see Table 1.

Table 4.

Comparison of hemodynamic effects of $\mathrm{LV}, \mathrm{BiV}$ and multisite pacing in animal experiments.

\begin{tabular}{|c|c|c|c|c|c|c|c|c|}
\hline Ref. & Model & Prep & VIAV & $\mathrm{CO}$ & LVSP & LVEDP & LV dP/dtmax & LV dP/dtmin \\
\hline 28 & $A \vee B$ & 0 & V & $\begin{array}{l}L V a=L V I=L V p> \\
L V O T\end{array}$ & & & & \\
\hline 29 & & $\mathrm{O}$ & AV & $L^{*}=B i V=M S$ & $\mathrm{LV}^{*}=\mathrm{BiV}=\mathrm{MS}$ & $\mathrm{LV}^{*}=\mathrm{BiV}=\mathrm{MS}$ & $I V^{*}=B i V=M S$ & $L V^{*}=B i V=M S$ \\
\hline 94 & $A \vee B$ & C & V & $L V a=L V \mid=L V p$ & $L V a=\lfloor V \mid=L V p$ & & & \\
\hline 100 & $A \vee B$ & C & $A V$ & $M S>L V$ & $\mathrm{MS}>\mathrm{BiV}=1 \mathrm{Va}$ & & & \\
\hline 101 & $A \vee B$ & c & $v$ & $\begin{array}{l}\mathrm{LVa}=L \mathrm{~L} p>L V \mathrm{~L}= \\
\mathrm{LVOT}\end{array}$ & & & & \\
\hline 106 & $A \vee B$ & $\mathrm{O}$ & AV & $M S=B i V=L V$ & $M S=B i V=L V$ & $\mathrm{MS}=\mathrm{BiV}>\mathrm{L} \mathrm{V}$ & $M S=B i V=L V$ & $M S=B i V=L V$ \\
\hline
\end{tabular}

LVa, LVI, LVp and LVOT are LV apex, LV lateral, LV posterior wall and LV outflow tract, respectively. MS: multisite, BiV: biventricular. Other abbreviations as in Table 1. 
There are several ways by which asynchronous activation, as for example induced by ventricular pacing, can cause the disadvantageous hemodynamic effects mentioned above. In some studies the decrease in preload could explain (part of the loss of ventricular pump function ${ }^{50,103}$, but in most studies preload changes appear to play a minor role. Mitral valve insufficiency ${ }^{55,110}$ obviously reduces LV pump function directly by reducing the volume ejected into the aorta and indirectly by reducing LV cavity volume (and so: preload). Mitral valve regurgitation during RV apex pacing may be caused by the early activation of the septum, leading to leftward motion of the septum ${ }^{57}$, while the papillary muscles are still passive, because trans-septal conduction is slow ${ }^{33}$.

An obvious cause of reduced pump function during abnormal electrical activation seems the asynchronous contraction of the different parts of the ventricular muscle. This idea has been explored by Suga et al. in a mathematical simulation ${ }^{125}$. The LV wall was divided into two elements with similar contractile properties. Contractility of the whole LV decreased considerably when the asynchrony increased to more than $100 \mathrm{~ms}$, a value similar to those observed duration during ventricular pacing ${ }^{12.5}$.

Some experimental studies report a correlation between QRS duration and systolic LV function ${ }^{102,103,126}$, but such correlation was absent in other studies ${ }^{29,109,119}$. A possible explanation for the inconsistent correlation between QRS duration and LV function is that QRS duration is a measure of the duration of activation of both RV and LV. This idea is supported by the finding that LV function correlates better with the duration of LV endocardial activation than with QRS duration ${ }^{103}$.

Beside the asynchrony of activation, also the pathway of activation may be a determinant of ventricular function. In this respect Wiggers ${ }^{90}$ already suggested that the poor chamber function is due to activation of the ventricular muscle in two phases: muscle fibers in the vicinity of the pacing site by myocardial conduction and more remote myocardium by conduction via the Purkinje system. The premature contraction of the early-activated myocardium was considered ineffective, because it occurs before onset of the rise in LV pressure. LV function should, therefore, be dependent on the amount of remaining, late-activated, myocardium. Indeed Lister et al. ${ }^{28}$ reported a relation between the size of the area with muscle conduction and the reduction in pump function. In an isovolumically contracting canine heart preparation Burkhoff et al. ${ }^{102}$ found that ventricular pacing reduces the slope of the end-systolic P-V relation and that the reduction in myocardial oxygen consumption is proportional to the reduction in systolic LV pressure. Both findings can also be explained by a loss of effective muscle mass.

The "effective muscle mass" theory does, however, not take into account that early and late-activated regions of the ventricular muscle interfere mechanically with each other. In a preparation with two papillary muscles placed in series Tyberg et al. ${ }^{74}$ showed that early activation of the weaker muscle makes the later activated muscle 
stronger. Measurements of regional contraction patterns during ventricular pacing in vivo (Figure 3) ${ }^{3,56,56,60+4}$ have demonstrated the compensatory hyperfunction in late activated regions. In studies, where contraction patterns were mapped throughout the LV wall using MRI tagging, it was found that the number of hypocontractile regions (regions with systolic shortening below $50 \%$ of the value during atrial pacing) was significantly larger during RV apex than during LV base pacing. This corresponded with a larger loss of pump function during RV apex pacing, even though QRS duration was shorter ${ }^{62}$. An explanation for this paradoxical situation was found by closer examination of the pattern of LV mechanical activation. During RV apex pacing a major part of the septum is activated almost simultaneously, potentially due to coupling of RV activation into the right bundle branch system. Subsequently a significant delay occurred in activation of the LV free wall ${ }^{39}$, most likely due to slow trans-septal conduction ${ }^{33}$, leading to a biphasic pattern of (mechanical) activation. In contrast, during LV base pacing activation occurred more monotonically, though more asynchronous ${ }^{39}$. Nevertheless, LV function was maintained better, presumably due to a smaller number of early-activated regions ${ }^{62}$. These data indicate that LV function is determined by the (a)synchrony and the graduality of activation: biphasic activation is detrimental, because a large region of early-activated myocardium excludes the existence of a large hyperfunctional region.

Another explanation for the better LV function during LV than RV pacing emerges from studies performed by Little et al. They showed that earlier RV than LV activation causes a premature rise of RV pressure, leading to paradoxical septal motion. The abnormal septal motion was associated with poor LV function ${ }^{57}$. Therefore, they suggest that interventricular synchronization may be important because of mechanical coupling between the ventricles.

In addition to the importance of interventricular synchronization, also the sequence of activation from apex to base appears to be important. Among all LV pacing sites the LV apex appears to maintain LV pump function closest to that during atrial pacing $28.29,100,101$. The observation that adding more pacing sites to the $L V$ apex does not improve, sometimes even reduces, LV function ${ }^{29,100}$ emphasizes the importance of a ventricular activation directed from apex to base. Although the mechanism of the beneficial effect of the apex-to-base sequence of activation is not clear yet, it is striking that during normal sinus rhythm the ventricular myocardium is also activated from apex to base (see paragraph on "Normal impulse conduction").

Ventricular pacing in animal models of heart failure and abnormal conduction

All the abovementioned studies have been performed in animal hearts without pathology or, at most with AV-block to facilitate optimal AV-synchronization. Only a few studies have been performed in hearts with altered structure and function. Two 


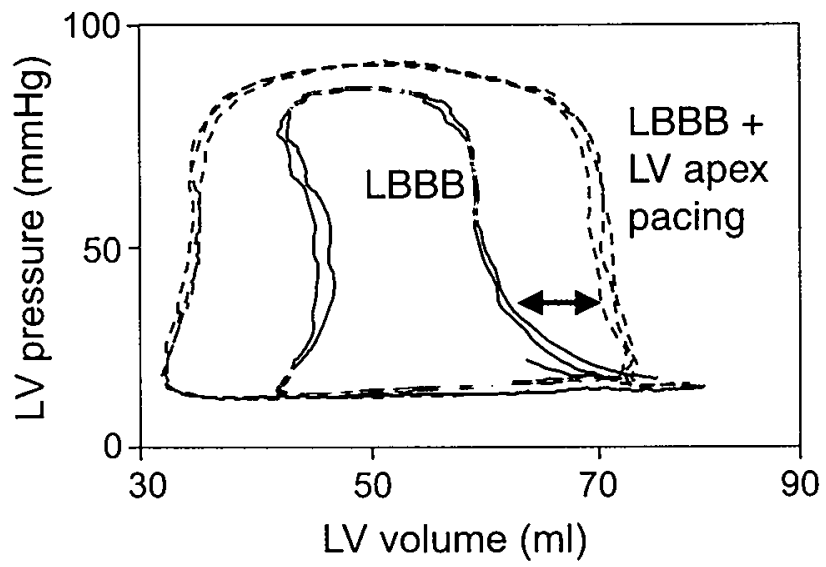

Figure 6. LV P-V diagrams during LBBB in sinus rhythm and during LBBB with pacing at the LV apex (VDD, AV-delay $50 \mathrm{~ms}$ ) in an anesthetized open-chest dog, measured using the conductance catheter technique ${ }^{1.30}$. LBBB was induced by radio-frequency ablation. The diagram shows that LV apex pacing does not significantly change end-diastolic volume (lower right corner of loop), but does increase systolic LV pressure and stroke volume, and decreases end-systolic volume (upper left corner of loop). The decrease in LV volume during early systole during LBBB in the absence of pacing (indicated by double pointed arrow) may be due to mitral regurgitation or due to an artifact of the conductance technique, caused by abnormal wall motion.

groups studied the effect of ventricular pacing in canines with heart failure, induced by rapid pacing ${ }^{106}$ or rapid pacing following myocardial infarction ${ }^{127}$. As in non-failing dog hearts, LV pacing improved LV pump function (LV dP/dt max $^{\prime}$ cardiac output) as compared to RV apex pacing ${ }^{106}$. When compared to atrial pacing LV pacing caused a small reduction of pump function ${ }^{127}$. Simultaneous stimulation of RV and LV did not significantly improve LV function, when compared with LV pacing or sinus rhythm 106,127. However, LV function was improved above the level during sinus rhythm when stimulating the LV approximately $20 \mathrm{~ms}$ before the RV ${ }^{127}$. Pacing at RV base and apex and LV base and apex simultaneously slightly increased cardiac output and LV dP/dt $\mathrm{dmax}_{\max }$ and $\mathrm{LV} \mathrm{dP/dt_{ \operatorname {min } }}$ as compared to LV apex pacing alone ${ }^{106}$.

While the aforementioned studies employed a failing heart model, electrical activation of these hearts was still normal. Recently an animal model of asynchronous activation has been developed: experimental LBBB in canine hearts ${ }^{128,129}$. LBBB was created by radio-frequency ablation, causing a doubling of $Q R S$ duration as compared with sinus rhythm and a QRS configuration similar to that in clinical LBBB. LBBB reduced pump function to a degree similar to that induced by RV apex pacing ${ }^{130}$.

In LBBB hearts LV pacing significantly improved LV pump function 128-131. Preliminary data on $\mathrm{P}-\mathrm{V}$ analysis demonstrate increased stroke volume and stroke work at unchanged preload, especially during LV apex pacing (Figure 6) ${ }^{130}$. Combining the LV apex with other pacing sites, including the RV apex, did not lead to further 
improvement ${ }^{130,131}$. The latter finding, and the observation that the degree of hemodynamic improvement was not correlated with reduction in QRS duration ${ }^{130}$ suggests that LV pacing improves pump function in canine LBBB hearts by correcting the sequence of activation, rather than the synchrony of activation.

The findings on LV pacing in canine LBBB hearts are quite comparable to those in patients with congestive heart failure and abnormally long QRS duration ${ }^{12-13}$. In this patient category endocardial ${ }^{12}$ or epicardial LV free wall pacing ${ }^{13}$ was superior to pacing at the RV apex or to the baseline sinus rhythm. Moreover, LV function was similar during LV pacing and during biventricular pacing and hemodynamic improvements were obtained even when QRS duration increased during LV pacing ${ }^{13}$. The fact that similar beneficial effects are found in failing patient hearts and in initially normal canine hearts, when they have LBBB in common, strongly suggests that LV pacing corrects the discoordinated contraction induced by LBBB.

\section{Conclusions}

It becomes increasingly clear that abnormal electrical activation of the ventricles, induced by ventricular pacing or conduction disturbances, has strong implications for hemodynamic performance. Normal physiological activation of the ventricles is characterized by minimal asynchrony, monotonic activation, earlier LV than RV activation and earlier apical than basal activation. During LBBB and RV apex pacing the activation sequence deviates significantly from the physiological one and is associated with considerable depression of LV function. Pacing at alternative sites (like RVOT, LV or multiple sites) causes less pronounced decreases in LV function in hearts with intact conduction system and improves LV function in hearts with LBBB. However, pacing at all ventricular sites used until now, except the His-bundle, results in a ventricular activation sequence different from sinus rhythm. Therefore, the quest for pacing site(s), leading more physiological activation sequence and optimal pump function of the ventricles needs to be continued. 


\section{References}

1. van Oosterhout MFM, Prinzen FW, Arts $T$, et al. Asynchronous electrical activation induces inhomogeneous hypertrophy of the left ventricular wall. Circulation 1998;98:588-595.

2. Adomian GE. Myofibrillar disarray produced in normal hearts by chronic electrical pacing. Am Heart /. 1986;112:79-83.

3. Karpawich PP, Justice CD, Cavitt DL, et al. Developmental sequelae of fixed-rate ventricular pacing in the immature canine heart: An electrophysiologic, hemodynamic and histopathologic evaluation. Eur Heart I. 1990;119:1077-1083.

4. Lee MA, Dae MW, Langberg IJ, et al. Effects of long-term right ventricular apical pacing on left ventricular perfusion, innervation, function and histology. I Am Coll Cardiol. 1994;24:225-232.

5. Tse H-F, Lau C-P. Long-term effect of right ventricular pacing on myocardial perfusion and function. I Am Coll Cardiol. 1997;29:744-749.

6. Nielsen JC, Boetcher $M$, Toftegaard Nielsen $T$, et al. Regional myocardial blood flow in patients with sick sinus syndrome randomized to long-term single chamber atrial or dual chamber pacing-effect of pacing mode and rate. I Am Coll Cardiol. 2000;35:1453-1461.

7. Santini $M$, Alexidou $G$. Ansalone $G$, et al. Relation of prognosis in sick sinus syndrome to age, conduction defects and modes of permanent cardiac pacing. Am / Cardiol. 1990;65:729-735.

8. Rosenqvist $M, B$ randt J, Schueller $H$. Atrial versus ventricular pacing in sinus node disease: a treatment comparison study. Am Heart / 1986;111:292-297.

9. Rosenquist $M, B$ randt J, Schueller $H$. Long-term pacing in sinus node disease: effects of stimulation mode on cardiovascular morbidity and mortality. Am Heart 1. 1988;116:16-22.

10. Andersen HR, Nielsen JC, Thomsen PEB, et al. Long-term follow-up of patients from a randomised trial of atrial versus ventricular pacing for sick-sinus syndrome. Lancet 1997;350:1210-1216.

11. Nielsen IC, Andersen HR, Thomsen PEB, et al. Heart failure and echocardiographic changes during long-term follow-up of patients with sick-sinus syndrome randomized to single-chamber atrial or ventricular pacing. Circulation 1998;97:987-995.

12. Blanc JI, Etienne $Y$, Gilard $M$, et al. Evaluation of different ventricular pacing sites in patients with severe heart failure: results of an acute hemodynamic study. Circulation 1997:96:3273-3277.

13. Kass DA, Chen $\mathrm{C}-\mathrm{H}$, Curry $\mathrm{C}$, et al. Improved left ventricular mechanics from acute VDD pacing in patients with dilated cardiomyopathy and ventricular conduction delay. Circulation 1999; 99:1567-1573.

14. Auricchio A, Stellbrink C, Block M, et al. Effect of pacing chamber and atrioventricular delay on acute systolic function of paced patients with congestive heart failure. Circulation 1999;99:2993-3001.

15. Uhley HN, Rivkin L. Peripheral distribution of the canine A-V conduction system. Am / Cardiol. 1960; 5:688-691.

16. Esmond WG, Moulton GA, Cowley RA, et al. Peripheral ramification of the cardiac conduction system. Circulation 1963;27:732-738.

17. Myerburg RJ, Nilsson K, Gelband H. Physiology of canine intraventricular conduction and endocardial excitation. Circ Res. 1972;30:217-243.

18. Abramson DI, Margolin S. A Purkinje conduction network in the myocardium of the mammalian ventricles. / Anat. 1936;70:251-259.

19. Truex RC, Copenhaver WM. Histology of the moderator band in man and other mammals with special reference to the conduction system. Am / Ana. 1947;80:173-200.

20. Hoffman BF, Cranefield PF, Stuckley JH, et al. Direct measurement of conduction velocity in in situ specialized conduction system of mammalian heart. Proc Soc Exp Biol Med. 1959;102:55-57.

21. Scher AM, Young AC, Malmgren AL, et al. Spread of electrical activity through the wall of the ventricle. Circ Res. 1953;1:539-547.

22. Scher AM, Young AC, Malmgreen AL, et al. Activation of the interventricular septum. Circ Res. 1955; 3:56-64.

23. Durrer D, van Dam RT, Freud GE, et al. Total excitation of the isolated human heart. Circulation 1970;41:899-912. 
24. Burchell HB, Essex HE, Pruitt RD. Studies on the spread of excitation through the ventricular myocardium. Circulation 1952;6:161-171.

25. Sodi-Pallares D, Rodriguez MI, Chait LO, et al. The activation of the interventricular septum. Am Heart /. 1951:41:569-608.

26. Sodi-Pallares D, Bisteni A, Medrano GA, et al. The activation of the free left ventricular wall in the dog heart. Am Heart 1. 1955;49:587-602.

27. Spach MS, Barr RC. Ventricular intramular and epicardial potential distributions during ventricular activation and repolarization in the intact dog. Circ Res. 1975;37:243-257.

28. Lister JW, Klotz DH, Jomain SL, et al. Effect of pacemaker site on cardiac output and ventricular activation in dogs with complete heart block. Am / Cardiol. 1964;14:494-503.

29. Prinzen FW, van Oosterhout MFM, Vanagt WYR, et al. Optimization of ventricular function by improving the activation sequence during ventricular pacing. Pacing Clin Electrophysiol. 1998; 21:2256-2260.

30. Vassallo JA, Cassidy DM, Marchlinski FE, et al. Endocardial activation of left bundle branch block. Circulation 1984;69:914-923.

31. Durrer D, Roos JP. Epicardial excitation of the ventricles in a patient with a Wolff-Parkinson-White syndrome (type B). Circulation 1967;35:15.

32. Vassallo JA, Cassidy DM, Miller JM, et al. Left ventricular endocardial activation during right ventricular pacing: effect of underlying heart disease. / Am Coll Cardiol. 1986;7:1228-1233.

33. Spach MS, Barr RC. Analysis of ventricular activation and repolarization from intramural and epicardial potential distributions for ectopic beats in the intact dog. Circ Res. 1975;37:830-843.

34. Prinzen FW, Augustijn $\mathrm{CH}$, Arts T, et al. Redistribution of myocardial fiber strain and blood flow by asynchronous activation. Am / Physiol. 1990;259:H300-H308.

35. Prinzen FW, Augustijn $\mathrm{CH}$, Allessie MA, et al. The time sequence of electrical and mechanical activation during spontaneous beating and ectopic stimulation. Eur Heart J. 1992;13:535-543.

36. Spach MS, Miller WT, Geselowitz DB, et al. The discontinuous nature of propagation in normal canine cardiac muscle. Evidence for recurrent discontinuities of intracellular resistance that affect the membrane currents. Circ Res. 1981;48:39-54.

37. Frazier DW, Krassowska W, Chen P-S, et al. Transmural activations and stimulus potentials in three dimensional anisotropic canine myocardium. Circ Res. 1988;63:135-146.

38. Myerburg RJ, Gelband $\mathrm{H}$, Nilsson K, et al. The role of canine superficial ventricular fibers in endocardial impulse conduction. Circ Res. 1978;42:27-35.

39. Wyman BT, Hunter WC, Prinzen FW, et al. Mapping propagation of mechanical activation in the paced heart with MRI tagging. Am / Physiol. 1999;276:H881-H891.

40. Askenazi J, Alexander JH, Koenigsberg DI, et al. Alteration of left ventricular performance by left bundle branch block simulated with atrioventricular sequential pacing. Am / Cardiol. 1984;53:99-104.

41. Rosenbush SW, Ruggie N, Turner DA, et al. Sequence and timing of ventricular wall motion in patients with bundle branch block. Circulation 1982;66:113-119.

42. Hirzel HO, Senn M, Nuesch K, et al. Thallium-201 scintigraphy in complete left bundle branch block. Am / Cardiol. 1984;53:764-769.

43. Ono $S$, Nohara $R$, Kambara $H$, et al. Regional myocardial perfusion and glucose metabolism in experimental left bundle branch block. Circulation 1992;85:1125-1131.

44. Prinzen FW, Augustijn $\mathrm{CH}$, Allessie MA, et al. The time sequence of electrical and mechanical activation during spontaneous beating and ectopic stimulation. Eur Heart J. 1992;13:535-543.

45. Rosenqvist $M$, Bergfeldt $L$, Haga $Y$, et al. The effect of ventricular activation sequence on cardiac performance during pacing. Pacing Clin Electrophysiol. 1996;19:1279-87.

46. Karpawich PP, Gates J, Stokes KB. Septal his-purkinje ventricular pacing in canines: a new endocardial electrode approach. Pacing Clin Electrophysiol. 1992;15:2011-15.

47. Scherlag BI, Kosowsky BD, Damato AN. A technique for ventricular pacing from the His bundle of the intact heart. Am / Physiol. 1967; 22: 584-587.

48. Kosowsky BD, Scherlag Bj, Damato AN. Re-evaluation of the atrial contribution to ventricular function. Am / Cardiol. 1968;21:518-524. 
49. Deshmukh $P$, Casavant DA, Romanyshyn $M$, et al. Permanent, direct his-bundle pacing. A novel approach to cardiac pacing in patients with normal his-purkinje activation. Circulation 2000;101: 869-877.

50. Grover M, Glantz SA. Endocardial pacing site affects left ventricular end-diastolic volume and performance in the intact anesthetized dog. Circ Res. 1983;53:72-85.

51. Buchalter MB, Rademakers $\mathrm{FE}$, Weiss $\mathrm{JL}$, et al. Rotational deformation of the canine left ventricle measured by magnetic resonance tagging: effects of catecholamines, ischaemia, and pacing. Cardiovasc Res. 1994;28:629-635.

52. Owen $\mathrm{CH}$, Esposito DJ, Davis JW, et al. The effects of ventricular pacing on left ventricular geometry, function, myocardial oxygen consumption and efficiency of contraction in conscious dogs. Pacing Clin Electrophysiol. 1998;21:1417-1429.

53. Torres MAR, Corday $E$, Meerbaum $S$, et al. Characterization of left ventricular mechanical function during arrhythmias by two-dimensional echocardiography. II Location of the site of onset of premature ventricular systoles. / Am Coll Cardiol. 1983;1:819-829.

54. Wilson JR, Douglas P, Hickey WF, et al. Experimental congestive heart failure produced by rapid ventricular pacing in the dog: cardiac effects. Circulation 1987;75:857-867.

55. Maurer G, Torres MA, Corday E, et al. Two-dimensional echocardiographic contrast assessment of pacing-induced mitral regurgitation: relation to altered regional left ventricular function. / Am Coll Cardiol. 1984;3:986-991.

56. Badke FR, Boinay $P$, Covell JW. Effect of ventricular pacing on regional left ventricular performance in the dog. Am / Physiol. 1980;238:H858-H867.

57. Little WC, Reeves RC, Arciniegas \}, et al. Mechanism of abnormal interventricular septal motion during delayed left ventricular activation. Circ Res. 1982;65:1486-1490.

58. Gomes JAC, Damato AN, Akhtar $M$, et al. Ventricular septal motion and left ventricular dimensions during abnormal ventricular activation. Am / Cardiol. 1977;39:641-650.

59. Miyazawa $K$, Honna $T$, Haneda $T$, et al. Dynamic geometry of the left ventricle during ventricular pacing: correlation with cardiac pumping action. Tohoku / Exp Med. 1978;124:261-266.

60. Saito D, Takeda $K$, Hyode $T$, et al. Effect of pacemaker sites on contractile forces of the local myocardium and blood flow in the major branches of the left coronary artery in anesthetized open-chest dogs. Jap Circ J. 1984;48:331-335.

61. Waldman LK, Covell JW. Effects of ventricular pacing on finite deformation in canine left ventricles. Am I Physiol. 1987;252:H1023-H1030.

62. Prinzen FW, Hunter WC, Wyman BT, et al. Mapping of regional myocardial strain and work during ventricular pacing: experimental study using Magnetic Resonance Imaging tagging. / Am Coll Cardiol. 1999;33:1735-1742.

63. Delhaas $T$, Arts $T$, Prinzen FW, et al. Relation between regional electrical activation time and subepicardial fiber strain in the canine left ventricle. Pflugers Arch. 1993;423:78-87.

64. Delhaas T, Arts T, Prinzen FW, et al. Regional fibre stress-fibre strain area as estimate of regional oxygen demand in the canine heart. J Physiol. 477;3:481-496.

65. McVeigh ER, Prinzen FW, Wyman BT, et al. Mapping of asynchronous mechanical activation of the paced heart with tagged MRI. Magn Res Med. 1998;39:507-513.

66. Augustijn $\mathrm{CH}$, Arts T, Prinzen FW, et al. Mapping the sequence of contraction of the canine left ventricle. Eur / Physiol. 1991;419:529-533.

67. Curry CW, Nelson GS, Wyman BT, et al. Mechanical dyssychrony in dilated cardiomyopathy with intraventricular conduction delay as depicted by 3D tagged magnetic resonance imaging. Circulation 2000;101:1.

68. Boucher CA, Pohost GM, Okada RD, et al. Effect of ventricular pacing on left ventricular function assessed by radionuclide angiography. Am Heart J. 1983;106:1105-1111.

69. Botvinick $E$, Frais $M$, Shosa $D$, et al. The phase image: its relationship to patterns of contraction and conduction. Am / Cardiol. 1982;50:289-298.

70. Nagai H, Takata S, Sakagami S, et al. Two-dimensional guided M-mode color tissue Doppler echocardiography in artificial preexcitation models. / Am Soc Echocardiogr. 1999;12:582-589.

71. Allen DG, Kentish DG. The cellular basis of the length-tension relation in cardiac muscle. / Mo/ Cell Cardiol. 1985;17:821-840. 
72. Ford LE. Mechanical manifestations of activation in cardiac muscle. Circ Res. 1991;68:621-637.

73. Kil PJ, Schiereck P. Influence of the velocity of changes in end-diastolic volume on the starling mechanism of isolated left ventricles. Pflugers Arch. 1983;396:243-253.

74. Tyberg IV, Parmley WW, Sonnenblick EH. In-vitro studies of myocardial asynchrony and regional hypoxia. Circ Res. 1969;25:569-579.

75. Prinzen FW, Delhaas T, Arts T, et al. Regional electromechanical coupling during ventricular pacing. Cardiac arrhythmias, pacing and electrophysiology, Athens, 1998.

76. Suga $\mathrm{H}$. Total mechanical energy of a ventricle model and cardiac oxygen consumption. Am / Physiol. 1979;236:H498-H505.

77. Suga $H$, Hayashi $T$, Suehiro $S$, et al. Equal oxygen consumption rates of isovolumic and ejecting contractions with equal systolic pressure-volume areas in canine left ventricle. Circ Res. 1981;49: 1082-1091.

78. Beppu $S$, Matsuda $H$, Shishido $T$, et al. Functional myocardial perfusion abnormality induced by left ventricular asynchronous contraction: experimental study using myocardial contrast echocardiography. I Am Coll Cardiol. 1997;29:1632-1638.

79. Amitzur G, Manor D. Pressman A, et al. Modulation of the arterial coronary blood flow by asynchronous activation with ventricular pacing. Pacing Clin Electrophysiol. 1995;18:697-710.

80. Feigl EO. Coronary Physiology. Physiol Rev. 1983;63:1-205.

81. Helmer GA, McKirnan MD, Shabetai R, et al. Regional deficits of myocardial blood flow and function in left ventricular pacing-induced heart failure. Circulation 1996;94:2260-2267.

82. Hofmann JIE. Why is myocardial ischaemia so commonly subendocardial? Clin SCi. 1981;61:657-662.

83. Starzl TE, Gaertner RA, Webb RC. The effects of repetitive electric cardiac stimulation in dogs with normal hearts, complete heart block and experimental cardiac arrest. Circulation 1955;11:952-962.

84. Daggett WM, Bianco JA, Powel WJ, et al. Relative contribution of the atrial systole-ventricular systole interval and of patterns of ventricular activation to ventricular function during electrical pacing of the dog heart. Circ Res. 1970;27:69-79.

85. Zile MR, Blaustein AS, Shimizu G, et al. Right ventricular pacing reduces the rate of left ventricular relaxation and filling. / Am Coll Cardiol. 1987;10:702-709.

86. Samet $P$, Castillo $P, B$ ernstein WH. Hemodynamic consequences of sequential atrioventricular pacing. Am / Cardiol. 1968;21:207-212.

87. Faerestrand S, Ohm O-J. A time-related study of the hemodynamic benefit of atrioventricular synchronous pacing evaluated by doppler echocardiography. Pacing Clin Electrophysiol. 1985;8: 838-848.

88. Masuyama T, Kodama S, Nakatani S, et al. Effects of atrioventricular interval on left ventricular diastilic filling assessed with pulsed Doppler echocardiography. Cardiovasc Res. 1989;23:1034-1042.

89. Mehta D, Gilmour S, Ward DE, et al. Optimal atrioventricular delay at rest and during exercise in patients with dual chamber pacemakers: a non-invasive assessment by continuous wave Doppler. Br Heart J. 1989;61:161-166.

90. Wiggers C]. The muscular reactions of the mammalian ventricles to artificial surface stimuli. Am I Physiol. 1925;73:346-378.

91. Tanabe A, Mohri T, Ohga M, et al. The effects of pacing-induced left bundle branch block on left ventricular systolic and diastolic performances. Ipn Heart /. 1990;31:309-317.

92. Bedotto JB, Grayburn PA, Black $W H$, et al. Alterations in left ventricular relaxation during atrioventricular pacing in humans. I Am Coll Cardiol. 1990;658-664.

93. Miyazawa $K$, Shirato $K$, Haneda $T$, et al. Effects of varying pacemakers sites on left ventricular performance. Tohoku J Exp Med. 1976;120:301-308.

94. Fletcher FW, Theilen EO, Lawrence MS, et al. Effect of pacemaker location on cardiac function in complete A-V heart block. Am / Physiol. 1963;205:1232-1234.

95. William-Olsson G, Andersen MN. The effect of pacemaker electrode site on cardiac output. I Thor Cardiovasc Surg. 1963;45:618-621.

96. Tsagaris TJ, Sutton RB, Kuida H. Hemodynamic effects of varying pacemaker sites. Am / Physiol. 1970;1:246-250.

97. Gibson DG, Chamberlain DA, Coltart DJ, et al. Effect of changes in ventricular activation on cardiac haemodynamics in man. Br Heart /. 1971;33:397-400. 
98. Finney JO. Hemodynamic alterations in left ventricular function consequent to ventricular pacing. Am I Physiol. 1965;208:275-282.

99. Gilmore JP, Sarnoff SI, Mitchell JH, et al. Synchronicity of ventricular contraction: observations comparing haemodynamic effects of atrial and ventricular pacing. Br Heart /. 1963;25:299-307.

100. Tyers GFO. Comparison of the effect on cardiac function of single-site and simultaneous multiple site ventricular stimulation after A-V block. / Thor Cardiovasc Surg. 1970;59:211-217.

101. Klotz DH, Lister $\mathrm{WW}$, Jomain SL, et al. Implantation sites of pacemakers after right ventriculotomy and complete heart block. IAMA 1963;186:929-931.

102. Burkhoff D, Oikawa RY, Sagawa K. Influence of pacing site on left ventricular contraction. Am J Physiol. 1986;251:H428-H435.

103. Park RC, Little WC, O'Rourke RA. Effect of alteration of left ventricular activation sequence on the left ventricular end-systolic pressure-volume relation in closed-chest dogs. Circ Res. 1985;57:706-717.

104. Little WC, Park RC, Freeman GL. Effects of regional ischemia and ventricular pacing on LV dP/dTmax-end-diastolic volume relation. Am / Physiol. 1987;252:H933-H940.

105. Boerth RC, Covell JW: Mechanical performance and efficiency of the left ventricle during ventricular stimulation. Am / Physiol. 1971;221:1686-1691.

106. Fei $L$, Wrobleski $D$, Groh $W$, et al. Effects of multisite ventricular pacing on cardiac function in normal dogs and dogs with heart failure. / Cardiovasc Electrophysiol. 1999;10:935-946.

107. Henning RJ, Levy MN. Effects of autonomic nerve stimulation, asynchrony, and load on dP/dTmax and on dP/dTmin. Am / Physiol. 1991;260:H1290-H1298.

108. Zhou $Q$, Henein $M$, Coats $A$, et al. Different effects of abnormal activation and myocardial disease on left ventricular ejection and filling times. Heart 2000;84:272-76.

109. de Swart H, Prinzen FW, Peschar M. Pacing site influences contractility of the normal heart. Pacing Clin Electrophysiol. 2000;23:682.

110. Mark JB, Chetham PM: Ventricular pacing can induce hemodynamically significant mitral valve regurgitation. Anesthesiology 1991;74:375-377.

111. Twidale $N$, Manda $V$, Holliday R, et al. Mitral regurgitation after atrioventricular node catheter ablation for atrial fibrillation and heart failure: acute hemodynamic features. Am Heart J. 1999;138:1166-1175.

112. Brutsaert DL, Sys SU. Relaxation and diastole of the heart. Physiological Reviews. 1989;69:1228-1301.

113. Blaustein AS, Gaasch WH. Myocardial relaxation. VI. Effects of beta-adrenergic tone and asynchrony on LV relaxation rate. Am / Physiol. 1983;244:H417-H422.

114. Bahler RC, Martin P. Effects of loading conditions and inotropic state on rapid filling phase of left ventricle. Am / Physiol. 1985;248:H523-H533.

115. Heyndrickx GR, Vantrimpont PI, Rousseau MF, et al. Effects of asynchrony on myocardial relaxation at rest and during exercise in conscious dogs. Am / Physiol. 1988;254:H817-H822.

116. Baller D, Wolpers H-G, Zipfel J, et al. Comparison of the effects of right atrial, right ventricular apex and atrioventricular sequential pacing on myocardial oxygen consumption and cardiac efficiency: a laboratory investigation. Pacing Clin Electrophysiol. 1988;11:394-403.

117. Prinzen FW, Cheriex EM, Delhaas $T$, et al. Asymmetric thickness of the left ventricular wall resulting from asynchronous electrical activation. A study in patients with left bundle branch block and in dogs with ventricular pacing. Am Heart /. 1995;130:1045-1053.

118. Iberer F. Cardiac pacing via the right ventricular outflowtract. A human open chest study. Acta Chirurg Austriaca 1990;22:3-14.

119. Buckingham TA, Candinas R, Schlapfer J, et al. Acute hemodynamic effects of atrioventricular pacing at different sites in the right ventricle individually and simultaneously. Pacing Clin Electrophysiol. 1997;20:909-915.

120. de Cock CC, Meijer A, Kamp O, et al. Hemodynamic benefits of right ventricular outflow tract pacing: comparison with right ventricular apex pacing. Pacing Clin Electrophysiol. 1998;21:536-541.

121. Schwaab B, Frohlig G, Alexander C, et al. Influence of right ventricular stimulation site on left ventricular funrction in atrial synchronous ventricular pacing. I Am Coll Cardiol. 1999;33:317-323.

122. Harris $\mathrm{ZI}, \mathrm{Gammage} \mathrm{MD}$. Alternative right ventricular pacing sites - where are we going? Europace 2000;2:93-98.

123. Daubert JC, Ritter $P$, Le Breton $H$, et al. Permanent left ventricular pacing with transvenous leads inserted into the coronary veins. Pacing Clin Electrophysiol. 1998;21:239-245. 
124. Rosenqvist $M$, Isaaz K, Botvinick EH, et al. Relative importance of activation sequence compared to atrioventricular synchrony in left ventricular function. Am / Cardiol. 1991;67:148-156.

125. Suga $H$, Goto $Y$, Yaku $H$, et al. Simulation of mechanoenergetics of asynchronously contracting ventricle. Am / Physiol. 1990;259:R1075-R1082.

126. Karpawich PP, Justice $C D$, Chang $C-H$, et al. Septal ventricular pacing in the immature canine heart: $A$ new perspective. Am Heart \%. 1991;121:827-833.

127. Hill MRS, Taepke RT, Hilpisch KE, et al. Independent pacing of right and left ventricles with biventricular pacing improves hemodynamics in heart failure. Europace 2000;1:D41.

128. Prinzen FW, van Oosterhout MFM, Vanagt WYR, et al. Optimal sequence rather than minimal synchrony of activation improves ventricular function during ventricular pacing. Eur Heart 1. 1999;20 Suppl.:464.

129. Liu L, Belalcazar A, Walcott GP, et al. Heart failure therapies improve left ventricular electromechanical coordination in a canine model of left bundle branch block. Circulation 1999; 100:1-122.

130. Prinzen FW, de Swart H, Peschar M. Optimal pacing regime for canine hearts with left bundle branch block. Europace 2000;1:D107.

131. Liu L, Tockman B, Belalcazar A, et al. The role of left bundle branch block in heart failure pacing therapies- a study in a canine model of left bundle branch block. Europace 2000;1:D107. 


\section{CHAPTER 3}

\section{Biphasic contractile and progressive structural remodeling during chronic volume overload in dogs}

Maaike Peschar, Gijs Baaten, Theo van der Nagel, Jodil Willems, Richard N.M. Cornelussen, Luc H.E.H. Snoeckx, Robert S. Reneman, Marc A. Vos* and Frits W. Prinzen

Departments of Physiology and *Cardiology, Cardiovascular Research Institute Maastricht, Maastricht University, Maastricht, the Netherlands

Submitted for publication 


\section{Abstract}

Background: A negative force-frequency relation (FFR) and decreased sarcoplasmic reticular $\mathrm{Ca}^{2+}$-ATPase (SERCA) $/ \mathrm{Na}^{+} / \mathrm{Ca}^{2+}$ exchanger (NCX) ratios have been observed in failing hearts. The time course of these parameters in early stages of adaptation, and their relation with contractile function, however, is poorly understood. We investigated the temporal behavior of contractile remodeling (left ventricular (LV) dP/dt ${ }_{\max }$ and FFR) in relation to the structural remodeling (LV hypertrophy and dilatation) and protein contents of SERCA and NCX during 16 weeks of bradycardia induced volume overload. Methods: Volume overload was induced by atrio-ventricular (AV) block in 13 dogs. The FFR was assessed by determining $\mathrm{LV} \mathrm{dP} / \mathrm{dt}_{\max }$ during temporary ventricular pacing at $40-130$ beats $/ \mathrm{min}$ at 0,6 and 16 weeks of AV-block. LV dimensions and mass were derived from serial 2D-echocardiograms. LV protein contents of SERCA and NCX were assessed by Western blotting and compared to control dogs $(n=7)$. Data are presented as mean $\pm \mathrm{SD} ;{ }^{*}=\mathrm{p}<0.05$.

Results: Two phases of adaptation to volume overload were recognized. Until 6 weeks of AV-block systolic function (LV dP/dt ${ }_{\max }$ at idioventricular rhythm) increased by $57 \pm 21 \% *$ compared to baseline and the slope of the FFR became negative $(-1029 \pm 491$ * $\mathrm{mmHg}$ ). During this phase LV wall mass and cavity volume increased by $25 \pm 15 \% *$ and $37 \pm 19 \% *$ compared to baseline, respectively, but the SERCANNCX protein ratio did not change significantly. Between 6 and 16 weeks of AV-block systolic function decreased by $27 \pm 19 \% *$ and LV wall mass and cavity volume further increased by $12 \pm 7 \% *$ and $25 \pm 11 \% *$, respectively, while the slope of the FFR remained negative $\left(-557 \pm 471^{*}\right.$ $\mathrm{mmHg}$ ). Although the absolute values of SERCA and NCX protein contents were not changed after 16 weeks of AV-block, the SERCANNCX protein ratio was $32 \pm 14 \% *$ lower than in the control dogs.

Conclusions: In this model of compensated volume overload hypertrophy the FFR is already negative in the early hypercontractile phase. The decrease in SERCANNCX protein ratio after 16 weeks of AV-block appears to indicate the end of the hypercontractile phase and coincides with progression of LV cavity dilatation. 


\section{Introduction}

Cardiac remodeling is considered to be an adaptive response of the heart to chronically increased workload. While at an early stage of hypertrophy cardiac function is well maintained and is sometimes even overcompensated ${ }^{1-3}$, cardiac function may become impaired above a certain duration and severity of hypertrophy. An important part of the systolic and/or diastolic dysfunction has been attributed to abnormalities in $\mathrm{Ca}^{2+}$ homeostasis ${ }^{t-6}$. At the molecular level two proteins play a prominent role: the sarcoplasmic reticular $\mathrm{Ca}^{2+}$-ATPase (SERCA) and the sarcolemmal $\mathrm{Na}^{+} / \mathrm{Ca}^{2+}$ exchanger (NCX). Protein expression of SERCA is decreased in patients with compensated hypertrophy ${ }^{7,3}$ and in several ${ }^{9,10}$, but not all ${ }^{11,12}$ studies on heart failure, while NCX protein expression has been reported to be either increased ${ }^{8}$ or unchanged ${ }^{12,13}$. When SERCA and NCX expression levels are related, a decrease in SERCANCX ratio was found to be more consistent with heart failure than a decrease in SERCA protein content alone ${ }^{8,12}$.

Although the exact working mechanism is still under debate, it has been proposed that the reduced SERCANCX ratio leads to a lower force of contraction at increasing heart rates (i.e. a negative force-frequency relation) ${ }^{6,12,14,15}$. Such a shift to a (partly) negative force-frequency relation is suggested to delineate the transition from compensated to decompensated hypertrophy ${ }^{16}$. However, detailed descriptions on the temporal behavior of force-frequency relations in hypertrophied hearts are lacking. In apparent conflict with the study of Inagaki et al. ${ }^{16}$ is our observation in canine hearts, in which after 6 weeks of compensated volume overload hypertrophy due to atrio-ventricular (AV) block, increased contractility coincides with a negative force-frequency relation ${ }^{17,18}$.

Therefore, it was the aim of the present study to investigate the temporal behavior of left ventricular (LV) systolic and diastolic function and the slope of the force-frequency relation in relation to structural changes and myocardial protein contents of SERCA and NCX during 16 weeks of AV-block. To this purpose hemodynamic and echocardiographic measurements were performed and myocardial SERCA and NCX protein contents were determined at sinus rhythm and after 6 and 16 weeks of AV-block.

\section{Methods}

Animal handling was performed according to the Dutch Law on Animal Experimentation (WOD) and the European Directive for the protection of Vertebrate Animals used for experimental and other purposes (86/609/EU). The protocol was approved by the Animal Experimental Committee of the Maastricht University. 


\section{Experimental preparation}

Adult mongrel dogs of either sex with body weights of $27 \pm 5 \mathrm{~kg}$ were premedicated with $10 \mathrm{mg}$ oxycodon $\mathrm{HCl}, 1 \mathrm{mg}$ acepromazine and $0.5 \mathrm{mg}$ atropine sulphate $(1 \mathrm{ml} / 5 \mathrm{~kg}$, i.m.). After pentothal induction (15 mg/kg i.v.), anesthesia was maintained by ventilation with $\mathrm{O}_{2}$ and $\mathrm{N}_{2} \mathrm{O}(1: 2)$ in combination with infusion of midazolam 0.1 $\mathrm{mg} / \mathrm{kg} / \mathrm{hr}$ ) and sufentanyl $(3 \mu \mathrm{g} / \mathrm{kg} / \mathrm{hr})$. Surface ECG was derived from limb leads and a thermal mattress was used to maintain body temperature. Chronic complete AV-block was created by radiofrequency (RF) ablation " ${ }^{19}$. A dual chamber pacemaker (Medtronic Synergist H7027, H7071, Elite II or Thera DR 7941) was implanted to prevent the occurrence of ventricular rates below 30 beats $/ \mathrm{min}$.

Hemodynamic measurements

Hemodynamic measurements were performed at $0,6 \pm 2$ and $16 \pm 1$ weeks of AV-block. Anesthesia was induced and maintained as described above. LV pressure and cavity volume were measured with a combined cathetertip manometer and conductance catheter (7F, Sentron), connected to a Leycom Sigma 5DF signal conditioner processor (CardioDynamics). Parallel conductance was estimated by injecting $7.5 \mathrm{ml}$ of hypertonic saline $(6.5 \%)$ into the pulmonary artery ${ }^{20}$. Cardiac output was measured by thermodilution (Swan-Ganz catheter through a femoral vein). Calibration of absolute LV volume was performed by calibrating stroke volume, as determined with the conductance catheter, with stroke volume measured with thermodilution. The

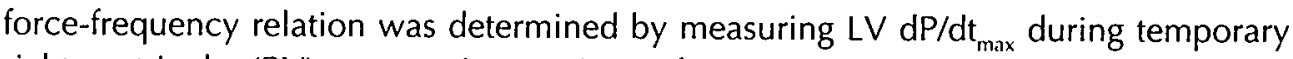
right ventricular (RV) apex pacing at $40-130$ beats $/ \mathrm{min}$.

\section{Echocardiography}

Echocardiographic recordings were made before and biweekly after creation of AV-block. The animals were premedicated with acepromazine $(0.6 \mathrm{mg} / \mathrm{kg}, \mathrm{i} . \mathrm{m}$.) and sedated with propofol $(0.4 \mathrm{mg} / \mathrm{kg}$, i.v.). Two-dimensional echocardiographic images of the LV were made and recorded on videotape ${ }^{21}$. Parasternal cross-sectional images at mid-papillary level were used for analysis.

\section{Terminal procedure}

After the last hemodynamic measurements the thorax was opened and the heart was arrested with ice-cold $\mathrm{KCl}$. Transmural sections of the LV free wall were taken and stored at $-80^{\circ} \mathrm{C}$ for Western blot analysis. 
The dedicated data analysis software package CIRCLAB was used for analysis of all data obtained with the conductance catheter, including the calculation of the maximal first

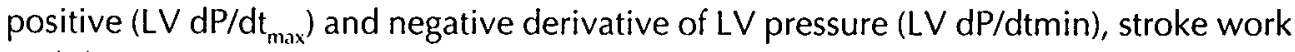
and the time constant of relaxation tau. CIRCLAB was developed by Dr. P. Steendijk (Leiden University Medical Center, the Netherlands). Due to poor signal quality at week 0 , one dog was excluded from hemodynamic analysis.

$\mathrm{LV}$ fiber stress was calculated as $\sigma=\mathrm{P}_{\mathrm{LV}} \times\left(1+3 \mathrm{~V}_{\mathrm{LV}} N_{\mathrm{W}}\right)^{22}$ with $\mathrm{P}_{\mathrm{LV}}=\mathrm{LV}$ pressure, $\mathrm{V}_{\mathrm{LV}}=$ $L V$ cavity volume and $V_{W}=L V$ wall volume. The slope and intercept of the force-frequency relation were derived from a linear trendline, which was fitted through all 4-5 points. In the linear equation $y=a x+b$, $a$ represents the slope and $b$ the intercept of the force-frequency relation.

\section{Echocardiographic analysis}

Global LV dimensions were measured as described in detail before ${ }^{21}$. In short, for each time-point end-diastolic video images of 3 heartbeats were digitized off-line. The images were analyzed after blinding the images to the observer. The endocardium, epicardium and papillary muscle contours were marked manually. LV wall volume and LV cavity volume were calculated by fitting the original epicardial and endocardial contourpoints to a cylinder-ellipsoid model ${ }^{21}$. Correlation between LV mass as calculated by echocardiography and assessed post mortem was $r=0.84$.

\section{SERCA and NCX analysis}

Protein contents of SERCA and NCX were determined after $6 \pm 2(n=7)$ and $16 \pm 1$ weeks of AV-block $(n=5)$. Hearts from dogs in sinus rhythm served as controls $(n=7)$.

Western blotting was performed as described in detail before ${ }^{7}$. Protein concentrations were determined by the method of Bradford ${ }^{23}$. Blots were incubated for $2 \mathrm{~h}$. at room temperature with monoclonal mouse anti-SERCA2a ATPase IgG1 (Affinity Bioreagent, 1:2500) or monoclonal mouse anti- $\mathrm{Na}^{+} / \mathrm{Ca}^{2+}$ exchanger antibody (Affinty Bioreagent, 1:1000). ${ }^{125}$ I-anti-mouse IgG (Amersham, 1:1000) was used as secondary antibody. X-OMAT AR X-ray films (Kodak) were exposed to the membranes at $-80^{\circ} \mathrm{C}$ for $48 \mathrm{~h}$. According to the signals on the films, nitrocellulose membranes were cut and single band signals were quantified in a $\gamma$-counter (LB 2104, Berthold, FRG).

Statistical analysis

Because of considerable interindividual differences in hemodynamic values, the time course of LV function was derived from paired measurements within animals. 
Successful paired measurements were performed at week 0 and 6 in six dogs and at week 6 and 16 in seven dogs. Differences between these time points were evaluated using a paired $t$-test. Non-paired observations were evaluated for statistical significance using ANOVA. Changes in echocardiographic variables during the course of the experiment were evaluated using ANOVA for repeated measurements. If significant differences were found, significant points were isolated using a Bonferroni Multiple Comparison test. Data are presented as mean values \pm SD. $p<0.05$ was considered significant.

\section{Results}

Biphasic contractile remodeling

During the AV-block procedure, under general anesthesia, AV-block decreased heart rate and cardiac output significantly (Table 1). Under sedation during the echocardiography, heart rate decreased from $83 \pm 21$ beats/min during sinus rhythm to $42 \pm 8$ beats $/ \mathrm{min}$ at the various time points after AV-block. After 6 weeks of AV-block, cardiac output normalized to sinus rhythm values, without changes in heart rate (Table 1). This recovery was due to increased LV performance, as evidenced by enhanced LV stroke work, LV dP/dt ${ }_{\max }$ and LV dS/dt ${ }_{\max }$ (Table 1 and Figure 1). Also peak LV pressure

Table 1.

Hemodynamic changes after AV-block.

\begin{tabular}{lllll}
\hline & SR & $\begin{array}{l}\text { AAVB } \\
\text { Rel. to SR }\end{array}$ & $\begin{array}{l}\text { Wk 6 } \\
\text { Rel. to SR }\end{array}$ & $\begin{array}{l}\text { Wk 16 } \\
\text { Rel. to wk 6 }\end{array}$ \\
\hline Heart rate $(\mathrm{bpm})$ & $75 \pm 9$ & $0.74 \pm 0.14^{*}$ & $0.64 \pm 0.09^{*}$ & $0.92 \pm 0.20$ \\
Cardiac output $(\mathrm{l} / \mathrm{min})$ & $3.4 \pm 1.5$ & $0.82 \pm 0.16^{*}$ & $1.00 \pm 0.22$ & $0.92 \pm 0.21$ \\
LV ED pressure $(\mathrm{mmHg})$ & $7 \pm 4$ & $1.32 \pm 0.65$ & $1.90 \pm 1.13$ & $1.53 \pm 1.45$ \\
LV peak pressure $(\mathrm{mmHg})$ & $103 \pm 5$ & $1.01 \pm 0.16$ & $1.16 \pm 0.10^{*}$ & $0.92 \pm 0.09$ \\
LV stroke work $(\mathrm{mmHg} \cdot \mathrm{ml})$ & $4364 \pm 1817$ & $1.05 \pm 0.21$ & $1.56 \pm 0.23^{*} \dagger$ & $0.99 \pm 0.39$ \\
LV dP/dtmax $(\mathrm{mmHg} / \mathrm{s})$ & $2412 \pm 437$ & $1.07 \pm 0.33$ & $1.57 \pm 0.21^{*} \dagger$ & $0.73 \pm 0.19 \neq$ \\
LV dP/dtmin $(\mathrm{mmHg} / \mathrm{s})$ & $2213 \pm 390$ & $0.98 \pm 0.25$ & $0.83 \pm 0.16^{*}$ & $0.88 \pm 0.18$ \\
Tau $(\mathrm{ms})$ & $22 \pm 5$ & $1.02 \pm 0.12$ & $1.28 \pm 0.37$ & $1.31 \pm 0.41 \S$ \\
LV peak fiber stress $(\mathrm{mmHg})$ & $378 \pm 58$ & $1.05 \pm 0.12$ & $1.20 \pm 0.13^{*}$ & $1.00 \pm 0.11$ \\
LV dS/dtmax $(\mathrm{mmHg} / \mathrm{s})$ & $8898 \pm 2499$ & $1.11 \pm 0.26$ & $1.62 \pm 0.27^{* \dagger}$ & $0.78 \pm 0.19 \neq$ \\
\hline
\end{tabular}

Hemodynamic parameters at sinus rhythm (SR), acutely after creation of AV-block (AAVB) and after 6 and 16 weeks of AV-block. ED: end-diastolic. Values at week 6 are expressed as a fraction of SR, values at week 16 as fraction of week $6 .{ }^{*} p<0.05 \mathrm{vs}$. SR, $+p<0.05 \mathrm{vs}$. AAVB and $\neq p<0.05 \mathrm{vs}$. wk 6 using paired analysis and $\S p$ $<0.05$ vs. SR using group comparison. 


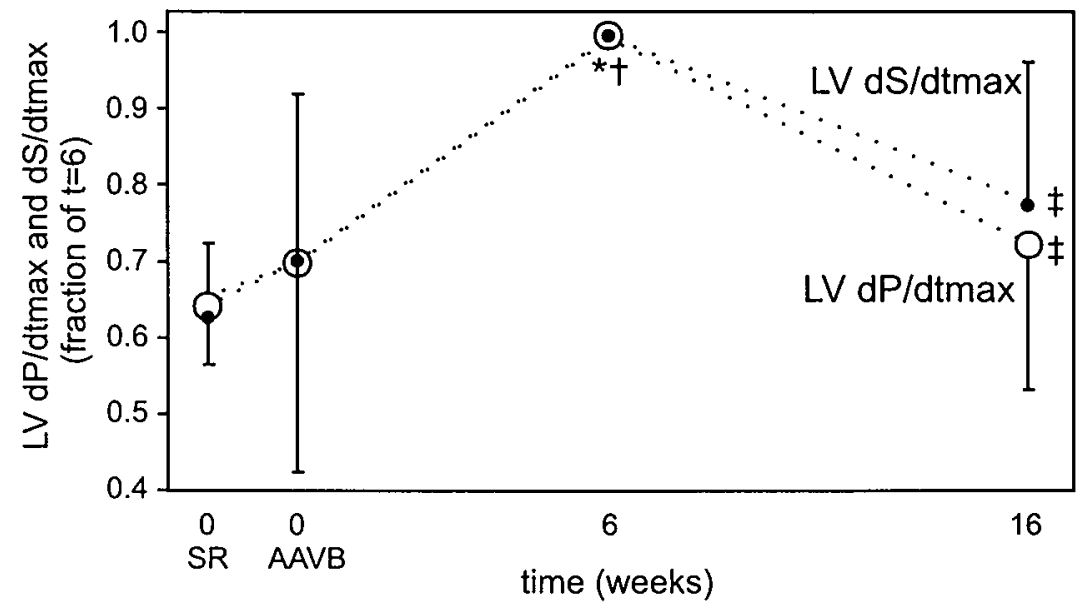

Figure 1. Time course of $L V d P / d t_{\max }$ (large open symbols) and $L V d S / d t_{\max }$ (small closed symbols) as fraction of $t=6 .{ }^{*} p<0.05$ vs. sinus rhythm (SR), $+p<0.05$ vs. acute AV-block (AAVB) and $\neq p<0.05$ vs. wk 6 .

and fiber stress increased during the first 6 weeks of AV-block. In contrast, LV dP/dt ${ }_{\min }$ decreased significantly during this period. Between 6 and 16 weeks of AV-block cardiac output and LV end-diastolic pressure levels were maintained, but $L V \mathrm{dP} / \mathrm{dt}_{\max }$ and $\mathrm{LV} \mathrm{dS} / \mathrm{dt}_{\max }$ decreased significantly. LV peak systolic stress was still higher after 16 weeks of AV-block than during sinus rhythm (Table 1). As compared to the sinus rhythm phase only, the time constant of relaxation (tau) was significantly longer after 16 weeks of AV-block (Table 1), indicative for impaired relaxation.

The force-frequency relations of one dog at different time points are illustrated in Figure 2. The force-frequency relation was flat at week 0 and negative after 6 and 16 weeks of AV-block. The y-axis (force-axis) intercept was lower at week 16 than at week 6 .

The data on the force-frequency relations of all animals are presented in Figure 3. Within 6 weeks of AV-block the slope of the force-frequency relation decreased to values significantly below zero, indicative of a negative force-frequency relation. The higher $y$-axis intercept of the force-frequency relation at week 6 indicates a higher contractility at low heart rates. At week 16 the slope of the force-frequency relation was still negative, but the intercept was lower than at week 6 , indicating lower baseline contractility.

\section{Progressive structural remodeling}

Echocardiographic images of one dog illustrate the development of structural remodeling (Figure 4). The data of LV wall mass and cavity volume for all animals are depicted in Table 2 and Figure 5. Six weeks of AV-block lead to a significant increase in LV wall mass and cavity volume. Between 6 and 16 weeks of AV-block, especially LV 


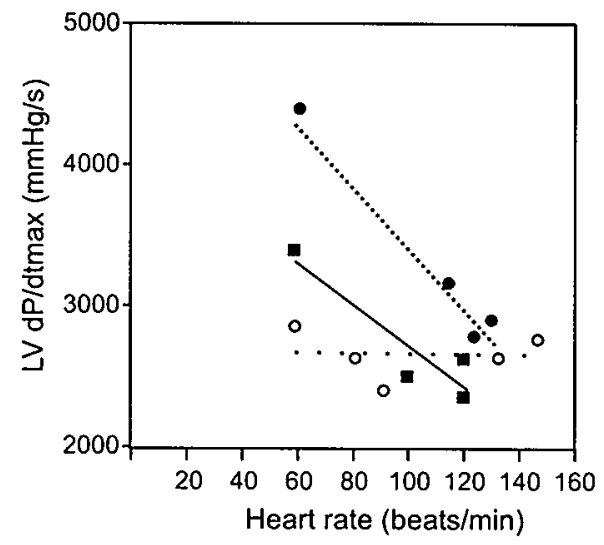

Figure 2. Example of the force-frequency relation at week 0 (open circles) and after 6 (closed circles) and 16 weeks of AV-block (closed squares).
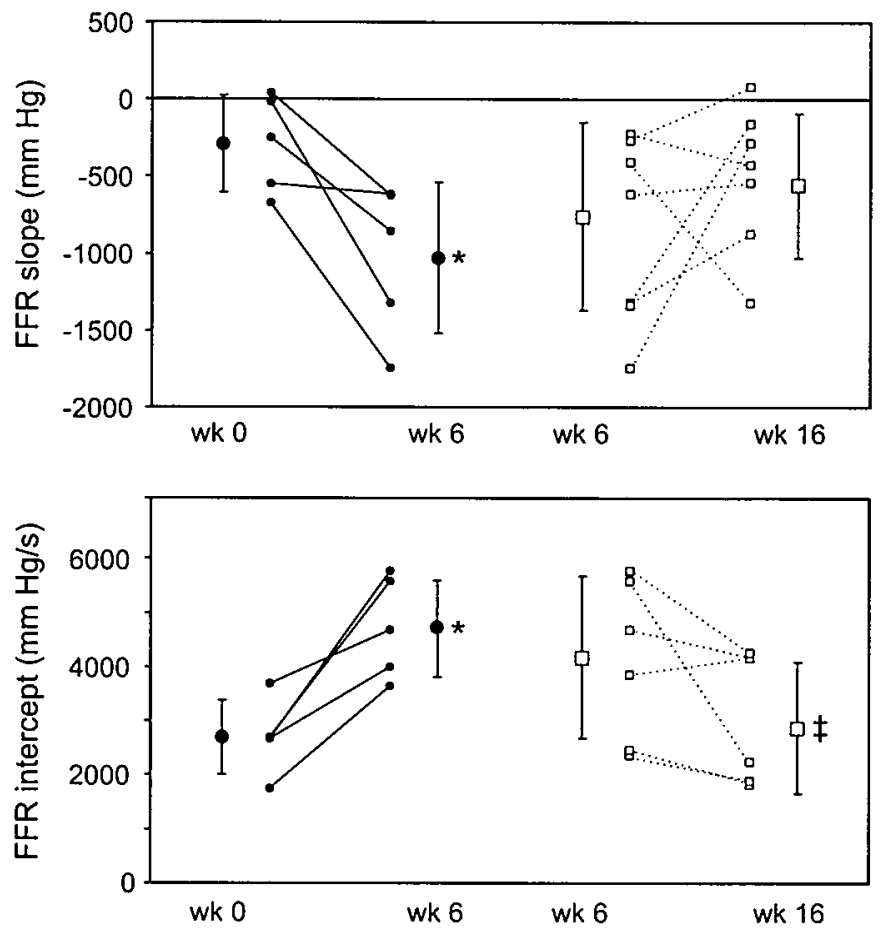

Figure 3. Slope and $y$-axis intercept of the force-frequency relation (FFR). ${ }^{*} p<0.05$ vs. week $0, \neq p<0.05$ vs. wk 6. 

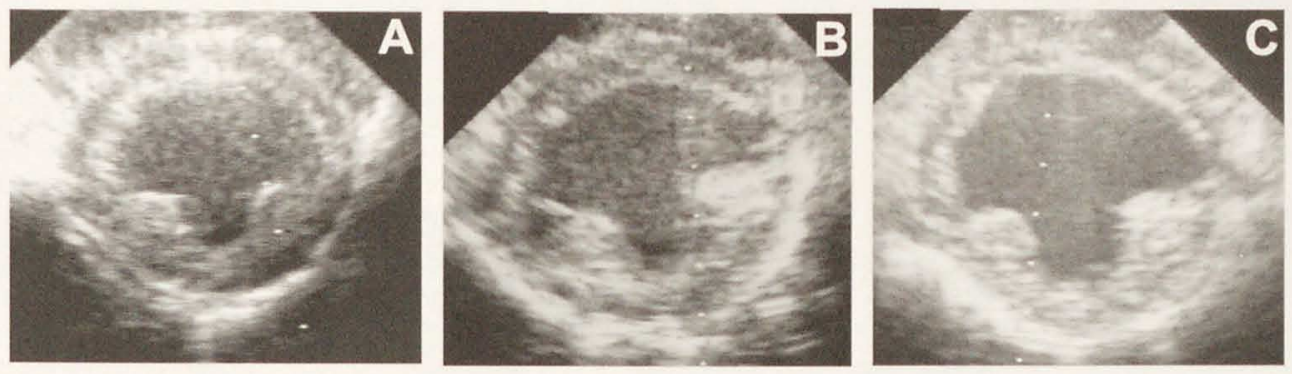

Figure 4. Example of changes in LV echocardiograms in sinus rhythm (panel A) and after 6 (panel B) and 16 weeks of AV-block (panel C).

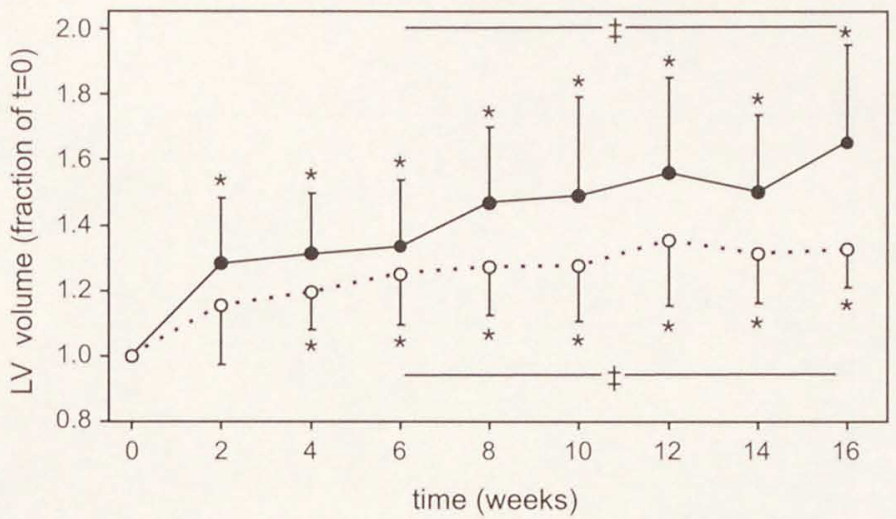

Figure 5. Time course of LV wall volume (open symbols) and end-diastolic LV cavity volume (closed symbols) expressed as fraction of $\mathrm{t}=0,{ }^{*} \mathrm{p}<0.05 \mathrm{vs} . \mathrm{t}=0, \neq \mathrm{p}<0.05 \mathrm{vs}$. wk 6 .

Table 2.

Structural changes after AV-block.

\begin{tabular}{llll}
\hline & Wk 6 & Wk 16 & Wk 16 \\
& Rel. to SR & Rel. to SR & Rel. to wk 6 \\
\hline LV cavity volume & $1.37 \pm 0.19^{*}$ & $1.62 \pm 0.33^{* \neq}$ & $1.25 \pm 0.11^{* \neq}$ \\
LV wall volume & $1.25 \pm 0.15^{*}$ & $1.31 \pm 0.13^{* \neq}$ & $1.12 \pm 0.07^{* \neq}$ \\
LV cavity/wall & $1.09 \pm 0.12^{*}$ & $1.23 \pm 0.20^{* \neq}$ & $1.12 \pm 0.09^{* \neq}$ \\
\hline
\end{tabular}

LV wall volume, cavity volume and the LV cavity to wall volume ratio at end-diastole after 6 and 16 weeks of AV-block. Values at week 6 are expressed as a fraction of sinus rhythm (SR), values at week 16 as a fraction of SR and of week $6 .{ }^{*} p<0.05$ vs. SR, $\neq p<0.05$ vs. wk 6 . 


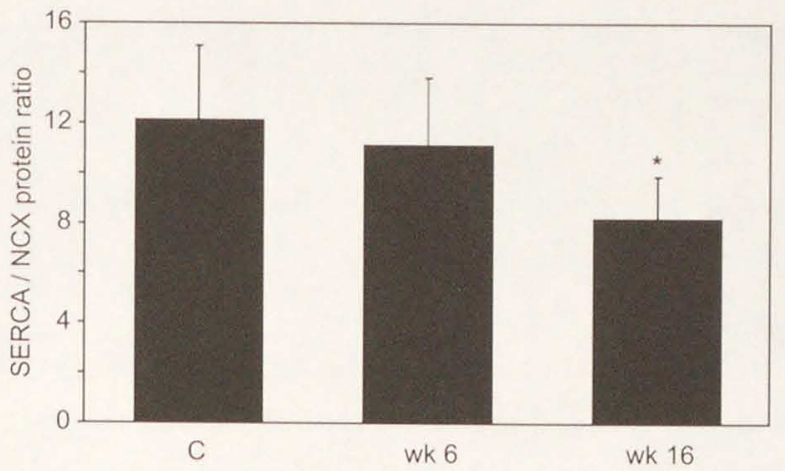

Figure 6. Left ventricular SERCA to NCX protein ratio in control dogs (C) and after 6 and 16 weeks of AV-block. ${ }^{*} \mathrm{p}<0.05$ vs. SR.

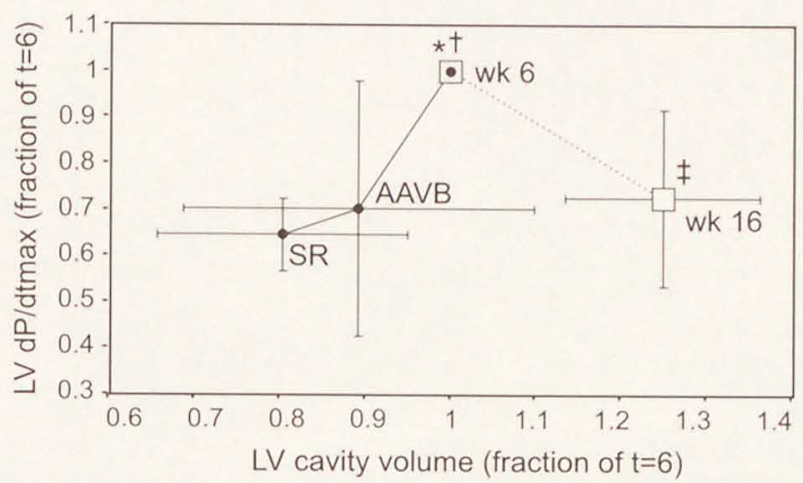

Figure 7. $\quad L V \mathrm{dP} / \mathrm{dt}_{\max }$ as a function of LV cavity volume. Values for both parameters were expressed as fraction of week 6. LV cavity volume was derived from echocardiograms at sinus rhythm and after 6 and 16 weeks of AV-block; LV cavity volume at acute AV-block (AAVB) was calculated using the total cavity volume as measured by the conductance catheter. ${ }^{*} p<0.05$ vs. SR, $+p<$ 0.05 vs. $A A \vee B$ and $\neq p<0.05$ vs. wk 6 .

cavity volume increased (to $62 \pm 33 \%$ above sinus rhythm), leading to an increase in LV cavity/wall volume ratio.

After 6 and 16 weeks of AV-block myocardial SERCA protein content $(3153 \pm 340$ and $2860 \pm 748 \mathrm{cpm} / \mathrm{mg}$ tissue wet weight, respectively) was similar to that in control hearts (3554 $\pm 415 \mathrm{cpm} / \mathrm{mg}$ tissue wet weight). Also absolute myocardial NCX protein contents did not change over a period of 16 weeks of AV-block $(314 \pm 101,296 \pm 63$ and $357 \pm 101 \mathrm{cpm} / \mathrm{mg}$ tissue wet weight in control hearts and in hearts after 6 and 16 weeks of AV-block, respectively). However, the myocardial SERCANCX protein ratio was significantly lower $(-32 \pm 14 \%)$ after 16 weeks AV-block than in control hearts (Figure 6). 


\section{Contractile and structural remodeling}

In order to illustrate the biphasic character of LV contractility and the progressive structural remodeling of $\mathrm{LV}$ end-diastolic volume, changes in $\mathrm{LV} \mathrm{dP/dt}{ }_{\max }$ are plotted as a function of changes in LV end-diastolic volume, using the values at week 6 as a reference (Figure 7). Acutely after creation of AV-block LV end-diastolic volume increased without an increase in LV dP/dt max . After 6 weeks of AV-block both LV end-diastolic volume and LV dP/dt $t_{\max }$ increased. Compared to week 6, 16 weeks of AV-block was characterized by further LV cavity dilation (progression), accompanied by a decrease in LV dP/dt ${ }_{\max }$ to sinus rhythm level.

\section{Discussion}

The findings in the present study indicate that in the initial phase of bradycardia induced volume overload hypertrophy (up to 6 weeks) LV function is supranormal, as

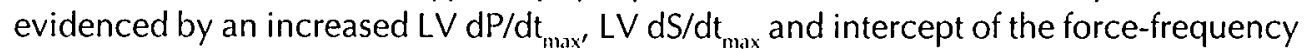
relation. At later stages (up to 16 weeks) LV performance decreases, as demonstrated by the reduction in $\mathrm{LV} \mathrm{dP/dt} t_{\max }$ and $\mathrm{dS} / \mathrm{dt}_{\max }$. The supranormal performance during the early stage is associated with a negative slope of the force-frequency relation. After 16 weeks of AV-block this slope remains negative, but the intercept with the $y$-axis decreases significantly. The latter is associated with a decreased SERCANNCX protein ratio and with progression of LV cavity dilatation.

\section{Stages of LV function in hypertrophy}

The increased LV performance during the first phase of this type of hypertrophy, as initially observed by de Groot et al. ${ }^{17}$, may be explained by a transient elevation of plasma levels of ANF, angiotensin II and norepinephrine, which are most pronounced between 2-4 weeks of AV-block and which normalized after 6 weeks ${ }^{25}$. Similar results of hypertrophy and overcompensation are found in animal models of arteriovenous shunt ${ }^{26}$ and aortic banding ${ }^{27}$. Supranormal LV function has also been reported in subgroups of hypertensive patients ${ }^{1-3}$.

In this model of chronic volume overload cardiac output, as determined during anesthesia, is normalized during the initial phase of hypertrophy. However, peak fiber stress remains elevated. This suggests that the increase in LV mass does not fully compensate for the increased hemodynamic load. This may explain the further ventricular dilatation between 6 and 16 weeks of AV-block.

After 16 weeks of AV-block, there is still no evidence of overt heart failure, which is in agreement with earlier observations ${ }^{17,25,28-32}$ and with the normal cardiac output. In 
dogs, even after 6 months ${ }^{28}$ to 3 years ${ }^{30}$ of AV-block no signs of heart failure have been observed.

Force-frequency relation

The present study shows that the force-frequency relation becomes negative already in the initial hypercontractile phase and remains negative in the subsequent phase. Therefore, at least in the AV-block model, a negative force-frequency relation is not a sign for the onset of heart failure, as has been proposed by Inagaki et al. ${ }^{16}$. These investigators showed that patients with a (partly) negative force-frequency relation had a lower systolic function (ejection fraction) than in an otherwise similar group with a positive force-frequency relation. In patients with overt heart failure a negative force-frequency relation has been consistently observed ${ }^{12,14-16,33}$. Our observation is in agreement with the finding of Gwathmey et al., who also showed a negative force-frequency relation in an animal model of compensated pressure overload hypertrophy ${ }^{34}$. Therefore, in hypertrophied myocardium a negative force-frequency relation may be present already during (early) phases of compensated hypertrophy.

\section{SERCA/NCX ratio and LV function}

In the initial phase of volume overload hypertrophy, associated with supranormal LV function, the negative force-frequency relation is not related to a decrease in SERCANNCX protein ratio, as in patients with heart failure ${ }^{3,12}$. In the second phase, the decrease in SERCAVNCX protein ratio coincides with a decrease in systolic function (LV $\mathrm{dP} / \mathrm{dt}_{\max }$ and intercept of the force-frequency relation) and diastolic function (tau, LV

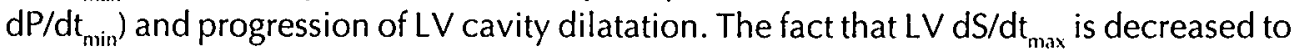
the same extent as LV dP/dt ${ }_{\text {max }}$ indicates that the decrease of the latter is due to myocardial changes rather than to geometrical changes (dilatation). These data support a pivotal role of the SERCANNCX protein ratio in LV systolic and possibly diastolic function. It is unlikely that the changes in diastolic LV function over time are due to changes in the extracellular matrix, because no changes in myocardial collagen fraction were found ${ }^{25} 35$.

The negative slope of the force-frequency relation in the absence of a decreased SERCA/NCX protein ratio after 6 weeks of AV-block could be explained by alterations in NCX exchanger function. Patch-clamp studies, however, showed increased NCX currents at this time point ${ }^{18}$. It is tempting to suggest that the activity of this exchanger may have been stimulated by increased intracellular $\mathrm{Na}^{+36}$ and/or increased circulating hormones ${ }^{25}$. Whether the NCX current is still increased after 16 weeks of AV-block is not known.

The finding that absolute protein levels of SERCA and NCX are not changed, is in agreement with earlier observations. In experimental studies a decrease in SERCA was 
only found after onset of heart failure ${ }^{9,10}$. Even in patients with heart failure SERCA is not always decreased (for review see ref 37). The ratio of SERCA and NCX protein content, however, is consistently decreased in heart failure ${ }^{6,15}$, as well as in patients with compensated hypertrophy '. Our study is a further support for the idea that the SERCAVNCX protein ratio is a valuable index of changes in myocardial function.

\section{Conclusions}

In this model of bradycardia induced volume overload the intercept, rather than the slope of the force-frequency relation reflects the biphasic changes in contractility over time. The decrease in SERCANCX protein ratio after 16 weeks of AV-block appears to indicate the onset of reduced contractile function and coincides with progression of $L V$ cavity dilatation. 


\section{References}

1. Blake 1, Devereux RB, Herrold EM, et al. Relation of concentric left ventricular hypertrophy and extracardiac target organ damage to supranormal left ventricular performance in established essential hypertension. Am / Cardiol. 1988;62:246-52.

2. Kass DA. Force-frequency relation in patients with left ventricular hypertrophy and failure. Basic Res Cardiol. 1998;93:108-16.

3. de Simone G, Greco R, Mureddu $G$, et al. Relation of left ventricular diastolic properties to systolic function in arterial hypertension. Circulation. 2000;101:152-7.

4. Morgan JP, Erny RE, Allen PD, et al. Abnormal intracellular calcium handling, a major cause of systolic and diastolic dysfunction in ventricular myocardium from patients with heart failure. Circulation. 1990; 81:lii21-32.

5. Gwathmey JK, Copelas L, MacKinnon R, et al. Abnormal intracellular calcium handling in myocardium from patients with end-stage heart failure. Circ Res. 1987;61:70-6.

6. Houser SR, Piacentino V, 3rd, Mattiello J, et al. Functional properties of failing human ventricular myocytes. Trends Cardiovasc Med. 2000;10:101-7.

7. Schotten $U$, Koenigs B, Rueppel M, et al. Reduced myocardial sarcoplasmic reticulum Ca "-ATPase protein expression in compensated primary and secondary human cardiac hypertrophy. I Mol Cell Cardiol. 1999;31:1483-94.

8. Studer R, Reinecke $\mathrm{H}$, Bilger J, et al. Cene expression of the cardiac $\mathrm{Na}^{*}-\mathrm{Ca}^{2 \cdot}$ exchanger in end-stage human heart failure. Circ Res. 1994;75:443-53.

9. de la Bastie D, Levitsky D, Rappaport $L$, et al. Function of the sarcoplasmic reticulum and expression of its Ca"'-ATPase gene in pressure overload-induced cardiac hypertrophy in the rat. Circ Res. 1990;66: 554-64.

10. Kiss E, Ball NA, Kranias EG, et al. Differential changes in cardiac phospholamban and sarcoplasmic reticular $\mathrm{Ca}^{2 "}$-ATPase protein levels. Effects on $\mathrm{Ca}^{2 *}$ transport and mechanics in compensated pressure-overload hypertrophy and congestive heart failure. Circ Res. 1995;77:759-64.

11. Schwinger RH, Bohm $M$, Schmidt $U$, et al. Unchanged protein levels of SERCA II and phospholamban but reduced $\mathrm{Ca}^{* *}$ uptake and Ca" $\mathrm{CATPase}^{\prime}$ activity of cardiac sarcoplasmic reticulum from dilated cardiomyopathy patients compared with patients with nonfailing hearts. Circulation. 1995;92:3220-8.

12. Hasenfuss $\mathrm{G}$, Schillinger $\mathrm{W}$, Lehnart $\mathrm{SE}$, et al. Relationship between $\mathrm{Na}{ }^{\circ}-\mathrm{Ca}^{*}$ " exchanger protein levels and diastolic function of failing human myocardium. Circulation. 1999;99:641-8.

13. Schwinger RH, Wang J, Frank K, et al. Reduced sodium pump alpha1, alpha3, and beta 1-isoform protein levels and $\mathrm{Na}-K^{\prime}$ ATPase activity but unchanged $\mathrm{Na}^{\circ}-\mathrm{Ca}^{2}{ }^{\cdot}$ exchanger protein levels in human heart failure. Circulation. 1999;99:2105-12.

14. Hasenfuss $G$, Reinecke $H$, Studer $R$, et al. Calcium cycling proteins and force-frequency relationship in heart failure. Basic Res Cardiol. 1996;91 Suppl 2:17-22.

15. Hasenfuss $G$, Reinecke $H$, Studer $R$, et al. Relation between myocardial function and expression of sarcoplasmic reticulum Ca"-ATPase in failing and nonfailing human myocardium. Circ Res. 1994; 75:434-42.

16. Inagaki $M$, Yokota $M$, Izawa $H$, et al. Impaired force-frequency relations in patients with hypertensive left ventricular hypertrophy. A possible physiological marker of the transition from physiological to pathological hypertrophy. Circulation. 1999;99:1822-30.

17. de Groot $\mathrm{SH}$, Schoenmakers $\mathrm{M}$, Molenschot $\mathrm{MM}$, et al. Contractile adaptations preserving cardiac output predispose the hypertrophied canine heart to delayed afterdepolarization-dependent ventricular arrhythmias. Circulation. 2000;102:2145-51.

18. Sipido KR, Volders $\mathrm{PG}$, de Groot $\mathrm{SH}$, et al. Enhanced $\mathrm{Ca}{ }^{2 *}$ release and $\mathrm{Na} / \mathrm{Ca}$ exchange activity in hypertrophied canine ventricular myocytes : potential link between contractile adaptation and arrhythmogenesis. Circulation. 2000;102:2137-44.

19. Rodriguez LM, Leunissen J, Hoekstra A, et al. Transvenous cold mapping and cryoablation of the AV node in dogs: observations of chronic lesions and comparison to those obtained using radiofrequency ablation. / Cardiovasc Electrophysiol. 1998;9:1055-61. 
20. Steendijk P, Baan J. Comparison of intravenous and pulmonary artery injections of hypertonic saline for the assessment of conductance catheter parallel conductance. Cardiovasc Res. 2000;46:82-9.

21. van Oosterhout MF, Prinzen FW, Arts T, et al. Asynchronous electrical activation induces asymmetrical hypertrophy of the left ventricular wall. Circulation. 1998;98:588-95.

22. Arts $T$, Bovendeerd $\mathrm{PH}$, Prinzen FW, et al. Relation between left ventricular cavity pressure and volume and systolic fiber stress and strain in the wall. Biophys /. 1991;59:93-102.

23. Bradford MM. A rapid and sensitive method for the quantitation of microgram quantities of protein utilizing the principle of protein-dye binding. Anal Biochem. 1976;72:248-54.

24. van Opstal IM, Schoenmakers M, Verduyn SC, et al. Chronic amiodarone evokes no Torsade de Pointes arrhythmias despite QT lengthening in an animal model of acquired long.QT syndrome. Circulation. $2001 ; 104: 2722-7$.

25. Vos MA, de Groot SH, Verduyn SC, et al. Enhanced susceptibility for acquired Torsade de Pointes arrhythmias in the dog with chronic, complete AV block is related to cardiac hypertrophy and electrical remodeling. Circulation. 1998;98:1125-35.

26. Gerdes AM, Clark LC, Capasso JM. Regression of cardiac hypertrophy after closing an aortocaval fistula in rats. Am / Physiol. 1995;268:H2345-51.

27. Litwin SE, Katz SE, Weinberg EO, et al. Serial echocardiographic-Doppler assessment of left ventricular geometry and function in rats with pressure-overload hypertrophy. Chronic angiotensin-converting enzyme inhibition attenuates the transition to heart failure. Circulation. 1995;91:2642-54.

28. Wusten B, Flameng W, Schaper W. Cardiac function in the chronically volume-overloaded canine heart. Basic Res Cardiol. 1977;72:172-7.

29. Turina M, Bussmann WD, Krayenbuhl HP. Contractility of the hypertrophied canine heart in chronic volume overload. Cardiovasc Res. 1969;3:486-95.

30. Newman WH. Contractile state of hypertrophied left ventricle in long-standing volume overload. Am / Physiol. 1978;234:H88-93.

31. Todaka K, Leibowitz D, Homma S, et al. Characterizing ventricular mechanics and energetics following repeated coronary microembolization. Am / Physiol. 1997;272:H186-94.

32. Lucas $\mathrm{CM}$, Cheriex EC, van der Veen FH, et al. Imipramine induced heart failure in the dog: a model to study the effect of cardiac assist devices. Cardiovasc Res. 1992;26:804-9.

33. Hasenfuss G, Holubarsch $C$. Hermann $H P$, et al. Influence of the force-frequency relationship on haemodynamics and left ventricular function in patients with non-failing hearts and in patients with dilated cardiomyopathy. Eur Heart /. 1994;15:164-70.

34. Gwathmey JK, Morgan JP. Sarcoplasmic reticulum calcium mobilization in right ventricular pressure-overload hypertrophy in the ferret: relationships to diastolic dysfunction and a negative treppe. Pflugers Arch. 1993;422:599-608.

35. Peschar $M$, Vernooy $K$, Vanagt $W Y R$, et al. Absence of reverse electrical remodeling during regression of volume overload hypertrophy in canine ventricles. Thesis chapter 5.

36. Verdonck F, Volders PGA, Vos MA, et al. Cardiac hypertrophy is associated with an increase in subsarcolemmal Na'. / Biophys. 2001;80:598a.

37. Houser SR, Piacentino V, 3rd, Weisser J. Abnormalities of calcium cycling in the hypertrophied and failing heart. / Mol Cell Cardiol. 2000;32:1595-607. 


\section{CHAPTER 4}

\section{Metabolic remodeling in global and regional hypertrophy of the canine heart}

Maaike Peschar, Matthijs F.M. van Oosterhout, Jodil Willems, Annita M.J. Rousseau, Jan F.C. Glatz, Robert S. Reneman and Frits W. Prinzen

Department of Physiology,

Cardiovascular Research Institute Maastricht, Maastricht University, Maastricht, the Netherlands 


\begin{abstract}
Background: Hypertrophy is associated with altered myocardial energy metabolism. It is not clear whether these changes are related to the degree or to the type of hypertrophy. We determined activities of selected metabolic enzymes in the left ventricle (LV) in global volume and pressure overload hypertrophy and in asymmetric LV hypertrophy.

Methods: In dogs, volume overload hypertrophy $(\mathrm{VOH})$ was induced by atrio-ventricular block, pressure overload hypertrophy ( $\mathrm{POH}$ ) by aortic constriction and regional hypertrophy by LV free wall pacing (PACE). Global and regional LV wall volume was determined by 2D-echocardiography. The activities of enzymes involved in glycolysis (PFK', LDH), $\beta$-oxidation (HAD), Krebs cycle (CS) and energy transfer (CK) were measured and compared with data from control animals.

Results: VOH, POH and PACE animals developed $\sim 30 \%$ LV hypertrophy. In the PACE animals LV wall volume was not changed in the early-activated free wall but increased $\sim 40 \%$ in the late-activated septum. As compared to control hearts, CS was significantly higher in $\mathrm{VOH}$ hearts $(+54 \%)$ and significantly lower in POH and PACE hearts $(-33 \%$ and $-37 \%$, respectively). The activities of the other four enzymes were either increased in $\mathrm{VOH}$ hearts or decreased in POH and PACE hearts. No differences were found in enzyme activities between early and late-activated regions in PACE hearts.

Conclusions: Metabolic remodeling, as indicated by the activity of five enzymes involved in myocardial energy metabolism, is not dependent on the degree of (regional) hypertrophy. Metabolic remodeling appears to be specific for the type of hypertrophy and to depend on systemic factors. The results of the present study do not support the hypothesis that cardiac hypertrophy is obligatory associated with a shift from fatty acid to carbohydrate metabolism.
\end{abstract}

* PFK: 6-phoshofructo-1-kinase, LDH: lactate dehydrogenase, HAD: 3-hydroxy-acyl-CoA dehydrogenase, CS: citrate synthase and CK: creatine kinase. 


\section{Introduction}

When the heart is chronically subjected to increased workload, it enlarges as a consequence of hypertrophy. This increase in wall mass also results in remodeling of the myocardial structure and function. Different types of hypertrophy have different consequences for structure and composition of the cardiac tissue. Volume overload leads to eccentric left ventricular (LV) hypertrophy, i.e. the relative increase in chamber volume is at least as large as the increase in wall mass. Typically, volume overloaded myocytes become longer but not thicker ${ }^{1-3}$, the collagen volume fraction remains unchanged ${ }^{3,4}$, while the capillary density is either unchanged ${ }^{5}$ or decreased ${ }^{4}$. Pressure overload results in concentric LV hypertrophy, meaning that wall thickness increases relative to chamber volume. The increased myocyte width ${ }^{6}$ is accompanied by decreased capillary density ${ }^{7}$ and an unchanged ${ }^{6}$ or increased collagen fraction ${ }^{8}$.

From uptake studies there is evidence that cardiac hypertrophy alters myocardial substrate utilization and metabolism ",10. Compared to normal hearts, in hypertrophied hearts, lower rates of fatty acid oxidation and higher glycolysis rates have been reported, especially in pressure overload hypertrophy ${ }^{11-13}$. Little is known, however, about volume overload hypertrophy. In addition, to the best of our knowledge, no studies have been performed on a possible relation between changes in metabolic enzyme activities and the degree of ventricular hypertrophy.

The aim of the present study was to investigate whether there is a relation between the type and degree of hypertrophy on the one hand and changes in activities of enzymes involved in myocardial energy metabolism on the other. For this purpose we measured the activities of enzymes involved in glycolysis, conversion of pyruvate and lactate, fatty acid oxidation, the Krebs cycle and energy transfer.

The activities of these enzymes were determined in myocardial tissue from hearts subjected to volume overload hypertrophy (atrio-ventricular (AV) block) ${ }^{3}$, pressure overload hypertrophy (aortic constriction) ${ }^{6}$ or regional LV hypertrophy as induced by long term LV free wall pacing ${ }^{14}$. Chronic asynchronous activation leads to asymmetrical hypertrophy, i.e. hypertrophy in the late-activated septum and absence of hypertrophy in the early-activated free wall ${ }^{14}$.

\section{Methods}

Animal handling was performed according to the Dutch Law on Animal Experimentation (WOD) and the European Directive for the protection of Vertebrate Animals used for experimental and other purposes (86/609/EU). The protocol was approved by the Animal Experimental Committee of the Maastricht University. The experiments were performed on 24 adult mongrel dogs of either sex. The dogs were divided into four groups: control ( $C, n=13$ with body weight of $24 \pm 2 \mathrm{~kg}$ ), volume 
overload hypertrophy for 4 months ( $V O H, n=3,24 \pm 5 \mathrm{~kg}$ ), pressure overload hypertrophy for 12 months ( $\mathrm{POH}, \mathrm{n}=4,24 \pm 1 \mathrm{~kg}$ ) and $\mathrm{LV}$ pacing for 6 months (PACE, $\mathrm{n}=8,29 \pm 10 \mathrm{~kg})$.

\section{Implantation procedure}

Dogs were premedicated with acepromazine $0.2 \mathrm{mg} / \mathrm{kg}$, atropine $0.1 \mathrm{mg} / \mathrm{kg}$ and oxycodon $2 \mathrm{mg} / \mathrm{kg}$ i.m. Anesthesia was induced with thiopental, $15 \mathrm{mg} / \mathrm{kg}$ i.v., and maintained by ventilation with halothane $(0.75-1.5 \%)$ in a $1: 2$ mixture of $\mathrm{O}_{2}$ and $\mathrm{N}_{2} \mathrm{O}$.

$\mathrm{VOH}$ was a consequence of chronic complete atrio-ventricular block, as induced by $\mathrm{RF}$ ablation as previously described in chapter 3 . $\mathrm{POH}$ was induced by aortic constriction. In brief, in 8-week-old puppies a slightly constricting ligature was placed around the ascending aorta to induce pressure overload ${ }^{6}$. Regional hypertrophy was induced by LV pacing as previously described ${ }^{14}$. In brief, in an open thorax procedure, a ventricular pacing lead was placed at the epicardium of the $L V$ free wall, $1 \mathrm{~cm}$ below the base. The heart was stimulated at its own rhythm by pacing in the VDD-mode, i.e. atrial sensing and ventricular pacing. The AV-delay was $25 \mathrm{~ms}$ to insure complete ventricular capture.

\section{Echo protocol and analysis}

Two-dimensional echocardiographic images of the short axis of the LV were made before induction of hypertrophy and before sacrifice. Total LV wall volume and in the PACE-group also LV free wall and LV septal volume were measured using semi-automated contouring of endo and epicardial borders and dividing the LV into sectors using the papillary muscles as landmarks, as described in detail by van Oosterhout et al. ${ }^{14}$. Global and regional LV wall volume was expressed relative to week 0 . In the $\mathrm{POH}$ group LV wall volume was also corrected for body weight, since the dogs were puppies at implantation.

\section{Terminal procedure}

Under general anesthesia the thorax was opened and the heart was quickly removed. The LV was weighed and transmural LV free wall samples were taken. In the PACE-group also samples from the septum, opposite to the pacing site, were taken. Non-muscular structures like fat and vessels at the epicardium and chordae tendinae were removed. For histological analysis samples were immersion-fixed in zinc-buffered formalin $(10 \%)$ and embedded in paraffin. For biochemical analysis samples where quickly immersed in liquid nitrogen and stored at $-80^{\circ} \mathrm{C}$. 


\section{Histological analysis}

Morphometry was performed with a Quantimed 570 image analyzer (Leica) 14 Myocyte width was determined using a modification of the Azan technique and collagen fraction was determined using Sirius Red staining ${ }^{15}$.

\section{Biochemical analysis}

Activities of individual metabolic enzymes were measured spectrophotometrically in supernatants of sonicated muscle homogenates at $37^{\circ} \mathrm{C}$. Citrate synthase (CS) was assayed by the method of Shepherd and Garland ${ }^{16}$ and 6-phoshofructo-1-kinase (PFK) activity by the method of Ling et al. " ${ }^{17}$. 3-hydroxy-acyl-CoA dehydrogenase (HAD) was determined according to Bergmeyer et al. ${ }^{18}$. Lactate dehydrogenase (LDH) activity (pyruvate as substrate, Boehringer Mannheim, FRG) and creatine kinase (CK) activity (NAC-activated CK test from Merck Diagnostica) were both assayed using standard test kits. All activities are expressed in units $(1 \mu \mathrm{mol} / \mathrm{min})$ per $\mathrm{mg}$ of total protein. Protein content was determined by the Bicinchoninic acid (BCA) assay (Pierce) with bovine serum albumin as the standard.

\section{Statistical analysis}

Differences between early and late-activated regions within the PACE group were evaluated for statistical significance with the Wilcoxon signed rank test, while differences between the groups were evaluated with the Mann-Whitney $U$ test. Data are presented as mean values $\pm S D . p<0.05$ was considered significant.

\section{Results}

\section{Structural changes}

Post mortem data of LV weight to body weight (BW) ratio are presented in Figure $1 \mathrm{~A}$. Chronic volume and pressure overload and chronic ventricular pacing all resulted in significant LV hypertrophy $(22 \%, 18 \%$ and $24 \%$, respectively). Relative LV wall volume, determined by serial $2 \mathrm{D}$-echocardiography and relative to week 0 , is depicted in Figure 1B. LV wall volume was increased by $33 \pm 12 \%$ in $\mathrm{VOH}$ hearts and by $29 \pm 10 \%$ in $\mathrm{POH}$ hearts. LV wall mass was not changed in the early-activated region, but increased by $39 \pm 13 \%$ in the late-activated region of PACE hearts. LV collagen fraction was not significantly different between the four groups (Figure 1C), but myocyte width was significantly larger in pressure overload hypertrophy and in the late-activated region of the paced hearts (Figure 1D). 


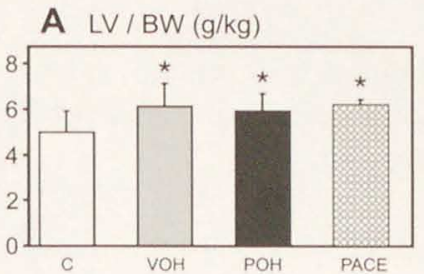

B LV wall vol. (fraction of $\mathrm{t}=0$ )

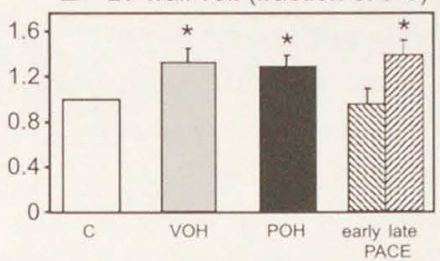

C LV collagen fraction (\%)

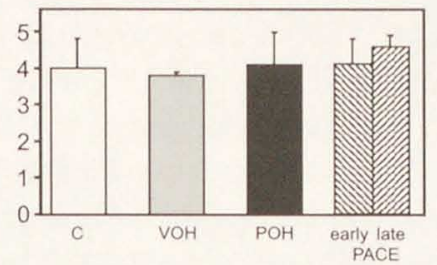

D LV myocyte width $(\mu \mathrm{m})$

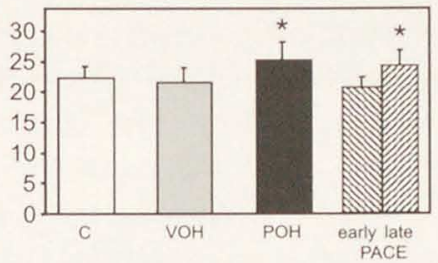

Figure 1. Post mortem LV to bodyweight (BW) ratio (panel A), relative changes in LV wall volume as determined by serial 2D-echocardiography (panel B), LV collagen fraction (panel C) and LV myocyte width (panel D) in Control (white bar), $\mathrm{VOH}$ (gray bar), $\mathrm{POH}$ (black bar), PACE (cross hatched bar) and in early and late activated areas in PACE (hatched bars). ${ }^{*} p<0.05 \mathrm{vs}$. Control

A PFK (U/mg protein)

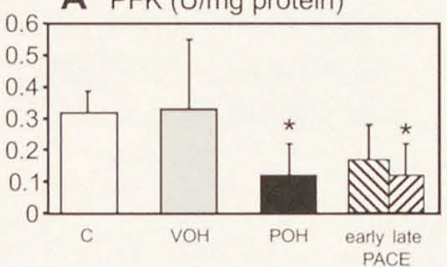

C LDH (U/mg protein)

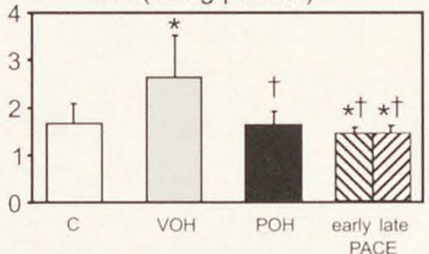

E CK (U/mg protein)

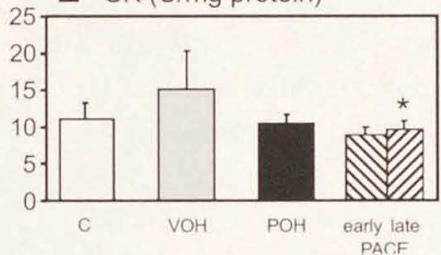

B $\operatorname{HAD}(\mathrm{U} / \mathrm{mg}$ protein)

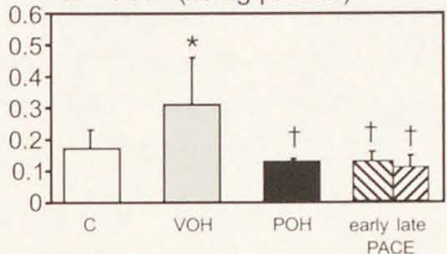

D CS (U/mg protein)

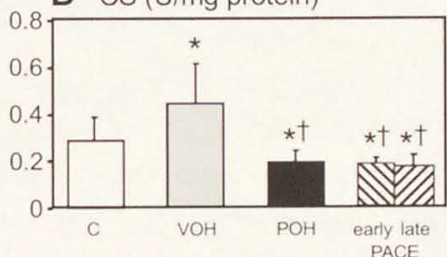

Figure 2. Enzyme activities of PFK, HAD, LDH, CS and CK in LV free wall in Control (white bar), VOH (gray bar), $\mathrm{POH}$ (black bar) and in early and late activated areas in PACE (hatched bars). ${ }^{*} \mathrm{p}<$ 0.05 vs. Control and $+p<0.05$ vs. $\mathrm{VOH}$. 
In general, the activities of the five enzymes were considerably different between $\mathrm{VOH}$ hearts on the one hand and POH and PACE hearts on the other, being markedly higher in VOH hearts (Figure 2). Compared to the controls, the activities of HAD, LDH and CS were significantly increased in $\mathrm{VOH}$ hearts, reaching $82 \%, 58 \%$ and $54 \%$ higher values, respectively. In contrast, PFK and CS were significantly decreased in $\mathrm{POH}$ hearts, reaching $62 \%$ and $33 \%$ lower values than in controls, respectively. The same two enzymes, but also LDH, were significantly decreased in PACE hearts, both in early and late-activated regions. Only CK remained essentially unchanged in the various types of hypertrophy.

\section{Discussion}

The present study shows that the type of hemodynamic load strongly determines the expression of metabolic enzyme activity during the subsequent development of hypertrophy. In general, enzyme activities are increased in volume overload induced hypertrophy and decreased in pacing and pressure overload induced hypertrophy as compared to control. The uniform distribution of the activities of metabolic enzymes in the asymmetrically hypertrophied left ventricle suggests that systemic factors may play a role in the metabolic adaptation of hypertrophied myocardium. It should be emphasized that these changes all occurred in the absence of heart failure.

Metabolic enzyme activities in various types of hypertrophy

To the best of our knowledge, this is the first report on differences in metabolic enzyme activities among different types of cardiac hypertrophy. While all enzymes respond differently to volume than to pressure overload and ventricular pacing, this is most pronounced for CS. Its activity is increased in the former type and decreased in the latter types of hypertrophy. These differences are in agreement with the increase in CS activity reported in dogs after exercise training ${ }^{19}$ and the decrease in CS activity observed in rabbits with pressure overload hypertrophy ${ }^{20}$. In patients with myocardial hypertrophy due to aortic stenosis no significant changes in CS were observed as compared to controls ${ }^{21}$. The study of Stuewe et al. ${ }^{19}$ shows that increased CS activity corresponds with increased protein content without a change in substrate specificity, so enzyme activity reflects the content of the enzyme.

The tendency to a decrease in CK activity in pressure overload hypertrophy is in keeping with several studies in the literature ${ }^{21-23}$, while the decrease in LDH activity, is not so consistent ${ }^{11,21-23}$. 
The finding that different hemodynamic loading conditions lead to different metabolic adaptations in the myocardium is in agreement with studies showing different changes in enzyme activities between different physical training protocols, even in the absence of hypertrophy ${ }^{19,2.4}$.

\section{Degree of hypertrophy}

Two findings in the present study support the idea that the changes in activities of metabolic enzymes are poorly related to the degree of hypertrophy. First of all, volume and pressure overload showed a similar degree of LV hypertrophy $(\sim 30 \%)$, but opposite changes in activities of metabolic enzymes. Secondly, in pacing induced hypertrophy the enzyme activities were similar in the early and late-activated regions, while the degree of hypertrophy was different. Most remarkable are the decreased enzyme activities in the early-activated myocardium, which is not hypertrophied at all. This observation seems to be equivalent to the observation by Smith et al. ${ }^{23}$ that systemic hypertension, inducing left but not right ventricular hypertrophy, is associated with increased tissue levels of myocardial LDH and decreased levels of CK in both ventricles. The fact that enzyme activities can change without increase in muscle mass 19,2. , is an additional indication that metabolic and structural remodeling do not have to go hand in hand.

Possible cause of metabolic remodeling

The functional importance of a change in metabolic enzyme activity is not well understood. The changes in enzyme activities could be cause or consequence of the alterations in workload. In all three models of hypertrophy no decompensation has occurred ${ }^{6,14,25}$. However, peak systolic fiber stress was (presumably) increased due to elevated systolic LV pressure in pressure overload hypertrophy and increased cavity to wall volume ratio in volume overload and pacing induced hypertrophy. Within the chronically paced hearts the workload per unit mass of tissue was the same everywhere in the left ventricle since an acute increase of workload in the late-activated area is compensated by regional hypertrophy ${ }^{26}$. The only difference between volume overload due to AV-block and pressure overload and pacing induced hypertrophy is, that work is generated in fewer heartbeats per minute, and thus a larger amount of work per beat has to be performed. Investigation whether the latter factor leads to metabolic remodeling requires a comparison of these $\mathrm{AV}$-block data with those from other types of volume overload hypertrophy with a normal heart rate.

Alternatively, low activity of metabolic enzymes may eventually lead to less energy and to reduced pump function. This is especially interesting for CS, a key enzyme in oxidative phosphorylation. Its activities are lower in pressure than in volume overload hypertrophy, while also a greater preponderance to heart failure exists in the former 
type of hypertrophy ${ }^{27}$. However, until now no hard evidence is available that a decreased capacity of metabolic enzymes is a trigger for heart failure.

The lower enzyme activities in pressure than in volume overload hypertrophy could be due to different adaptations at the cellular level. For instance, pressure overload leads to increased myocyte width, which is known to result in increased diffusion distance for oxygen (increased myocyte width without an increase in the number of capillaries) and decreased coronary reserve ${ }^{28-30}$. The combination of these two factors hampers myocardial oxygenation ${ }^{31,32}$, which is in agreement with a smaller relative increase in mitochondrial volume in pressure overload hypertrophy ${ }^{33}$. This could explain why in pressure overload hearts the activities of enzymes involved in oxidative metabolism, like HAD and CS, are decreased. Moreover, oxygenation and perfusion are probably well maintained in volume overload hypertrophy due to AV-block ${ }^{3.4}$ because the long diastolic periods allow ample coronary perfusion.

In conflict with the idea that oxygen diffusion distance could influence enzyme expression locally, in the asymmetrical hypertrophied hearts, regional differences in myocyte width exist without differences in metabolic enzyme activities. This may suggest a possible role for systemic factors, at least in paced hearts. Such factors may include neurohumoral and sympathetic stimulation. To what extent these factors could also play a role in volume and pressure overload hypertrophy is not clear, but increases in plasma levels of norepinephrine and angiotensin II have been reported ${ }^{4,35}$. In volume overload due to AV-block, this increase is transient, since plasma levels are normalized after 6 weeks ${ }^{4}$. In contrast, in a rat study with aortic banding plasma levels are still elevated after 8 weeks ${ }^{35}$. Such a difference and possibly accompanying changes, like changes in $\beta$-adrenergic responsiveness, could explain the underlying difference in metabolic remodeling. However, the published studies do not allow proper comparison of the time course and degree of stimulation between our three experimental models. Moreover, many other (unknown) factors may be involved.

\section{Carbohydrate vs. fatty acid metabolism}

Irrespective of the type of hypertrophy, the changes in activities were comparable for enzymes involved in carbohydrate and fatty acid metabolism. These findings are remarkable, because studies on uptake of labeled glucose and fatty acids showed that in hypertrophic hearts, utilization of glycolytic pathways is increased and utilization of fatty acids is often impaired ${ }^{11-13,36-38}$. The discrepancy between these data and the enzyme activity data obtained in the present study may be explained by the fact that enzyme activity is determined in vitro under optimal, artificial conditions and is closely related to the protein content of the enzyme ${ }^{19}$. In contrast, the results obtained in uptake studies are also dependent on the metabolic regulation of the myocardium in vivo. Furthermore, differences in species, degree of hypertrophy and presence of heart 
failure may contribute to the discrepancy between the present study and the uptake studies.

\section{Conclusions}

Metabolic remodeling, as determined by the activity of five enzymes operational at crucial points of myocardial substrate metabolism, appears to be specific for the type of hypertrophy. The differences in metabolic remodeling despite comparable degrees of hypertrophy and the observation that enzyme activity is uniformly reduced in pacing induced asymmetric hypertrophy, indicate that the activities of these enzymes are not determined by the degree of (regional) hypertrophy but that systemic factors may play a role. A shift from fatty acid to carbohydrate metabolism, if any, is not due to changes in protein expression of the various enzymes in any of the three types of hypertrophy studied. 


\section{References}

1. Volders PG, Sipido KR, Vos MA, et al. Cellular basis of biventricular hypertrophy and arrhythmogenesis in dogs with chronic complete atrioventricular block and acquired torsade de pointes. Circulation. 1998;98:1136-47.

2. Verduyn SC, Ramakers C, Snoep G, et al. Time course of structural adaptations in chronic AV block dogs: evidence for differential ventricular remodeling. Am / Physiol Heart Circ Physiol. 2001;280: H2882-90.

3. Peschar $M$, Baaten $G$, van der Nagel Th, et al. Biphasic contractile and progressive structural remodeling during chronic volume overload in dogs. Thesis chapter 3.

4. Vos MA, de Groot SH, Verduyn SC, et al. Enhanced susceptibility for acquired Torsade de Pointes arrhythmias in the dog with chronic, complete AV block is related to cardiac hypertrophy and electrical remodeling. Circulation. 1998;98:1125-35.

5. Legault F, Rouleau IL, Juneau C, et al. Functional and morphological characteristics of compensated and decompensated cardiac hypertrophy in dogs with chronic infrarenal aorto-caval fistulas. Circ Res. 1990;66:846-59.

6. van Oosterhout MF, Arts T, Muijtjens AM, et al. Remodeling by ventricular pacing in hypertrophying dog hearts. Cardiovasc Res. 2001;49:771-778.

7. van Oosterhout MFM, Prinzen FW, Clatz JFC, et al. Regional blood flow and activity of metabolic enzymes in canine hearts with pacing induced asymmetric hypertrophy. PhD thesis, Maastricht University, the Netherlands; 1999.

8. Weber KT, Brilla CG. Pathological hypertrophy and cardiac interstitium. Fibrosis and reninangiotensin-aldosterone system. Circulation. 1991;83:1849-65.

9. Kagaya $Y, K a n n o ~ Y, T a k e y a m a ~ D$, et al. Effects of long-term pressure overload on regional myocardial glucose and free fatty acid uptake in rats. A quantitative autoradiographic study. Circulation. 1990;81:1353-61.

10. Allard MF, Schonekess BO, Henning SL, et al. Contribution of oxidative metabolism and glycolysis to ATP production in hypertrophied hearts. Am / Physiol. 1994;267:H742-50.

11. Bishop SP, Altschuld RA. Increased glycolytic metabolism in cardiac hypertrophy and congestive failure. Am / Physiol. 1970;218:153-9.

12. Wambolt RB, Henning SL, English DR, et al. Regression of cardiac hypertrophy normalizes glucose metabolism and left ventricular function during reperfusion. / Mol Cell Cardiol. 1997;29:939-48.

13. Massie BM, Schaefer S, Garcia J, et al. Myocardial high-energy phosphate and substrate metabolism in swine with moderate left ventricular hypertrophy. Circulation. 1995;91:1814-23.

14. van Oosterhout MF, Prinzen FW, Arts T, et al. Asynchronous electrical activation induces asymmetrical hypertrophy of the left ventricular wall. Circulation. 1998;98:588-95.

15. Junqueira LC, Bignolas G, Brentani RR. Picrosirius staining plus polarization microscopy, a specific method for collagen detection in tissue sections. Histochem I. 1979;11:447-55.

16. Shepherd D, Garland PB. Citrate synthase from rat liver. Methods Enzymol. 1969;13:1 1-16.

17. Ling KH, Paetkau V, Marcus F, et al. Phophofructokinase in sketetal muscle. Methods Enzymol. 1966;9: 425-429.

18. Bergmeyer HU. New York, NY: Academic Press; 1974.

19. Stuewe SR, Gwirtz PA, Agarwal N, et al. Exercise training enhances glycolytic and oxidative enzymes in canine ventricular myocardium. / Mol Cell Cardiol. 2000;32:903-13.

20. Gibbs CL, Wendt IR, Kotsanas $G$, et al. Mechanical, energetic, and biochemical changes in long-term pressure overload of rabbit heart. Am / Physiol. 1990;259:H849-59.

21. Ingwall JS, Kramer MF, Fifer MA, et al. The creatine kinase system in normal and diseased human myocardium. N Engl / Med. 1985;313:1050-4.

22. van der Laarse $A$, Vliegen $\mathrm{HW}$, van der $\mathrm{Nat} \mathrm{KH}$, et al. Comparison of myocardial changes between pressure induced hypertrophy and normal growth in the rat heart. Cardiovasc Res. 1989;23:308-14.

23. Smith $\mathrm{SH}, \mathrm{Kramer} M \mathrm{~F}$, Reis I, et al. Regional changes in creatine kinase and myocyte size in hypertensive and nonhypertensive cardiac hypertrophy. Circ Res. 1990;67:1334-44. 
24. Taegtmeyer $\mathrm{H}$, Overturf $\mathrm{ML}$. Effects of moderate hypertension on cardiac function and metabolism in the rabbit. Hypertension. 1988;11:416-26.

25. Peschar $M$, Baaten $G$, van der Nagel $T$, et al. Biphasic contractile and progressive structural remodeling during bradycardia induced volume overload hypertrophy. Thesis chapter 3.

26. van Oosterhout MF, Arts T, Bassingthwaighte JB, et al. Relation between local myocardial growth and blood flow during chronic ventricular pacing. Cardiovasc Res. 2002;53:831-40.

27. Grossman W. Cardiac hypertrophy: useful adaptation or pathologic process? Am / Med. 1980;69: 576-84.

28. Rakusan K, Hrdina PW, Turek $Z$, et al. Cell size and capillary supply of the hypertensive rat heart: quantitative study. Basic Res Cardiol. 1984;79:389-95.

29. Henquell L, Odoroff CL, Honig CR. Intercapillary distance and capillary reserve in hypertrophied rat hearts beating in situ. Circ Res. 1977;41:400-8.

30. Engelmann GL, Vitullo JC, Gerrity RG. Morphometric analysis of cardiac hypertrophy during development, maturation, and senescence in spontaneously hypertensive rats. Circ Res. 1987;60: 487-94.

31. Qian SF, Brum JM, Bove AA. Energy production, $\mathrm{O}_{2}$ consumption, and blood flow reserve in experimental aortic valve disease. Am / Physiol. 1987;252:H243-51.

32. Snoeckx LH, van der Vusse GJ, Coumans WA, et al. Differences in ischaemia tolerance between hypertrophied hearts of adult and aged spontaneously hypertensive rats. Cardiovasc Res. 1993;27: 874-81.

33. Kayar SR, Weiss HR. Diffusion distances, total capillary length and mitochondrial volume in pressure-overload myocardial hypertrophy. I Mol Cell Cardiol. 1992;24:1155-66.

34. Carabello BA, Nakano K, Ishihara K, et al. Coronary blood flow in dogs with contractile dysfunction due to experimental volume overload. Circulation. 1991;83:1063-75.

35. Akers WS, Cross A, Speth R, et al. Renin-angiotensin system and sympathetic nervous system in cardiac pressure-overload hypertrophy. Am I Physiol Heart Circ Physiol. 2000;279:H2797-806.

36. Zhu YC, Zhu YZ, Spitznagel $\mathrm{H}$, et al. Substrate metabolism, hormone interaction, and angiotensinconverting enzyme inhibitors in left ventricular hypertrophy. Diabetes. 1996;45 Suppl 1:S59-65.

37. Rossi A, Lortet S. Energy metabolism patterns in mammalian myocardium adapted to chronic physiopathological conditions. Cardiovasc Res. 1996;31:163-71.

38. Wittels B, Spann JF, Jr. Defective lipid metabolism in the failing heart. / Clin Invest. 1968;47:1787-94. 


\title{
CHAPTER 5
}

\section{Absence of reverse electrical remodeling during regression of volume overload hypertrophy in canine ventricles}

\author{
Maaike Peschar, Kevin Vernooy, Ward Y.R. Vanagt, \\ Robert S. Reneman, Marc A. Vos* and Frits W. Prinzen \\ Departments of Physiology and *Cardiology, \\ Cardiovascular Research Institute Maastricht, Maastricht University, \\ Maastricht, the Netherlands
}

Submitted to Cardiovasc Res (under revision) 


\begin{abstract}
Background: Ventricular hypertrophy predisposes for cardiac arrhythmias, presumably due to prolongation of repolarization (electrical remodeling). The temporal relation between the development of hypertrophy and electrical remodeling, as well as their reversibility upon restoration of normal load, however, are poorly understood. This was investigated in the present study using volume overload hypertrophy induced by atrio-ventricular (AV) block and normalization of load by pacing.

Methods: Dogs were subjected to either 16 weeks of AV-block (CAVB group, $n=9$ ) or 8 weeks of $A V$-block followed by 8 weeks of right ventricular (RV) pacing at physiological heart rate (CAVB+PACE group, $n=9$ ).

Results: Left ventricular (LV) mass (2D-echocardiography) increased after 8 weeks of AV-block to $\sim 30 \%$ above baseline and returned to $10 \pm 14 \%$ after 8 weeks of pacing. QT-time (surface ECG) also increased after AV-block. However, 8 weeks of pacing did not decrease QT-time, neither during physiological pacing nor during temporary pacing at 100 beats $/ \mathrm{min}$, and $\mathrm{QT}_{\mathrm{c}}$-time ( $\mathrm{c}=$ corrected for heart rate). Lack of reverse electrical remodeling was confirmed by the absence of changes in LV and RV action potential duration (monophasic action potentials) at week 8 and 16.

Conclusions: In volume overload hypertrophy due to AV-block, structural and electrical remodeling develop in parallel but restoration of physiological heart rate causes dissociation between reverse structural remodeling and reverse electrical remodeling.
\end{abstract}




\section{Introduction}

Cardiac hypertrophy is an adaptive response of the heart to chronically increased workload. Ventricular hypertrophy significantly increases the risk of ventricular arrhythmias and sudden (arrhythmic) death, even in the absence of heart failure ${ }^{i-4}$. The arrhythmias in hypertrophic hearts seem to result from prolonged repolarization (for review see ref 5).

These and other studies ${ }^{4,6-8}$ showed an association between hypertrophy and prolonged repolarization, but did not investigate their temporal relationship. Our group has recently shown that hypertrophy and prolongation of QT-time seem to develop along a similar time path during the first weeks of volume overload ${ }^{9}$. Reversibility of prolongation of repolarization during regression of hypertrophy may be of greater clinical importance than the association between these parameters during their development, because treatment of patients usually starts when pathological changes are already apparent. In experimental ${ }^{6,10}$ and clinical studies ${ }^{7,8,11}$ (partial) regression of pressure overload hypertrophy is accompanied by reduction of prolongation of repolarization. However, in a model of age-related hypertrophy, electrical remodeling appeared to be irreversible ${ }^{12}$. Interestingly, the degree of prolongation of repolarization in the latter study was greater than that in the studies on pressure overload hypertrophy, but similar to the prolongation observed in bradycardia induced volume overload hypertrophy, induced by chronic complete atrio-ventricular (AV) block ${ }^{4,9}$.

In the present study we investigated the development of hypertrophy and electrical remodeling in time, as well as their reversibility using serial measurements in dogs with chronic AV-block. Pacing at physiological heart rate was used to reverse structural and electrical remodeling, if any.

\section{Methods}

Animal handling was performed according to the Dutch Law on Animal Experimentation (WOD) and the European Directive for the protection of Vertebrate Animals used for experimental and other purposes (86/609/EU). The protocol was approved by the Animal Experimental Committee of the Maastricht University. The experiments were performed on 18 adult mongrel dogs of either sex, body weight $28 \pm 5$ $\mathrm{kg}($ mean $\pm \mathrm{SD})$.

\section{Experimental protocol}

Complete AV-block was created by RF ablation ${ }^{13}$. Prior to AV-block, a pacemaker (Medtronic Synergist H7027, H7071, Elite II or Thera DR 7941) was implanted subcutaneously in the neck. Transvenous leads (Bakken Research Center, Medtronic, 
Maastricht, the Netherlands) were positioned in the right atrium and right ventricular (RV) apex. The ventricular $(4057 \mathrm{M} 65 \mathrm{~cm}$ ) and atrial leads (Capsure $4503 \mathrm{M} 53 \mathrm{~cm}$ ) were guided subcutaneously towards the pacemaker-pocket. The animals received ampicillin before ( $1000 \mathrm{mg}$ i.v.) and after (1000 mg i.m.) surgery.

Subsequently, dogs were randomly divided into two groups: 16 weeks of AV-block (CAVB, $n=9$ ) and 8 weeks of AV-block followed by 8 weeks of ventricular pacing $(C A V B+P A C E, n=9)$. During the period of $A V$-block, the pacemaker was programmed at VVI 30 in order to prevent heart rate to fall below 30 beats $/ \mathrm{min}$. In the CAVB+PACE group, the pacemaker was reprogrammed after 8 weeks of AV-block to the VDD-mode (atrial sensing and ventricular pacing with $100 \mathrm{~ms} \mathrm{AV-delay)} \mathrm{to} \mathrm{restore} \mathrm{physiological}$ heart rate.

\section{Echocardiography}

Echocardiographic recordings were made before and biweekly after creation of AV-block. The animals were premedicated with acepromazine $(0.6 \mathrm{mg} / \mathrm{kg}, \mathrm{i} . \mathrm{m}$.) and sedated with propofol $(0.4 \mathrm{mg} / \mathrm{kg}$, i.v.). Two-dimensional echocardiographic images of the left ventricle (LV) were made and recorded on videotape ${ }^{14}$. Parasternal cross-sectional images were made at mid-papillary level (Figure 1). QT-time was measured in lead II of simultaneously recorded ECGs.

\section{Monophasic action potentials}

Monophasic action potentials (MAPs) were measured at week 4 and 16 (CAVB group) or at week 8 and 16 (CAVB+PACE group). The different time points for the first MAP study between the groups was chosen in order to obtain more information on the time course of action potential duration (APD) changes after induction of AV-block without too many interventions. After pentothal induction, anesthesia was maintained by ventilation with $\mathrm{O}_{2}$ and $\mathrm{N}_{2} \mathrm{O}(1: 2)$ in combination with infusion of midazolam $(0.1 \mathrm{mg} / \mathrm{kg} / \mathrm{hr}$ i.v.) and sufentanyl ( $3 \mu \mathrm{g} / \mathrm{kg} / \mathrm{hr}$ i.v.). LV and RV endocardial MAPs were recorded simultaneously using quadripolar contact electrodes ${ }^{4}$. The experiment was started when MAPs were stable, had a constant configuration and slope and an amplitude of at least $15 \mathrm{mV}{ }^{15}$. Measurements were recorded after a $3 \mathrm{~min}$. stabilizing period, during idioventricular rhythm (IVR), during VDD-pacing and during fixed rate pacing at 100 beats/min. Due to irregular heart rate, one CAVB+PACE dog was excluded at both time points (at 8 and 16 weeks). Two CAVB+PACE dogs and one CAVB dog were excluded from the 8 and 16 week measurement, respectively, because of poor quality of the MAPs. 
Terminal procedure

After the last MAP-measurements at 16 weeks the thorax was opened and the heart was arrested with ice cold $\mathrm{KCl}$. The heart was quickly removed and both ventricles were weighed. For histological analysis a transmural section of the LV free wall was taken, immersion fixed in zinc-buffered formalin $10 \%$ and embedded in paraffin.

\section{Echocardiographic analysis}

Global LV dimensions were measured as described previously ${ }^{14}$. In short, for each time-point end-diastolic video images of 3 heartbeats were digitized off-line. The images were analyzed after blinding the images for the observer. The endocardium, epicardium and papillary muscle contours were marked manually. Inner and outer radii were determined by fitting the original epicardial and endocardial contourpoints ${ }^{14}$. LV wall volume was calculated using cylinder-ellipsoid model calculations. Correlation between echocardiographically determined LV mass and LV weight, assessed post mortem, was $r=0.84$.

\section{MAP analysis}

Applying a custom made computer program (ECGVIEW, Maastricht University) with a resolution of $2 \mathrm{~ms}$ and adjustable gain and time scale, the following parameters were measured: cycle length of the idioventricular or paced rhythm, LV and RV APD at $90 \%$ repolarization. All electrophysiological data reported are the mean of 5 consecutive beats. QT-time and APD were corrected for heart rate according to van de Water (QT, and $A P D_{c^{\prime}}$ respectively) ${ }^{16}$, a method which corrects $Q T$ and $A P D$ accurately under a wide range of frequencies.

\section{Histological analysis}

Morphometry was performed with a Quantimed 570 image analyzer (Leica) ${ }^{14}$. Myocyte width was determined using a modification of the Azan technique and collagen fraction was determined using Sirius Red staining. The data for myocyte width and collagen fraction were compared with data from dogs in sinus rhythm used in a previous study in our laboratory ${ }^{14}$.

\section{Statistical analysis}

For group comparison ANOVA was used. ANOVA for repeated measurements was used to evaluate changes in echocardiographic and electrophysiologic variables during the course of the experiment. If significant differences were found, significant points were isolated using a Bonferroni Multiple Comparison test. Data are presented as mean values $\pm S D . p<0.05$ was considered significant. 


\section{Results}

In all dogs of the CAVB+PACE group, cardiac pacing was successfully applied. One CAVB dog showed temporary signs of failure (ascites) and received furosemide $5 \mathrm{mg} / \mathrm{kg}$ orally for 5 days; one CAVB dog suffered from ascites at sacrifice.

\section{Serial changes of LV mass}

The time course of changes in LV mass of one dog in the CAVB+PACE group is illustrated in Figure 1, the average time course of LV mass in both groups in Figure 2. Both groups of dogs showed approximately $30 \%$ LV hypertrophy after 8 weeks of AV-block (CAVB $27 \pm 14 \%$, CAVB+PACE $29 \pm 19 \%$ ). In the CAVB group LV mass did not increase beyond the value reached at week 8 (maximum increase $33 \pm 11 \%$ at week 16 ). In the CAVB+PACE group pacing caused a rapid reduction of LV hypertrophy in the first 2 weeks, followed by a more gradual reduction till $10 \pm 14 \%$ above baseline (not significantly different from baseline LV mass) after 8 weeks of pacing. During pacing, the difference between the CAVB and CAVB+PACE group became significant from week 14 on.

\section{Post mortem observations}

Post mortem data from CAVB and CAVB+PACE animals were compared with those of dogs with normal sinus rhythm (SR group, $n=14$ ) from virtually concurrent studies 4,14 . Total heart weight to body weight $(\mathrm{H} / \mathrm{BW})$ ratio was significantly larger in the CAVB group $(12.5 \pm 1.6 \mathrm{~g} / \mathrm{kg})$ than in the SR group $(7.7 \pm 1.2 \mathrm{~g} / \mathrm{kg}) . \mathrm{H} / \mathrm{BW}$ in the CAVB+PACE group $(8.9 \pm 1.6 \mathrm{~g} / \mathrm{kg})$ was not significantly different from the H/BW in the SR-group, but significantly smaller than the H/BW in the CAVB group. Similarly, LV/BW and RV/BW (Figure 3) were significantly larger in CAVB dogs $(7.1 \pm 1.0$ and $2.6 \pm 0.5 \mathrm{~g} / \mathrm{kg}$, respectively) than in $S R$ dogs $(4.5 \pm 0.9$ and $1.6 \pm 0.5 \mathrm{~g} / \mathrm{kg}$, respectively) and in CAVB+PACE dogs $(5.0 \pm 0.9$ and $1.9 \pm 0.4 \mathrm{~g} / \mathrm{kg}$, respectively). Myocyte width and collagen fraction were not significantly different between the three groups (Figure 3).

\section{Repolarization parameters}

Acutely after AV-block QT-time increased slightly (Figure 4) due to bradycardia, because $\mathrm{QT}_{\mathrm{c}}$-time did not increase (Table 1). A significant increase in QT and $\mathrm{QT}_{c}$-time occurred during chronic AV-block (electrical remodeling). $\mathrm{QT}_{c}$-time increased after creation of AV-block by approximately $20 \%$ within 2 weeks (Figure 5) and did not change significantly till 8 ( $18 \pm 14 \%$ above baseline) and till 16 weeks (CAVB, $23 \pm 20 \%$ above baseline). Sustained prolonged repolarization was confirmed by the similar APD c values at 4 and 16 weeks in both LV and RV (Figure 6A). 

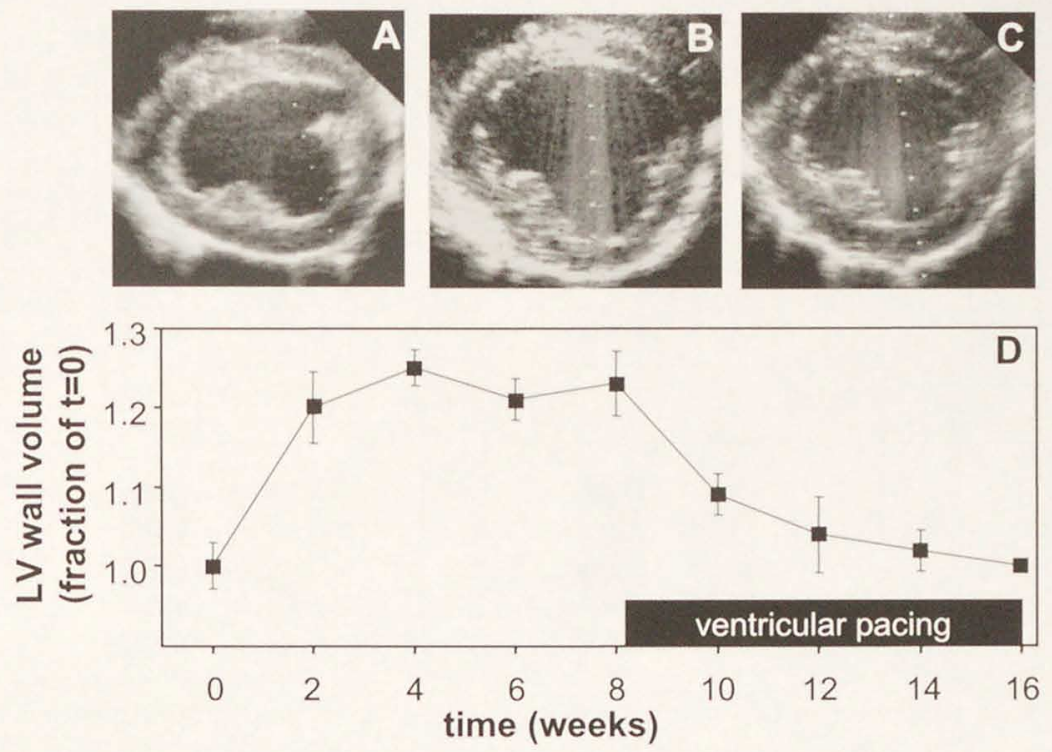

Figure 1. Examples of LV echocardiograms in sinus rhythm (panel A), after 8 weeks of AV-block (panel B), and after 8 weeks of AV-block followed by 8 weeks of pacing (panel C). Panel D displays the time course of LV mass in this dog, expressed as a fraction of $\mathrm{t}=0$.

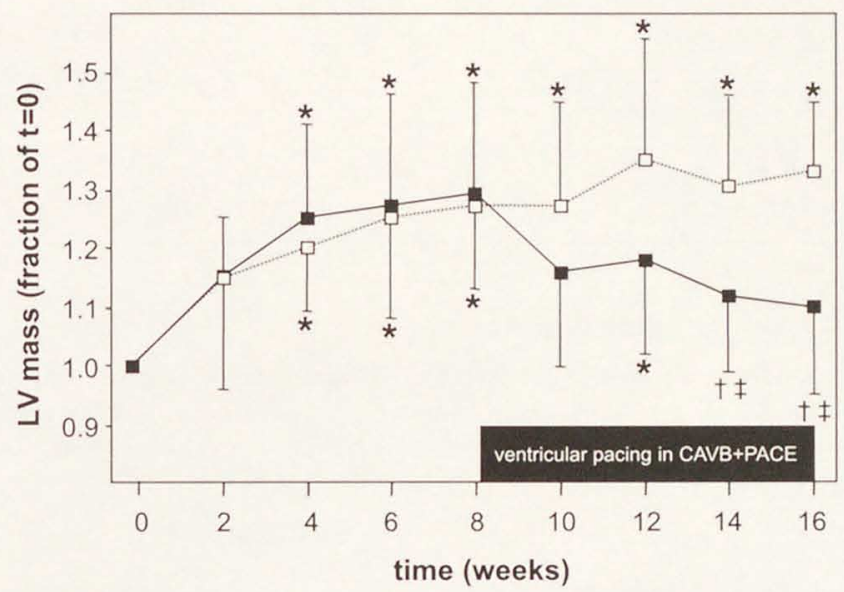

Figure 2. Time course of LV mass, expressed as a fraction of $t=0$, in the CAVB (open symbols) and CAVB+PACE group (closed symbols). ${ }^{*} \mathrm{p}<0.05$ vs. $\mathrm{t}=0$ weeks, $t \mathrm{p}<0.05 \mathrm{vs}$. $\mathrm{t}=8$ weeks and $\neq \mathrm{p}$ $<0.05$ vs. CAVB. 

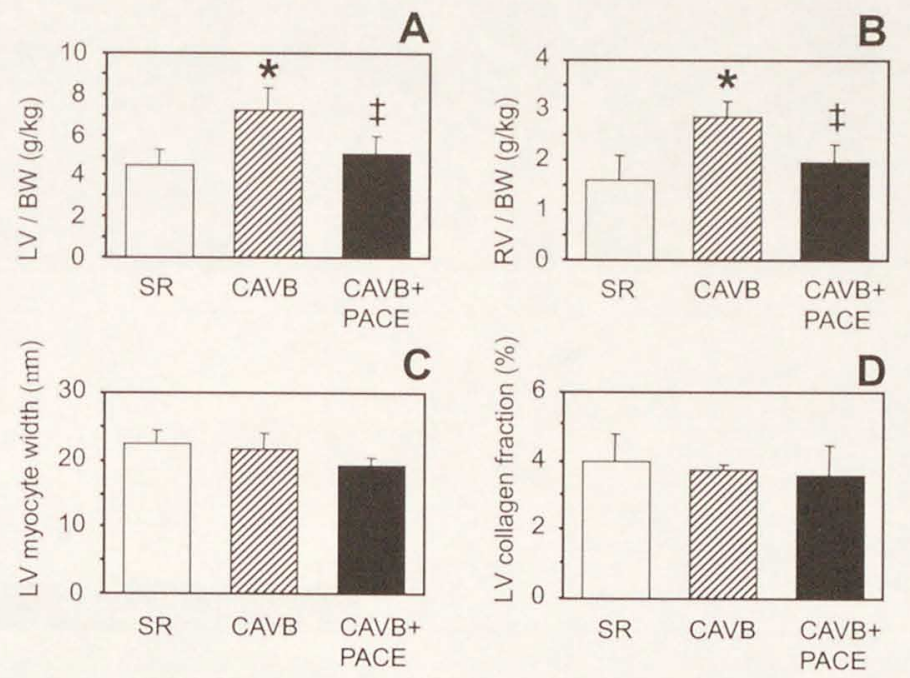

Figure 3. Parameters of hypertrophy in three groups of dogs: sinus rhythm (SR, white bars), CAVB (hatched bars) and CAVB+PACE (black bars). ${ }^{*} p<0.05$ vs. $S R, \neq p<0.05$ vs. CAVB.

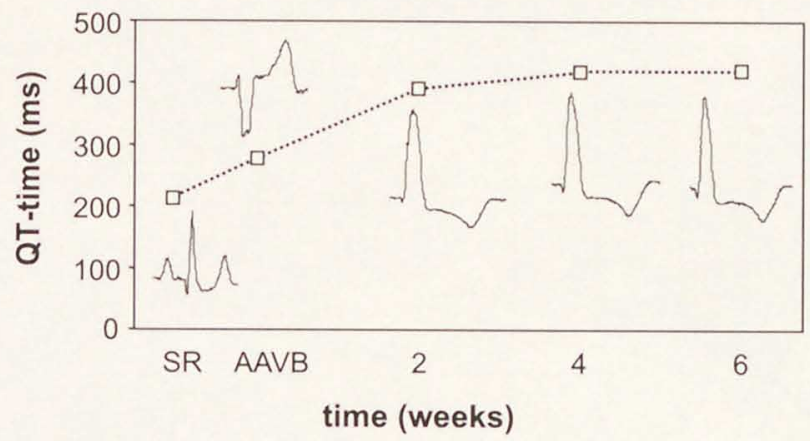

Figure 4. Example of changes in QT-time in one dog due to the creation of AV-block. QT-time increased from $215 \mathrm{~ms}$ in SR to $275 \mathrm{~ms}$ acute after creation AV-block (AAVB). After 6 weeks of AV-block, QT-time stabilized at $415 \mathrm{~ms}$. Note changes in QRS-morphology, which contribute to but are not the cause of the QT prolongation.

Table 1.

Electrophysiological changes after AV-block.

\begin{tabular}{llll}
\hline & SR & Acute AV-block & Chronic AV-block \\
\hline RR interval (ms) & $870 \pm 175$ & $1240 \pm 245^{*}$ & $1335 \pm 220^{*}$ \\
QT $(\mathrm{ms})$ & $295 \pm 35$ & $315 \pm 35^{*}$ & $380 \pm 45^{* \dagger}$ \\
QTc $(\mathrm{ms})$ & $305 \pm 25$ & $290 \pm 35$ & $350 \pm 30^{* \dagger}$ \\
\hline
\end{tabular}

Electrophysiological parameters were determined in a subset of dogs from both groups at sinus rhythm (SR) and during acute and chronic (4-8 weeks) AV-block ( $n=8)$. ${ }^{*} p<0.05$ vs. SR, $+p<0.05$ vs. acute AV-block. 


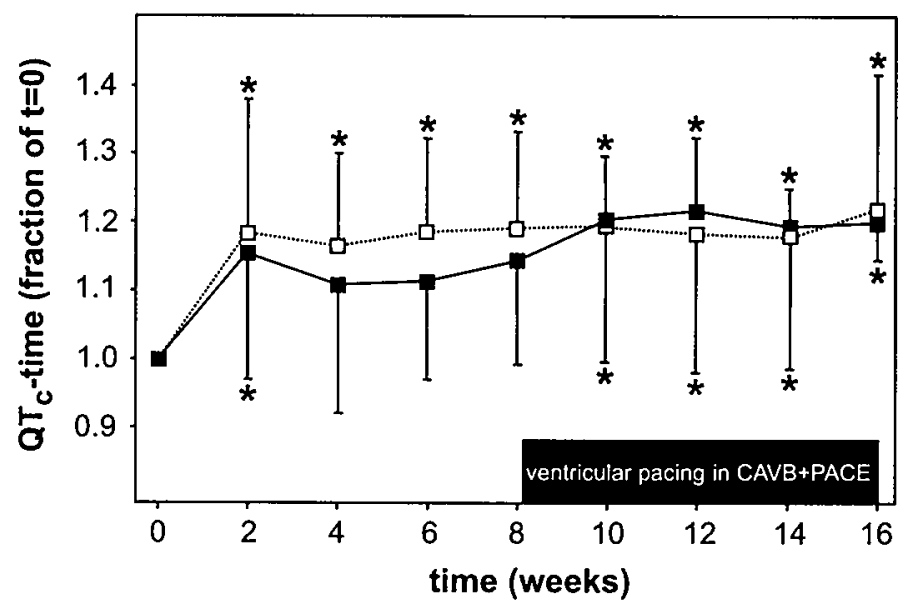

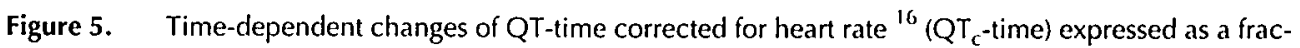
tion of $t=0$ in CAVB (open symbols) and CAVB+PACE (closed symbols). CAVB dogs were measured during IVR while CAVB+PACE dogs were measured during IVR till week 8 , thereafter during pacing. ${ }^{*} \mathrm{p}<0.05$ vs. wk 0 .
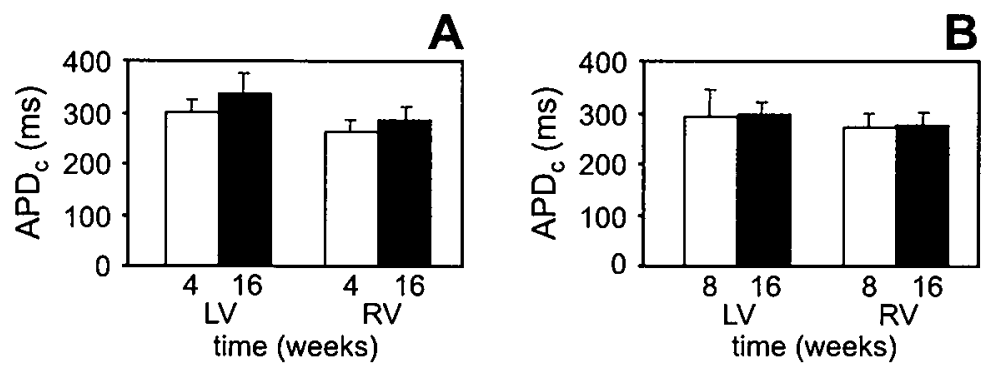

Figure 6. $L V$ and RV $A P D_{c}$ at 4 and 16 weeks of $A V$ block (CAVB group, panel $A$ ) and after 8 weeks of $A V$-block and 8 weeks of pacing (CAVB+PACE group, panel B). CAVB dogs were measured during IVR and CAVB+PACE dogs during pacing. White bars depict the first measurement, the black bars the last measurement.

After 8 weeks of pacing in the CAVB+PACE group $\mathrm{QT}_{c}$-time remained prolonged $(21 \pm 5 \%$ above baseline) despite the regression of LV mass (Figure 5$)$. Also, during temporary pacing at 100 beats/min absolute QT-time and IT-time (=QT-time - QRS duration) were not significantly different between week 8 and 16 . The absence of reduction in prolongation of repolarization was confirmed by $A P D_{c}$ measurements, which showed similar values of both LV and RV at week 8 and 16 (Figure 6B). The data presented in Figure 6 were obtained during IVR in the CAVB group and during VDD-pacing in the CAVB+PACE group, but similar values were found during temporary VDD-pacing in the CAVB group and temporary IVR in the CAVB+PACE group. No sig- 


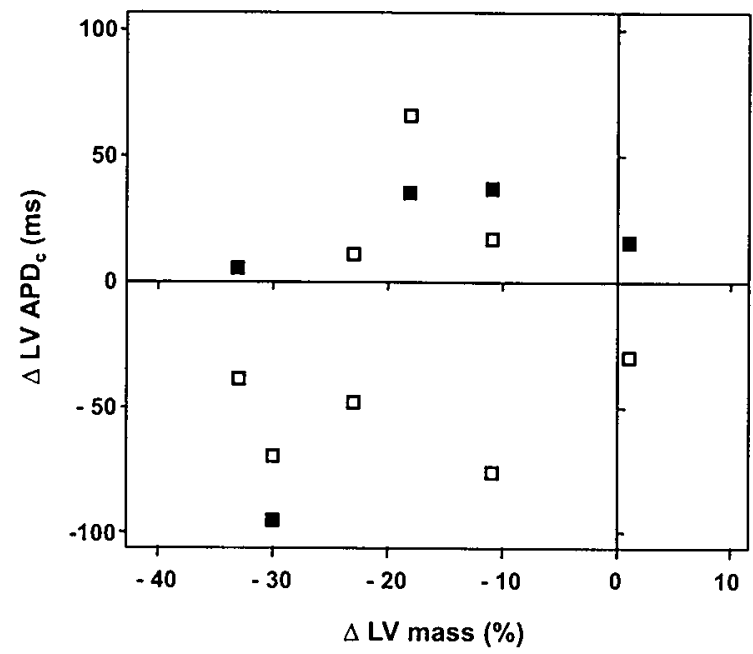

Figure 7 Lack of relation between changes in LV mass and LV APD, between week 8 and 16 (CAVB+PACE group). APD, was measured during VDD-pacing ( $n=5$, closed symbols) and during IVR ( $n=7$, open symbols). $r^{2}=0.24$ for pooled data.

nificant relation was observed between changes in LV mass and LV APD, between week 8 and $16\left(r^{2}=0.24\right.$, Figure 7). Interventricular dispersion (LV-RV APD $)$ was not significantly different between week 4 and 16 in the CAVB group $(36 \pm 20$ and $49 \pm 25$ $\mathrm{ms}$, respectively) or between week 8 and 16 in the CAVB+PACE group $(32 \pm 38$ and $25 \pm 16 \mathrm{~ms}$, respectively).

\section{Discussion}

The present study in dogs demonstrates that after 8 weeks of AV-block restoration of physiological heart rate by ventricular pacing leads to almost complete regression of biventricular hypertrophy. This regression, however, is not accompanied by reversal of electrical remodeling: repolarization remains prolonged after up to 8 weeks of pacing despite regression of hypertrophy within 2 weeks of pacing.

\section{AV-block dog}

In previous studies, the phenotype of the dog with chronic AV-block has been characterized extensively ${ }^{+17-20}$. The bradycardia induced volume overload leads to a number of contractile, structural and electrical adaptations. Hemodynamically, the dog has no signs of heart failure at the slow heart rate ${ }^{19}$ due to a clear increase in inotropism. This is in part based on an increased $\mathrm{Ca}^{2+}$ influx via the $\mathrm{Na}^{+} / \mathrm{Ca}^{2+}$ exchanger and increased $\mathrm{Ca}^{2+}$ storage in the sarcoplasmic reticulum, leading to an increased $\mathrm{Ca}^{2+}$ transient ${ }^{20}$. Struc- 
turally, the biventricular hypertrophy is more pronounced in the RV than in the LV (Figure $3 A$ and $B$ and ref 17) and is accompanied by an increase in cell length but not in width (Figure $3 \mathrm{C}$ and ref 17 ), an unchanged collagen content (Figure 3D and ref 4) and a normal capillary to myocyte ratio ${ }^{*}$.

During chronic AV-block prolongation of repolarization develops within 2 weeks (Figure 5) and was confirmed by action potential duration measurements using micro-electrode techniques in isolated myocytes ${ }^{17}$. This electrical remodeling is more pronounced in the LV than in the RV, leading to an increase in interventricular dispersion of action potential duration ${ }^{4,19}$. Multiple monophasic action potential measurements in both ventricles showed that the endocardial RV and LV monophasic action potential recordings, as used in the present study, provide the upper and lower limits of action potential duration in chronic AV-block hearts ${ }^{21,22}$. Patch clamp studies in myocytes revealed a decrease in $I_{K}$ currents but not in other potassium currents ${ }^{18}$.

Structural adaptations: time dependency and reversibility

The serial echocardiographic measurements show that AV-block leads to rapid development of LV hypertrophy, which levels off after 4-6 weeks and slightly increases till 16 weeks of AV-block. Regression follows a similar pathway: a rapid decrease in LV mass after 2 weeks of pacing followed by a more gradual reduction up to 8 weeks of pacing. Post mortem measurements also show complete regression of RV hypertrophy. Collagen fraction was not different between the groups investigated, indicating that the amount of collagen increased in proportion to myocyte growth during hypertrophy and decreased proportionally during regression.

The faster regression of LV mass in the present study ( 2 weeks), compared to other experimental (3-6 months) $6,10,23$ and clinical studies (6 months to 5 years) ${ }^{7,8,11,24-26}$ could be explained by the shorter duration of hypertrophy in the present study ( 8 weeks), compared to the other experimental studies (3-6 months) ${ }^{6,10,23}$ and (probably) the patient studies $7,8,11,2+-26$. Moreover, in the present study the degree of hypertrophy $(\sim 30 \%)$ was less severe than in the other studies $(\sim 65 \%)^{6-8,10,11,23-26}$. In this respect it is important to note that in order to calculate the degree of hypertrophy in patients, values of LV mass index were compared to those of control values ${ }^{27-29}$.

Electrophysiological adaptations: time dependency and absence of reversibility

After creation of AV-block electrical and structural remodeling seem to develop in parallel with each other, electrical remodeling appearing slightly quicker than hypertrophy (the increase in QT-time was already significant at week 2, whereas the increase in LV mass became significant at week 4, Figures 2 and 5). In contrast, regression of volume overload hypertrophy was not associated with reduction of 
prolonged repolarization (Figures 5 and 6). This was the case for the LV, where electrical remodeling is more pronounced than in the RV ${ }^{4,19}$ as well as for the RV, where hypertrophy is more pronounced than in the LV. The lack of change of the repolarization parameters is independent of heart rate and activation sequence because the measurements during idioventricular rhythm, VDD-pacing, and pacing at 100 beats/min showed the same results. The fact that our measurements of repolarization were performed serially and that there is no correlation between the changes in relative LV mass and LV APD (Figure 7) supports the idea that regression of hypertrophy occurs independently of electrical changes. The finding that more than half of the regression of hypertrophy occurs within 2 weeks of pacing and that repolarization has not significantly changed at all after 8 weeks of pacing indicates that different stimuli mediate the maintenance of structural and electrical remodeling. Apparently processes responsible for absence of reverse electrical remodeling, like reversal of the enhanced activity of the $\mathrm{Na}^{+} / \mathrm{Ca}^{2+}$ exchanger and reversal of reduced $I_{K}$ current occur considerably slower than processes responsible for reverse structural remodeling. A role for the extracellular matrix in electrical remodeling in the chronic AV-block model is not likely, because collagen fraction did not change during development and regression of hypertrophy.

The absence of reverse electrical remodeling in volume overload hypertrophied hearts is in contrast with findings in pressure overload hypertrophied hearts ${ }^{6-8,10,11,29}$. In four of these studies ${ }^{6-8,29}$ the hypertrophy was related to overactivation of the renin-angiotensin system and was regressed using ACE inhibitors or AT1-blockers ${ }^{6-8,29}$, whereas in two studies hypertrophy was due to increased aortic outflow resistance and regression occurred due to surgical repair ${ }^{10,11}$. Beside the present study, only one other study showed lack of electrical remodeling during regression of hypertrophy ${ }^{12}$. In that study treatment of 30-month old non-hypertensive rats with ACE-inhibitors caused regression of hypertrophy, but had no effect on $\mathrm{QT}_{\mathrm{c}}$-time. A common feature in our and Kreher's ${ }^{12}$ study is that the increase in $\mathrm{QT}_{\mathrm{c}}$-time is more (20-30\%) than in the studies sharing reduced prolongation of repolarization $(7-16 \%)^{6-8,10}$. Reversibility of electrical remodeling may, therefore, depend on the severity of electrical remodeling and/or on the kind of hypertrophy, i.e. more reversible in pressure than in volume overload hypertrophy. The latter idea suggests that the stimulus for hypertrophy determines the reversibility of the electrical abnormalities, even though the structural remodeling is reversible.

A potentially confounding factor for the measurement of repolarization parameters is the abnormal sequence of electrical activation of the ventricles, especially during pacing. Previous studies from our laboratory, however, showed that chronic ventricular pacing in non-hypertrophied ${ }^{14}$ and in pressure overload-hypertrophied dog hearts ${ }^{30}$ has no effect on $\mathrm{QT}_{\mathrm{c}}$-time. This suggests that the unchanged repolarization in the CAVB+PACE group is not due to electrophysiological changes as a consequence of the abnormal activation induced by ventricular pacing. Therefore, T-wave variability due 
to pacing can be excluded as a confounding factor in the analysis. This is further supported by the unchanged $A P D_{c}$ values, which, after all, were measured locally.

It is unlikely that the conclusions on the absence of reverse electrical remodeling are flawed by the difference in timing of the first APD measurement (week 4 in the CAVB and week 8 in the CAVB+PACE group). Intergroup comparison showed no significant difference in APD. Moreover, serial QT-time measurements reveal no change between 4 and 8 weeks, both in the CAVB and in the CAVB+PACE group.

\section{Conclusions}

The findings in the present study show that after the creation of AV-block electrical remodeling develops slightly quicker than structural remodeling. Restoration of physiological heart rate, and thereby normalization of volume load, causes dissociation between reverse structural (rapid and almost complete regression of hypertrophy) and electrical remodeling (no reversion of prolonged repolarization). These data suggest that structural and electrical remodeling are mediated by different stimuli. 


\section{References}

1. Kannel WB, Gordon T, Offutt D. Left ventricular hypertrophy by electrocardiogram. Prevalence, incidence, and mortality in the Framingham study. Ann Intern Med. 1969;71:89-105.

2. Messerli FH, Grodzicki T. Hypertension, left ventricular hypertrophy, ventricular arrhythmias and sudden death. Eur Heart /. 1992;13 Suppl D:66-9.

3. Swynghedauw B, Chevalier B, Charlemagne D, et al. Cardiac hypertrophy, arrhythmogenicity and the new myocardial phenotype. II. The cellular adaptational process. Cardiovasc Res. 1997;35:6-12.

4. Vos MA, de Groot SH, Verduyn SC, et al. Enhanced susceptibility for acquired Torsade de Pointes arrhythmias in the dog with chronic, complete AV block is related to cardiac hypertrophy and electrical remodeling. Circulation. 1998;98:1125-35.

5. Tomaselli GF, Marban E. Electrophysiological remodeling in hypertrophy and heart failure. Cardiovasc Res. 1999;42:270-83.

6. Rials SI, $, \mathrm{Y}, \mathrm{Y}, \mathrm{Xu} X$, et al. Regression of left ventricular hypertrophy with captopril restores normal ventricular action potential duration, dispersion of refractoriness, and vulnerability to inducible ventricular fibrillation. Circulation. 1997:96:1330-6.

7. Mayet J, Shahi M, McGrath $\mathrm{K}$, et al. Left ventricular hypertrophy and QT dispersion in hypertension. Hypertension. 1996;28:791-6.

8. Gonzalez Juanatey IR, Garcia Acuna JM, Pose A, et al. Reduction of QT and QTc dispersion during long-term treatment of systemic hypertension with enalapril. Am / Cardiol. 1998;81:170-4.

9. Verduyn SC, Ramakers C, Snoep C, et al. Time course of structural adaptations in chronic AV block dogs: evidence for differential ventricular remodeling. Am / Physiol Heart Circ Physiol. 2001;280: H2882-90.

10. Rials S],, $\mathrm{u} Y$, Ford $N$, et al. Effect of left ventricular hypertrophy and its regression on ventricular electrophysiology and vulnerability to inducible arrhythmia in the feline heart. Circulation. 1995;91: 426-30.

11. Darbar D, Cherry C], Kerins DM. QT dispersion is reduced after valve replacement in patients with aortic stenosis. Heart. 1999;82:15-8.

12. Kreher P, Ristori MT, Corman B, et al. Effects of chronic angiotensin I-converting enzyme inhibition on the relations between ventricular action potential changes and myocardial hypertrophy in aging rats. I Cardiovasc Pharmacol. 1995;25:75-80.

13. Rodriguez LM, Leunissen J, Hoekstra A, et al. Transvenous cold mapping and cryoablation of the AV node in dogs: observations of chronic lesions and comparison to those obtained using radiofrequency ablation. / Cardiovasc Electrophysiol. 1998;9:1055-61.

14. van Oosterhout MF, Prinzen FW, Arts T, et al. Asynchronous electrical activation induces asymmetrical hypertrophy of the left ventricular wall. Circulation. 1998;98:588-95.

15. Franz MR. Monophasic action potentials. Bridging cell and bedside. New York: Futura Publishing Company; 2000.

16. van de Water $A$, Verheyen J, Xhonneux $R$, et al. An improved method to correct the QT interval of the electrocardiogram for changes in heart rate. I Pharmacol Methods. 1989;22:207-17.

17. Volders PG, Sipido KR, Vos MA, et al. Cellular basis of biventricular hypertrophy and arrhythmogenesis in dogs with chronic complete atrioventricular block and acquired Torsade de Pointes. Circulation. 1998;98:1136-47.

18. Volders PGA, Sipido KR, Vos MA, et al. Downregulation of delayed rectifier $K^{\prime}$ currents in dogs with chronic complete atrioventricular block and acquired Torsades de Pointes. Circulation. 1999; 100:2455-2461.

19. de Groot $\mathrm{SH}$, Schoenmakers $M$, Molenschot MM, et al. Contractile adaptations preserving cardiac output predispose the hypertrophied canine heart to delayed afterdepolarization-dependent ventricular arrhythmias. Circulation. 2000;102:2145-51.

20. Sipido KR, Volders PG, de Groot $\mathrm{SH}$, et al. Enhanced Ca" release and $\mathrm{Na} / \mathrm{Ca}$ exchange activity in hypertrophied canine ventricular myocytes : potential link between contractile adaptation and arrhythmogenesis. Circulation. 2000;102:2137-44. 
21. Jungschleger JGM, van der Hulst FF, Verduyn SC, et al. Enhancement of dispersion in repolarization after atrio-ventricular block in the canine heart. Submitted.

22. Verduyn SC, Vos MA, van der Zande J, et al. Role of interventricular dispersion of repolarization in acquired Torsade de Pointes arrhythmias: reversal by magnesium. Cardiovasc Res. 1997;34:453-63.

23. Is hihara $K$, Zile MR, Tomita $M$, et al. Left ventricular hypertrophy in a canine model of reversible pressure overload. Cardiovasc Res. 1992;26:580-5.

24. Monrad ES, Hess OM, Murakami T, et al. Time course of regression of left ventricular hypertrophy after aortic valve replacement. Circulation. 1988;77:1345-55.

25. Lund $\mathrm{O}$, Emmertsen $\mathrm{K}$, Nielsen TT, et al. Impact of size mismatch and left ventricular function on performance of the St. Jude disc valve after aortic valve replacement. Ann Thorac Surg. 1997;63: 1227-34.

26. Gilchrist IC, Waxman HL, Kurnik PB. Improvement in early diastolic filling dynamics after aortic valve replacement. Am / Cardiol. 1990;66:1124-9.

27. Massie BM, Tubau JF, Szlachcic 1, et al. Hypertensive heart disease: the critical role of left ventricular hypertrophy. I Cardiovasc Pharmacol. 1989;13 Suppl 1:S18-24.

28. McLenachan JM, Henderson $\mathrm{E}$, Morris KI, et al. Ventricular arrhythmias in patients with hypertensive left ventricular hypertrophy. New England lournal of Medicine. 1987;317:787-792.

29. Tomiyama H, Doba N, Fu Y, et al. Left ventricular geometric patterns and QT dispersion in borderline and mild hypertension: their evolution and regression. Am / Hypertens. 1998;11:286-92.

30. van Oosterhout MF, Arts T, Muijtjens AM, et al. Remodeling by ventricular pacing in hypertrophying dog hearts. Cardiovasc Res. 2001;49:771-778. 


\section{CHAPTER 6}

\section{Reverse structural and contractile but not electrical remodeling following chronic AV-block \\ Comparison of biventricular and right ventricular apex pacing}

Maaike Peschar, Gijs Baaten, Theo van der Nagel, Xander A. A. M. Verbeek, Marc A. Vos*, Robert S. Reneman and Frits W. Prinzen

Departments of Physiology and *Cardiology,

Cardiovascular Research Institute Maastricht, Maastricht University, Maastricht, the Netherlands 


\begin{abstract}
Introduction: We have previously shown that 8 weeks of complete atrio-ventricular (AV) block leads to left ventricular (LV) hypertrophy (structural remodeling), a negative force-frequency relation (contractile remodeling) and prolongation of repolarization (electrical remodeling). Normalization of heart rate by right ventricular (RV) apex pacing for 8 weeks leads to almost complete regression of LV hypertrophy, but not to reverse electrical remodeling. In the present study we investigated whether after 8 weeks of AV-block normalization of heart rate leads to reverse contractile remodeling and whether improvement of synchrony of activation can reverse electrical remodeling. Methods: Dogs with 8 weeks of AV-block were paced AV-sequentially for 8 weeks at the RV apex (RVa, $n=7$ ) or biventricularly (BiV, $n=6$ ). Structural and electrical remodeling were assessed by biweekly measurement of LV wall mass (2D-echocardiography) and QT, -time (c=corrected for heart rate). Moreover, LV and RV monophasic action potentials were measured at week 8 and 16 . At these same time points also the force-frequency relation was assessed by determining $L V \mathrm{dP} / \mathrm{dt}_{\max }$ during temporary ventricular pacing at 40-130 bpm.

Results: After 8 weeks of AV-block structural and electrical remodeling occurred as significant increases in LV mass $(+27 \pm 17 \%)$ and QT,-time $(+14 \pm 13 \%)$, respectively. Contractile remodeling was confirmed by a negative force-frequency relation (slope: $-629 \pm 314 \mathrm{mmHg}$ ). Eight weeks of RVa and BiV pacing almost completely normalized LV mass ( $+9 \pm 14 \%$ and $+10 \pm 9 \%$ compared to before AV-block, respectively), while BiV pacing resulted in a slightly faster and more homogeneous regression of hypertrophy. Normalization of heart rate by RVa and BiV pacing both resulted in a significantly less negative force-frequency relation (slopes: $-364 \pm 122$ and $-238 \pm 215 \mathrm{mmHg}$, respectively). QT -time, however, remained elevated after $\mathrm{RVa}$ and BiV pacing $(+21 \pm 5 \%$ and $+16 \pm 7 \%$ compared to before AV-block, respectively). Absence of reverse electrical remodeling was confirmed by LV and RV monophasic action potentials.

Conclusions: In canine hearts with bradycardia induced volume overload hypertrophy normalization of heart rate leads to reverse structural and contractile remodeling. The degree of reverse remodeling is independent of the degree of synchrony of activation. Electrical remodeling is not reversible, even when LV activation is more synchronous.
\end{abstract}




\section{Introduction}

Ventricular hypertrophy is considered to be an adaptive response of the heart to chronically increased workload. However, depending on the duration, degree and type of overload, hypertrophy can impair cardiac function ${ }^{1-3}$. Moreover, hypertrophy is associated with prolonged repolarization and increased risk of ventricular arrhythmias ${ }^{4-18}$. For these reasons the stressor(s) causing hypertrophy are treated. An important question in this respect is as to whether normalization of cardiac workload leads to normalization of structure, function and electrophysiology.

We have previously shown that 8 weeks of volume overload due to complete atrio-ventricular (AV) block induces left ventricular (LV) hypertrophy and prolongation of repolarization ". Normalization of this volume overload by right ventricular (RV) apex pacing for 8 weeks lead to almost complete regression of LV hypertrophy ". This regression, however, was not associated with reverse electrical remodeling, i.e. repolarization time remained prolonged.

A possible explanation for the absence of reverse electrical remodeling and the slightly incomplete reverse structural remodeling is that pacing was performed at the RV apex. Although the RV apex is the conventional site for pacing in bradycardia patients, various studies showed that RV apex pacing causes asynchrony of activation and reduction of pump function ${ }^{10-13}$.

We have also shown that after 6 weeks of AV-block LV contractility is increased ${ }^{14,15}$. In contrast to normal hearts, this increase is more pronounced at lower than at higher heart rates, resulting in a negative force-frequency relation. This alteration in contractile response is assumed to reflect changes in $\mathrm{Ca}^{2+}$ handling ${ }^{16,17}$. As yet, it is unknown whether this contractile remodeling is reversible upon normalization of load. Moreover, because pacing affects LV contractile function, it is of interest to know whether asynchrony of electrical activation influences reverse contractile remodeling.

Therefore, it was the aim of the present study to investigate the effect of normalization of load and improvement of synchrony of activation on reverse structural, contractile and electrical remodeling. Eight weeks of AV-block was followed by 8 weeks of ventricular pacing at physiological heart rate, either at the RV apex or biventricularly. Structural remodeling was determined by means of 2D-echocardiography, contractile remodeling by assessing the force-frequency relation and electrical remodeling by measurement of QT-time and monophasic action potential duration.

\section{Methods}

Animal handling was performed according to the Dutch Law on Animal Experimentation (WOD) and the European Directive for the protection of Vertebrate 
Animals used for experimental and other purposes (86/609/EU). The protocol was approved by the Animal Experimental Committee of the Maastricht University. The experiments were performed on 13 adult mongrel dogs of either sex and body weight of $30 \pm 5 \mathrm{~kg}($ mean $\pm \mathrm{SD})$.

\section{Experimental protocol}

The dogs were randomly assigned to two groups: 8 weeks of AV-block followed by either 8 weeks of $R V$ apex pacing ( $R \vee a, n=7$ ) or 8 weeks of simultaneous RVa and LV pacing (biventricular, BiV, $\mathrm{n}=6$ ). After pentothal induction, anesthesia was maintained by ventilation with $\mathrm{O}_{2}$ and $\mathrm{N}_{2} \mathrm{O}(1: 2)$ in combination with infusion of midazolam $(0.1$ $\mathrm{mg} / \mathrm{kg} / \mathrm{hr}$ i.v.) and sufentanyl ( $3 \mu \mathrm{g} / \mathrm{kg} / \mathrm{hr}$ i.v.). Complete AV-block was created by RF ablation ${ }^{18}$. In the RVa animals the pacemaker (Medtronic Synergist H7027; H7071, Elite II or Thera DR 7941) was implanted subcutaneously in the neck during the AV-block procedure. Transvenous leads (Bakken Research Center, Medtronic, Maastricht, the Netherlands) were positioned in the right atrium and RV apex. The ventricular screw-in lead $(4057 \mathrm{M} 65 \mathrm{~cm}$ ) and the atrial lead (Capsure $4503 \mathrm{M} 53 \mathrm{~cm}$ ) were guided subcutaneously towards the pacemaker-pocket. In the BiV animals the pacemaker and leads were implanted in a procedure 2 weeks prior to the creation of AV-block. The LV pacing lead (Medtronic 2187 or 2188) was implanted on the LV lateral free wall. All animals received ampicillin before (1000 $\mathrm{mg}$ i.v.) and after (1000 mg i.m.) surgery.

During the 8 weeks of AV-block the pacemaker was programmed at VVI 30 in order to prevent heart rate to fall below 30 beats $/ \mathrm{min}$. Thereafter the pacemaker was programmed in VDD mode (atrial sensing and ventricular pacing with $100 \mathrm{~ms}$ AV-delay) to restore physiological heart rate.

\section{Echo- and electrocardiography}

Echocardiographic recordings were made before and biweekly after creation of AV-block. The animals were premedicated with acepromazine $(0.6 \mathrm{mg} / \mathrm{kg}$, i.m.) and sedated with propofol $(0.4 \mathrm{mg} / \mathrm{kg}$, i.v.). Two-dimensional echocardiographic images of the LV were made and were recorded on videotape ". Parasternal cross-sectional images were made at mid-papillary level. QRS duration and QT-time were measured in lead II of simultaneously recorded ECGs.

\section{Monophasic action potentials}

Monophasic action potentials (MAPs) were measured at week 8 and 16 . The same anesthesia was used as during the AV-block procedure. Endocardial MAPs at the free wall of the LV and RV were recorded simultaneously using quadripolar contact electrodes ${ }^{7}$. The experiment was started when MAPs were stable, had a constant 
configuration and slope and an amplitude of at least $15 \mathrm{mV}{ }^{20}$. Measurements were recorded after a $3 \mathrm{~min}$ stabilizing period, during idioventricular rhythm (IVR), VDD-pacing and during fixed rate pacing (VVI) at 100 beats/min.

\section{Hemodynamic measurements}

Hemodynamic measurements were also performed at week 8 and 16. The same anesthesia was used as during the MAP measurements. LV pressure and cavity volume were measured with a combined cathetertip manometer and conductance catheter ( $7 \mathrm{~F}$, Sentron), connected to a Leycom Sigma 5DF conditioner processor (CardioDynamics). Parallel conductance was estimated by injecting $7.5 \mathrm{ml}$ of hypertonic saline $(6.5 \%)$ into the pulmonary artery ${ }^{21}$. Cardiac output was measured with thermodilution (Swan-Ganz catheter through a femoral vein). Calibration of absolute LV volume was performed by calibrating stroke volume, as determined with the conductance catheter, with stroke volume measured with thermodilution. The force-frequency relation was determined by measuring LV $\mathrm{dP} / \mathrm{dt}_{\operatorname{mix}}$ during temporary ventricular apex pacing at $40-130$ beats/min.

\section{Terminal procedure}

After the last hemodynamic measurements at week 16 the thorax was opened and the heart was arrested with ice-cold $\mathrm{KCl}$. The heart was quickly removed and the LV was weighed.

\section{Echocardiographic analysis}

Global LV dimensions were measured as described in detail before ${ }^{19}$. In short, for each time-point end-diastolic video images of 3 heartbeats were digitized off-line. The images were analyzed after blinding the images to the observer. The endocardium, epicardium and papillary muscle contours were marked manually. LV wall volume and LV cavity volume were calculated by fitting the original epicardial and endocardial contourpoints to a cylinder-ellipsoid model "1". Regional LV septal volume was determined by using the papillary muscle as landmarks, and the septum as the opposite region. The LV septum to free wall ratio was used as index of asymmetry. Correlation between LV mass calculated by echocardiography and as assessed post mortem was $\mathrm{r}=0.88$.

MAP analysis

Applying a custom made computer program (ECGVIEW, Maastricht University) with a resolution of $2 \mathrm{~ms}$ and adjustable gain and time scale, the following parameters were 
measured: cycle length of the idioventricular or paced rhythm and LV and RV action potential duration (APD) at $90 \%$ repolarization. All electrophysiological data reported are the mean of 5 consecutive beats. QT-time and APD were corrected for heart rate according to van de Water (QT, and APD, respectively) ${ }^{22}$, a method which corrects $Q T$ and $A P D$ accurately over a wide range of frequencies. Because of poor quality of the MAPs, in the RVa group one dog was excluded from analysis.

Hemodynamic analysis

The dedicated data analysis software package CIRCLAB was used for analysis of all data obtained with the conductance catheter, including the calculation of the maximal first

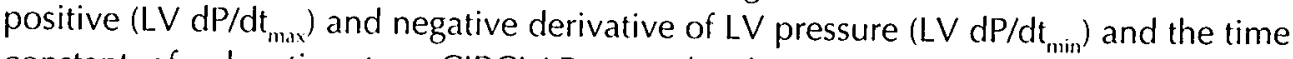
constant of relaxation tau. CIRCLAB was developed by Dr. P. Steendijk (Leiden University Medical Center, the Netherlands).

The slope and intercept of the force-frequency relation was derived from fitting a linear trendline, which was fitted through all points. In the linear equation $y=a x+b, a$ represents the slope and $b$ the intercept of the force-frequency relation.

Statistical analysis

For group comparison ANOVA was used. ANOVA for repeated measurements was used to evaluate changes in echocardiographic and electrophysiologic variables during the course of the experiment. If significant differences were found, significant points were isolated using a Bonferroni Multiple Comparison test. Hemodynamic and action potential measurements were tested with paired analysis. Data are presented as mean values \pm SD. $p<0.05$ was considered significant.

\section{Results}

Structural remodeling

During the 8 weeks of AV-block, the dogs developed a comparable degree of LV hypertrophy (RVa: $+28 \pm 20 \%$, BiV: $+25 \pm 15 \%$, Figure $1 \mathrm{~A}$ ). After onset of pacing, LV mass decreased slightly faster in BiV than in RVa group, as evidenced by the significant decrease in LV mass after 2 weeks in the BiV group, compared to 6 weeks in the RVa group. After 8 weeks of pacing a comparable LV wall mass was found in both groups of paced hearts, the values of which were only $9 \pm 14 \%$ and $10 \pm 9 \%$ above the value before AV-block. The LV septum to free wall ratio was significantly below $1(10 \pm 9 \%)$ in the $R V a$ group and not significant from 1 in the BiV group (Figure $1 B$ ), indicating a more uniform regression of hypertrophy after biventricular pacing. 

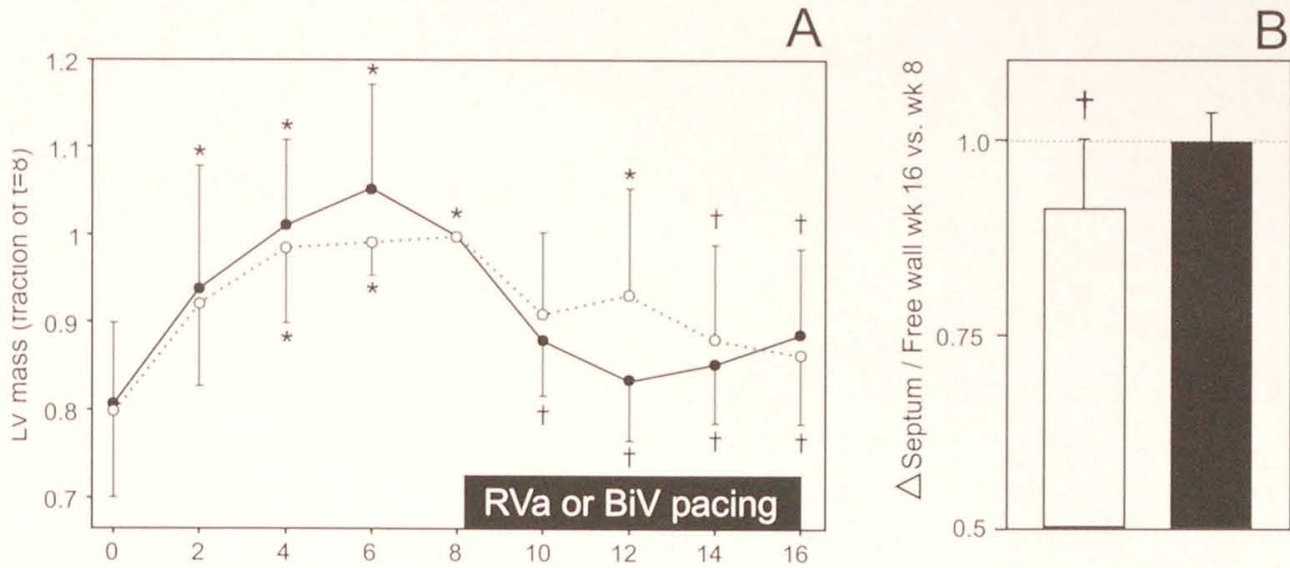

Figure 1. A: Time course of LV mass expressed as fraction of week 8 , in the RVa (open symbols) and BiV group (closed symbols). B: Asymmetry index after 16 weeks expressed as fraction of week 8 in the RVa (white bar) and BiV group (black bar). ${ }^{*} p<0.05$ vs. SR (sinus rhythm at $t=0$ ), $+p<0.05$ vs. wk 8.

Table 1.

Structural changes after pacing.

\begin{tabular}{lll}
\hline & RVa & BiV \\
& wk 16 vs. wk 8 & wk 16 vs. wk 8 \\
\hline LV cavity & $0.72 \pm 0.15^{+}$ & $0.87 \pm 0.18^{\dagger}$ \\
LV cavity/wall & $0.83 \pm 0.12^{\dagger}$ & $0.97 \pm 0.13$ \\
\hline
\end{tabular}

Values of LV cavity volume and LV cavity wall to volume ratio at week 16 are expressed as a fraction of week 8. $+p<0.05$ vs. wk 8 .

After 8 weeks of AV-block the LV cavity volume was increased by $43 \pm 22 \%$ and $49 \pm 24 \%$ in the RVa and BiV group, respectively. Compared to the start of the pacing protocol, LV cavity volume was significantly smaller after 8 weeks of pacing, in both RVa $(-28 \pm 15 \%)$ and BiV hearts $(-13 \pm 18 \%$ ) (see also Table 1$)$. The smaller reduction in LV cavity volume in the BiV group resulted in an unchanged LV cavity to wall ratio at week 16 , as compared to week 8 , whereas this ratio was significantly decreased in the RVa group.

Acute hemodynamic effects of pacing after 8 weeks of AV-block

The creation of AV-block reduced resting heart rate during anesthesia from $\sim 80$ beats/min to $\sim 40$ beats/min. When after 8 weeks of AV-block heart rate was normalized by pacing, cardiac output increased, but this increase reached the level of significance only during biventricular pacing (Table 2 and Figure 2A). Pacing did not change LV 
Table 2.

Hemodynamic changes before and after pacing.

\begin{tabular}{|c|c|c|c|c|}
\hline & & Wk 8 & Wk 8 & Wk 16 \\
\hline & & IVR & PACE & PACE \\
\hline \multirow[t]{2}{*}{ Heart rate (bpm) } & RVa & $45 \pm 8$ & $85 \pm 27^{*}$ & $84 \pm 19^{*}$ \\
\hline & Biv & $49 \pm 10$ & $81 \pm 10^{*}$ & $104 \pm 17^{* t}$ \\
\hline \multirow[t]{2}{*}{ Cardiac output (l/min) } & RVa & $2.3 \pm 0.3$ & $3.2 \pm 0.9$ & $3.0 \pm 0.4^{*}$ \\
\hline & BiV & $2.6 \pm 0.7$ & $4.1 \pm 1.7^{*}$ & $4.3 \pm 1.1^{* \S}$ \\
\hline \multirow[t]{2}{*}{ LV ED pressure $(\mathrm{mmHg})$} & RVa & $9 \pm 3$ & $9 \pm 5$ & $8 \pm 7$ \\
\hline & BiV & $8 \pm 3$ & $6 \pm 5$ & $2 \pm 4^{*}$ \\
\hline \multirow{2}{*}{ LV peak pressure $(\mathrm{mmHg})$} & RVa & $111 \pm 12$ & $119 \pm 17$ & $107 \pm 22$ \\
\hline & Biv & $115 \pm 16$ & $112 \pm 14$ & $100 \pm 14^{* t}$ \\
\hline \multirow[t]{2}{*}{ LV Stroke work (mmHg.ml) } & RVa & $4622 \pm 684$ & $4025 \pm 1849$ & $3278 \pm 874^{*}$ \\
\hline & Biv & $5222 \pm 1353$ & $5096 \pm 2380$ & $3860 \pm 1337$ \\
\hline \multirow[t]{2}{*}{$\mathrm{LV} \mathrm{dP/dtmax}(\mathrm{mmHg} / \mathrm{s})$} & RVa & $3206 \pm 501$ & $2569 \pm 314^{*}$ & $2001 \pm 532^{*}$ \\
\hline & $\mathrm{BiV}$ & $3580 \pm 1112$ & $3070 \pm 1080^{*}$ & $1985 \pm 652^{* \dagger}$ \\
\hline \multirow[t]{2}{*}{$\mathrm{LV} \mathrm{dP} / \mathrm{dtmin}(\mathrm{mmH} \mathrm{g} / \mathrm{s})$} & $\mathrm{RVa}$ & $1740 \pm 254$ & $2167 \pm 627$ & $2075 \pm 351$ \\
\hline & Biv & $2079 \pm 415$ & $2317 \pm 486^{*}$ & $2243 \pm 565$ \\
\hline \multirow[t]{2}{*}{ Tau (ms) } & RVa & $29 \pm 5$ & $30 \pm 6$ & $29 \pm 5$ \\
\hline & $\mathrm{BiV}$ & $26 \pm 4$ & $23 \pm 4^{* \leqq}$ & $22 \pm 5^{5}$ \\
\hline
\end{tabular}

Hemodynamic parameters before and acutely after onset pacing (first 2 colums) and after 8 weeks of pacing (last 2 columns) in RVa and BiV group. ED: end-diastolic . ${ }^{*} p<0.05$ vs. idioventricular rhythm (IVR), $\uparrow p<$ 0.05 vs. wk 8 and $\S<$ p 0.05 vs. RVa.

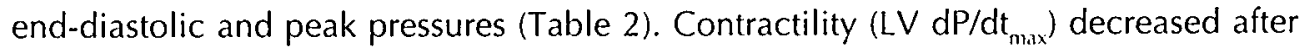
onset of pacing in both groups, while relaxation only improved after biventricular pacing (increase in LV dP/dt ${ }_{\text {nin }}$ and decrease in tau). The different changes in tau between the two pacing strategies are also illustrated in Figure 2B. Moreover, Figure 2 also shows that the acute response to pacing was similar at week 8 and 16 .

\section{Contractile remodeling}

Effects of 8 weeks of ventricular pacing at physiological heart rate are also presented in Table 2. At week 16 none of the hemodynamic parameters in the RVa group were significantly changed compared to week 8 . In the BiV group, however, heart rate was significantly higher at week 16 than at week 8 , while LV peak pressure and LV dP/dt $t_{\max }$ were significantly lower. Group differences between the RVa and BiV animals were only found for cardiac output, being significantly higher (week 16) and tau being significantly shorter (week 8 and 16) after biventricular pacing. 

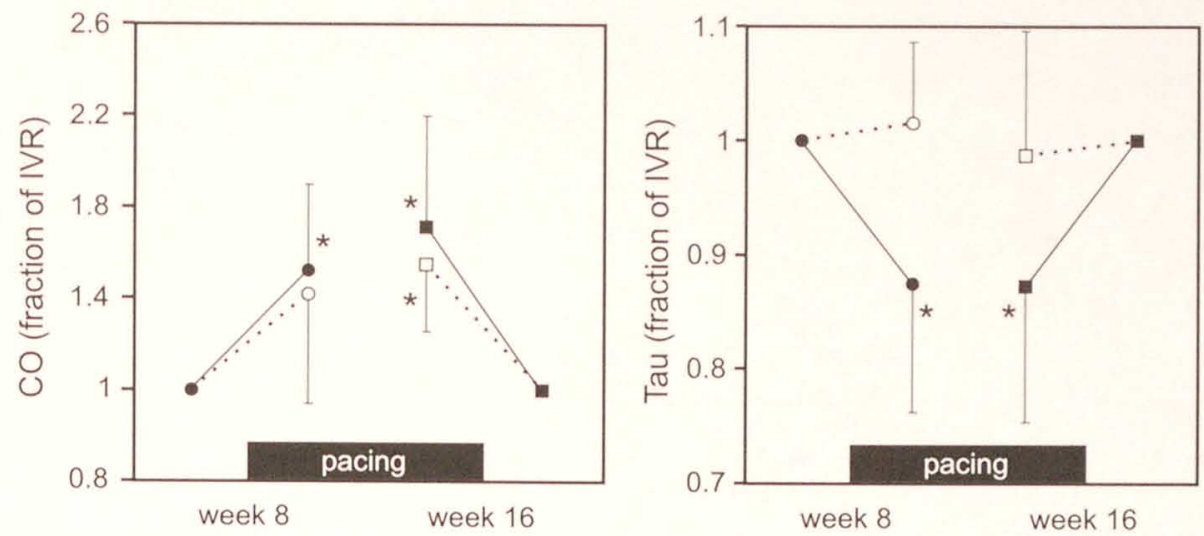

Figure 2. Acute effects of pacing on cardiac output (left panel) and tau (right panel) at week 8 and 16 in the $\mathrm{RVa}$ (open symbols) and BiV group (closed symbols). Values are expressed as fraction of pacing of during idioventricular rhythm (IVR). ${ }^{*} \mathrm{p}<0.05 \mathrm{vs}$. IVR.

Typical force-frequency relations of one RVa dog (left panel) and one BiV dog (right panel) are illustrated in Figure 3. The force-frequency relation was negative at week 8 and week 16 , but the slope became significantly less negative between week 8 and 16 , while the $y$-axis (force-axis) intercept decreased significantly.

The data on the force-frequency relation for all animals are presented in Figure 4. For comparison the range of values at week 0 from chapter 3 is indicated by the gray area. Between week 8 and 16 the slope of the force-frequency relation (upper panel) became significantly less negative in both groups. The $y$-axis intercept of the force-frequency relation (lower panel) was significantly lower at week 16 than at week 8, indicating lower LV performance at idioventricular rhythm.

To illustrate the reversibility of both structural and contractile remodeling more clearly changes in LV end-diastolic volume were plotted against changes in LV dP/dt ${ }_{\max }$ using the values at week 8 as a reference (Figure 5). For comparison the values of these parameters at week 0 , derived from chapter 3 , were added to the figure. In both chronic pacing strategies $L V$ end-diastolic volume and $L V \mathrm{dP} / \mathrm{dt}_{\max }$ decreased to near normal values, although end-diastolic volume was substantially larger in the BiV than RVa paced group.

\section{Electrical remodeling}

Acutely after onset of pacing QRS duration was slightly, but not significantly, shorter in the BiV group than in the RVa group ( $96 \pm 16$ and $107 \pm 12 \mathrm{~ms}$, respectively). Throughout the pacing period no changes in QRS duration were observed in either group.

During the 8 weeks of AV-block, QT -time prolonged nearly as much in the BiV group as in the RVa group (Figure 6). Throughout the 8 weeks of pacing QT - -time did 

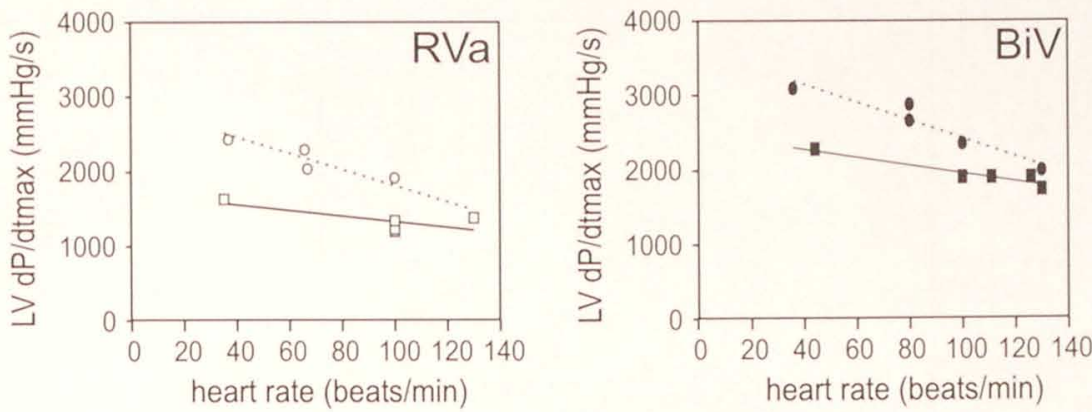

Figure 3. Examples of the force-frequency relation at week 8 (circles) and week 16 (squares) in the RVa (left panel) and BiV group (right panel).
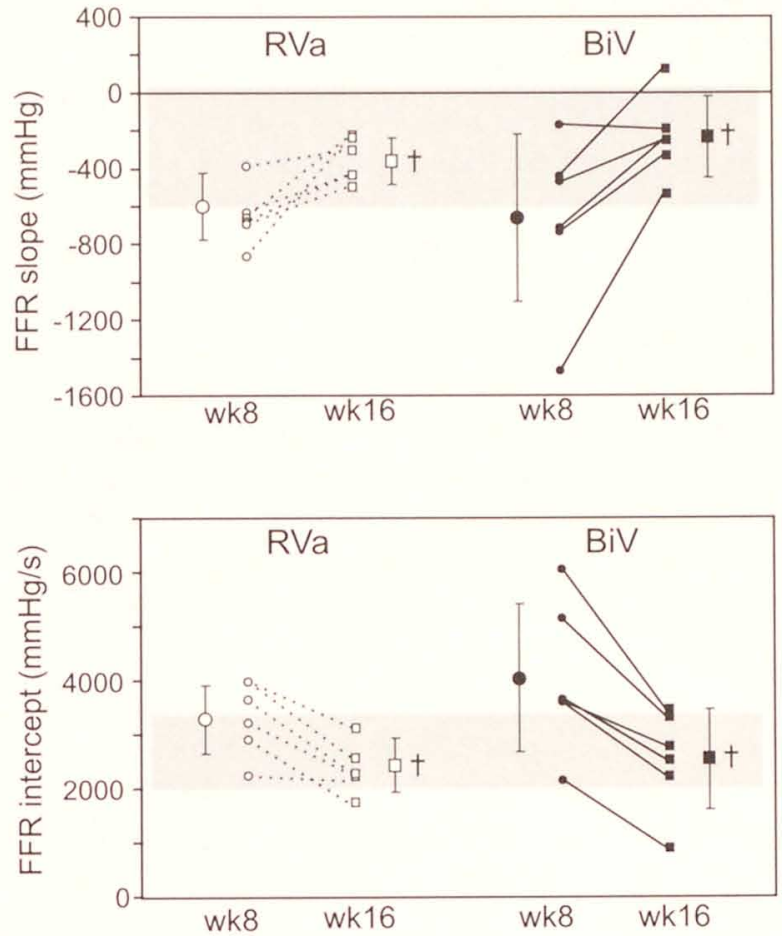

Figure 4. Slope and $y$-axis intercept of the force-frequency relation (FFR) at week 8 and 16 in the RVa (left side, open symbols) and BiV group (right side, closed symbols). $+p<0.05$ week 16 vs. week 8 . Gray area indicates range of mean \pm SD of normal values at week 0 . 


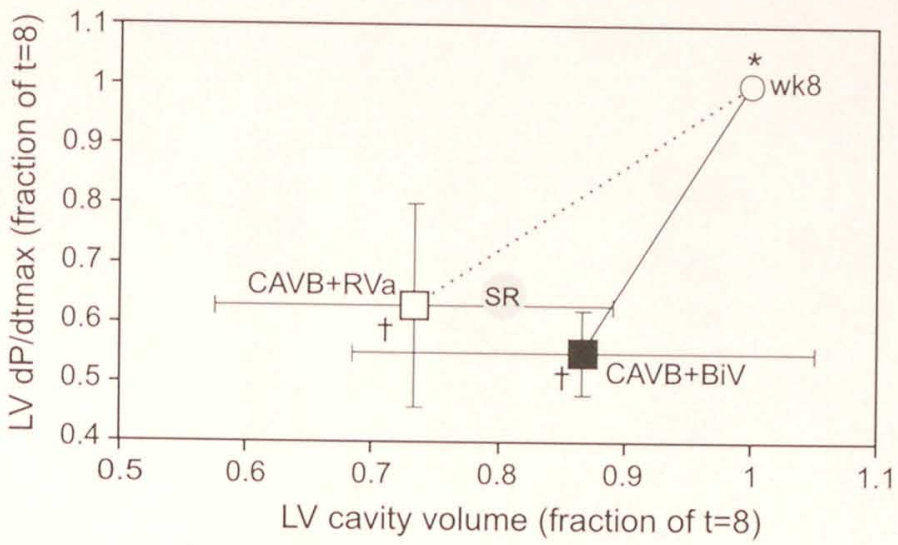

Figure 5. LV dP/dt $\max$ as a function of LV cavity volume at week 8 and 16 in the RVa (open symbols) and BiV group (closed symbols). Values are expressed as fraction of week 8 . Large gray symbol represent values at sinus rhythm (SR). ${ }^{*} p<0.05$ vs. SR and $+p<0.05$ vs. wk 8 .

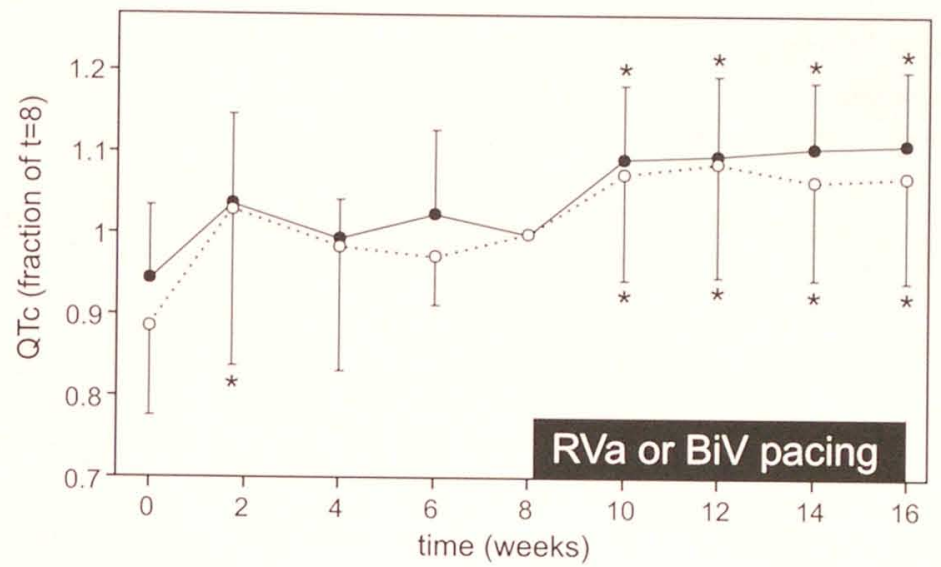

Figure 6. Time-dependent changes of QT-time corrected for heart rate ${ }^{22}$ (QT -time) expressed as a fraction of its value at week 8 in RVa (open symbols) and BiV group (closed symbols). QT c data presented have been obtained at idioventricular rhythm until week 8, thereafter during pacing. ${ }^{*} \mathrm{p}<0.05$ vs. SR.

not reverse to normal, despite regression of LV mass. The absence of reduction of repolarization time in both groups was confirmed by the measurement of monophasic action potentials measurements, which showed comparable values of LV and RV APD at week 8 and 16. The data presented in Figure 7 were obtained during VDD-pacing, but similar values were found during temporary idioventricular rhythm. 


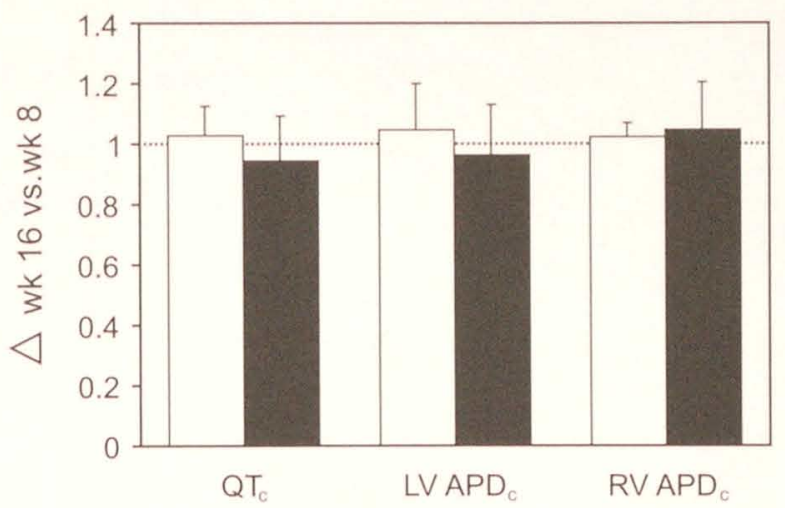

Figure 7. $\mathrm{QT}_{c}$-time and LV and RV APD at week 16 as fraction of week 8 in the RVa (white bars) and BiV group (black bars).

\section{Discussion}

The present study demonstrates that, in hearts hypertrophied due to chronic bradycardia, normalization of heart rate by ventricular pacing leads to reverse structural and reverse contractile remodeling without reverse electrical remodeling. Biventricular pacing leads to a slightly but significantly quicker and more uniform regression of hypertrophy than RV apex pacing, but this does not influence (the absence of) reverse electrical remodeling.

Hemodynamic effects of BiV and RVa pacing

Comparison of hemodynamic variables between the BiV and RVa group indicates a better hemodynamic performance during acute biventricular pacing than during acute RV apex pacing. Cardiac output is increased only after onset of biventricular pacing. After 8 weeks of pacing cardiac output is higher in the biventricular than in the RV apex group, but this is at a higher heart rate. Relaxation during biventricular pacing is better at both week 8 and 16 , as indicated by a shorter tau. Other studies show more pronounced differences between biventricular and RV apex pacing, when comparing both pacing modes within one experiment ${ }^{12,23}$.

Reverse structural remodeling

Since the final degree of regression of hypertrophy in the present study is similar after biventricular and RV apex pacing, the (a)synchrony of activation apparently does not play an important role in reverse structural remodeling after chronic AV-block. At first sight this seems remarkable because asynchronous activation (left bundle branch block 
and LV pacing) in non-hypertrophic hearts leads to ventricular hypertrophy, especially in the late-activated areas ${ }^{19.24}$. Therefore, pacing bradycardic hearts could have shown a mixture of reduction of $L V$ mass due to increase of heart rate and an increase of $L V$ mass due to asynchrony of activation. Apparently in the situation of AV-block, the normalization of heart rate is a stronger stimulus than the induction of asynchrony. Alternatively, the hypertrophic response to asynchronous activation could be less pronounced in hypertrophic hearts. This idea was supported by study where RV apex pacing in pressure overload hypertrophy did not lead to (further) hypertrophy ${ }^{25}$.

Although biventricular pacing does not lead to QRS durations similar to those in sinus rhythm, activation of the LV is significantly more synchronous, as evidenced by MRI tagging ${ }^{26}$. The more synchronous $L V$ activation in biventricular pacing results in symmetrical regression of hypertrophy, as indicated by a LV septum to free wall ratio close to 1 , while this ratio is $0.9 \pm 0.09$ after $R V$ apex pacing. The asymmetric hypertrophy as observed in RV apex pacing is consistent with observations in other studies ${ }^{2-1,25}$.

\section{Reverse contractile remodeling}

The findings in the present study indicate that restoration of heart rate in bradycardia induced volume overload leads to reverse structural remodeling, which is accompanied by reverse contractile remodeling. Reverse contractile remodeling is evidenced by the less negative slope and the decreased $y$-axis intercept of the force-frequency relation after 8 weeks of pacing. It has been suggested that a decrease in sarcoplasmic reticular $\mathrm{Ca}^{2+}$-ATPase (SERCA) and/or an increase in $\mathrm{Na}^{+} / \mathrm{Ca}^{2+}$ exchanger (NCX) expression leads to a negative force-frequency relation ${ }^{16,27-29}$. In the AV-block dog the negative force-frequency relation at week 6 is not associated with an change in NCX protein content ${ }^{15}$. The current through the NCX, however, is increased, especially at low heart rates ${ }^{30}$. The normalization of the force-frequency relation in the present study suggests a normalization of $\mathrm{Ca}^{2+}$ homeostasis and NCX current.

Only a few studies report on reverse contractile remodeling. Gerdes et al. showed that regression of hypertrophy after aorto-caval shunt occlusion in rats was accompanied by a normalization of $\mathrm{LV} \mathrm{dP} / \mathrm{dt}_{\max }{ }^{31}$. Reverse structural and reverse contractile remodeling run not necessarily parallel, as demonstrated by Nakano et al., who showed that after valve replacement for mitral regurgitation reverse contractile remodeling is not associated with regression of hypertrophy ${ }^{32}$.

Longer action potential duration can lead to more $\mathrm{Ca}^{2+}$ influx, thus resulting in an increased contractility. The reverse contractile remodeling, despite unchanged action potential duration (see below), suggests that the latter does not contribute to contractility, at least not in the experimental model used in the present study. 
Despite more synchronous electrical activation, biventricular pacing, like RV apex pacing, does not lead to reverse electrical remodeling: repolarization remains prolonged, as are $Q T_{c}$-time and LV and RV action potential duration. The lack of change of the repolarization parameters is independent of heart rate and activation sequence because the measurements during idioventricular rhythm, VDD-pacing, and pacing at 100 beats/min show the same results.

In AV-block the $I_{10}$ current is reported to be unchanged ${ }^{33}$. Electrical remodeling in this model has been associated with an increased $N C X$ current ${ }^{30}$ and a decreased $I_{k}$ current ${ }^{3.4}$. This decrease in $I_{K}$ current is accompanied by downregulation of $I_{K s}$ protein ${ }^{35}$ and mRNA ${ }^{36}$. Since reverse contractile remodeling implies that $\mathrm{Ca}^{2+}$ handling is probably normalized, irreversible changes in the $\mathrm{K}^{+}$channel are likely to be responsible for the absence of reverse electrical remodeling. This suggests that in chronic AV-block one gene is irreversibly changed, while many other genes, encoding for structural and contractile proteins, are reversibly altered.

\section{Conclusions}

In canine hearts with bradycardia induced volume overload normalization of heart rate leads to reverse structural and contractile remodeling. The degree of reverse remodeling is independent of the degree of synchrony of activation. Electrical remodeling is not reversible, even when LV activation is more synchronous. 


\section{References}

1. Blake J, Devereux RB, Herrold EM, et al. Relation of concentric left ventricular hypertrophy and extracardiac target organ damage to supranormal left ventricular performance in established essential hypertension. Am / Cardiol. 1988;62:246-52.

2. Kass DA. Force-frequency relation in patients with left ventricular hypertrophy and failure. Basic Res Cardiol. 1998;93:108-16.

3. de Simone G, Greco R, Mureddu G, et al. Relation of left ventricular diastolic properties to systolic function in arterial hypertension. Circulation. 2000;101:152-7.

4. Kannel WB, Gordon T, Offutt D. Left ventricular hypertrophy by electrocardiogram. Prevalence, incidence, and mortality in the Framingham study. Ann Intern Med. 1969;71:89-105.

5. Messerli FH, Grodzicki T. Hypertension, left ventricular hypertrophy, ventricular arrhythmias and sudden death. Eur Heart /. 1992;13 Suppl D:66-9.

6. Swynghedauw B, Chevalier B, Charlemagne D, et al. Cardiac hypertrophy, arrhythmogenicity and the new myocardial phenotype. II. The cellular adaptational process. Cardiovasc Res. 1997;35:6-12.

7. Vos MA, de Groot SH, Verduyn SC, et al. Enhanced susceptibility for acquired Torsade de Pointes arrhythmias in the dog with chronic, complete AV block is related to cardiac hypertrophy and electrical remodeling. Circulation. 1998;98:1125-35.

8. Tomaselli GF, Marban E. Electrophysiological remodeling in hypertrophy and heart failure. Cardiovasc Res. 1999:42:270-83.

9. Peschar $M$, Vernooy $K$, Vanagt $W Y R$, et al. Absence of reverse electrical remodeling during regression of volume overload hypertrophy in canine ventricles. Thesis chapter 5 .

10. Park RC, Little WC, O'Rourke RA. Effect of alteration of left ventricular activation sequence on the left ventricular end-systolic pressure-volume relation in closed chest dogs. Circ Res. 1985;57:706-717.

11. Burkhoff D, Oikawa RY, Sagawa K. Influence of pacing site on canine left ventricular contraction. Am J Physiol. 1986;251:H428-35.

12. Prinzen FW, Van Oosterhout MF, Vanagt WY, et al. Optimization of ventricular function by improving the activation sequence during ventricular pacing. Pacing Clin Electrophysiol. 1998;21:2256-60.

13. Peschar $M$, de Swart $H$, Michels KJ, et al. Left ventricular septal and apex pacing for optimal pump function in canine hearts. Thesis chapter 7.

14. de Groot SH, Schoenmakers $M$, Molenschot MM, et al. Contractile adaptations preserving cardiac output predispose the hypertrophied canine heart to delayed afterdepolarization-dependent ventricular arrhythmias. Circulation. 2000;102:2145-51.

15. Peschar M, Baaten $G$, van der Nagel T, et al. Biphasic contractile and progressive structural remodeling during bradycardia induced volume overload hypertrophy. Thesis chapter 3 .

16. Hasenfuss $G$, Reinecke $H$, Studer $R$, et al. Relation between myocardial function and expression of sarcoplasmic reticulum Ca"-ATPase in failing and nonfailing human myocardium. Circ Res. $1994 ; 75: 434-42$.

17. Houser SR, Piacentino V, 3rd, Weisser J. Abnormalities of calcium cycling in the hypertrophied and failing heart. / Mol Cell Cardiol. 2000;32:1595-607.

18. Rodriguez LM, Leunissen J, Hoekstra A, et al. Transvenous cold mapping and cryoablation of the AV node in dogs: observations of chronic lesions and comparison to those obtained using radiofrequency ablation. / Cardiovasc Electrophysiol. 1998;9:1055-61.

19. van Oosterhout MF, Prinzen FW, Arts T, et al. Asynchronous electrical activation induces asymmetrical hypertrophy of the left ventricular wall. Circulation. 1998;98:588-95.

20. Franz MR. Monophasic action potentials. Bridging cell and bedside. New York: Futura Publishing Company; 2000.

21. Steendijk P, Baan J. Comparison of intravenous and pulmonary artery injections of hypertonic saline for the assessment of conductance catheter parallel conductance. Cardiovasc Res. 2000;46:82-9.

22. van de Water A, Verheyen J, Xhonneux R, et al. An improved method to correct the QT interval of the electrocardiogram for changes in heart rate. I Pharmacol Methods. 1989;22:207-17.

23. Fei $L$, Wrobleski $D$, Groh $W$, et al. Effects of multisite ventricular pacing on cardiac function in normat dogs and dogs with heart failure. / Cardiovasc Electrophysiol. 1999;10:935-46. 
24. Vernooy K, Verbeek XAAM, Cheriex EC, et al. Ventricular remodeling due to left bundle branch block: an echocardiographic study in dogs and patients. Pacing Clin Electrophysiol. 2002;24:528.

25. van Oosterhout MF, Arts T, Muijtjens AM, et al. Remodeling by ventricular pacing in hypertrophying dog hearts. Cardiovasc Res. 2001;49:771-778.

26. Wyman BT, Hunter WC, Prinzen FW, et al. Effects of single- and biventricular pacing on temporal and spatial dynamics of ventricular contraction. Am / Physiol Heart Circ Physiol. 2002;282:H372-9.

27. Houser SR, Piacentino V, 3rd, Mattiello J, et al. Functional properties of failing human ventricular myocyles. Trends Cardiovasc Med. 2000;10:101-7.

28. Hasenfuss G, Schillinger W, Lehnart SE, et al. Relationship between $\mathrm{Na}^{\circ}$-Ca"'-exchanger protein levels and diastolic function of failing human myocardium. Circulation. 1999;99:641-8.

29. Hasenfuss G, Reinecke $H$, Studer R, et al. Calcium cycling proteins and force-frequency relationship in heart failure. Basic Res Cardiol. 1996;91 Suppl 2:17-22.

30. Sipido KR, Volders $\mathrm{PG}$, de Groot $\mathrm{SH}$, et al. Enhanced Ca" release and $\mathrm{Na} / \mathrm{Ca}$ exchange activity in hypertrophied canine ventricular myocytes : potential link between contractile adaptation and arrhythmogenesis. Circulation. 2000;102:2137-44.

31. Gerdes AM, Clark LC, Capasso IM. Regression of cardiac hypertrophy after closing an aortocava! fistula in rats. Am / Physiol. 1995;268: H2345-51.

32. Nakano $K$, Swindle $M M$, Spinale $F$, et al. Depressed contractile function due to canine mitral regurgitation improves after correction of the volume overload. / Clin Invest. 1991;87:2077-86.

33. Volders PG, Sipido KR, Carmeliet $E$, et al. Repolarizing $K^{\circ}$ currents $I_{t: 1}$ and $I_{h}$ are larger in right than left canine ventricular midmyocardium. Circulation. 1999;99:206-10.

34. Volders PGA, Sipido KR, Vos MA, et al. Downregulation of delayed rectifier K' currents in dogs with chronic complete atrioventricular block and acquired Torsades de Pointes. Circulation. 1999;100: 2455-2461.

35. Volders PGA, Stengl $M$, Sipido KR, et al. Biophysical properties of downregulated $I_{h}$ in canine ventricular hypertrophy. Biophys /. 2002;82:358a.

36. Ramakers $C$, Dumaine R, Doevedans $P$, et al. Both KCNQ1 and KCNE1 expression is reduced in dogs with chronic AV-block. Eur Heart 1. 2000;21:239. 


\section{CHAPTER 7}

\section{Left ventricular septal and apex pacing for optimal pump function in canine hearts}

Maaike Peschar, Hans de Swart*, Koen J. Michels", Robert S. Reneman and Frits W. Prinzen

Departments of Physiology and *Cardiology,

Cardiovascular Research Institute Maastricht, Maastricht University, Maastricht, the Netherlands and

"Medtronic, Bakken Research Center, Maastricht, the Netherlands

Submitted to / Am Coll Cardiol (under revision) 


\section{Abstract}

Background: Pacing at the conventional site, the right ventricular (RV) apex, adversely affects hemodynamics. During normal sinus rhythm electrical activation of the working myocardium starts at the LV septal endocardium and spreads from apex to base. It was our aim to investigate whether left ventricular (LV) pump function is optimal when pacing is performed at the LV near the sites where the impulses exit the Purkinje system.

Methods: Experiments were conducted in anesthetized open chest dogs to investigate hemodynamic effects of pacing at various epicardial LV sites, the RV apex, and combinations of these sites $(n=11)$ and of RV and LV septal pacing $(n=8)$. The LV septal endocardium was reached via the RV by puncturing a barbed electrode through the

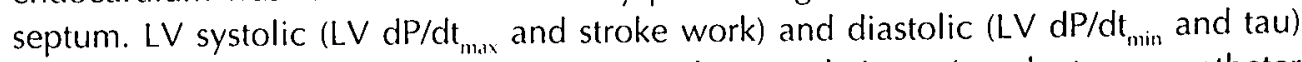
function were assessed using pressure-volume relations (conductance catheter technique).

Results: LV systolic and diastolic function were highly dependent on the site of pacing, but not on QRS duration. LV function was maintained at sinus rhythm level during LV septal, LV apex and multisite pacing, was moderately depressed during pacing at epicardial LV free wall sites and most severely depressed during RV apex pacing. On average RV septal pacing did not improve LV function as compared to RV apex pacing, but in each experiment one (variable) RV pacing site was found, which only moderately reduced LV function.

Conclusions: During ventricular pacing LV pump function is maintained best (i.e. at sinus rhythm level) when pacing at the LV septum or LV apex, potentially because pacing from these sites creates a physiological propagation of electrical conduction. 


\section{Introduction}

Ventricular pacing is becoming a generally accepted way to resynchronize ventricular activation in hearts with conduction abnormalities. However, there are indications that the original application of ventricular pacing, restoring physiological heart rate in patients with bradycardia, could still be improved. Ventricular pacing induces abnormal, asynchronous electrical activation and contraction ', leading to impaired cardiac pump function, even when atrio-ventricular synchronization is optimized using a dual-chamber pacemaker ${ }^{2-4}$. Long-term ventricular pacing is associated with maintained hemodynamic deterioration ${ }^{3.5,6}$ and pathological changes in myocardial structure ${ }^{5.7}$.

There is considerable evidence that the severity of impairment of ventricular function depends on the site of pacing. The conventional pacing site, the right ventricular (RV) apex, is one of the worst sites. Single site left ventricular (LV) and multisite pacing improve cardiac function as compared to RV apex pacing ${ }^{4,8-13}$. In several studies LV function was found to be better during RV septal than during RV apex pacing ${ }^{4,7,1+17}$, but others were unable to demonstrate such a difference ${ }^{18-22}$.

Results from a previous study, comparing values of $L V d P / d t_{\max }$ during pacing from the LV apex, LV lateral wall and RV apex, alone or in combination with each other, suggested that the sequence of activation is more important than its synchrony ${ }^{12}$. It seems likely that the activation sequence leading to the best LV pump function would be that occurring during sinus rhythm (SR). Under these conditions the electrical impulse exits the Purkinje system at sites located at the LV endocardial surface of the septum ${ }^{23,2-4}$, especially the lower third part ${ }^{25}$.

The aim of the present study was to test the hypothesis that pacing near LV exit sites of the Purkinje system (LV apex, LV septum) results in optimal LV systolic and diastolic function. To this purpose LV pressure-volume analysis was performed in two series of experiments. Series 1 was designed to compare single site pacing at RV apex and at various epicardial LV sites (various activation sequences) with multisite pacing (optimal synchrony). In series 2 the hemodynamic effects of pacing at the RV and LV endocardial surface of the septum were compared with pacing at the best epicardial LV site (the LV apex).

\section{Methods}

Animal handling was performed according to the Dutch Law on Animal Experimentation (WOD) and the Guide for the Care and Use of Laboratory Animals published by the US National Institutes of Health (NIH Publication No. 85-23, revised 1996). The protocol was approved by the Experimental Animal Committee of the Maastricht University. Two series of experiments were conducted: series $1(n=11)$ for 
comparison of hemodynamic effects of RV apex, single LV, multiple LV, biventricular $(R V+L V)$ and multiple (up to 4) $L V+R V$ pacing and series $2(n=8)$ for comparison of $R V$ and LV septal pacing.

\section{Preparation}

Dogs were premedicated with acepromazine $0.2 \mathrm{mg} / \mathrm{kg}$, atropine $0.1 \mathrm{mg} / \mathrm{kg}$ and oxycodone $2 \mathrm{mg} / \mathrm{kg}$ i.m. Anesthesia was induced with thiopental $15 \mathrm{mg} / \mathrm{kg}$ i.v. and maintained by ventilation with halothane $(0.8$ to $1.0 \%)$ in a $1: 2$ mixture of $\mathrm{O}_{2}$ and $\mathrm{N}_{2} \mathrm{O}$. ECG was recorded from the limb leads. A $7 F$ combined cathetertip manometer and conductance catheter (Sentron) was introduced through a carotid artery into the LV cavity and the correct position verified using fluoroscopy. A 7F cathetertip manometer (Sentron) was introduced into a femoral artery and advanced to measure ascending aortic pressure. After opening the chest an aortic flowprobe (Transonic) was positioned around the ascending aorta to measure stroke volume (SV), except for two animals in series 2, where cardiac output was measured by means of thermodilution (Baxter thermodilution catheter and computer).

Temporary myocardial pacing leads (Medtronic, type 6500) were attached to the epicardium of the right atrium $(1-2 \mathrm{~cm}$ from the sinus node) and to the epicardium of the LV apex and the anterior wall (along the LAD, immediately below the first diagonal branch), lateral and posterior wall (both $\sim 2 \mathrm{~cm}$ below the base, Figure 1). A Medtronic 5076 screw-in lead was introduced through the jugular vein and advanced until the endocardium of the RV apex. Pacing at the RV septum was performed using a Medtronic MarinR steerable ablation catheter or a Medtronic 5076 screw-in lead, which were repositioned after each hemodynamic measurement. Exact location was facilitated by fluoroscopic visualization of various opaque markers attached to the outer surface of the heart and of the Swan-Ganz catheter, which depicted the trajectory from the RV inflow to the RV outflow tract.

In order to pace the LV endocardium of the septum (series 2) leads were constructed by attaching a silver wire to a curved needle-tip. This curved tip served as a barb for active fixation and as stimulation electrode. The lead was introduced in an $8 \mathrm{~cm}$ long $\sim 18$ gauge needle, with the hook just outside the needle. The needle was introduced into the RV cavity through the lower RV free wall and pushed through the interventricular septum until the LV cavity was reached. Subsequently the needle was withdrawn, allowing the barbed electrode of the pacing lead to fix position at the LV septal endocardium (Figure 1). LV endocardial position was verified post mortem and proved to be in the lower $1 / 2$ to $1 / 3$ part of the septum.

The leads were connected to an external pacemaker (Medtronic AV pacing System Analyzer Model 5311B). In series 1 the four LV electrodes were connected to a four-channel external pulse stimulator (Medtronic model 2883), allowing to set thresholds for each electrode separately and to pace each of the electrodes separately or 


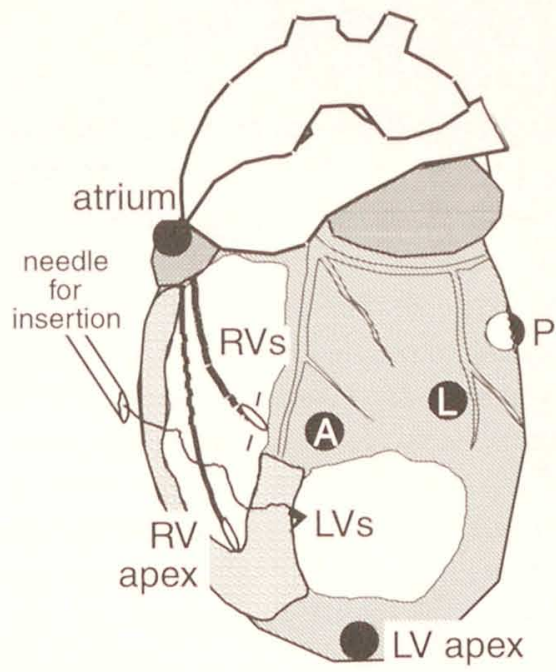

Figure 1. Schematic representation of position of pacing electrodes. Black dots denote epicardial electrodes, A: anterior, L: lateral and P: posterior LV wall electrode. The LV septal (LVs) electrode was positioned by pushing the barbed electrode inside a needle through the RV free wall and the septum, so that the barbed tip attached to the LV endocardial surface of the septum. RVs: RV septum. For further details: see methods.

in combination with one or more other electrodes. By connecting the RV apex electrode to a splitter in between the external pacemaker and the external stimulator it was possible to pace up to 4 LV sites and the RV apex simultaneously. Pacing was unipolar with an indifferent electrode between intercostal muscles.

\section{Measurements}

LV Pressure, aortic flow and ECG signals were digitized at $200 \mathrm{~Hz}$ using a DASH $16 \mathrm{G} 2$ A/D converter and stored on disk for off-line analysis. Duration of the QRS complex of the surface ECG was used as measure of the synchrony of electrical activation of the ventricles.

LV cavity volume was measured using a 12-electrode dual field conductance catheter (7F, Sentron), connected to a Leycom Sigma 5DF signal conditioner processor (CardioDynamics). Parallel conductance was estimated by injecting $7.5 \mathrm{ml}$ of hypertonic saline $(6.5 \%)$ into the pulmonary artery ${ }^{26}$. Calibration of absolute LV volume was performed by calibrating SV, as determined with the conductance catheter, with SV measured with the aortic flow probe. 


\section{Protocol}

Following completion of the preparation the measurements started after a stabilization period of minimally $15 \mathrm{~min}$. In series 1 the heart was paced from the 4 epicardial LV ventricular sites, and from the RV apex alone and subsequently from the LV apex simultaneous with the RV apex ("biventricular"), with 2-3 other LV sites ("multi-LV") and with all LV sites in combination with the RV apex ("multi- $L V+R V$ "). In series 2 the heart was paced from the LV apex, the RV apex, the LV septum (transseptal electrode) and from various RV septal sites. In order to pace several RV septal sites, the (steerable) pacing lead was repositioned after each measurement, aiming at the lower, middle, high mid and the high septum.

Pacing was performed in the VDD mode, so that atrial sensing was used to govern ventricular pacing. A short (25-40 ms) atrio-ventricular (AV) interval, assured that the entire ventricle was activated from the ectopic site(s). Measurements were performed on 5-10 heart beats, 1-2 min. after starting at a particular pacing site. The various sites were paced in random order. After studying two or three different pacing sites and after pacing each RV septal site measurements were repeated during SR, serving as baseline.

\section{Data analysis}

The dedicated data analysis software package CIRCLAB (developed by Dr. P. Steendijk (Leiden University Medical Center, the Netherlands) was used for analysis of all data from the conductance catheter, including calculation of the maximal first positive (LV

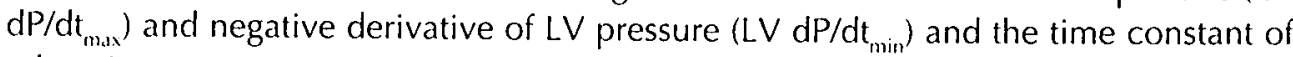
relaxation tau.

In order to improve comparison of the data obtained throughout the experiment absolute values were normalized to those obtained during the SR measurement most adjacent to the measurement during pacing at each site.

\section{Statistical analysis}

For comparison of the effect of pacing from the various sites each animal was used as its own control. One way ANOVA for repeated measurements was used to evaluate the significance of the effect of pacing site on a hemodynamic variable. If significant differences were found, significant points were isolated using Fisher's protected LCD as post-hoc test followed by Bonferroni correction. The level of significance was set at $p<$ 0.05 . Data are presented as mean values \pm SD . 


\section{Results}

Single site RV apex and LV pacing

During ventricular pacing QRS duration was almost twice as wide as during SR, QRS duration being longest during LV apex and LV lateral pacing (Table 1). RV apex pacing significantly deteriorated all measures of systolic (SV, stroke work (SW), LV dP/dt mux' $^{\prime}$ end-systolic LV pressure) and diastolic function (LV dP/dt nin' tau, end-diastolic LV pressure, Table 1). Pacing at the LV wall induced less pronounced reductions in LV systolic and diastolic function. SV and SW were not significantly depressed during LV anterior and lateral wall pacing and tended to be even higher during LV apex pacing than during $\operatorname{SR}(0.05<p<0.10$, Table 1, Figure 2$)$. LV apex and LV anterior wall pacing did not change $L V d P / d t_{\text {max }}$ as compared to $S R$, but $L V d P / d_{\max }$ was reduced significantly during LV lateral and LV posterior wall pacing (Table 1). Pacing at LV sites slowed down

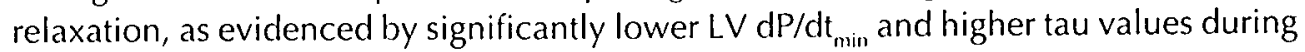
LV pacing than during SR. These changes were least pronounced during LV apex pacing. Moreover, LV apex and LV anterior wall pacing reduced LV dP/dt ${ }_{\min }$ less than $\mathrm{RV}$ apex pacing. The increase in tau was greater during LV lateral and anterior wall pacing than during LV apex pacing. End-diastolic and end-systolic LV pressures were hardly influenced by pacing from any LV site (Table 1).

Table 1.

Hemodynamic effects of pacing at various sites in hearts with normal impulse conduction.

\begin{tabular}{|c|c|c|c|c|c|c|}
\hline & SR & $\begin{array}{l}\text { RV apex } \\
\text { Rel. to } S R\end{array}$ & $\begin{array}{l}\text { LV apex } \\
\text { Rel. to SR }\end{array}$ & $\begin{array}{l}\text { LV lat } \\
\text { Rel. to SR }\end{array}$ & $\begin{array}{l}\text { IV post } \\
\text { Rel. to SR }\end{array}$ & $\begin{array}{l}\text { LV ant } \\
\text { Rel. to SR }\end{array}$ \\
\hline Heart rate (bpm) & $110 \pm 20$ & $1.05 \pm 0.08^{*}$ & $1.05 \pm 0.10^{*}$ & $1.03 \pm 0.10$ & $1.02 \pm 0.06$ & $1.02 \pm 0.08$ \\
\hline LV Stroke volume $(\mathrm{ml})$ & $30 \pm 9$ & $0.93 \pm 0.13^{* t}$ & $1.14 \pm 0.21^{\ddagger}$ & $0.99 \pm 0.13^{t}$ & $0.87 \pm 0.14^{* t}$ & $0.94 \pm 0.08^{t}$ \\
\hline LV Stroke work $(\mathrm{mmH} \cdot \mathrm{g} \cdot \mathrm{ml})$ & $2081 \pm 579$ & $0.79 \pm 0.20^{* t}$ & $1.09 \pm 0.22^{\ddagger}$ & $0.98 \pm 0.19^{t t}$ & $0.87 \pm 0.21^{\dagger}$ & $0.93 \pm 0.13^{1 \neq}$ \\
\hline LV dP/dtmax (mmHg/s) & $1192 \pm 251$ & $0.93 \pm 0.07^{* \dagger}$ & $0.99 \pm 0.06^{\ddagger}$ & $0.93 \pm 0.07^{* t}$ & $0.93 \pm 0.08^{* \dagger}$ & $0.96 \pm 0.09$ \\
\hline $\mathrm{LV} \mathrm{dP} / \mathrm{dtmin}(\mathrm{mmHg} / \mathrm{s})$ & $1293 \pm 202$ & $0.80 \pm 0.13^{*^{\dagger}}$ & $0.90 \pm 0.10^{* \neq}$ & $0.84 \pm 0.11^{*}$ & $0.85 \pm 0.10^{*}$ & $0.90 \pm 0.16^{*}$ \\
\hline Tau (ms) & $28 \pm 4$ & $1.18 \pm 0.13^{*}$ & $1.12 \pm 0.10^{*}$ & $1.19 \pm 0.11^{* t}$ & $1.20 \pm 0.13^{* \dagger}$ & $1.15 \pm 0.14^{*}$ \\
\hline LV ES pressure (mmHg) & $82 \pm 11$ & $0.95 \pm 0.07^{*}$ & $0.96 \pm 0.05$ & $0.98 \pm 0.05$ & $0.98 \pm 0.04$ & $0.98 \pm 0.06$ \\
\hline IVED pressure $(\mathrm{mmHg})$ & $10 \pm 4$ & $1.14 \pm 0.43^{*}$ & $1.10 \pm 0.36$ & $1.23 \pm 0.43^{*}$ & $1.22 \pm 0.47$ & $1.13 \pm 0.34$ \\
\hline QRS duration (ms) & $54 \pm 8$ & $1.86 \pm 0.33^{* t}$ & $1.93 \pm 0.23^{*}$ & $1.20 \pm 0.22^{*}$ & $1.82 \pm 0.29^{* t}$ & $1.70 \pm 0.38^{* t}$ \\
\hline
\end{tabular}

All values during ventricular pacing are expressed relative to the corresponding value during sinus thythm (SR); ES:end-systolic, ED: end-diastolic. * $t$ and $\neq p<0.05$ as compared to SR, LV apex and $R V$ apex, respectively. ANOVA for repeated measurements and post hoc test. $n=11$. 


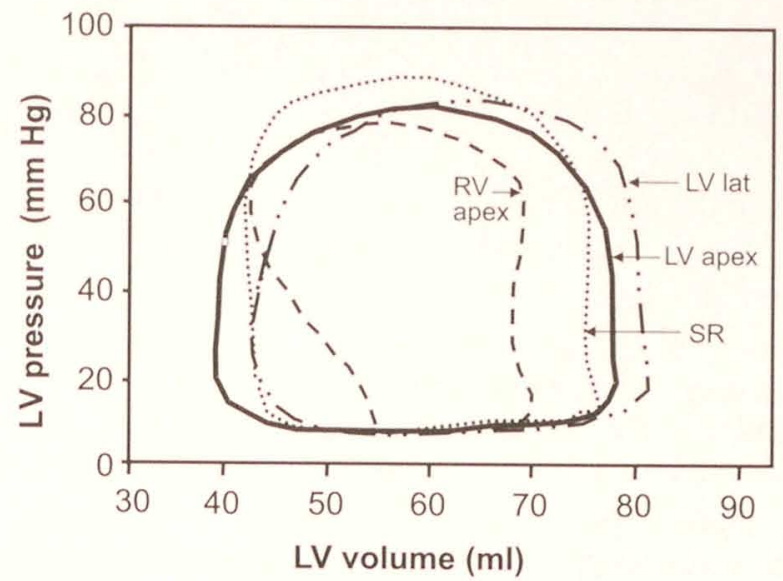

Figure 2. Pressure-volume diagrams during sinus rhythm (SR) and during pacing from the LV apex, LV lateral wall (lat) and from the RV apex.

Pacing at multiple sites

Pacing the LV apex in combination with the RV apex, with the 3 other LV sites or with all sites together reduced QRS duration by approximately $25 \%$ as compared to single site LV apex pacing, but QRS duration remained significantly (approximately 70\%) higher than during SR. The pressure-volume diagrams in Figure 3 illustrate that pressure development, SV and SW were not improved by pacing from more sites than from the LV apex alone. The bar graphs in Figure 3 show that this was also the case for the group as a whole. Also for the other hemodynamic variables no significant differences were found between single site LV apex pacing and pacing at multiple sites.

Pacing at the RV and LV septum

In series 2 it was investigated how pacing from the various septal sites affected LV function. The size and shape of the LV pressure-volume diagrams varied considerably with the site of pacing at the RV septum (Figure 4). LV dP/dt max $_{\text {and }}$ SW were not significantly different between RV septum and RV apex pacing but significantly lower than during SR (bar graphs in Figure 4).

For each experiment LV dP/dt $t_{\max }$ and SW varied with the site of RV septal pacing (Figure 5). The figure also depicts that in each experiment a site at the RV apex or septum was found, which resulted in only moderate reduction of LV function and that the position of that site varied between the experiments. When pacing from this "best RV site", SW was still significantly lower than during SR, but LV dP/dt max was not (Table 2). 

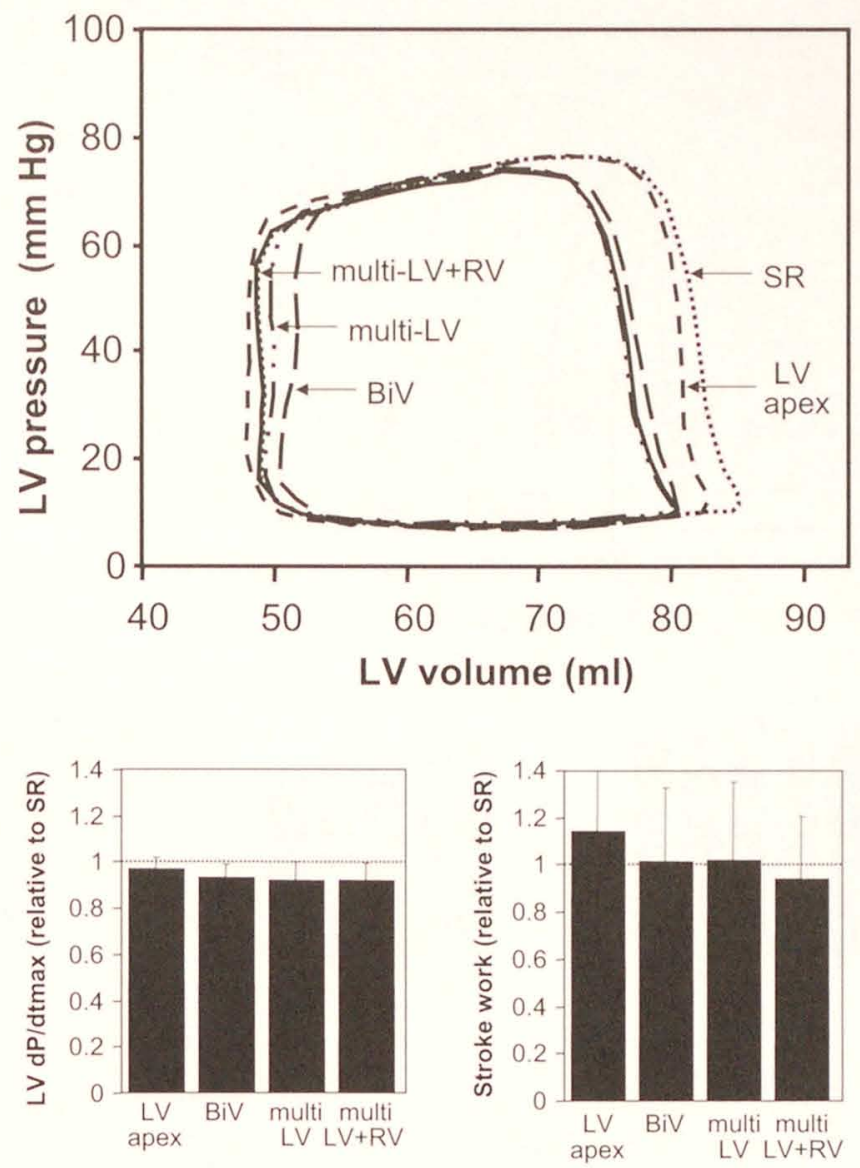

Figure 3. Upper panel: pressure-volume diagrams during sinus rhythm (SR), LV apex pacing, biventricular pacing, multi LV pacing and multi LV+RV pacing. Lower panels: mean values \pm SD of LV $\mathrm{dP} / \mathrm{dt} t_{\max }$ and $\mathrm{SW}$ during $\mathrm{LV}$ apex, biventricular $(\mathrm{BiV})$, multi $L V$ and multi $L V+R V$ pacing relative to SR. Differences in SW and LV dP/dt $\max$ between the four pacing modes were not statistically significant.

Per experiment only one or two LV septal sites were paced. In each case SW (Figure 6) and $\mathrm{LV} \mathrm{dP/dt}$ max were close to the value during SR. For the entire group the values of LV $\mathrm{dP} / \mathrm{dt}_{\max }$ and SW and the other hemodynamic variables were similar during LV septal pacing, LV apex pacing and SR (Table 2). QRS duration was prolonged during pacing at any ventricular site, but significantly longer during pacing at the epicardium of the LV apex than during pacing the RV or LV septal endocardium (Table 2). 

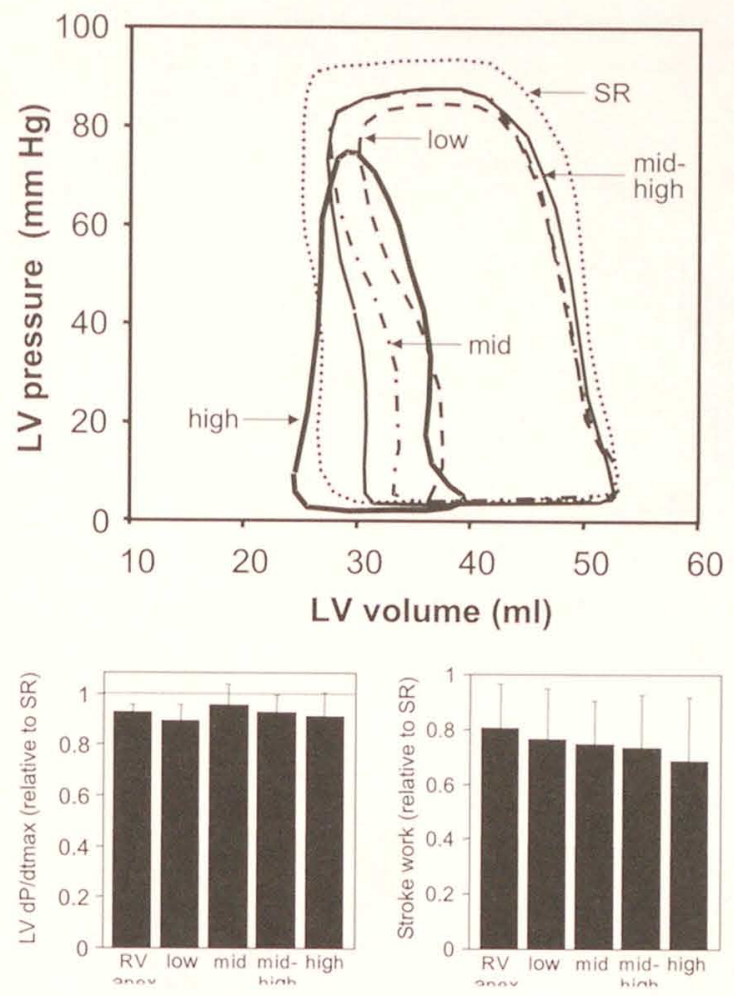

Figure 4. Upper panel: Pressure-volume diagrams during sinus rhythm (SR) and pacing at the low, mid,

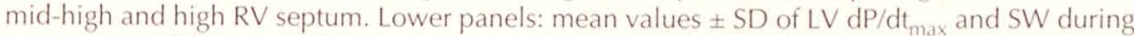
pacing at the RV apex and the various RV septal sites relative to SR. Differences in SW and LV $\mathrm{dP} / \mathrm{dtmax}$ between the five pacing modes were not statistically significant, but SW was significantly lower than SR during pacing at all five sites and LV dP/dt $\max$ was significantly below SR during low and high septal pacing.
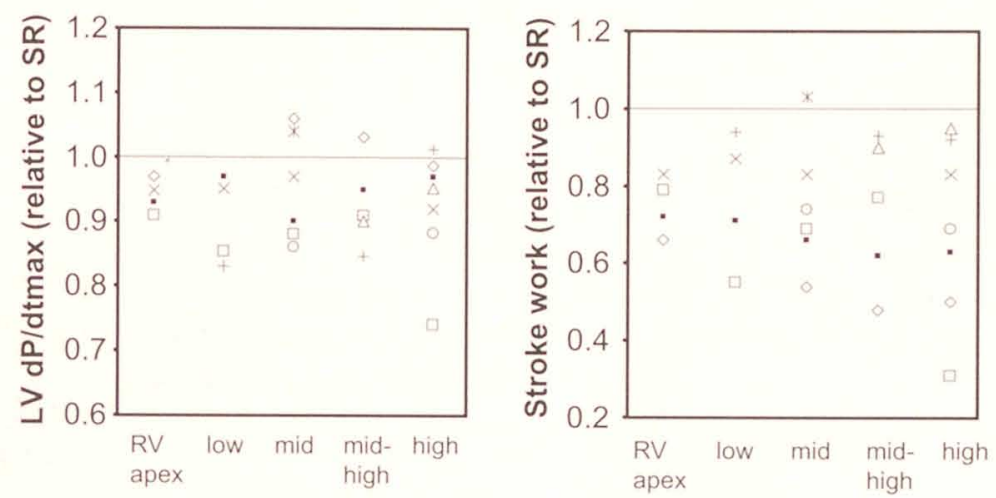

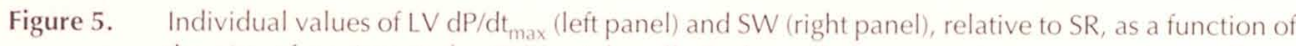
the site of pacing at the RV septal wall. Each symbol represents one experiment. Some datapoints are missing due to instable pacing at some RV septal sites. 
Table 2.

Hemodynamic effects of pacing at the RV and LV septum and at the LV apex in hearts with normal impulse conduction.

\begin{tabular}{lllll}
\hline & SR & $\begin{array}{l}\text { Best RVsep } \\
\text { Rel. to SR }\end{array}$ & $\begin{array}{l}\text { LV apex } \\
\text { Rel. to SR }\end{array}$ & $\begin{array}{l}\text { LV septum } \\
\text { Rel. to SR }\end{array}$ \\
\hline Heart rate $(\mathrm{bpm})$ & $124 \pm 13$ & $1.01 \pm 0.02$ & $1.01 \pm 0.01$ & $1.01 \pm 0.01$ \\
LV Stroke volume $(\mathrm{ml})$ & $27 \pm 10$ & $0.98 \pm 0.08$ & $1.07 \pm 0.14$ & $1.03 \pm 0.04$ \\
LV Stroke work $(\mathrm{mmHg} \cdot \mathrm{ml})$ & $2057 \pm 1235$ & $0.84 \pm 0.16^{*+\neq}$ & $1.08 \pm 0.15$ & $1.00 \pm 0.07$ \\
LV dP/dt $\max (\mathrm{mmHg} / \mathrm{s})$ & $1338 \pm 368$ & $0.99 \pm 0.05$ & $1.00 \pm 0.05$ & $1.00 \pm 0.07$ \\
LV dP/dt $\min (\mathrm{mmHg} / \mathrm{s})$ & $1470 \pm 406$ & $0.92 \pm 0.10$ & $0.98 \pm 0.17$ & $0.93 \pm 0.05$ \\
Tau (ms) & $26 \pm 6$ & $1.07 \pm 0.08$ & $1.03 \pm 0.13$ & $1.04 \pm 0.11$ \\
LV ES pressure $(\mathrm{mmHg})$ & $80 \pm 16$ & $0.98 \pm 0.03$ & $0.96 \pm 0.06$ & $0.99 \pm 0.06$ \\
LV ED pressure $(\mathrm{mmHg})$ & $8 \pm 5$ & $1.60 \pm 1.54$ & $1.51 \pm 1.19$ & $1.22 \pm 0.49$ \\
QRS duration $(\mathrm{ms})$ & $56 \pm 15$ & $1.60 \pm 0.28^{* \dagger}$ & $1.94 \pm 0.19^{*}$ & $1.67 \pm 0.17^{*}$ \\
\hline
\end{tabular}

All values during ventricular pacing are expressed relative to the corresponding value during SR. "best RV sep" refers to the data obtained during pacing at that RV septal site which resulted in each experiment in the best LV pump function; ES: end systolic, ED: end diastolic. *, + and $\neq p<0.05$ as compared to SR and LV apex and LV septum pacing, respectively. ANOVA for repeated measurements and post hoc test. $n=8$.

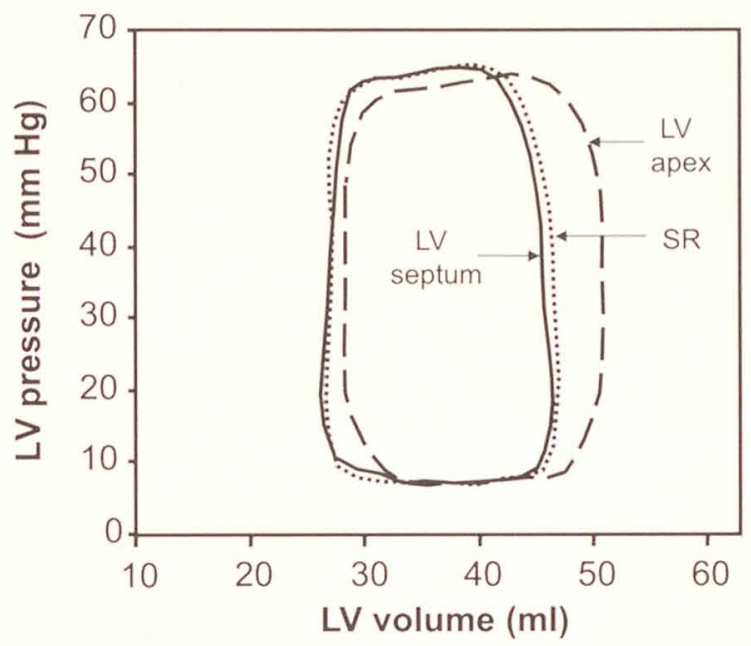

Figure 6. Pressure-volume diagrams during sinus rhythm (SR) and pacing at the LV apex and LV septal endocardium. 


\section{Discussion}

The present study, performed in canine hearts with normal ventricular conduction, demonstrate that $L V$ function is maintained at $S R$ level when pacing from the LV apex or $L V$ endocardial surface of the interventricular septum. Pacing at the RV apex and RV septum reduces $L V$ function significantly. The RV pacing site, which lead to the best LV function is not predicted by anatomical position or by QRS duration. The hemodynamic superiority of LV apex and LV septum pacing may be explained by a relatively physiological sequence of electrical activation when pacing from these sites.

The optimal pacing site

The favorable hemodynamic effect of LV apex pacing has been recognized before $8,9,12,13$, but the finding of the equally good performance during LV septal pacing is novel. The finding that pacing at these two sites did not reduce LV systolic function as compared to SR, even though activation was more asynchronous (wide QRS) and the $A V$ delay of pacing was relatively short, is interesting. This suggests that a good sequence of electrical activation is sufficient to allow for normal LV function. During normal SR the electrical impulse travels from the His bundle towards the apex, but this first part of ventricular activation concerns the rapid conduction system, not the working myocardium. In the LV the working myocardium is activated first at the LV endocardium in low septal and anterior free wall regions, so close to the LV apex and LV septal endocardium ${ }^{23,2-1}$. From these exits of the Purkinje system the LV activation wavefront travels from apex to base ${ }^{23,24}$. Pacing at the LV apex and the lower LV septal endocardium would thus provide a fairly physiological sequence of activation.

The importance of a proper sequence of activation is further supported by the finding that, in normal hearts, biventricular and multisite pacing does not improve LV function as compared with LV apex pacing alone (present study and refs 9,13), even though QRS duration is shorter in the former pacing modes. The situation might be different in pathological situations, because in dogs ${ }^{13}$ and patients with heart failure but still normal conduction ${ }^{27}$, biventricular pacing improved LV function beyond that during LV pacing alone. This might be explained by an increased heart size and, therefore, longer total conduction times in the failing hearts as compared to normal hearts.

RV septal pacing

The present study does not confirm earlier findings in dogs, showing that high septal pacing is associated with narrow QRS complexes, resynchronized LV contraction and improved IV function ${ }^{4,28.29}$. There are two possible explanations for this controversy. The three previous studies indicate to have paced at the very basal part of the septum in 
the vicinity of, or even within, the His bundle. They also have used screw-in electrodes rather than an endocardial approach, as in the present study. The use of the long screw may have enabled to deliver the impulses close to the Purkinje system, a prerequisite for quick spread of activation within the ventricular myocardium during ectopic stimulation ". Use of a long screw-in electrode to pace the His-bundle in patients also improved hemodynamics and clinical status significantly ${ }^{30}$.

In the present study we used pacing electrodes attaching to the RV endocardium, similar to the ones used in most clinical studies on the effect of high septal pacing. The variable results during RV septal pacing in the present study may explain the inconsistent findings in patients. Schwaab et al. found a positive correlation between QRS duration and LV function during RV septal and RV apex pacing, but in the majority of their patients QRS duration was longer and LV function was lower during RV septal than during RV apex pacing ${ }^{31}$. Other studies are less clear in describing the lead implant procedure and report either no difference between RV apex and RV septal pacing ${ }^{18-12}$ or a significant improvement in at least one hemodynamic variable during $R V$ septal pacing ${ }^{1+17}$. In some of these studies the alternative pacing site was referred to as the "RV oufflow tract". This nomenclature has lead to confusion, because some investigators considered this to be part of the high RV septum, whereas others meant the upper RV free wall and again other investigators did not specify the site. The upper RV free wall was not studied in the present study, because previous studies already showed that this "RV outflow tract" site deteriorated LV function significantly ${ }^{32}$.

The present study shows that some RV septal sites provide a sequence of activation, which maintains LV function fairly well. These sites are, however, are not consistently located at a certain level in the septum nor correlated with the narrowest paced QRS complexes. Therefore, hemodynamic monitoring would be required to find the best RV pacing site.

\section{Preference for LV sites}

The present study extends the finding in other studies that, in general, LV pacing maintains LV function better than RV pacing (for review see ref 33). The explanation for this phenomenon is not entirely clear. In the present study QRS duration tends to be shorter during pacing at the endocardial RV sites than at the epicardial LV sites. Also in other studies the best $L V$ function did not occur at the shortest QRS duration ${ }^{12,11,3.4 .}$. MRI tagging studies of contraction patterns showed similar degrees of mechanical asynchrony within the LV wall during RV apex and LV lateral wall pacing, but a larger number of hypocontractile regions during $R V$ apex pacing '. The latter might be due to a larger region of early-activated myocardium during RV apex pacing. Alternatively, an abnormal sequence of septal activation (from the RV to the LV side) could lead to abnormal septal motion and abnormal interventricular coupling, evidenced by paradoxical septal motion ${ }^{10,35}$. 
The better LV than RV performance has been found in closed chest conscious dogs " and in dogs ${ }^{13}$ and patients with heart failure and an opened thorax ${ }^{27}$ and thus appears to be a universal property. The short AV delay $(25 \mathrm{~ms})$, which was used to acquire complete ventricular capture, is not normal but well tolerated in healthy canine hearts, because LV function was similar during LV apex, LV septal pacing and during SR. Also end-diastolic pressure is not significantly different between $S R$ and ventricular pacing, indicating sufficient time for filling, despite lack of "atrial kick". The finding that the optimal (combination of) pacing site(s) was different in normal than in failing dog hearts ${ }^{13}$ and different in the absence and presence of coronary artery disease ${ }^{36}$ indicates that extrapolation of the data from the present study in non-failing dog hearts to patients should be done with care. Nevertheless, it appears worthwile to investigate whether LV apex and LV septal pacing has the same beneficial hemodynamic effects in patients with normal ventricular conduction systems. Improved hemodynamic function during pacing in bradycardia patients is desirable in the light of the increasing evidence that chronic ventricular pacing leads to acute and chronic deterioration of cardiac structure and function ${ }^{3,5-7}$, increased risk for development of heart failure in sick sinus syndrome patients ${ }^{37}$ and increased risk of cardiac death in heart failure patients ${ }^{38}$ and in patients over 70 years of age ${ }^{39}$. Because the present study indicates the importance of a good sequence of activation for proper ventricular function, its data do not permit to predict a possible beneficial effect of LV apex and LV septum pacing in patients with intrinsic conduction system disease.

With the currently available pacing electrodes the LV apex could be reached using the trans-coronary venous approach, if the lead can be advanced far enough. Alternatively, a minimally invasive thoracotomy can be used to place the lead at the LV apex. The LV septal endocardium may become an attractive site, because it can be reached when using the conventional transvenous route towards the RV cavity followed by a trans-ventricular-septal approach. Such approach would require the development of a dedicated delivery system, facilitating penetration of the interventricular septum. If only the tip of this lead is in contact with the blood in the LV cavity thromboembolic complications are unlikely.

\section{Conclusions}

In canine hearts with normal ventricular conduction LV apex and LV septal pacing result in significantly better $L V$ function than conventional $R V$ apex pacing. Pacing at some RV septum sites also results in fairly well maintained LV function, but these sites can only be found using hemodynamic monitoring. 


\section{References}

1. Wyman BT, Hunter WC, Prinzen FW, et al. Mapping propagation of mechanical activation in the paced heart with MRI tagging. Am / Physiol. 1999;276:H881-H91.

2. Kosowsky BD, Scherlag BI, Damato AN. Re-evaluation of the atrial contribution to ventricular function. Am / Cardiol. 1968:21:518-24.

3. Nielsen JC, Boetcher M, Toftegaard Nielsen T, et al. Regional myocardial blood flow in patients with sick sinus syndrome randomized to long-term single chamber atrial or dual chamber pacing-effect of pacing mode and rate. I Am Coll Cardiol. 2000;35:1453-61.

4. Rosenqvist $M$, Bergfeldt $L$, Haga $Y$, et al. The effect of ventricular activation sequence on cardiac performance during pacing. Pacing Clin Electrophysiol 1996;19:1279-87.

5. van Oosterhout MFM, Prinzen FW, Arts $T$, et al. Asynchronous electrical activation induces inhomogeneous hypertrophy of the left ventricular wall. Circulation 1998;98:588-95.

6. Tantengco MV, Thomas RL, Karpawich PP. Left ventricular dysfunction after long-term tight ventricular apical pacing in the young. I Am Coll Cardiol. 2001;37:2093-100.

7. Karpawich PP, Justice CD, Cavitt DL, et al. Developmental sequelae of fixed-rate ventricular pacing in the immature canine heart: An electrophysiologic, hemodynamic and histopathologic evaluation. Eur Heart J. 1990;119:1077-83.

8. Lister JW, Klotz DH, Jomain SL, et al. Effect of pacemaker site on cardiac output and ventricular activation in dogs with complete heart block. Am / Cardiol. 1964;14:494-503.

9. Tyers GFO. Comparison of the effect on cardiac function of single-site and simultaneous multiple site ventricular stimulation after A-V block. / Thor Cardiovasc Surg. 1970;59:211-7.

10. Little WC, Reeves RC, Arciniegas ), et al. Mechanism of abnormal interventricular septal motion during delayed left ventricular activation. Circ Res. 1982;65:1486-90.

11. Rosencivist $M$, Isaaz $K$, Botvinick $E H$, et al. Relative importance of activation sequence compared to atrioventricular synchrony in left ventricular function. Am / Cardiol. 1991;67:148-56.

12. Prinzen FW, van Oosterhout MFM, Vanagt WYR, et al. Optimization of ventricular function by improving the activation sequence during ventricular pacing. Pacing Clin Electrophysiol. 1998;21: 2256-60.

13. Fei L, Wrobleski D, Groh W, et al. Effects of multisite ventricular pacing on cardiac function in normal dogs and dogs with heart failure. / Cardiovasc Electrophysiol. 1999;10:935-46.

14. Giudici $M$, Thornburg G, Buck D, et al. Comparison of right ventricular outflow tract and apical lead permanent pacing on cardiac output. Am / Cardiol. 1997;79:209-12.

15. de Cock CC, Meyer A, Kamp O, et al. Hemodynamic benefits of right ventricular outflow tract pacing: comparison with right ventricular apex pacing. Pacing Clin Electrophysiol. 1998;21:536-41.

16. Mera $F$, DeLurgio DB, Patterson RE, et al. A comparison of ventricular function during high right ventricular septal and apical pacing after his-bundle ablation for refractory atrial fibrillation. Pacing Clin Electrophysiol. 1999;22:1234-9.

17. Kolettis TM, Kyriakides ZS, Tsiapras $D$, et al. Improved left ventricular relaxation during short-term right ventricular outflow tract compared to apical pacing. Chest. 2000;117:60-4.

18. Barold SS, Linhart JW, Hildner FJ, et al. Hemodynamic comparison of endocardial pacing of outiflow and inflow tracts of the right ventricle. Am / Cardiol. 1969;23:697-701.

19. Buckingham TA, Candinas R, Schlapfer l, et al. Acute hemodynamic effects of atrioventricular pacing at different sites in the right ventricle individually and simultaneously. Pacing Clin Electrophysiol. 1997; 20:909-15.

20. Gold MR, Shorofsky SR, Metcalf MD, et al. The acute hemodynamic effects of right ventricular septal pacing in patients with congestive heart failure secondary to ischemic or idiopathic dilated cardiomyopathy. Am / Cardiol. 1997;79:679-81.

21. Blanc Jl, Etienne $Y$, Gilard $M$, et al. Evaluation of different ventricular pacing sites in patients with severe heart failure: results of an acute hemodynamic study. Circulation. 1997;96:3273-7.

22. Victor $F$, Leclercq $C$, Mabo $P$, et al. Optimal right ventricular pacing site in chronically implanted patients: a prospective randomized crossover comparison of apical and outílow tract pacing. / Am Coll Cardiol. 1999;33:311-6. 
23. Durrer D, van Dam RT, Freud GE, et al. Total excitation of the isolated human heart. Circulation. 1970;41:899-912.

24. Spach MS, Barr RC. Ventricular intramular and epicardial potential distributions during ventricular activation and repolarization in the intact dog. Circ Res. 1975;37:243-57.

25. Myerburg RJ, Nilsson K, Gelband $\mathrm{H}$. Physiology of canine intraventricular conduction and endocardial excitation. Circ Res. 1972;30:217-43.

26. Steendijk P, Baan J. Comparison of intravenous and pulmonary artery injections of hypertonic saline for the assessment of conductance catheter parallel conductance. Cardiovasc Res. 2000;46:82-9.

27. Saxon LA, Kerwin WF, Cahalan MK, et al. Acute effects of intraoperative multisite ventricular pacing on left ventricular function and activation/contraction sequence in patients with depressed ventricular function. / Cardiovasc Electrophysiol. 1998;913-21.

28. Karpawich PP, Justice $C D$, Chang $C-H$, et al. Septal ventricular pacing in the immature canine heart: $A$ new perspective. Am Heart /. 1991;121:827-33.

29. Takagi $Y$, Dumpis $Y$, Usui A, et al. Effects of proximal ventricular septal pacing on hemodynamics and ventricular activation. Pacing Clin Electrophysiol. 1999;22:1777-81.

30. Deshmukh P, Casavant DA, Romanyshyn $M$, et al. Permanent, direct his-bundle pacing. A novel approach to cardiac pacing in patients with normal his-purkinje activation. Circulation. 2000;101: 869--77.

31. Schwaab B, Frohlig G, Alexander C, et al. Influence of right ventricular stimulation site on left ventricular funrction in atrial synchronous ventricular pacing. I Am Coll Cardiol. 1999;33:317-23.

32. Prinzen FW, Augustijn $\mathrm{CH}$, Arts T, et al. Redistribution of myocardial fiber strain and blood flow by asynchronous activation. Am / Physiol. 1990;259:H300-H8.

33. Prinzen FW, Peschar M. Relation between the pacing induced sequence of activation and left ventricular pump function in animals. Pacing Clin Electrophsyiol. 2002;25:484-98.

34. Park RC, Little WC, O'Rourke RA. Effect of alteration of left ventricular activation sequence on the left ventricular end-systolic pressure-volume relation in closed-chest dogs. Circ Res. 1985;57:706-17.

35. Kingma I, Tyberg JV, Smith ER. Effects of diastolic transseptal pressure gradient on ventricular septal position and motion. Circulation. 1983;68:1304-14.

36. Raichlen IS, Campbell FW, Edie RN et al. The effect of the site of placement of temporary epicardial pacemakers on ventricular function in patients undergoing cardiac surgery. Circulation. 1984:70; $118-23$.

37. Sweeney MO, Hellkamp AS, Greenspon Al, et al. Effect of pacing mode and cumulative percent time ventricular paced on heart failure in patients with sick sinus synchrome and baseline $Q R S$ duarion $<120$ milliseconds in MOST. Pacing Clin Electrophysiol. 2002;25:561.

38. Saxon LA, Stevenson WG, Middlekauff HR, et al. Increased risk of progressive hemodynamic deterioration in advanced heart failure patients requiring permanent pacemakers. Am Hearl ). 1993;125: 1306-10.

39. Santini $M$, Alexidou $G$, Ansalone $G$, et al. Relation of prognosis in sick sinus syndrome to age, conduction defects and modes of permanent cardiac pacing. Am / Cardiol. 1990;65:729-35. 


\section{CHAPTER 8}

\section{General discussion}




\section{Introduction}

The main theme of this thesis is myocardial adaptation of structure, contractility and electrophysiology in bradycardia induced volume overload and its reversibility upon pacing at physiological heart rate. As such, the thesis adds information to the relatively limited literature on reversibility of myocardial remodeling. The studies presented in this thesis focus on volume overload hypertrophy, as induced by atrio-ventricular (AV) block. This type of hypertrophy was chosen, because it can be easily reversed by cardiac pacing, without the necessity of pharmacological or surgical intervention. Volume overload hypertrophy is often regarded to be less dangerous than pressure overload hypertrophy. The results show that in dogs chronic volume overload is not completely without harm, because repolarization is prolonged fairly soon after onset of AV-block and ventricular hypertrophy and dilatation are progressive until at least 16 weeks of AV-block. In this model of hypertrophy, LV function is initially overcompensated, but normalizes thereafter. Nevertheless, clinical signs of heart failure remain absent in the majority of the dogs.

In our model of bradycardia induced volume overload myocardial structure and contractile function are reversible when after 8 weeks of AV-block heart rate is normalized. Electrical remodeling, however, is not reversible, which is of great concern because prolongation of repolarization is associated with an increased incidence of arrhythmias ${ }^{1-4}$.

AV-block is generally treated by ventricular pacing. Ventricular pacing, however, induces abnormal electrical activation, which leads to reduced cardiac pump function ${ }^{3-7}$. We show that the choice of a good pacing site, like the LV septum or LV apex, can favor cardiac pump function. In chronic AV-block biventricular pacing slightly enhances structural, but not contractile and electrical remodeling, as compared to RV apex pacing.

Below we will discuss the main findings of the present thesis with respect to ventricular remodeling, reverse remodeling and pacing.

\section{Remodeling}

This thesis has extended our knowledge on the evolution of remodeling processes in the canine model of AV-block induced volume overload. The data on the time dependent structural, electrophysiological and contractile remodeling, as known from the present and previous studies, are summarized in Table 1. 
Table 1.

Remodeling during AV-block.

\begin{tabular}{|c|c|c|c|c|c|c|c|}
\hline & AAVB & Wk 2 & Wk 4 & Wk 6 & Wk 8 & Wk 16 & Ref. \\
\hline \multicolumn{8}{|l|}{ Structural } \\
\hline \multicolumn{8}{|l|}{ Geometry } \\
\hline LV/BW & & & $\uparrow$ & $\uparrow$ & $\uparrow$ & $\uparrow \uparrow$ & chap 5, ref 4 \\
\hline LV myocyte width & & & & $=$ & & $=$ & chap 5 , ref 51 \\
\hline LV myocyte length & & & & $\uparrow$ & & & ref 51 \\
\hline LV length (MRI) & & $\uparrow$ & & & & & ref 17 \\
\hline I.V collagen fraction & & & & $=$ & & $=$ & chap 5 , ref 4 \\
\hline LV cavity volume & & $\uparrow$ & $\uparrow$ & $\uparrow$ & $\uparrow$ & $\uparrow \uparrow$ & chap 3 \\
\hline LV cavity/wall ratio & & & & & $\uparrow$ & $\uparrow \uparrow$ & chap 3 \\
\hline $\mathrm{RV} / \mathrm{BW}$ & & $\uparrow$ & $\uparrow$ & $\uparrow$ & $\uparrow$ & $\uparrow$ & chap 5 , refs 4,17 \\
\hline \multicolumn{8}{|l|}{ Molecular } \\
\hline$I_{\text {Nex }}$ current & & & & & $\uparrow$ & & ref 22 \\
\hline NCX protein & & & & $=$ & & $=$ & chap 3 \\
\hline SERCA protein & & & & $=$ & & $=$ & chap 3 \\
\hline SERCANNCX protein ratio & & & & $=$ & & $\downarrow$ & chap 3 \\
\hline$I_{t,}$ current & & & & & $=$ & & refs 40,52 \\
\hline $\mathrm{I}_{\mathrm{K}_{2}}$ current & & & & & $\downarrow$ & & refs 40,52 \\
\hline $\mathrm{I}_{\mathrm{K}_{\mathrm{r}}}$ current & & & & & $\downarrow$ & & refs 40,52 \\
\hline ANF mRNA & & & & $=$ & & $=$ & refs 4,25 \\
\hline \multicolumn{8}{|l|}{ Neurohumoral } \\
\hline Plasma ANF & $=$ & $\uparrow$ & $=$ & $=$ & $=$ & & ref 4 \\
\hline Plasma Angiotensin II & $=$ & $\uparrow$ & $=$ & $=$ & $=$ & & ref 4 \\
\hline Plasma Norepinephrine & $=$ & $=$ & $\uparrow$ & $=$ & $=$ & & $\operatorname{ref} 4$ \\
\hline Plasma Aldosteron & $=$ & $=$ & $=$ & $=$ & $=$ & & $\operatorname{ref} 4$ \\
\hline \multicolumn{8}{|l|}{ Electrophysiological } \\
\hline QT-time & $\uparrow$ & $\uparrow \uparrow$ & $\uparrow \uparrow$ & $\uparrow \uparrow$ & $\uparrow \uparrow$ & $\uparrow \uparrow$ & chap 5, refs $4,14,15,17$ \\
\hline QT,-time & $=$ & $\uparrow$ & $\uparrow$ & $\uparrow$ & $\uparrow$ & $\uparrow$ & chap 5, refs 14,15 \\
\hline LV APD & $\uparrow$ & $\uparrow \uparrow$ & $\uparrow \uparrow$ & $\uparrow \uparrow$ & $\uparrow \uparrow$ & $\uparrow \uparrow$ & chap 5 , refs $4,14,15$ \\
\hline RV APD & $\uparrow$ & $\uparrow \uparrow$ & $\uparrow \uparrow$ & $\uparrow \uparrow$ & $\uparrow \uparrow$ & $\uparrow \uparrow$ & chap 5 , refs $4,14,15$ \\
\hline$\triangle A P D$ & $=$ & & & $\uparrow$ & & & refs $4,14,15$ \\
\hline \multicolumn{8}{|l|}{ Contractile } \\
\hline LV SV & $\uparrow$ & & & $\uparrow \uparrow$ & & & ref 14 \\
\hline LV CO & $\downarrow$ & & & $=$ & & $=$ & chap 3 , ref 14 \\
\hline LV ED pressure & $=/ \uparrow$ & & & $=$ & & $=$ & chap 3, refs 14,15 \\
\hline LV ES pressure & $=$ & & & $\uparrow$ & & & refs 14,15 \\
\hline $\mathrm{LV} \mathrm{dP} / \mathrm{dt} \mathrm{t}_{\max }$ & $=$ & $\uparrow$ & & $\uparrow$ & & $\uparrow /=$ & chap 3, refs $14,15,53$ \\
\hline LV FFR intercept & & & & $\uparrow$ & & $=$ & chap 3 , ref 14 \\
\hline LV FFR slope & & & & $\downarrow$ & & $\downarrow$ & chap 3 , ref 14 \\
\hline
\end{tabular}

$I_{\text {NCX: }}:$ NCX current, $I_{t o}$ : transient outward current, $I_{K_{S}}$ : slow delayed rectifier current, $I_{k r}:$ rapid delayed rectifier current, $\triangle A P D$ : LV-RV APD, SV: stroke volume, CO: cardiac output, ED: end-diastolic, ES: end-systolic and FFR: force-frequency relation, $\uparrow$ increased, $\downarrow$ decreased and $=$ no change. 


\section{Structural remodeling}

AV-block leads to structural remodeling, as evidenced by a $~ 30 \%$ increase in LV wall mass, which is seen within $\sim 6$ weeks (chapter 3 and 5). Structural remodeling shows progression till at least 16 weeks. LV cavity volume increases by $~ 30 \%$ within 6 weeks of AV-block and increases further till $\sim 60 \%$ above baseline level after 16 weeks (chapter 3). These observations were made during serial measurements within the same animal, in contrast to most other studies that used post mortem values obtained from different groups of animals ${ }^{8-11}$. The AV-block induced increase in cardiac mass is reached by elongation of cardiomyocytes, rather than through an increase in cell width (chapter 5).

The levels of most neurohormones show a transient increase, with a peak between 2-4 weeks of AV-block and normalize after 6 weeks ${ }^{4}$. In contrast, aortic banding in rats, plasma levels of norepinephrine and angiotensin II are still elevated after 8 weeks ${ }^{12}$.

\section{Electrical remodeling}

Acutely after the creation of AV-block repolarization, as measured by QT-time in the surface ECG (chapter 5) and by LV and RV monophasic action potentials, is prolonged 13,14 . This is exclusively due to the change in heart rate, since $Q T_{c}$-time is not increased. A further increase in QT-time occurs fast within 2 weeks of AV-block and is associated with an increase in $\mathrm{QT}_{\mathrm{c}}$-time of $\sim 20 \%$ (electrical remodeling, chapter 5). Electrical remodeling remained stable up to 16 weeks of AV-block. Prolongation of repolarization is more pronounced in chronic AV-block than in other models of cardiac hypertrophy 9,15 . The relative changes in repolarization after AV-block as found in chapter 5 are smaller than those in previous studies from our group ${ }^{4,13,1+1,16}$. This could be due to differences in anesthetics used, i.e. sufentanyl/midazolam infusion (present thesis) versus halothane inhalation. It is known that this type of anesthesia prolongs repolarization ${ }^{17}$.

\section{Contractile remodeling}

We used the force-frequency relation as a measure of contractile function. The slope of this relation is flat in the normal heart, but becomes negative in the chronic AV-block heart (chapter 3), as it does in heart failure ${ }^{18-20}$. Essential is that the $y$-axis (force-axis) intercept is increased in AV-block and decreased in failing hearts. The latter implies that force is depressed at higher heart rates. In our studies the increased intercept is expressed as a $\sim 60 \%$ larger $\mathrm{LV} \mathrm{dP/dt}$ max at low heart rate (idioventricular rhythm, chapter 3). Previous studies from our group reported an increase of $-100 \%{ }^{13}$ but in these

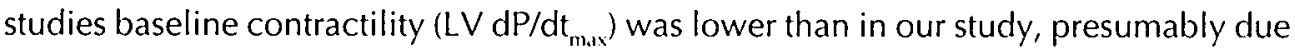
to the halothane anesthesia (see above). 
The increased contractility at idioventricular rhythm after 8 weeks of AV-block is associated with increased intracellular $\mathrm{Ca}^{2+}$ levels ${ }^{21}$. Furthermore, cellular studies confirmed this negative force-frequency relation and demonstrated an increased NCX current at this time point ${ }^{21}$. However, we found no changes in the absolute protein content of NCX (chapter 3), suggesting altered regulation of the NCX exchanger at that time.

After 16 weeks of AV-block, the return of LV dP/dt max $_{\text {max }}$ to normal and the increase of end-diastolic volume indicate that the hypercontractile phase is over (chapter 3). The absence of pulmonary edema and ascites, LV end-diastolic pressures over $20 \mathrm{mmHg}$ (chapter 3 and refs 22,23) and ANF expression ${ }^{4,2-4}$ indicate that heart failure does not (yet) occur in this model.

The lower contractility at 16 than at 6 weeks of AV-block, which is also represented by a lower $y$-axis intercept of the force-frequency relation, is associated with $\sim 30 \%$ decrease in SERCANNCX protein ratio (chapter 3), suggesting that the reduction of SERCANNCX leads to compromised $\mathrm{Ca}^{2+}$ handling. The observation that the slope of the force-frequency relation is equally negative at 6 and 16 weeks of AV-block, suggests that the changed NCX current or SERCA/NCX protein ratio does not contribute (chapter 3 ). While a negative force-frequency relation is often associated with heart failure, the present study shows that it can also occur in compensated stages of hypertrophy.

\section{Metabolic remodeling}

Metabolic remodeling in AV-block hearts is characterized by increased activity of several enzymes involved in myocardial energy metabolism (chapter 4). The functional importance of these findings is not well understood. This increase in enzyme activity could be a physiological adaptation to the larger amount of work per heartbeat in AV-block. In pressure overload hypertrophy metabolic remodeling is strikingly different from that in volume overload hypertrophy because in the former type enzyme activities are lower. Because the degree of hypertrophy is similar in both groups, the type of LV hypertrophy appears to determine metabolic remodeling (chapter 4). Moreover, asymmetrical hypertrophy, induced by LV pacing, results in comparable enzyme activities in hypertrophied and non-hypertrophied regions, implying a role for systemic factors. In contrast to substrate uptake studies in vivo, our in vitro enzyme activities do not show a shift from fatty acid to carbohydrate utilization, neither in volume nor in pressure overload hypertrophy.

\section{Concept of remodeling}

Until recently it was more or less accepted that hypertrophy was the cause of electrical and contractile remodeling (Figure 1A). Our findings, presented in chapters 3 and 5, however, show that the three remodeling processes have a different time path. Electrical 
A

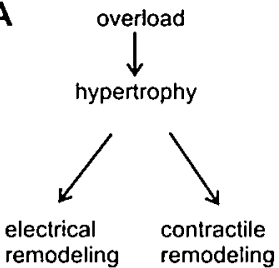

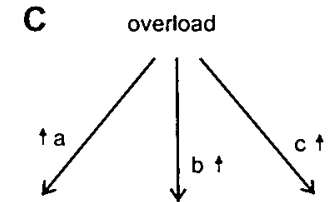

electrical structural contractile remodeling remodeling remodeling

$a \neq b \neq c$

B

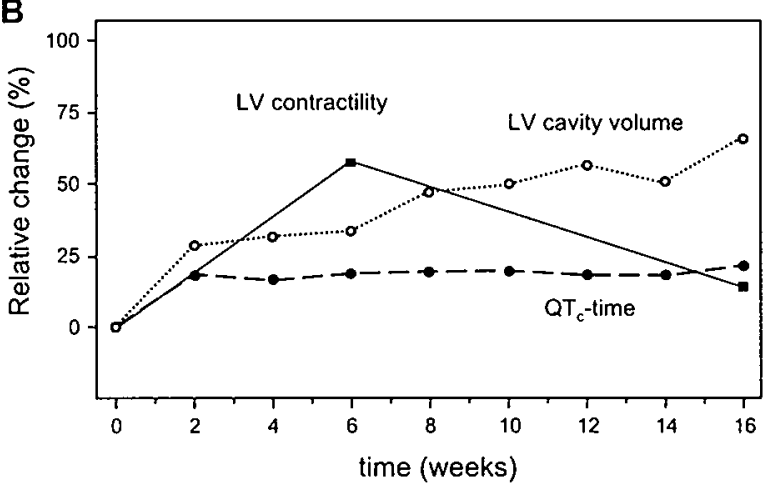

Figure 1. Schematic representation of conventional mechanisms of remodeling (A). Illustration of structural (LV cavity volume), contractile (LV contractility) and electrical remodeling (QT,-time) derived from chapter 3,5 and 6 (B) and proposed mechanisms of remodeling $(C)$ after volume overload due to AV-block. $a, b$ and $c$ represent independent factors leading to remodeling $(\uparrow)$.

remodeling is completed fairly soon after AV-block ( $\leq 2$ weeks), while structural remodeling is slower and progressive. In contrast, contractile remodeling has a biphasic character (Figure 1B). This leads to the concept that volume overload stimulates different factors, i.e. factor $\mathrm{a}, \mathrm{b}$ and $\mathrm{c}$, which on their turn independently induce electrical, structural and contractile remodeling (Figure 1C). Identification of these factors is a major research challenge for the near future, which would possibly allow new therapeutic strategies.

\section{Reverse remodeling}

\section{Reverse structural remodeling}

In dogs with AV-block normalization of heart rate, and hence, of (end-diastolic) LV volume, leads to almost complete regression of cardiac hypertrophy (chapter 5 ). This 
reverse structural remodeling seems to be independent of the pacing site since both $R V$ apex and biventricular pacing lead to a similar degree of regression (chapter 6).

The finding that normalization of heart rate by means of asynchronous electrical activation of the ventricle causes almost complete regression of hypertrophy is, at least to some extent remarkable, because asynchronous electrical activation at physiological heart rate in hearts without existing hypertrophy induces regional hypertrophy, especially in late-activated regions. This was observed in both chronic left bundle branch block ${ }^{25}$ and chronic LV pacing ${ }^{26}$. In hearts with chronic AV-block the hypertrophy reducing effect of normalization of heart rate is apparently stronger than the hypertrophy inducing effect of asynchronous activation. A similar observation was made in hearts with pressure overload hypertrophy, where chronic RV apex pacing did not lead to more pronounced regional hypertrophy ${ }^{27}$.

Compared to other models of hypertrophy, reverse structural remodeling in the AV-block model occurs fast. In pressure overload, due to aortic banding or hypertension, complete regression of hypertrophy is attained after only 3-6 months $9,15,23$, whereas regression of hypertrophy in our AV-block model is quick and almost complete within 8 weeks of pacing. In patients hypertrophy due to hypertension, is reversed after $\sim 6$ months of treatment with ACE-inhibitors ${ }^{29,30}$, while after aortic valve replacement regression of hypertrophy can take up to 8 years ${ }^{31.32}$.

The asymmetry in wall mass between septum and LV free wall after chronic RV apex pacing in AV-block is presumably due to the redistribution of workload ${ }^{26,33}$. Due to asynchronous activation, the septum is unloaded during early activation, so that workload in that particular area is decreased. This results in more regression of hypertrophy in the early-activated septum than in the late-activated LV free wall. A comparable degree of asymmetry was found after left bundle branch block $(5-10 \%)^{25}$. The more symmetric regression of hypertrophy after biventricular pacing can be logically explained by a more uniform workload during simultaneous left and right ventricular activation ${ }^{3.4}$.

In patients requiring a pacemaker for treatment of bradycardia it is not known whether reverse remodeling occurs. Therefore, 2D-echocardiographic images of patients with acquired complete AV-block have been analyzed in cooperation with $\mathrm{Dr}$. M.D. Gammage (Queen Elizabeth Hospital, Birmingham, United Kingdom). Hearts were paced at the RV apex or RV septum during 6 months, with a dual chamber pacemaker. Preliminary data of a small subset of patients $(n=12$, age 58-93) reveal that after 1 and 6 months of pacing changes in LV cavity volume ranged from $-45 \%$ to $+20 \%$ and from $-26 \%$ to $+112 \%$, respectively (Figure 2 ). Similarly, at these time points changes in LV wall volume ranged from $-51 \%$ to $+20 \%$ and from $-26 \%$ to $+66 \%$, respectively. Regression of hypertrophy, if any, seems to be transient, because both $\mathrm{LV}$ mass and cavity volume were slightly reduced in half of the patients after 1 month of pacing, but increased again during the subsequent 5 months of pacing. A possible explanation why after onset of pacing LV mass in patients does not decrease as 

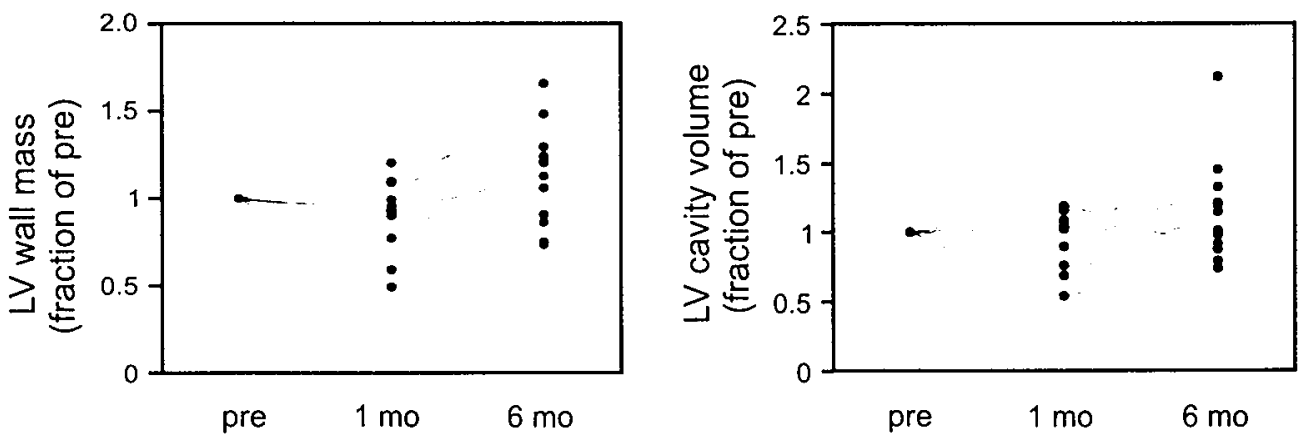

Figure 2. Changes in LV wall mass and LV cavity volume after 1 and 6 months of pacing, relative to pre-implant values in patients with acquired complete AV-block.

consistent as in dogs with AV-block includes the progression of underlying disease, the absence of hypertrophy or the duration of the volume overload.

\section{Reverse contractile remodeling}

In this thesis we clearly show that in volume overload hypertrophy due to AV-block in dogs, both RV apex and biventricular pacing lead to reverse contractile remodeling. Reverse contractile remodeling in volume overload hypertrophy is dependent on the model used. After closure of aorto-caval fistula in rats, reverse structural remodeling was accompanied by reversal of contractile remodeling ${ }^{\prime \prime}$. In contrast, mitral valve replacement in dogs with mitral regurgitation normalized contractile function, but not hypertrophy ${ }^{35}$. After treatment of hypertensive patients with a calcium antagonist reverse structural remodeling was accompanied by normalization of systolic function 36. In contrast, removal of the aortic band in dogs resulted in significant regression of pressure overload hypertrophy, but cardiac function remained unchanged ${ }^{28}$. Finally, in a study on heart failure patients in whom the LV was supported by an assist device, reverse structural remodeling was associated with reverse contractile remodeling ${ }^{37}$.

After 8 weeks of AV-block followed by 8 weeks of pacing not only the absolute

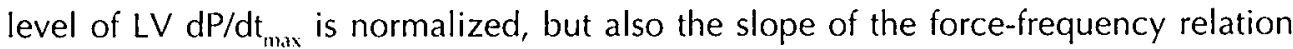
(chapter 6). Because the negative force-frequency relation is associated with an increased NCX current ${ }^{21}$, normalization of the force-frequency relation might imply normalization of the (regulation of the) NCX current. That reverse molecular remodeling is indeed possible, is shown after 20 days of LV support by an assist device, when regression of hypertrophy was found to be associated with upregulation of SERCA mRNA ${ }^{38}$. 
Despite the (almost) complete reverse structural and contractile remodeling, restoration of heart rate to physiological levels does not reverse the electrical remodeling (chapter 5). It is remarkable that reverse structural and electrical remodeling do not go hand in hand, because structural and electrical remodeling develop almost simultaneously after onset of AV-block. Reverse electrical and contractile remodeling are dissociated as well, which indicates that $\mathrm{Ca}^{2+}$ fluxes cannot be held responsible for the absence of reverse electrical remodeling.

The prolongation of repolarization in chronic AV-block is associated with an increased NCX current ${ }^{21}$ and a decreased $I_{K}$ current ${ }^{39}$. Since upon pacing the force-frequency relation normalizes (chapter 6 ) we assume that the NCX current normalizes also. Therefore, since repolarization remains prolonged after pacing, we postulate that the decreased $I_{K}$ current is the most likely candidate for the absence of reverse electrical remodeling. Interventions aimed at increasing this current will reveal definitive answers.

Sustained prolonged repolarization has not only been documented through biweekly measured QT-times but also by measuring the monophasic action potential duration at week 8 and 16 (chapter 5). Assessment of prolonged repolarization from QT-time can, in principle, be confounded by the abnormal sequence of activation due to ventricular pacing. However, at week 8 and 16 QT-time was determined both during idioventricular rhythm and ventricular pacing. The effect of changing heart rate between idioventricular rhythm and pacing was corrected using van de Water's equation ${ }^{40}$. Also, pacing was performed at a fixed rate, i.e. at 100 beats $/ \mathrm{min}$. In none of these situations a decrease in QT-time was observed between week 8 and 16 . Evaluation of locally measured LV and RV monophasic action potentials does not reveal reverse electrical remodeling either (chapter 5). Moreover, it is rather unlikely that monophasic action potentials are confounded by the sequence of activation.

The experiments described in chapter 6 add further evidence to the irreversibility of electrical remodeling by demonstrating that this is not only the case after RV apex pacing, but also after biventricular pacing. Thus, also long term more synchronous sequence of activation does not lead to reverse electrical remodeling.

In contrast to our observations, mentioned above, regression of pressure overload hypertrophy after aortic valve replacement in patients with aortic stenosis is accompanied by reverse electrical remodeling ". After treatment with ACE-inhibitors in hypertensive patients, QT-time is decreased ${ }^{30,42}$. In these studies, however, the starting point of measurement is the moment of clinical intervention, therefore baseline electrophysiological and structural parameters are unfortunately absent. In a renovascular hypertension rabbit model of hypertrophy, ACE-inhibitor administration leads to regression of hypertrophy, which is also accompanied by reverse electrical 
remodeling ". However, it cannot be excluded that pharmacological intervention has a direct effect on cellular processes, including ion homeostasis.

In a feline model of aortic banding, reverse structural remodeling was associated with reverse electrical remodeling, but in this study reverse electrical remodeling was defined as a decreased incidence of arrhythmias. In this model repolarization was not prolonged ${ }^{15}$.

While no other study on reverse electrical remodeling in volume overload hypertrophy was found in literature, absence of reverse electrical remodeling has been reported by Kreher et al. in a model of aging rats ${ }^{13}$. After treating these animals with ACE-inhibitors, hypertrophy regressed but repolarization remained prolonged. A similar observation, where reverse structural remodeling was not associated with reverse electrical remodeling, has been reported in the MUSTIC trial on resynchronization therapy in patients with heart failure. Long-term biventricular pacing caused a reduction in LV cavity volume but did not change QT-time significantly (Daubert, unpublished results). Because prolonged repolarization is associated with increased incidence of arrhythmias, it is important to investigate whether in other forms of overload electrical remodeling can be reversed, or whether intervening at a different time point (earlier) or with different interventions is more successfull.

\section{Concept of reverse remodeling}

The above-mentioned observations indicate that reverse remodeling is not simply the mirror image of remodeling. Moreover, there is no single factor mediating reversibility of all remodeling processes: reverse electrical remodeling is clearly dissociated from the other processes (Figure 3). Whether reverse structural and contractile remodeling have a common factor remains to be investigated.

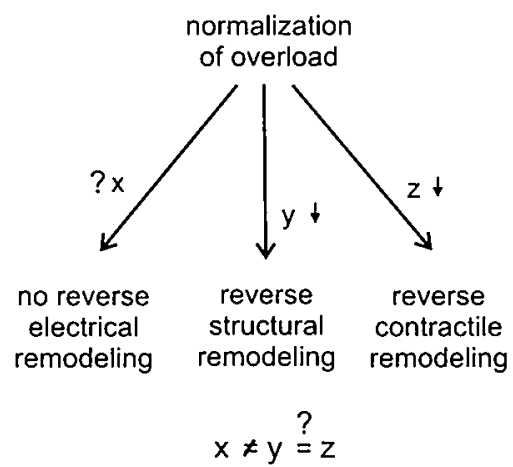

Figure 3. Schematic representation of propossed mechanisms of reverse remodeling after normalization of volume overload due to pacing. $x, y$ and $z$ represent independent factors leading to reverse remodeling $(\downarrow)$. It is not known whether factors $x, y$ and $z$ are equal to factors $a, b$ and $c$ mentioned in Figure 1. 


\section{Optimal pacing site}

While pacing site influences reverse structural remodeling to a minor extent, it does not seem to influence contractile and electrical remodeling in chronic AV-block, but it does influence LV pump function. We have shown that LV pump function is worst during pacing from the conventional RV apex compared to pacing from almost any other site. This is supported by various experimental studies (reviewed in chapter 2). Because it is presumably the abnormal sequence of activation, which leads to the impaired pump function, it is reasonable to suggest that pacing at a site, which leads to a physiological activation sequence, is hemodynamically preferable. The most obvious site, the His-bundle, is small and may be difficult to find, but once this is achieved, it leads to optimal LV function ${ }^{4.4}$. In chapter 7 is shown that pacing near the exit sites of the Purkinje system (LV apex and LV septum) also maintain LV function quite well. Several clinical studies investigated RV septal pacing as alternative for RV apex pacing, in half of the cases leading to a better function ${ }^{45-19}$. However, our detailed pressure-volume analyses do not confirm this difference between RV apex and RV septal pacing. In each dog an optimal RV septal pacing site is found, but the position of this site varies and can only be found with hemodynamic measurements (chapter 7).

As discussed above, asynchronous activation induces hypertrophy in non-hypertrophied hearts ${ }^{25,26}$ presumably due to loss of ventricular pump function. It is not known whether patients with acquired AV-block have hypertrophic hearts. The absence of hypertrophy and the asynchronous activation induced by ventricular pacing might explain the development of hypertrophy at least in part of these patients (Figure 2). Also, long-term ventricular pacing in patients with sick sinus syndrome has been associated with increased risks of development of heart failure and cardiac mortality ${ }^{50}$. The observation that these risks are lower in similar patients paced on the atrium " indicates the importance of proper activation sequence, not only for LV function, but also for better long-term prognosis. 


\section{References}

1. Kannel WB, Gordon T, Offutt D. Left ventricular hypertrophy by electrocardiogram. Prevalence, incidence, and mortality in the Framingham study. Ann Intern Med. 1969;71:89-105.

2. Messerli FH, Grodzicki T. Hypertension, left ventricular hypertrophy, ventricular arrhythmias and sudden death. Eur Heart 1. 1992;13 Suppl D:66-9.

3. Swynghedauw B, Chevalier B, Charlemagne D, et al. Cardiac hypertrophy, arrhythmogenicity and the new myocardial phenotype. Il. The cellular adaptational process. Cardiovasc Res. 1997;35:6-12.

4. Vos MA, de Groot SH, Verduyn SC, et al. Enhanced susceptibility for acquired Torsade de Pointes arrhythmias in the dog with chronic, complete AV block is related to cardiac hypertrophy and electrical remodeling. Circulation. 1998;98:1125-35.

5. Burkhoff D, Oikawa RY, Sagawa K. Influence of pacing site on canine left ventricular contraction. Am J Physiol. 1986;251:H428-35.

6. Park RC, Little WC, O'Rourke RA. Èffect of alteration of left ventricularactivation sequence on the left ventricular end-systolic pressure-volume relation in closed-chets dogs. Circ Res. 1985;57:706-717.

7. Prinzen FW, Van Oosterhout MF, Vanagt WY, et al. Optimization of ventricular function by improving the activation sequence during ventricular pacing. Pacing Clin Electrophysiol. 1998;21:2256-60.

8. Cooper G, Puga FJ, Zujko KJ, et al. Normal myocardial function and energetics in volume-overload hypertrophy in the cat. Circ Res. 1973;32:140-8.

9. Rials SJ, Wu $Y, X u X$, et al. Regression of left ventricular hypertrophy with captopril restores normal ventricular action potential duration, dispersion of refractoriness, and vulnerability to inducible ventricular fibrillation. Circulation. 1997;96:1330-6.

10. Gerdes AM, Clark LC, Capasso IM. Regression of cardiac hypertrophy after closing an aortocaval fistula in rats. Am / Physiol. 1995;268:H2345-51.

11. Yokoshiki $H$, Kohya $T$, Tomita $F$, et al. Restoration of action potential duration and transient outward current by regression of left ventricular hypertrophy. I Mol Cell Cardiol. 1997;29:1331-9.

12. Akers WS, Cross A, Speth R, et al. Renin-angiotensin system and sympathetic nervous system in cardiac pressure-overload hypertrophy. Am / Physiol Heart Circ Physiol. 2000;279:H2797-806.

13. de Groot $\mathrm{SH}$, Schoenmakers $M$, Molenschot $\mathrm{MM}$, et al. Contractile adaptations preserving cardiac output predispose the hypertrophied canine heart to delayed afterdepolarization-dependent ventricular arrhythmias. Circulation. 2000;102:2145-51.

14. van Opstal JM, Schoenmakers M, Verduyn SC, et al. Chronic amiodarone evokes no Torsade de Pointes arrhythmias despite QT lengthening in an animal model of acquired long-QT syndrome. Circulation. 2001;104:2722-7.

15. Rials S), $W u Y$, Ford $N$, et al. Effect of left ventricular hypertrophy and its regression on ventricular electrophysiology and vulnerability to inducible arrhythmia in the feline heart. Circulation. 1995;91: 426-30.

16. Verduyn SC, Ramakers C, Snoep G, et al. Time course of structural adaptations in chronic AV block dogs: evidence for differential ventricular remodeling. Am J Physiol Heart Circ Physiol. 2001;280: $\mathrm{H} 2882-90$.

17. Volders PGA, van Opstal JM, Stengl $M$, et al. Probing the contribution of $I_{k}$ to canine ventricular repolarization. Submitted.

18. Hasenfuss G, Holubarsch C, Hermann HP, et al. Influence of the force-frequency relationship on haemodynamics and left ventricular function in patients with non-failing hearts and in patients with dilated cardiomyopathy. Eur Heart 1. 1994;15:164-70.

19. Hasenfuss $G$, Reinecke $H$, Studer $R$, et al. Relation between myocardial function and expression of sarcoplasmic reticulum Ca" ${ }^{2 *}$-ATPase in failing and nonfailing human myocardium. Circ Res. 1994;75: 434-42.

20. Houser SR, Piacentino V, 3rd, Mattiello J, et al. Functional properties of failing human ventricular myocytes. Trends Cardiovasc Med. 2000;10:101-7.

21. Sipido KR, Volders $\mathrm{PG}$, de Groot $\mathrm{SH}$, et al. Enhanced $\mathrm{Ca}^{2 \cdot}$ release and $\mathrm{Na} / \mathrm{Ca}$ exchange activity in hypertrophied canine ventricular myocytes : potential link between contractile adaptation and arrhythmogenesis. Circulation. 2000;102:2137-44. 
22. Todaka K, Leibowitz D, Homma S, et al. Characterizing ventricular mechanics and energetics following repeated coronary microembolization. Am / Physiol. 1997;272:H186-94.

23. Lucas $\mathrm{CM}$, Cheriex $\mathrm{EC}$, van der veen $\mathrm{FH}$, et al. Imipramine induced heart failure in the dog: a model to study the effect of cardiac assist devices. Cardiovasc Res. 1992;26:804-9.

24. Peschar $M$. unpublished results.

25. Vernooy K, Verbeek XAAM, Cheriex EC, et al. Ventricular remodeling due to left bundle branch block: an echocardiographic study in dogs and patients. Pacing Clin Electrophysiol. 2002;24:528.

26. van Oosterhout MF, Prinzen FW, Arts T, et al. Asynchronous electrical activation induces asymmetrical hypertrophy of the left ventricular wall. Circulation. 1998;98:588-95.

27. van Oosterhoul MF, Arts T, Muijtjens AM, et al. Remodeling by ventricular pacing in hypertrophying dog hearts. Cardiovasc Res. 2001;49:771-778.

28. Ishihara K, Zile MR, Tomita $M$, et al. Left ventricular hypertrophy in a canine model of reversible pressure overload. Cardiovasc Res. 1992;26:580-5.

29. Mayet J, Shahi M, McGrath K, et al. Left ventricular hypertrophy and QT dispersion in hypertension. Hypertension. 1996;28:791-6.

30. Gonzalez Juanatey JR, Garcia Acuna JM, Pose A, et al. Reduction of QT and QTc dispersion during long-term treatment of systemic hypertension with enalapril. Am / Cardiol. 1998;81:170-4.

31. Gilchrist IC, Waxman HL, Kurnik PB. Improvement in early diastolic filling dynamics after aortic valve replacement. Am / Cardiol. 1990;66:1124-9.

32. Monrad ES, Hess OM, Murakami T, et al. Time course of regression of left ventricular hypertrophy after aortic valve replacement. Circulation. 1988;77:1345-55.

33. Prinzen FW, Augustijn $\mathrm{CH}$, Arts T, et al. Redistribution of myocardial fiber strain and blood flow by asynchronous activation. Am / Physiol. 1990;259:H300-8.

34. Wyman BT, Hunter WC, Prinzen FW, et al. Effects of single- and biventricular pacing on temporal and spatial dynamics of ventricular contraction. Am I Physiol Heart Circ Physiol. 2002;282:H372-9.

35. Nakano K, Swindle MM, Spinale F, et al. Depressed contractile function due to canine mitral regurgitation improves after correction of the volume overload. / Clin Invest. 1991;87:2077-86.

36. Habib GB, Mann DL, Zoghbi WA. Normalization of cardiac structure and function after regression of cardiac hypertrophy. Am Heart ). 1994;128:333-43.

37. Levin HR, Oz MC, Chen JM, et al. Reversal of chronic ventricular dilation in patients with end-stage cardiomyopathy by prolonged mechanical unloading. Circulation. 1995;91:2717-20.

38. Madigan JD, Barbone A, Choudhri AF, et al. Time course of reverse remodeling of the left ventricle during support with a left ventricular assist device. / Thorac Cardiovasc Surg. 2001;121:902-8.

39. Volders PGA, Sipido KR, Vos MA, et al. Downregulation of delayed rectifier $K^{\prime}$ currents in dogs with chronic complete atrioventricular block and acquired Torsades de Pointes. Circulation. 1999;100: $2455-2461$.

40. van de Water A, Verheyen I, Xhonneux R, et al. An improved method to correct the QT interval of the electrocardiogram for changes in heart rate. / Pharmacol Methods. 1989;22:207-17.

41. Darbar D, Cherry CJ, Kerins DM. QT dispersion is reduced after valve replacement in patients with aortic stenosis. Heart. 1999;82:15-8.

42. Karpanou EA, Vyssoulis GP, Psichogios A, et al. Regression of left ventricular hypertrophy results in improvement of QT dispersion in patients with hypertension. Am Heart 1. 1998;136:765-8.

43. Kreher $P$, Ristori MT, Corman B, et al. Effects of chronic angiotensin I-converting enzyme inhibition on the relations between ventricular action potential changes and myocardial hypertrophy in aging rats. I Cardiovasc Pharmacol. 1995;25:75-80.

44. Deshmukh P, Casavant DA, Romanyshyn $M$, et al. Permanent, direct His-bundle pacing: a novel approach to cardiac pacing in patients with normal His-Purkinje activation. Circulation. 2000;101: $869-77$.

45. Karpawich PP, Gates J, Stokes KB. Septal His-Purkinje ventricular pacing in canines: a new endocardial electrode approach. Pacing Clin Electrophysiol. 1992;15:2011-5.

46. Rosenqvist $M$, Bergfeldt $L$, Haga $Y$, et al. The effect of ventricular activation sequence on cardiac performance during pacing. Pacing Clin Electrophysiol. 1996;19:1279-86.

47. de Cock CC, Meyer A, Kamp O, et al. Hemodynamic benefits of right ventricular outflow tract pacing: comparison with right ventricular apex pacing. Pacing Clin Electrophysiol. 1998;21:536-41. 
48. Mera $F$, Delurgio DB, Patterson RE, et al. A comparison of ventricular function during high right ventricular septal and apical pacing after his-bundle ablation for refractory atrial fibrillation. Pacing Clin Electrophysiol. 1999;22:1234-9.

49. Buckingham TA, Candinas R, Schlapfer I, et al. Acute hemodynamic effects of atrioventricular pacing at differing sites in the right ventricle individually and simultaneously. Pacing Clin Electrophysiol. 1997;20: 909-15.

50. Greenspon AJ, Flaker G, Sweeney MO, et al. DDDR pacing reduces incidence of heart failure when compared to VVIR pacing in sinus node dysfunction. Pacing Clin Electrophysiol. 2002;24:553.

51. Nielsen JC, Andersen HR, Thomsen PE, et al. Heart failure and echocardiographic changes during long-term follow-up of patients with sick sinus syndrome randomized to single-chamber atrial or ventricular pacing. Circulation. 1998;97:987-95.

52. Volders PG, Sipido KR, Vos MA, et al. Cellular basis of biventricular hypertrophy and arrhythmogenesis in dogs with chronic complete atrioventricular block and acquired Torsade de Pointes. Circulation. 1998;98:1136 47.

53. Thomas GP, Vos MA, Antzelevitch C. The effect of volume overload hypertrophy on transmural distribution of the delayed rectifier $\left(I_{N}\right.$ and $I_{k,}$ ) and transient outward (Ito) currents in the canine heart. Pacing Clin Electrophysiol. 2001;24:597.

54. Wusten B, Flameng W, Schaper W. Cardiac function in the chronically volume-overloaded canine heart. Basic Res Cardiol. 1977;72:172-7. 


\section{SUMMARY}

Like any other muscle, the heart adapts its structure and function to changes in workload. While various remodeling processes are initially beneficial, on the long run they may become detrimental because adaptation is not only confined to muscle growth (structural remodeling), but also to disturbances in repolarization (electrical remodeling) and contractility (contractile remodeling). As a consequence ventricular remodeling may lead to increased incidence of arrhythmias, heart failure and sudden cardiac death. From clinical and experimental studies, much is known about the consequences of pressure overload but less about those of volume overload. Information on the reversibility of the various remodeling processes upon normalization of load is even more scarce.

In the present thesis remodeling is investigated in the dog with chronic volume overload due to complete atrio-ventricular (AV) block and reverse remodeling upon normalization of load by pacing at physiological heart rate. For this purpose, adult mongrel dogs are operated and their AV node is irreversibly damaged. This results in a heart rate of $\sim 40$ beats per minute (bradycardia).

Chapter 1 contains the introduction to the thesis. The background of the different types of remodeling (structural, contractile, electrical and metabolic remodeling) is discussed as well as their reversibility. In addition, the normal electrical activation of the heart is explained and the alterations in electrical activation during AV-block and during ventricular pacing are discussed. Finally, the goals of the thesis are formulated.

In chapter 2 an overview is given on the importance of the sequence of electrical activation during ventricular pacing and its effect on left ventricular performance. Pacing at the right ventricular apex, the conventional pacing site is associated with considerable depression of left ventricular function. This decrease is smaller when pacing from alternative sites, like left ventricular or multiple sites. However, pacing at all ventricular sites used until now, except the His-bundle, leads to an abnormal sequence of activation. Therefore, it seems worthwhile to search for pacing sites that mimic the physiological ventricular activation sequence and that result in an optimal left ventricular pump function.

Chapter 3 describes a study of structural and contractile remodeling during 16 weeks of bradycardia induced volume overload. Two phases were identified: up to 6 weeks and from 6 to 16 weeks of AV-block. In the first phase left ventricular wall mass and cavity volume increase quickly and left ventricular function is supranormal, as evidenced by increased contractility. This increase in contractility is much larger at the lower heart rates than at the higher heart rates, resulting in a negative slope of the 
force-frequency relation. In the second phase left ventricular performance decreases. This is demonstrated by the reduction in left ventricular contractility and the decreased $y$-axis intercept of the force-frequency relation, while the slope remains negative. The decrease in contractility between 6 and 16 weeks of AV-block is associated with a decreased ratio of the sarcoplasmic reticulum calcium ATPase (SERCA) and the sodium calcium exchanger (NCX), two proteins involved in calcium handling, and with progression of left ventricular cavity dilatation. Therefore, during 16 weeks of AV-block structural remodeling develops progressively while contractile remodeling has a biphasic character.

In chapter 4 the metabolic remodeling in global and regional hypertrophy of the canine heart is described. Global volume overload hypertrophy due to AV-block is compared to global pressure overload hypertrophy due to aortic banding and regional hypertrophy due to left ventricular pacing. As compared to control hearts, enzyme activities are generally increased in volume overload induced hypertrophy and decreased in pacing and pressure overload induced hypertrophy. In the asymmetrically hypertrophied left ventricle the distribution of the activities of metabolic enzymes is uniform. This suggests that systemic factors may play a role in the metabolic adaptation of hypertrophied myocardium. The data on the activity of the various enzymes do not support a shift from fatty acid to carbohydrate metabolism in these three models of hypertrophy.

In chapter 5 the effect of normalization of heart rate on reverse structural and reverse electrical remodeling is reported in dogs with chronic AV-block. After 8 weeks of AV-block the left ventricle is hypertrophied and dilated and repolarization is prolonged. In these animals physiological heart rate is now restored by pacing at the right ventricular apex for 8 weeks. This leads to initiation of regression of hypertrophy within 2 weeks of pacing and is almost complete after 8 weeks of pacing. However, electrical remodeling is not reversed: repolarization remains prolonged up to 8 weeks of pacing. Therefore structural and electrical remodeling appear closely associated after the increase in workload but they are dissociated upon normalization of workload.

Chapter 6 shows that beside structural remodeling, contractile remodeling is also reversible upon normalization of heart rate by ventricular pacing, not only left ventricular contractility, but also the slope of the force-frequency relation is normalized. Heart rate is normalized using either right ventricular or biventricular pacing, the latter leading to more synchronous activation of the left ventricle. Biventricular pacing leads to a slightly quicker and more uniform regression of hypertrophy than the former kind of pacing. Nevertheless, even after biventricular pacing repolarization remains prolonged. The findings of these studies in the AV-block model show a dissociation of reverse electrical and reverse structural and contractile remodeling upon normalization of load.

Chapter 7 describes the pacing site for optimal pump function in canine hearts with normal ventricular conduction. Left ventricular function is maintained at sinus rhythm level when pacing from the left ventricular apex or left ventricular septum. Pacing at the right ventricular apex and right ventricular septum reduce left ventricular function sig- 
nificantly. The right ventricular pacing site, which leads to the best left ventricular function, is not predicted by anatomical position or by QRS duration, but can only be found by hemodynamic monitoring. The hemodynamic superiority of left ventricular apex and left ventricular septum pacing may be explained by a relatively physiological sequence of electrical activation when pacing from these sites.

Finally, in chapter $\mathbf{8}$ the results of these studies are discussed in broader perspective. 



\section{SAMENVATTING}

Het hart is een holle spier die werkt als een pomp en alle organen in het lichaam van bloed voorziet. Net als iedere andere spier past het hart zich aan veranderde belasting aan. Extra belasting kan worden veroorzaakt doordat de bloeddruk hoog is (druk-overbelasting) of doordat een groter volume aan bloed rondgepompt moet worden (volume-overbelasting). In eerste instantie hebben aanpassingsprocessen tijdens overbelasting een gunstig effect, maar onder bepaalde omstandigheden kunnen zij nadelige gevolgen hebben, zoals hartritmestoornissen, hartfalen en plotse hartdood. Vanuit eerdere studies is relatief veel bekend over druk-overbelasting en veel minder over volume-overbelasting. Bovendien is er weinig bekend of het wegnemen van de overbelasting leidt tot herstel van de normale structuur en pompfunctie (terugaanpassing).

Het hart bestaan uit vier holtes: twee boezems (atria) en twee kamers (ventrikels). In rust pompt het hart pompt zo'n 80 keer per minuut. Hiervoor moet het hart eerst electrisch geprikkeld worden. Deze electrische prikkel onstaat automatisch in de rechterboezem en wordt via een geleidingssysteem aan de kamers doorgegeven. Wanneer er een onderbreking in dit geleidingssysteem tussen de boezems en de kamers onstaat, spreekt men over een atrio-ventrikulair (AV) blok. De electrische prikkel vanuit de rechterboezem komt dan niet in de kamers aan. Gelukkig kan het hart toch nog pompen omdat de kamers zelf een electrische prikkel op kunnen wekken. Dit gebeurt dan bij een hartritme van ongeveer 40 slagen per minuut (bradycardie). Dit kan tot gevolg hebben dat iemand zich gauw moe voelt, duizelingen heeft of flauw valt.

$\mathrm{Bij}$ iemand met AV-blok kan het normale hartritme hersteld worden met een pacemaker, een apparaatje dat een electrische prikkel aan het hart geeft. Een moderne pacemaker is klein (de helft van een luciferdoosje) en wordt onder de huid ingebracht. De pacemaker is met electroden aan het hart verbonden. Door te pacen kunnen de klachten door het trage ritme van het AV-blok opgeheven worden, maar de geleiding van de electrische prikkel binnen de kamers is hierdoor wel abnormaal, wat weer leidt tot abnormale samentrekking van het hart. Het is nog niet duidelijk wat de lange termijn effecten van pacen zijn, en wat de beste plaats is om de pace-electroden op het hart te bevestigen.

In dit proefschrift zijn aanpassingen ('remodeling') van de hartspier onderzocht die optreden als gevolg van een traag hartritme. Omdat het hart minder vaak pompt, moet het hart per slag meer bloed rondpompen, een vorm van volume-overbelasting. Het onderzoek is verricht in honden waarbij operatief AV-blok is gemaakt. Vervolgens is onderzocht ò en hoe terugaanpassingen ('reverse remodeling') verlopen als na 8 
weken AV-blok het hartritme weer genormaliseerd wordt d.m.v. een pacemaker, ook weer voor een periode van 8 weken.

Hoofdstuk 1 bevat de inleiding van dit proefschrift, waarin de verschillende typen aanpassingen worden besproken en wat hierover bekend is in de literatuur. Structurele aanpassingen hebben betrekking op zowel de holte van de linkerkamer als op de massa van de hartspier. Deze aanpassingen kunnen gemeten worden met echocardiografie. Als de massa van de hartspier toeneemt (hypertrofie), betekent dit dat de hartspiercel groter moet worden. De verhouding tussen eiwitten in de hartspiercel kan tevens veranderen. Dit geldt voor eiwitten in de calciumhuishouding (nodig voor het samentrekken (contractie) van het hart), in de energiehuishouding en in de geleiding van electrische prikkels. Voor meting van de electrische prikkels wordt een hartfilmpje (ECG) gemaakt en wordt een catheter tegen de binnenkant van de hartkamer aangelegd zodat de electrische signalen hiervan opgevangen kunnen worden (electrische aanpassingen). Aanpassingen op het gebied van de pompfunctie van het hart (contractiele aanpassingen) kunnen gemeten worden met een andere catheter in de holte van de linkerkamer. Als laatste is in kleine stukjes hartweefsel de activiteit van eiwitten (enzymen) bepaald die betrokken zijn in de energiehuishouding van de hartspiercel (metabole aanpassingen).

In hoofdstuk 2 wordt een overzicht van de literatuur gegeven over het belang van de electrische activatie zoals die tijdens pacen optreedt en de gevolgen hiervan voor de pompfunctie. Pacen op de punt van rechterkamer, de meest gebruikelijke plaats, is geassocieerd met een aanzienlijke achteruitgang van de pompfunctie. Pacen op andere plaatsen, zoals vanuit de linkerkamer of van meerdere plaatsen tegelijk, resulteert in aanzienlijk minder achteruitgang van de pompfunctie. Pacen op vrijwel alle plaatsen levert een abnormale electrische activatie op. Daarom lijkt het de moeite waard om te onderzoeken welke pace-plaats leidt tot de meest normale electrische activatie en tot de beste pompfunctie.

Hoofdstuk 3 beschrijft een studie naar de structurele en contractiele aanpassingen gedurende 16 weken AV-blok. Twee fases kunnen onderscheiden worden: tot 6 weken AV-blok en van 6 tot 16 weken AV-blok. In de eerste fase nemen de spiermassa en holte van de linkerkamer snel toe en is pompfunctie beter dan normaal. In de tweede fase nemen de spiermassa en de holte langzaam nog verder toe maar de pompfunctie neemt af tot normale waarden. Dit laatste is gekoppeld aan een verandering in de verhouding tussen twee eiwitten die een grote rol spelen in de calcium-huishouding (SERCA en $\mathrm{NCX}$ ). De verhouding tussen SERCA en NCX is lager in harten met 16 weken AV-blok dan in normale harten. Deze veranderde verhouding treedt gelijk op met een verdere vergroting van de holte van de linkerkamer. AV-blok leidt dus tot een progressieve structurele aanpassing en een tijdelijke verbetering van de contractiele functie.

In hoofdstuk 4 worden de metabole aanpassingen onderzocht in een aantal verschillende modellen van hypertrofie: ontstaan door volume-overbelasting (door AV-blok), druk-overbelasting (door hoge bloeddruk) en als gevolg van linkerkamer- 
pacen. De eerste twee modellen veroorzaken een algehele hypertrofie van de linkerkamer, het laatste model heeft slechts hypertrofie in één bepaald gebied van de linkerkamer tot gevolg (asymetrische hypertofie). In het algemeen is de enzym activiteit toegenomen in harten met hypertrofie door volume-overbelasting en afgenomen in de harten met hypertrofie door druk-overbelasting en door linkerkamer pacen. De gelijke enzym activiteit binnen de harten met asymetrische hypertrofie suggereert dat stoffen in het bloed een rol spelen bij de metabole aanpassingen van hypertrofe harten.

Hoofdstuk 5 gaat over de structurele en electrische aanpassingen gedurende 8 weken AV-blok. Niet alleen de spiermassa is toegenomen (zie ook hoofdstuk 3), maar ook de electrische prikkelduur is verlengd. Herstel van het normale hartritme door vervolgens 8 weken lang de rechterkamer te pacen leidt tot vrijwel volledige terugkeer van de spiermassa en de holte van de linkerkamer naar normale afmetingen. De electrische prikkelduur blijft echter verlengd, wat kan leiden tot hartritmestoornissen en plotse hartdood. Terwijl de structurele en electrische aanpassingen na het begin van de overbelasting ongeveer gelijk opgaan, lopen de terugaanpassingen dus uit elkaar tijdens normalisatie van die belasting.

In hoofdstuk 6 wordt aangetoond dat na het herstel van het normale hartritme door pacen niet alleen structurele terugaanpassing, maar ook contractiele terugaanpassing optreedt. In een vergelijking tussen rechterkamer en tweekamer pacen (rechter- en linkerkamer tegelijkertijd), blijkt dat de laatste methode zorgt voor een iets snellere en gelijkmatiger terugaanpassing van de structuur van het hart. Dit lijkt verband te houden met een betere electrische activatie, omdat de electrische prikkel van twee kanten komt. Desondanks treedt de electrische terugaanpassing ook bij tweekamer pacen niet op.

Uit hoofdstuk 3, 5 en 6 kan geconcludeerd worden dat na AV-blok de structurele, contractiele en electrische aanpassingen een verschillend tijdsverloop hebben. Pacen na AV-blok resulteert in een terugaanpassing van de structuur en van de contractiele functie, maar niet van de verlengde electrische prikkelduur. Met andere woorden, ook de terugaanpassingsprocessen hebben een verschillend tijdsverloop.

Hoofdstuk 7 beschrijft een studie waar in normale honden is onderzocht welke pace-plaats resulteert in de beste pompfunctie. De pompfunctie van het hart blijkt gehandhaafd te kunnen worden als vanuit de linkerkamer gepaced wordt, zowel vanuit de punt (apex) als aan de linkerzijde van het kamertussenschot (septum). Pacen op de apex en aan de rechterzijde van het septum resulteert in het algemeen in een verslechtering van pompfunctie. De plaats in de rechterkamer die leidt tot de beste pompfunctie, wordt niet voorspeld door anatomie van het hart of door naar het ECG te kijken, maar kan alleen gevonden worden als de pompfunctie wordt gemeten. Het feit dat de pompfunctie tijdens pacen op de linkerkamer apex en aan de linkerzijde van het septum zo goed is, zou verklaard kunnen worden door de relatief normale electrische activatie tijdens pacen van deze plaatsen.

Tot slot worden in hoofdstuk 8 de resultaten van al deze studies bediscussieerd in een breder verband. 


\section{UITLEIDING}

André, Anna-Marie, Anneke, Annett, Anouk, Ans, Ardy, Arne, Baron, Bart, Ben, Bibi, Camy, Carène, Chester, Christine, Claire, Claudia, Cora, Daan, David, Debbie, Dick, Dirk, Elín, Eva, Ewold, Ferenc, Floor, Frans, Frits, Gijs, Hans, Hans-Robert, Harry, Ilse, Jan G, Jan S, Jannie, anne, Jodil, Johan, Johann, Jules, Jurren, Karin vd L, Koen, Kristel, Leo, Linda, Marc, Marieke de G, Marieke Martijn, Matthijs, Maurits, meneer Beer, Milan, Mirese, Natasja, Oma, Paul S, Paul V,

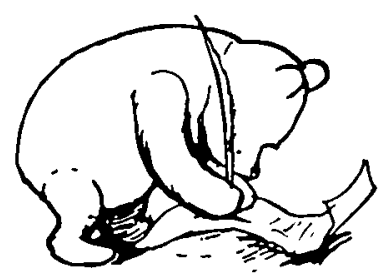
Heinz, Henny, Huub, Jérôme, Jet , Jo, JoJoke, Jos, Joyce, Karin S, Kevin, Kim, Luc, Luz-Maria, S, Marijke, Marissa, May, Michael, Monique, Morten, Per, Peter, Ramona, Remmert-Jan, René, Richard, Rob, Roel, Ruud K, Ruud L, Sabine, Sabrina, Tammo, Theo A, Theo vd N, Ton, Uli, Walter, Ward, Wendy, Wilfred en Xander.

Zonder jullie was het niet gelukt

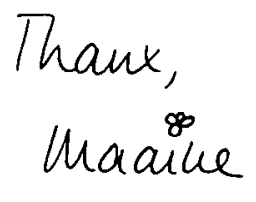




\section{CURRICULUM VITAE}

16 april 1971 Geboren te Hilversum

1983-1989 V.W.O diploma aan het Sint Maartens College te Haren (Gn)

1989-1994 Doctoraal examen Medische Biologie, Rijksuniversiteit Groningen

1994-1996 Onderzoeker bij de vakgroep Klinische Farmacologie en Laboratorium voor Celbiologie en ElectronenMicroscopie, Rijksuniversiteit Groningen

1996-2000 A.l.O. bij de vakgroep Fysiologie, Universiteit Maastricht

2000-heden Onderzoeker bij de vakgroep Fysiologie, Universiteit Maastricht 


\section{PUBLICATIONS}

\section{Papers}

- Verbeek XA, Willigers JM, Prinzen FW, Peschar M, Ledoux LA and Hoeks AP. High-resolution functional imaging with ultrasound contrast agents based on RF processing in an in vivo kidney experiment. Ultrasound Med Biol. 2001;27:223-233.

- Prinzen FW and Peschar M. Relation between the pacing induced sequence of activation and left ventricular pump function in animals. Pacing Clin Electrophysiol. 2002;25:484-498.

- Verbeek XAAM, Vernooy K, Peschar M, van der Nagel T, van Hunnik A and Prinzen FW. Quantification of interventricular asynchrony during LBBB and ventricular pacing. Am J Physiol Heart Circ Physiol 2002;283:H1370-78.

- Peschar M, de Swart H, Michels KJ, Reneman RS and Prinzen FW. Left ventricular septal and apex pacing for optimal pump function in canine hearts. Submitted to / Am Coll Cardiol (under revision).

- Verbeek XAAM, Vernooy K, Peschar M, Cornelussen RNM, van der Nagel T, van Hunnik A and Prinzen FW. Intraventricular asynchrony determines left ventricular function during pacing in canine hearts with left bundle branch block. Submitted.

- Peschar M, Vernooy K, Vanagt WYR, Reneman RS, Vos MA and Prinzen FW. Absence of reverse electrical remodeling during regression of volume overload hypertrophy in canine ventricles. Submitted to Cardiovasc Res (under revision).

- Peschar M, Baaten G, van der Nagel T, Willems ], Cornelussen RNM, Snoeckx LHEH, Reneman RS, Vos MA and Prinzen FW. Biphasic contractile and progressive structural remodeling during bradycardia induced volume overload hypertrophy. Submitted.

\section{Book section}

- Vos MA, Schoenmakers M, Peschar M and Prinzen FW. Regression of ventricular hypertrophy and its effect on electrical remodeling. In: Schalij MJ, Janse MJ, van Oosterom A, van de Wall EE, Wellens HJJ, eds. Einthoven 2002. 100 years of electrocardiography. Leiden, the Netherlands: The Einthoven Foundation; 2002:415-420. 


\section{Abstracts}

- Peschar M, Rousseau AMJ, van Oosterhout MFM, de Groot SHM, Vos MA, Reneman RS, Snoeckx LHEH and Prinzen FW. SERCA2 protein content in the adult canine heart, hypertrophied due to pressure or volume overload. Faseb J. 1998;12:A977.

- Peschar M, Vanagt WYR, Vos MA and Prinzen FW. Lack of reverse electrical remodeling during regression of volume overload hypertrophy. Pacing Clin Electrophysiol. 1999;22:881.

- Peschar M, van Oosterhout MFM, Snoeckx LHEH, Arts T, Reneman RS and Prinzen FW. Local contents of SERCA2a and metabolic enzymes in hearts with local and global ventricular hypertrophy. I Mol Cell Cardiol. 1999;31:A83.

- Peschar M, Vanagt WYR, Vos MA and Prinzen FW. Regression of volume overload hypertrophy in dog heart is not accompanied by reversion of electrical remodeling. Pflugers Arch. 1999;438:R71.

- van Oosterhout MFM, Peschar M, Snoeckx LHEH, Arts T, Reneman RS and Prinzen FW. Reduced SERCA2a content and activity of metabolic enzymes in chronically paced canine hearts. Pacing Clin Electrophysiol. 1999;22 part Il:A68.

- Peschar M, Vanagt WYR, Vos MA and Prinzen FW. Electrical remodeling is not reversed during regression of volume overload hypertrophy. Europace. 2000;I suppl B:B24.

- Prinzen FW, de Swart H and Peschar M. Optimal pacing regime for canine hearts with left bundle branch block. Europace. 2000;I suppl B:B24.

- Prinzen FW, de Swart H and Peschar M. Optimal pacing regime for hemodynamic improvements in canine hearts with left bundle branch block. Europace. 2000:B24.

- Prinzen FW, de Swart $\mathrm{H}$ and Peschar M. Optimization of left ventricular function by ventricular pacing in canine hearts with left bundle branch block. European Heart ). 2000;21. Suppl.:195.

- Prinzen FW, de Swart H and Peschar M. Optimal pacing regime for canine hearts with left bundle branch block. Europace. 2000;। Suppl:D107.

- Peschar M, Vernooy K and Prinzen FW. Time-dependent changes and reversibility of ventricular function during volume overload hypertrophy in the dog. I Physiol. 2001;533P:26P.

- Verbeek S, Vernooy K, van der Nagel T, Peschar M, de Swart H and Prinzen FW. Opposite changes in right and left ventricular function during LBBB and pacing therapy. Europace. 2001;2 Suppl:B88.

- Verbeek XAAM, Vernooy K, Dumitrescu G, Peschar M, van der Nagel T and Prinzen FW. Relation between interventricular asynchrony and opposite changes in left and right ventricular function during left bundle branch block and resynchronization. Circulation. 2001;104:11-279.

- Peschar M, van der Nagel Th, Reneman RS and Prinzen FW. Application of the conductance catheter to describe remodeling of LV end-diastolic volume. PV-loops, international congress on ventricular function and failure from mice to man. Maastricht, the Netherlands, 2002. 
- Peschar M, Michels K, van der Nagel T, van Hunnik A and Prinzen FW. Better pump function during left than during right ventricular septal pacing in canine hearts. Pacing Clin Electrophysiol. 2002;24:587.

- Peschar M, Michels K, van der Nagel T, van Hunnik A and Prinzen FW. Left but not right ventricular septal pacing maintains pump function in canine hearts. Europace. 2002;3:A130.

- Peschar M, Baaten G, van der Nagel T, Willems J, Cornelussen RNM, Snoeckx LHEH, Reneman RS, Vos MA and Prinzen FW. Biphasic contractile and progressive structural remodeling during bradycardia induced volume overload hypertrophy. Best poster prize at the International Symposium on CardioVascular Remodeling and Function. Osaka, Japan, 2002.

- Verbeek XAAM, Vernooy K, Peschar M, van Hunnik A and Prinzen FW. Intraventricular resynchronization leads to optimal ventricular pump function in hearts with left bundle branch block. Congress Cardiovascular System Dynamics Society. Sendai, Japan, 2002.

- Verbeek XAAM, Vernooy K, Peschar M, Mutsaers D, van Hunnik A and Prinzen FW. Intraventricular but not interventricular resynchronization is required for optimal pacing therapy in hearts with left bundle branch block. Accepted for Scientific Sessions American Heart Association, Chicago, USA, 2002.

- Verbeek XAAM, Vernooy K, Peschar M, van Hunnik A and Prinzen FW. Transseptal conduction time determines timing between left and right ventricular pacing to obtain optimal pump function in hearts with left bundle branch block. Accepted for Scientific Sessions American Heart Association, Chicago, USA, 2002. 